\title{
Synthetic Models for
}

Dizinc Metallohydrolases

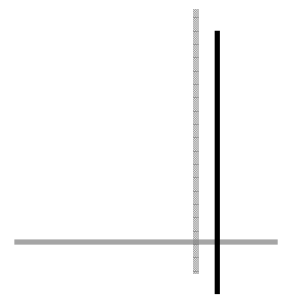

Dissertation

zur Erlangung des mathematisch-naturwissenschaftlichen Doktorgrades

"Doctor rerum naturalium"

der Georg-August-Universität Göttingen

vorgelegt von

Diplom-Chemikerin

Simone Wöckel

aus Schleiz

Göttingen 2011 
Referent: Prof. Dr. Franc Meyer Korreferent: Prof. Dr. Ulf Diederichsen

Tag der mündlichen Prüfung: 29.04.2011 




\section{Table of Contents}

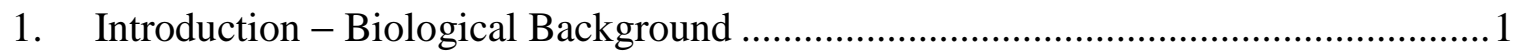

1.1. Zinc and its Biological Role ....................................................................... 1

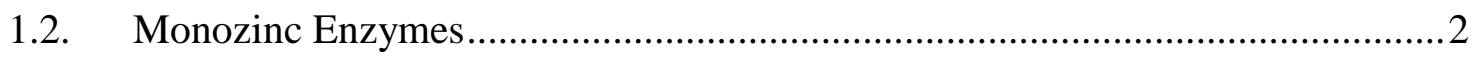

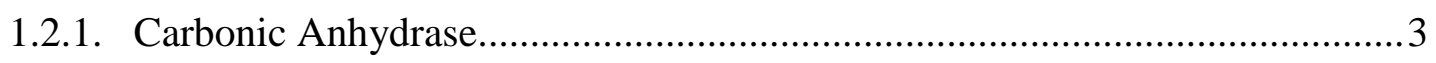

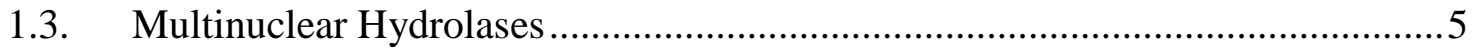

1.3.1. Enzymes Cleaving Phosphate Esters ...........................................................6

1.3.1.1. Purple Acid Phosphatase ......................................................................6

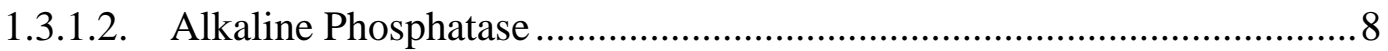

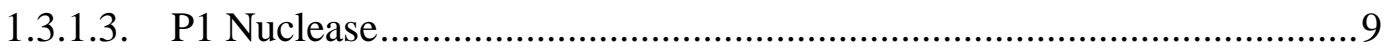

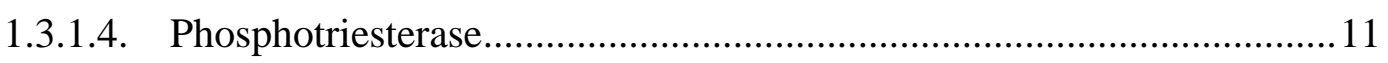

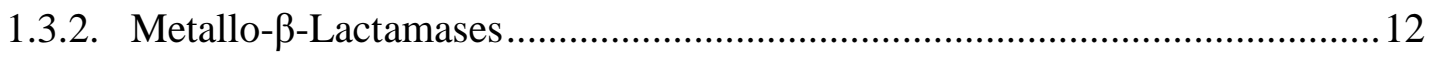

1.4. Synthetic Approach to Mimic Metallohydrolases ............................................ 15

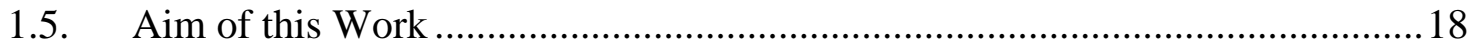

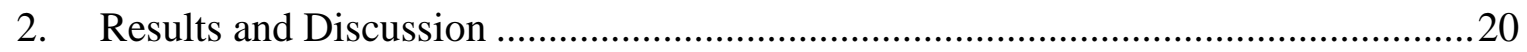

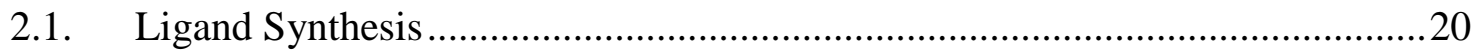

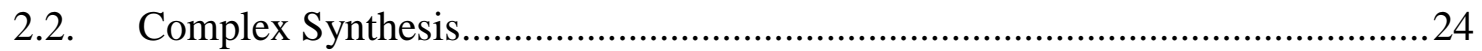

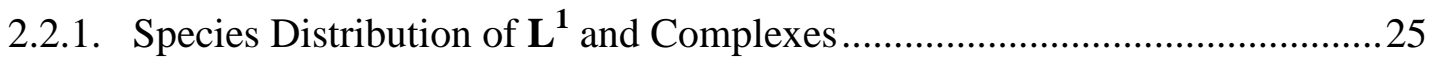

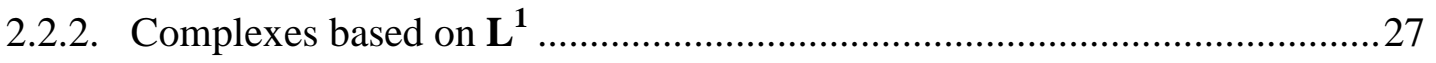

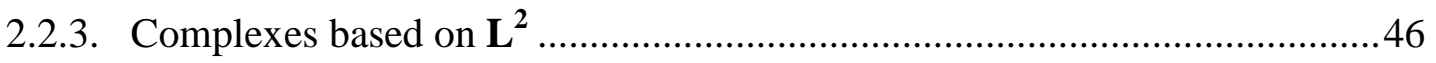

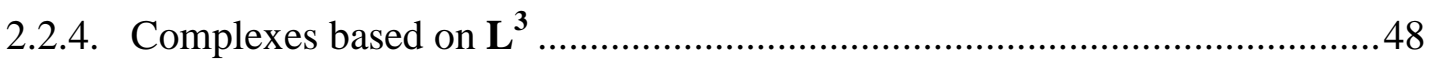

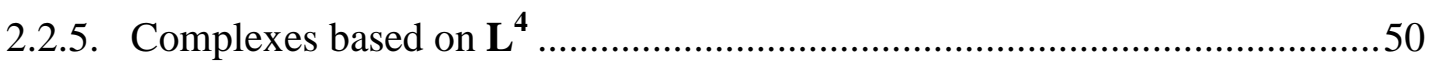

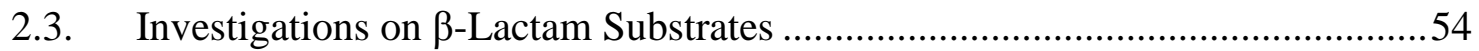

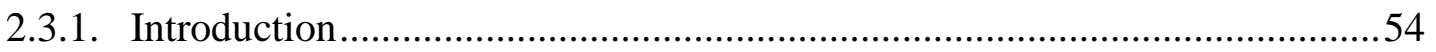

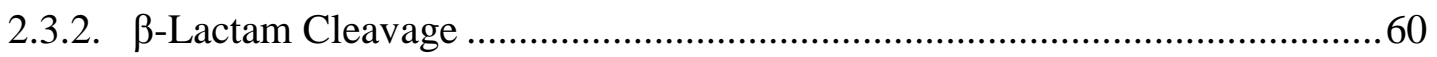

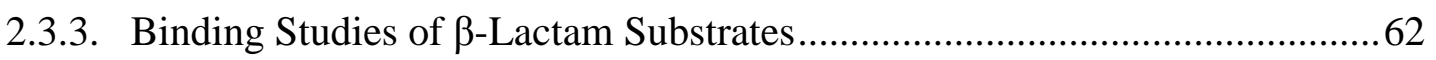

2.3.3.1. Binding Studies of Penicillin G (PenG) ...............................................64

2.3.3.2. Binding Studies of Ampicillin (Amp).................................................67 
2.3.3.3. Binding Studies of 6-Aminopenicillanic Acid (6-Apa) .........................68

2.3.3.4. Binding Studies of Cephalotin (Ceph) ..................................................69

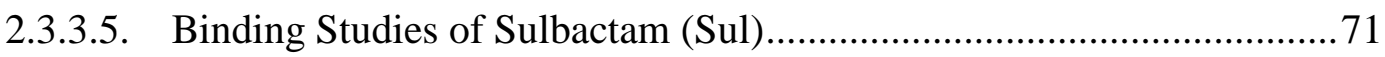

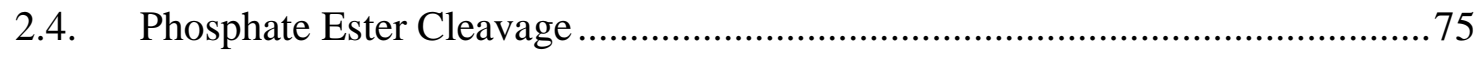

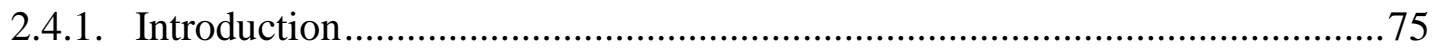

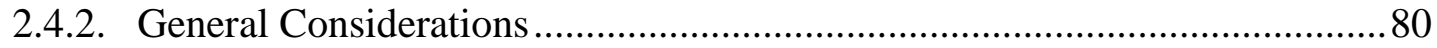

2.4.3. Cleavage of 2-Hydroxypropyl-p-nitrophenyl Phosphate (HPNP) .................81

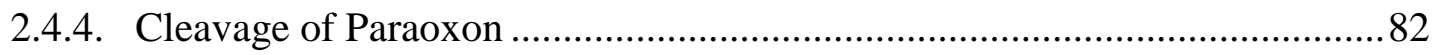

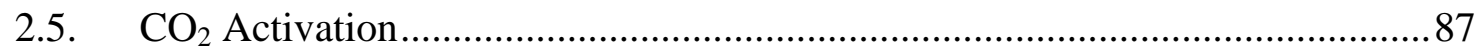

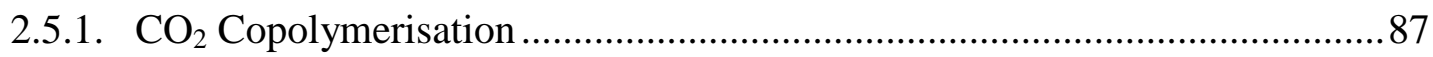

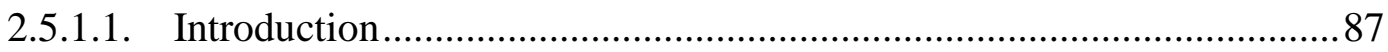

2.5.1.2. Activity of 2 in $\mathrm{CO}_{2}$ Copolymerisation .......................................... 90

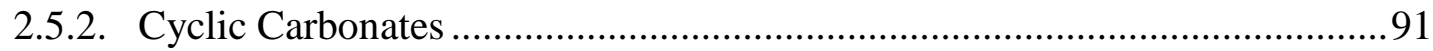

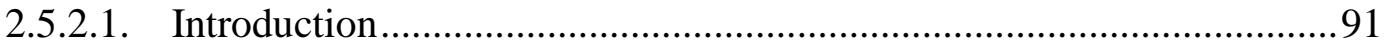

2.5.2.2. Activity of 2 to Form Cyclic Carbonates............................................ 92

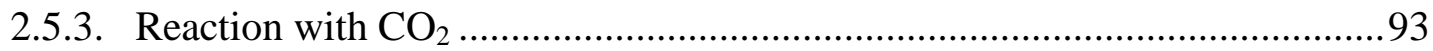

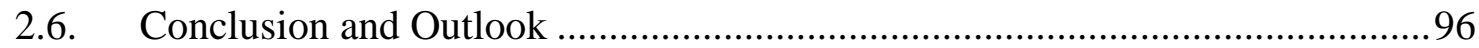

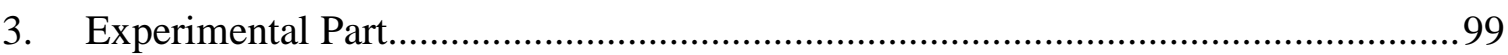

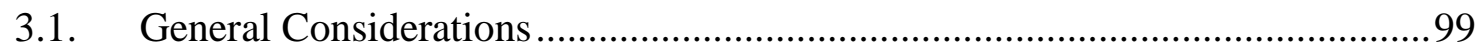

3.2. Synthesis of Ligand Precursors and Ligands ................................................ 100

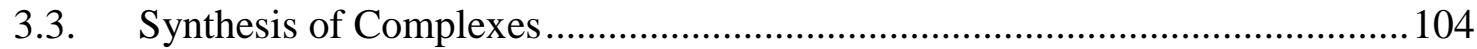

3.4. Binding Studies of $\beta$-Lactam Substrates ...................................................... 112

3.5. Hydrolytic Activity in Penicillin G Cleavage ................................................ 118

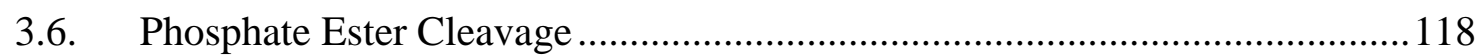

3.6.1. 2-Hydroxypropyl-p-nitrophenyl Phosphate (HPNP) .................................. 118

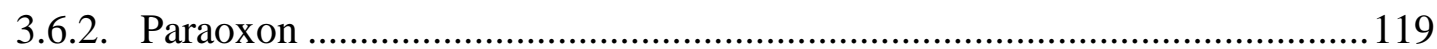

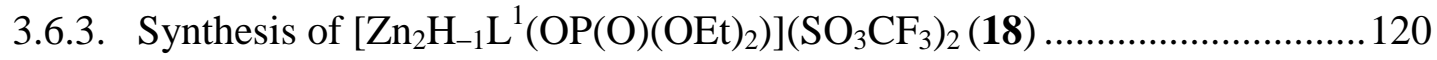

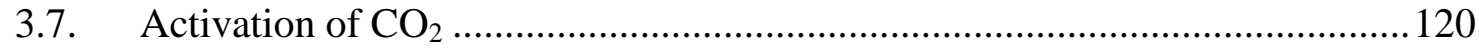

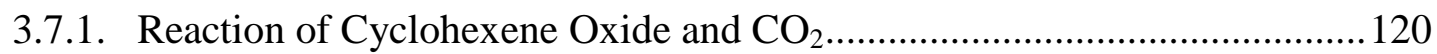

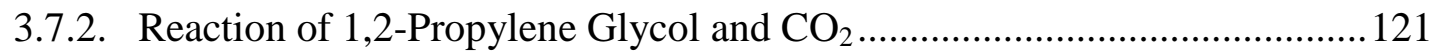

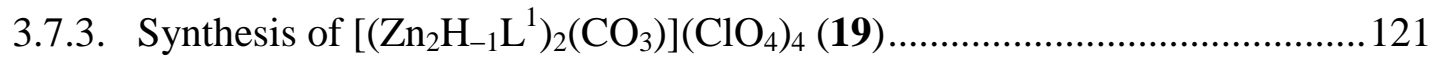


Appendix 122

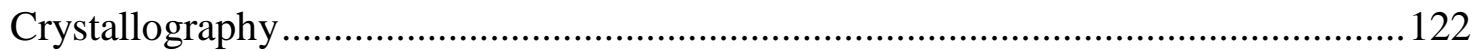

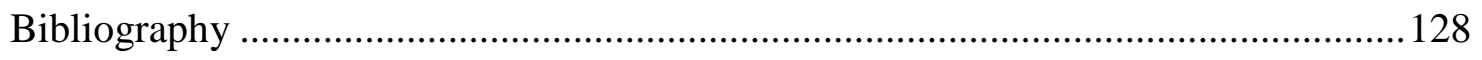

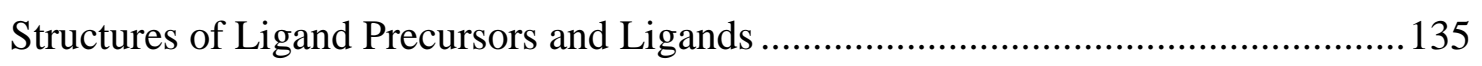

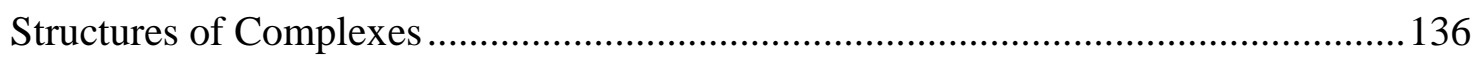

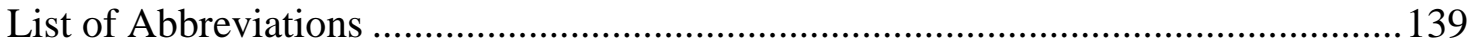

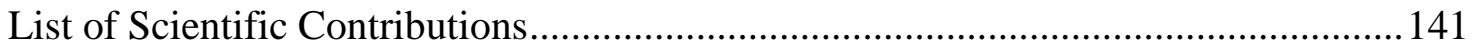

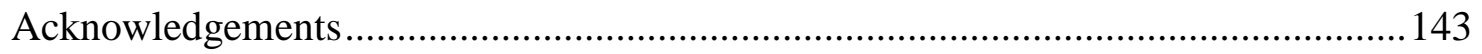

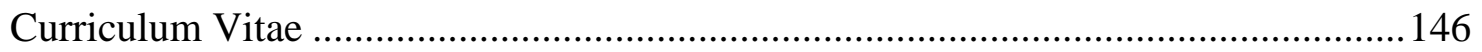





\section{Introduction - Biological Background}

\subsection{Zinc and its Biological Role}

The role of zinc in biology was underestimated for a long time due to its missing exciting properties. Under physiological conditions, it is existent as $\mathrm{Zn}^{2+}$ ion with a $d^{10}$ configuration that makes its role in coordination chemistry not very special. Complexes of $\mathrm{Zn}^{2+}$ are colourless, diamagnetic and because of its filled electron shell it is unreactive in redox processes. ${ }^{[1]}$ Owing to its unremarkable properties compared to other transition metals, zinc was mentioned to be a boring metal. ${ }^{[2]}$ In fact, zinc is an interesting element that stands in the same group as cadmium and mercury, which both are poisonous, but zinc is essential for life. With $2-3 \mathrm{~g}$, it is the second most abundant $3 d$-metal in the human body and was found to be present in all classes of enzymes (i.e., oxidoreductases, transferases, hydrolases, lyases, isomerases and ligases). This makes zinc important in various biological processes (e.g., development and function of the central nervous system, the immune defense and the production and function of insulin). ${ }^{[3]}$

Zinc is a metal with intermediate hard-soft behaviour making it attractive to be coordinated by nitrogen, oxygen and sulphur ligands and thus allows binding in many proteins compared to other metals. Resulting from the lack of ligand field stabilisation effects due to its $d^{10}$ configuration, $\mathrm{Zn}^{2+}$ is flexible in coordination number and geometry. ${ }^{[1 b]}$ Although coordination numbers from $2-8$ are possible, most common are 4 , 5 and 6. This labile coordination allows fast ligand exchange that is necessary in catalytic reactions. ${ }^{[2]}$ Another important property of $\mathrm{Zn}^{2+}$ is its high Lewis acidity. The ability to polarise substrates, especially water, is necessary in enzymatic hydrolytic reactions. If water coordinates to $\mathrm{Zn}^{2+}$, its $\mathrm{p} K_{\mathrm{a}}$ is lowered under physiological $\mathrm{pH}$ enabling to generate a nucleophile that is able to attack. ${ }^{[1 \mathrm{a}]}$

The importance of zinc in biology was not recognised for a long time, because of its spectroscopic silent properties that make zinc difficult to identify. With improvement of analytic methods, the first zinc containing enzyme was found in $1930 \mathrm{~s}^{[4]}$ and since this time, more than 400 enzymes have been discovered that bear $\mathrm{Zn}^{2+}$ in the active site indicating the important role in biological processes. ${ }^{[5]}$ The functions of zinc enzymes can be both catalytic and structural. Enzymes, like phosphatases, nucleases, peptidases and 
amidases are important in biological degradation reactions. In addition, zinc enzymes (e.g., synthetases, polymerases and transferases) are also necessary in biological growth processes. ${ }^{[6]}$ Pure structural functions of zinc are found in E. coli aspartate transcarbamoylase ${ }^{[7]}$ or in the zinc finger protein. ${ }^{[8]}$

The manifold applications of zinc containing enzymes make this element highly attractive in biomimetic investigations. To mimic the biological function of enzymes, the active centres are emulated by synthetic models. These simplified analogues enable the investigation of the mechanistic processes of the enzymes that is essential to understand their way of function. As mentioned above, more than 400 enzymes are known, which bear zinc in their active sites. Zinc is present in various mononuclear enzymes (e.g., carbonic anhydrase and alcohol dehydrogenase) and also in enzymes containing more than one zinc ion in their active site (e.g., phosphodiesterases and metallo- $\beta$-lactamases). Due to the large number of zinc containing enzymes, only few of them will be discussed here. With the focus on multinuclear enzymes, which hydrolyse chemical bonds, the active centres of phosphatases, phosphodiesterases, phosphotriesterases and metallo- $\beta$ lactamases, which serve as biological archetypes, will be presented. In addition, carbonic anhydrase is one of the most efficient mononuclear enzymes and is highly attractive in biomimetic reactions, since it is able to activate $\mathrm{CO}_{2}$.

\subsection{Monozinc Enzymes}

In many mononuclear zinc enzymes, the structural motif is a tetrahedrally coordinated zinc centre $\left[(\mathrm{XYZ}) \mathrm{Zn}^{2+}-\mathrm{OH}_{2}\right]$ that is bound to the protein by three amino acid residues (XYZ) as it is depicted in Scheme 1.1.

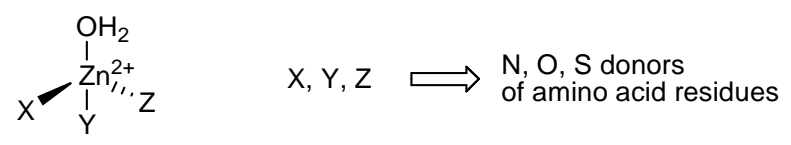

Scheme 1.1: Tetrahedral coordination of most mononuclear zinc enzymes. 
The fourth position is occupied by a water or hydroxide ligand (depends on $\mathrm{pH}$ ) and is the so called open site, where catalysis can take place. The flexible coordination geometry of zinc allows the change of tetrahedral coordination to a penta-coordinated zinc centre within the catalytic circle. ${ }^{[6]}$

\subsubsection{Carbonic Anhydrase}

One of the known most efficient mononuclear enzymes is carbonic anhydrase (CA).
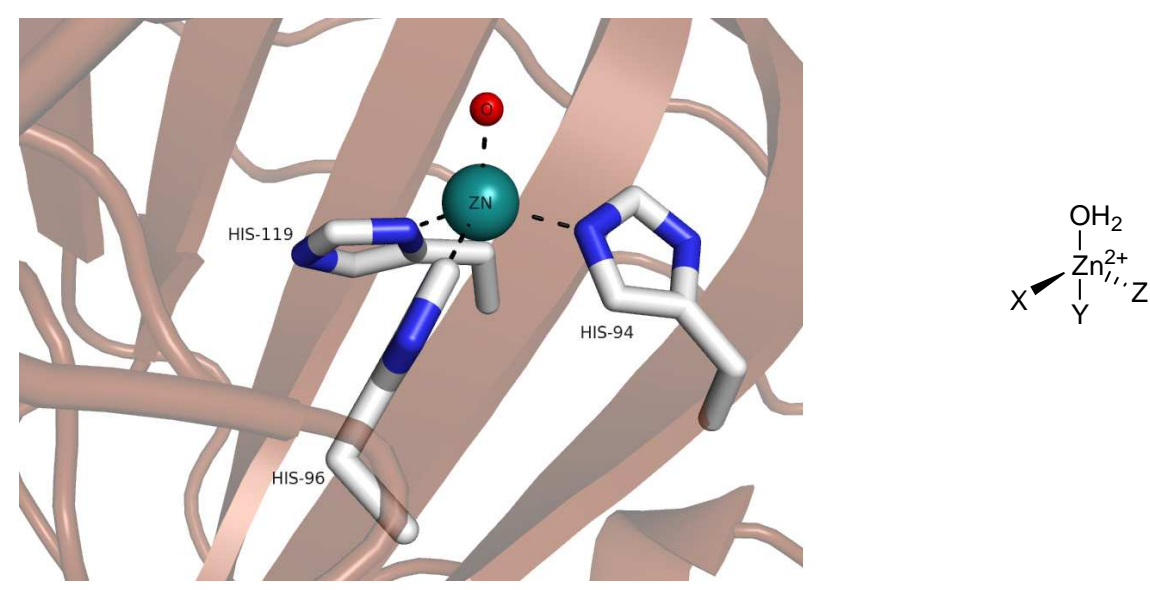

Figure 1.1: Tetrahedrally coordinated zinc centre in the active site of carbonic anhydrase; crystal structure (left, PDB Code: $4 \mathrm{CAC})^{[9]}$ and scheme (right).

This enzyme contains three histidine amino acid residues bound to the zinc centre. An additional water molecule leads to a tetrahedral coordination of zinc (Figure 1.1). CA was the first enzyme, which was known to contain zinc in its active site. ${ }^{[4]}$ As indicated in equation $(i)$, its function is the hydrolytic conversion of carbon dioxide to bicarbonate. This reaction is essential for life to maintain acid-base balance in blood and other tissues. The conversion of $\mathrm{CO}_{2}$ into bicarbonate allows the transport between metabolising tissues and the lungs that makes respiration possible. Its remarkable nature makes this enzyme ubiquitous, since it was found in animals, plants and bacteria. ${ }^{[6]}$

$$
\mathrm{CO}_{2}+\mathrm{H}_{2} \mathrm{O} \rightleftarrows \mathrm{HCO}_{3}^{-}+\mathrm{H}^{+}
$$


The mechanism of $\mathrm{CA}$ is illustrated in Scheme 1.2. The high Lewis acidity of $\mathrm{Zn}^{2+}$ polarises the water molecule that lowers its $\mathrm{p} K_{\mathrm{a}}$ to $\sim 7$. Proton shuttling occurs while a nearby located histidine $\left(\mathrm{B}^{-}\right)$acts as a proton acceptor generating the zinc-hydroxide form of the enzyme (b). ${ }^{[10]}$ Next step is the interaction of the $\mathrm{CO}_{2}$ molecule with the zinc centre, which has to attract, orientate and polarise the substrate to bring the $\mathrm{CO}_{2}$ closer to the hydroxide ligand $(\mathbf{c}){ }^{[1 \mathrm{a}]}$

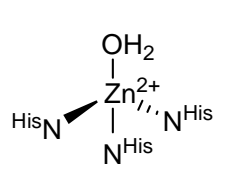

(a)
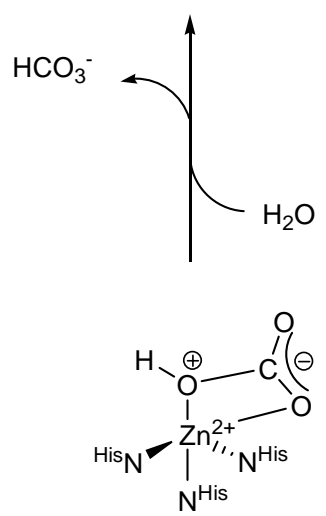

(d)
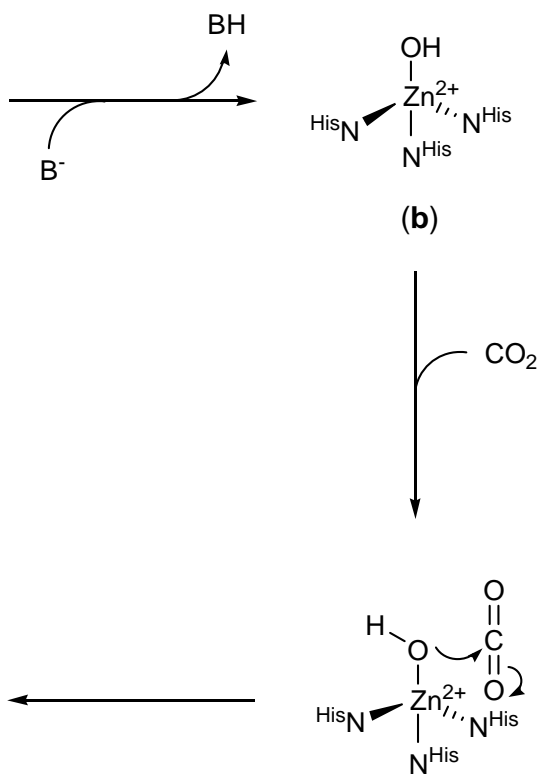

(c)

Scheme 1.2: Catalytic circle of carbonic anhydrase.

Nucleophilic attack of the hydroxide ligand forms an intermediate (d) that is degraded by water to release bicarbonate and closing the catalytic circle (a). ${ }^{[6]}$ Two different mechanisms have been proposed in bicarbonate formation (Scheme 1.3): (i) the "Lipscomb" mechanism that involves an internal proton transfer or (ii) the "Lindskog" mechanism that assumes a turn of the $\mathrm{Zn}-\mathrm{O}$ bond enabling the hydrogen atom to stay at the original nucleophile oxygen atom $\left(\mathrm{O}^{\star}\right)$. Although both intermediates were found experimentally, the "Lindskog" mechanism is favoured in theoretical calculations. ${ }^{[11]}$ 


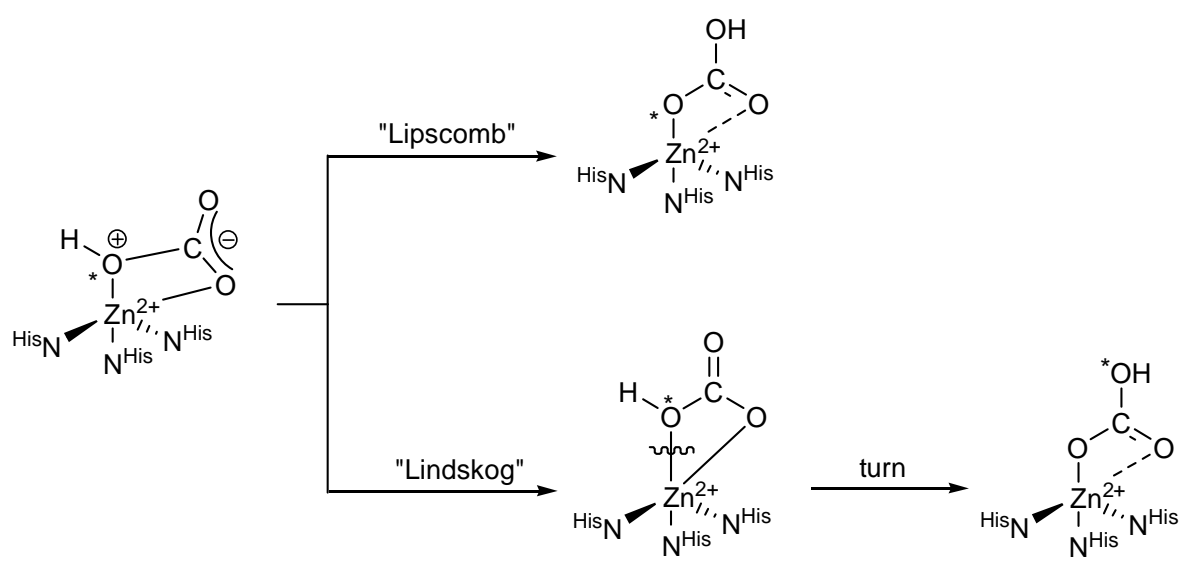

Scheme 1.3: Proposed mechanisms for bicarbonate formation.

\subsection{Multinuclear Hydrolases}

Hydrolases are a group of enzymes that catalyse the hydrolytic cleavage of chemical bonds. Members of this group like phosphatases and nucleases are able to cleave phosphate ester bonds of phosphorylated amino acids and saccharides, nucleotides, DNA and RNA. Other enzymes like metallo- $\beta$-lactamases hydrolyse the $\mathrm{C}-\mathrm{N}$ bond of $\beta$-lactam antibiotics. Most of these enzymes contain more than one metal ion in their active sites (e.g., $\mathrm{Zn}^{2+}, \mathrm{Fe}^{3+}$ or $\mathrm{Mg}^{2+}$ ). In binuclear zinc enzymes, both metal centres are in close proximity (3-5 $\AA$ ) and are bridged by a donor ligand, like aspartate, glutamate, water or a hydroxide ligand. ${ }^{[6 b, 12]}$ The synergistical work of both metal centres enables the binding and activation of substrate molecules (e.g., water) to generate a nucleophile that is able to attack under physiological conditions. ${ }^{[13]}$ 


\subsubsection{Enzymes Cleaving Phosphate Esters}

Enzymes that catalyse the cleavage of phosphate ester bonds are divided into phosphatases, phosphodiesterases and phosphotriesterases. Depending on the substrate, the enzymes are specialised to hydrolyse the $\mathrm{P}-\mathrm{O}$ bond of phosphate monoesters (e.g., purple acid phosphatase and alkaline phosphatase), phosphate diesters (like P1 nuclease) or triesters (e.g., phosphotriesterase). Some of these enzymes bear a third metal centre in the active site, like $\mathrm{Mg}^{2+}$ in alkaline phosphatase or a third $\mathrm{Zn}^{2+}$ centre in nuclease $\mathrm{P} 1$. This third metal centre is slightly apart from the binuclear active site $(\sim 5-7 \AA)$. Its functional role in biological processes is more structural than catalytic, for instance, stabilising intermediates or ensuring the protonation state of the nucleophile. ${ }^{[6 \mathrm{~b}]}$

\subsubsection{Purple Acid Phosphatase}

Specialised to cleave the $\mathrm{P}-\mathrm{O}$ bond of phosphate monoesters under acidic conditions (optimum $\mathrm{pH}$ of 4.9-6.0), purple acid phosphatases (PAP) are enzymes with two metal ions in their active site. ${ }^{[14]}$ Isolated from kidney beans the enzyme bears one $\mathrm{Zn}^{2+}$ and one $\mathrm{Fe}^{3+}$ ion in the catalytic centre. The purple colour of the enzyme is caused by a $\mathrm{Tyr} / \mathrm{Fe}^{3+}$ ligand-to-metal charge transfer. ${ }^{[6 \mathrm{~b}]}$
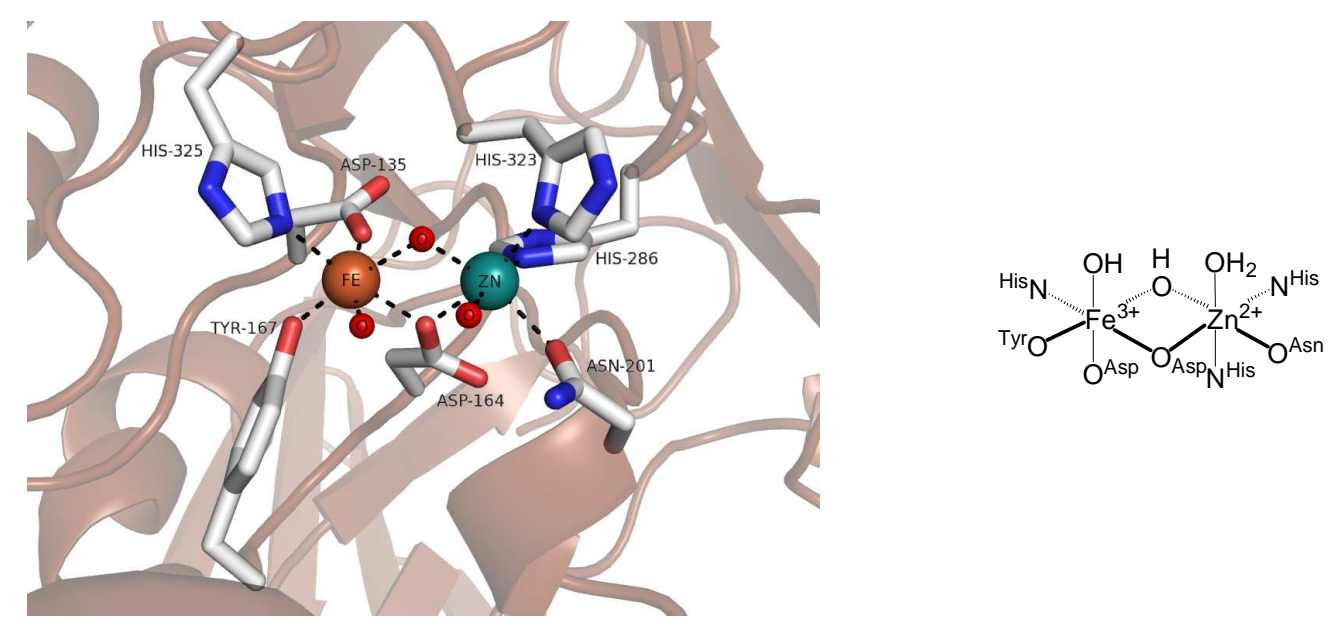

Figure 1.2: Updated crystal structure of the active site of purple acid phosphatase isolated from kidney beans (left, PDB Code: $1 \mathrm{KBP})^{[15]}$ and scheme (right). 
As depicted in Figure 1.2, the ferric centre in PAP of kidney beans is coordinated by two anionic (Asp, Tyr) and one neutral (His) amino acid residues. A terminal hydroxide and two bridging ligands (hydroxide and Asp) complete an octahedral coordination. The strong Lewis acidic character of $\mathrm{Fe}^{3+}$ ensures a constant deprotonation of the terminal coordinated hydroxide ligand. In addition to the two bridging ligands, $\mathrm{Zn}^{2+}$ is coordinated by three neutral amino acid residues (two His and one Asn) and one aqua ligand, which is not deprotonated. ${ }^{[16]}$

The mechanism of PAP is shown in Scheme 1.4. After substrate coordination to $\mathrm{Zn}^{2+}$ by elimination of the labile aqua ligand (b), the terminal hydroxide ligand at $\mathrm{Fe}^{3+}$ is able to attack the phosphorous atom resulting in a penta-coordinated intermediate (c). Release of the leaving group $\mathrm{ROH}$ (d) and exchange of $\mathrm{HPO}_{4}{ }^{2-}$ by solvent molecules completes the catalytic circle $(\mathbf{a}){ }^{[16]}$

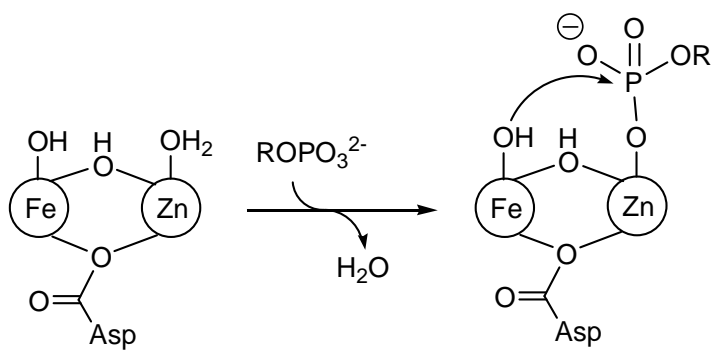

(a)

(b)

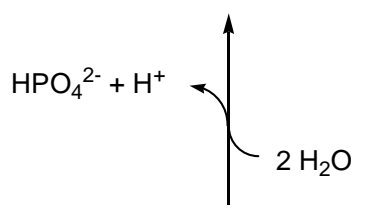

$$
\downarrow
$$

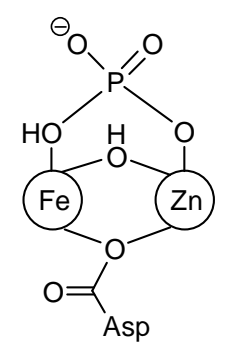

(d)

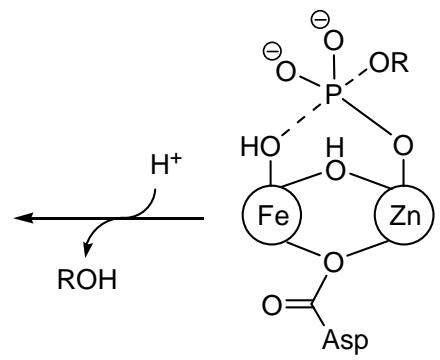

(c)

Scheme 1.4: Catalytic circle of purple acid phosphatase. 


\subsubsection{Alkaline Phosphatase}

Alkaline phosphatases (AP) cleave non-specific phosphate monoesters under basic conditions (optimum $\mathrm{pH}>7.5$ ). ${ }^{[14]}$ These enzymes require three metal ions for optimal activity. Two $\mathrm{Zn}^{2+}$ ions and one $\mathrm{Mg}^{2+}$ ion are present in the active site of E. coli AP (see Figure 1.3). ${ }^{[17]}$ Although enzymes containing only $\mathrm{Mg}^{2+}$ are not catalytically active, the activity of AP is dramatically decreased, if $\mathrm{Mg}^{2+}$ is substituted by other divalent metal ions. This third centre plays thus an ancillary role. In addition, the lack of one zinc centre reveals no activity. ${ }^{[13]}$ The active nucleophile is proposed to be a deprotonated serine residue, which is stabilised by one zinc centre.

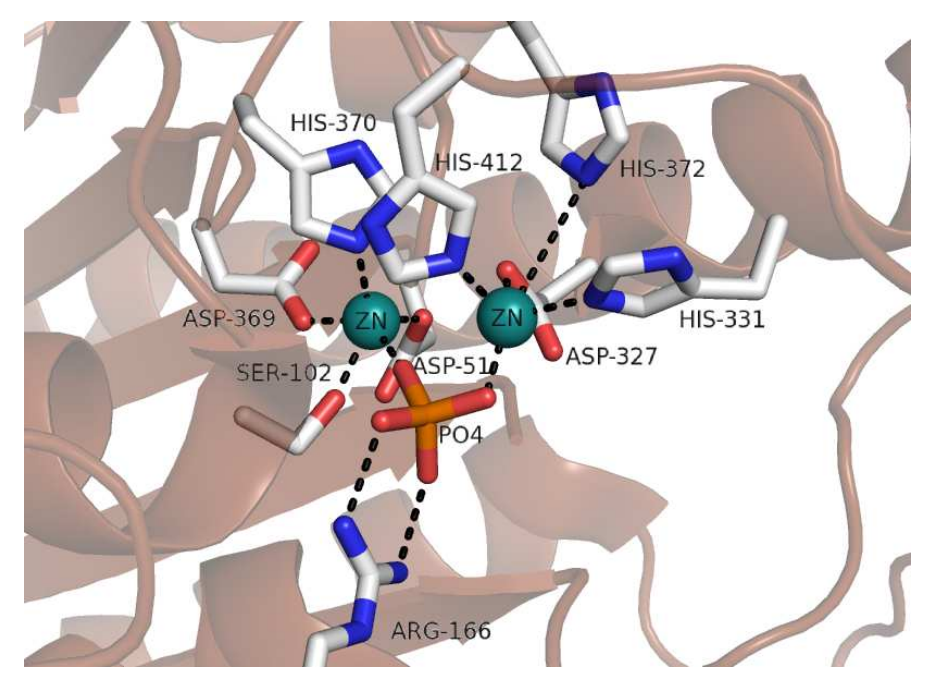

Figure 1.3: Crystal structure of the active site of alkaline phosphatase from E. coli with coordinated phosphate that is stabilised by hydrogen bonding to an arginine amino acid residue (PDB Code: 1 ALK). ${ }^{[17]}$

As illustrated in Scheme 1.5 the first step in catalysis is the coordination of the monophosphate to the zinc centres with release of the water molecule. The two not coordinating oxygen atoms of the phosphate form hydrogen bonds to an arginine residue for stabilisation (b). The active serine nucleophile then attacks the phosphorous atom resulting in the cleavage of the $\mathrm{P}-\mathrm{OR}$ bond. The alcohol $(\mathrm{ROH})$ is eliminated by water generating a new terminal nucleophile, which again attacks the phosphorous atom (c). This leads to the cleavage of the $\mathrm{P}(\mathrm{O})$-enzyme bond forming an phosphate bridging intermediate in accordance with release of the serine nucleophile (d). The phosphate is eliminated by water to generate the zinc-aqua complex (a) ${ }^{[6 a]}$ The function of $\mathrm{Mg}^{2+}$ during this process is proposed to regulate the protonation state of the serine residue. ${ }^{[13]}$ 


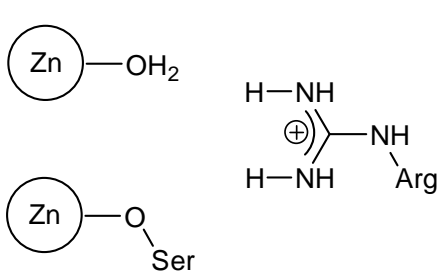

(a)
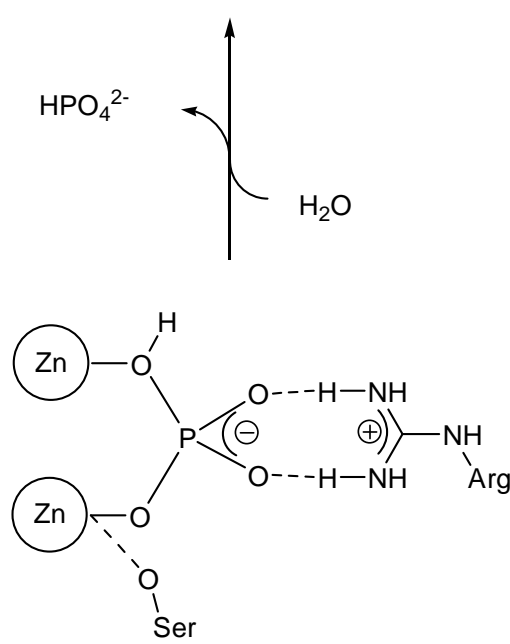

(d)

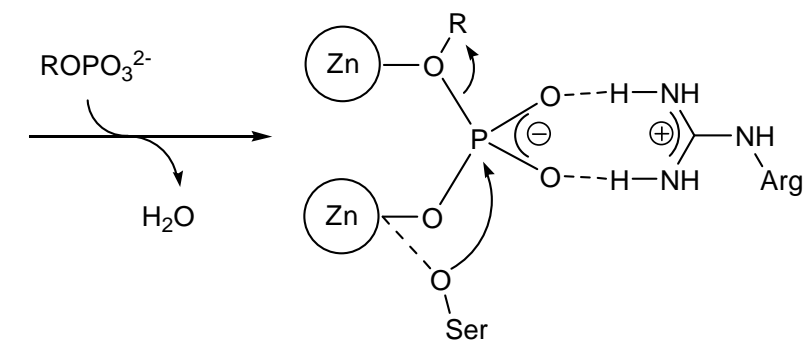

(b)
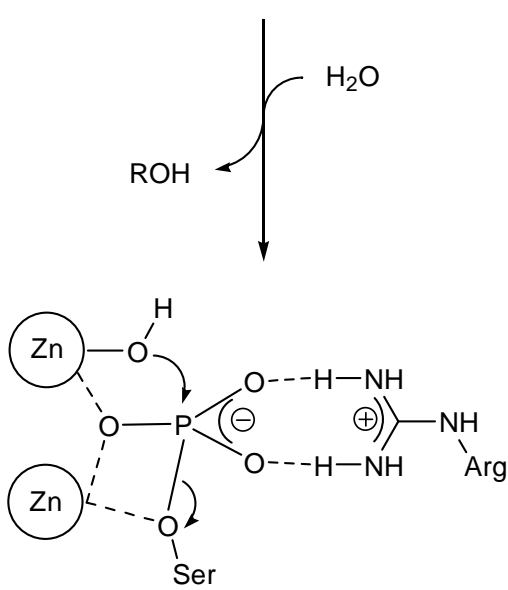

(c)

Scheme 1.5: Proposed mechanism of alkaline phosphatase.

\subsubsection{P1 Nuclease}

As an example for cleaving phosphate diesters, P1 nuclease is a glycoprotein isolated from the fungi Penicillium citrinum and catalyses the hydrolysis of single stranded DNA or RNA. The enzyme is a phosphodiesterase that cleaves the bond between the 3'-hydroxyl and 5'-phosphoryl group of adjacent nucleotides. At the same time it is also a phosphomonoesterase, removing the 3 '-terminal phosphate group. ${ }^{[18]}$ P1 nuclease requires three zinc centres in its active site (Figure 1.4). Two zinc ions (Zn1 and Zn3) are bridged by an aspartate residue and a water (or hydroxide) molecule. 

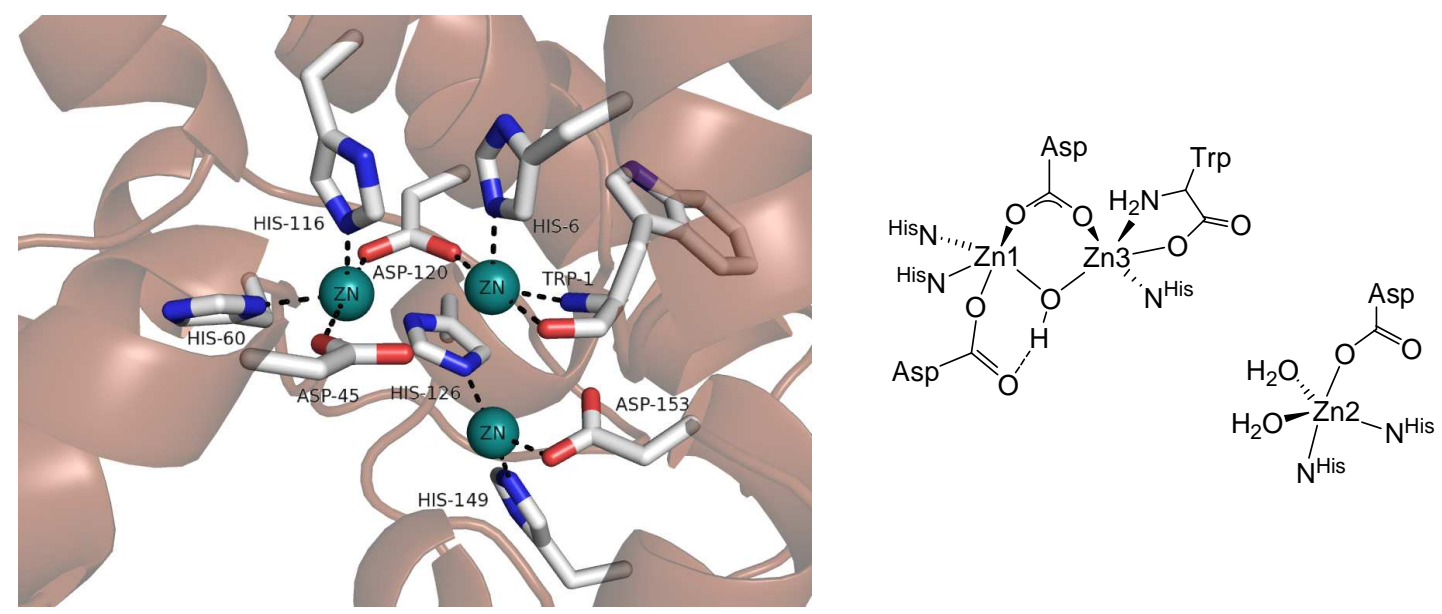

Figure 1.4: Crystal structure of the active site of $P 1$ nuclease without water ligands (left, PDB Code: $1 \mathrm{AK} 0)^{[19]}$ and scheme showing the hydroxide bridge of $\mathrm{Zn} 1$ and $\mathrm{Zn} 3$ and the coordination of two water molecules to $\mathrm{Zn} 2$ (right).

The zinc centres $\mathrm{Zn} 1$ and $\mathrm{Zn} 3$ are separated by $\sim 3.2 \AA$. The third zinc ion $(\mathrm{Zn} 2)$ is $\sim 5.8 \AA$ apart from $\mathrm{Zn} 1$ and $\sim 4.7 \AA$ from Zn3. In addition to the bridging ligands (aspartate and hydroxide), $\mathrm{Zn} 1$ is coordinated by two histidines and one aspartate. The $\mathrm{Zn} 3$ centre is additionally ligated by one histidine and the nitrogen and oxygen atoms of the $N$-terminus of tryptophan. Two histidines, one aspartate and two additional water molecules are coordinated to the single site containing $\mathrm{Zn} 2$. In conclusion, all three zinc centres are penta-coordinated by two nitrogen and three oxygen ligands. ${ }^{[18]}$ In the proposed catalytic mechanism of P1 nuclease (Scheme 1.6), the attacking nucleophile is assumed to be the bridging hydroxide. The phosphate group is not directly coordinated to zinc centres $\mathrm{Zn} 1$ and $\mathrm{Zn} 3$, but is stabilised by an arginine residue. The function of $\mathrm{Zn} 2$ is to trap the oxygen atom of the phosphate group that is cleaved to stabilise the intermediate. ${ }^{[19-20]}$
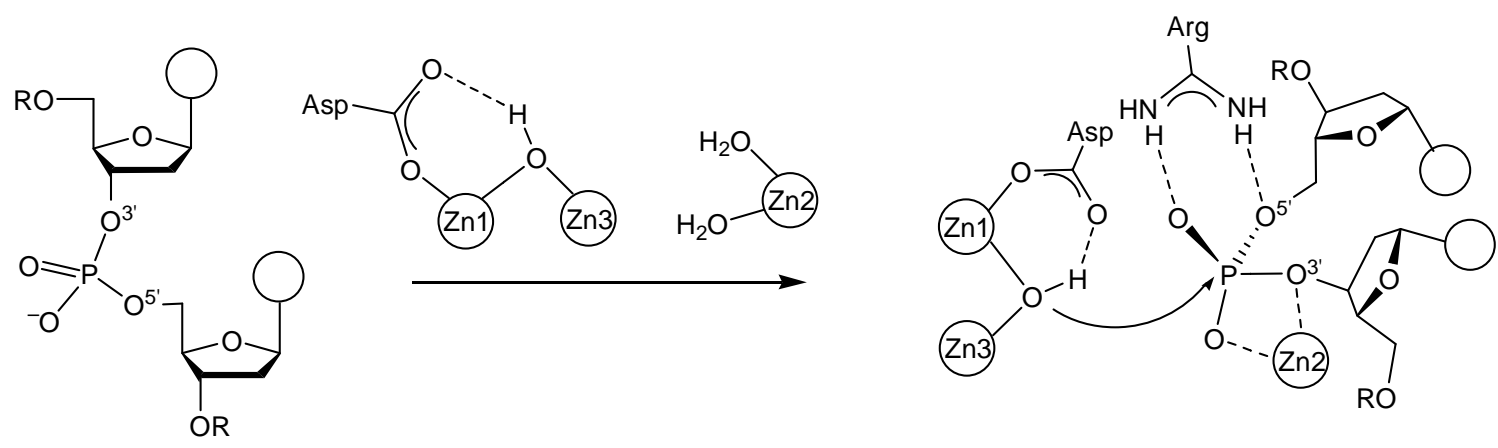

Scheme 1.6: Proposed mechanism of $P 1$ nuclease. 


\subsubsection{Phosphotriesterase}

Organophosphate triesters are no naturally occurring compounds. Because of their high toxicity, they are used as fungicides and insecticides (e.g., Paraoxon) and have also been used as warfare agents (e.g., Sarin or Soman). The resistance of some insects towards insecticides and soil bacteria towards pesticides led to the discovery of the phosphotriesterase enzyme. This binuclear enzyme is highly active in phosphotriester cleavage, but not able to hydrolyse phosphate monoesters or diesters. ${ }^{[12-13]}$ As depicted in Figure 1.5, the active site consists of two zinc centres that are bridged by a carboxylated lysine (KCX-169 in Figure 1.5) and a hydroxide ion. In addition, Zn1 is coordinated by two histidines and one aspartate, while $\mathrm{Zn} 2$ is ligated to two histidines and a water molecule. ${ }^{[21]}$
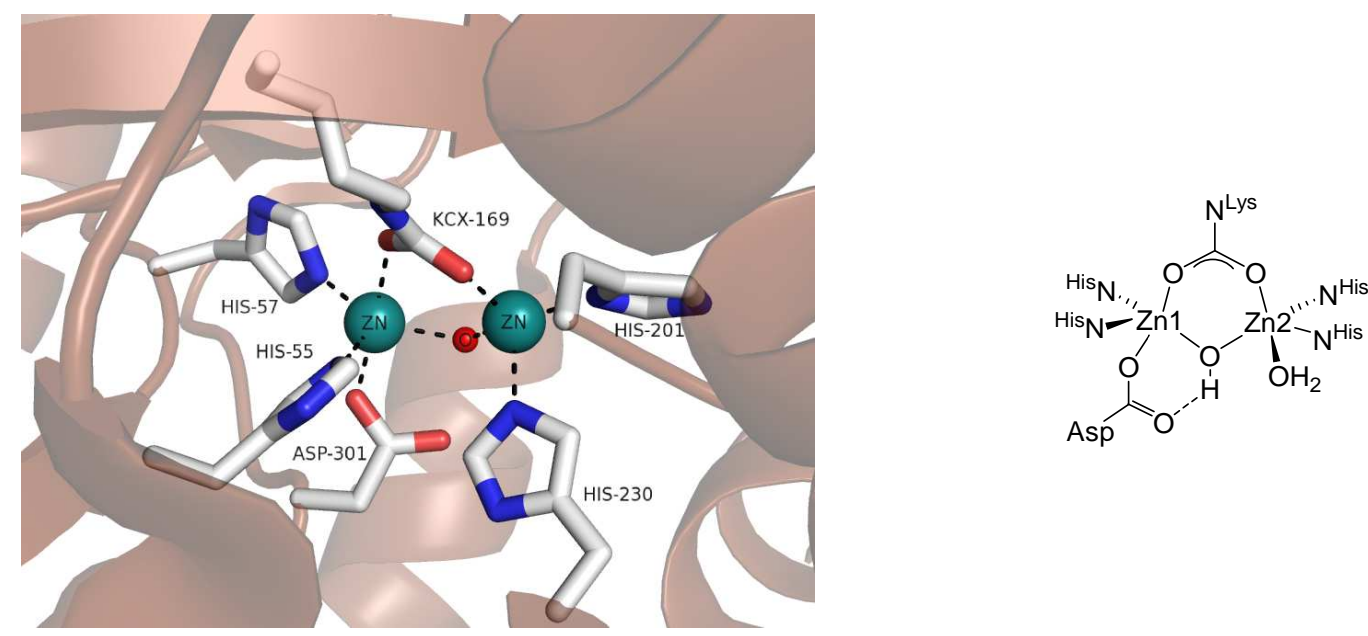

Figure 1.5: Crystal structure of the active site of Pseudomonas diminuta phosphotriesterase (left, PDB Code: $1 \mathrm{EYW})^{[22]}$ and scheme (right).

The proposed mechanism of phosphotriesterase is shown in Scheme 1.7. The initial step is the binding of the substrate $\mathrm{OP}(\mathrm{OR})_{3}$ to the $\mathrm{Zn} 2$ centre with release of the water molecule. This results in the formation of a strong $\mathrm{P}(\mathrm{O})-\mathrm{Zn} 2$ bond, which weakens the binding of $\mu-\mathrm{OH}$ to $\mathrm{Zn} 2$ (b). The nucleophile is then able to attack the phosphorous atom under elimination of the leaving group $\mathrm{RO}^{-}$. Upon proton shuttling with assistance of aspartate and a nearby located histidine, a phosphate bridging enzyme-product complex is formed (c). The hydrolysed product is then released by solvent molecules generating the active site hydroxide $(\mathbf{a}){ }^{[13,21,23]}$ 

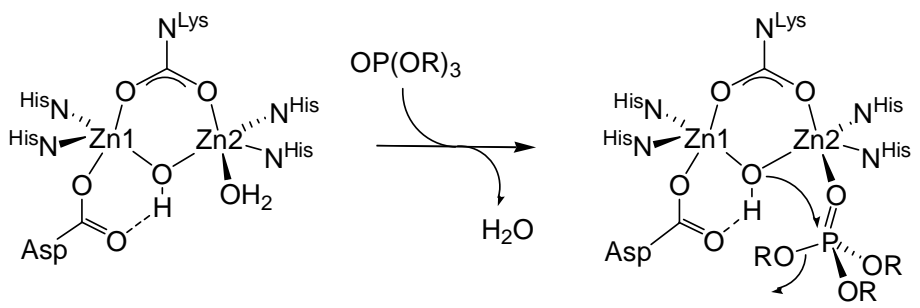

(a)

(b)
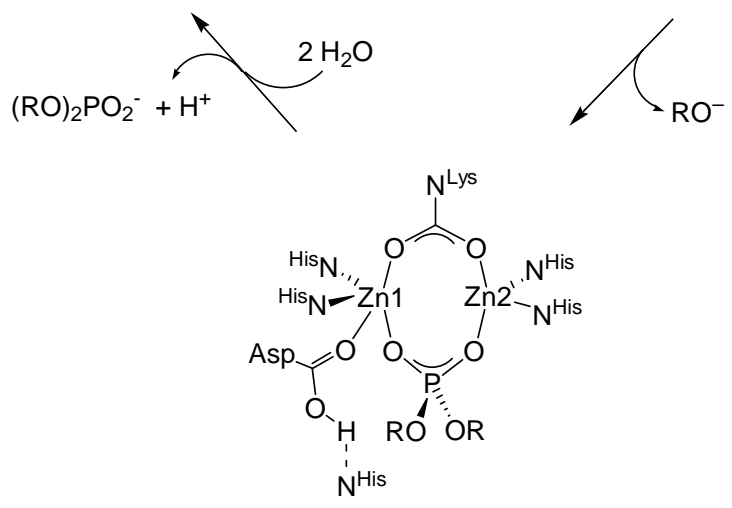

(c)

Scheme 1.7: Proposed mechanism of phosphotriesterase.

\subsubsection{Metallo- $\beta$-Lactamases}

$\beta$-Lactamases are a class of enzymes that are able to cleave the four-membered lactam ring of antibiotics. This cleavage results in the inactivation of the medicinal drug and makes bacteria resistant towards $\beta$-lactam antibiotics, e.g. penicillins, carbapenems and cephalosporins. ${ }^{[24]}$ The classification of $\beta$-lactamases into groups A, B, C and D depends on the molecular structure, which is directly related to their active site and amino acid sequences. ${ }^{[25]}$ Members of group A, C and D bear a serine amino acid residue in their active site and the mode of function is well known. ${ }^{[26]}$ Group B members contain at least one zinc ion in the catalytic centre and are the so called metallo- $\beta$-lactamases $(\mathrm{m} \beta 1 \mathrm{~s})$. Most binuclear $\mathrm{m} \beta 1 \mathrm{~s}$ are broad spectrum enzymes and hydrolyse a wide range of antibiotics, while most mononuclear enzymes are restricted to cleave exclusively carbapenems. $^{[26 \mathrm{a}, 27]}$ Enzyme BcII isolated from Bacillus cereus ${ }^{[28]}$ and CcrA from Bacillus fragilis ${ }^{[26 a, 29]}$ represent the class of $\mathrm{m} \beta 1$ s containing two zinc ions in the active site. 

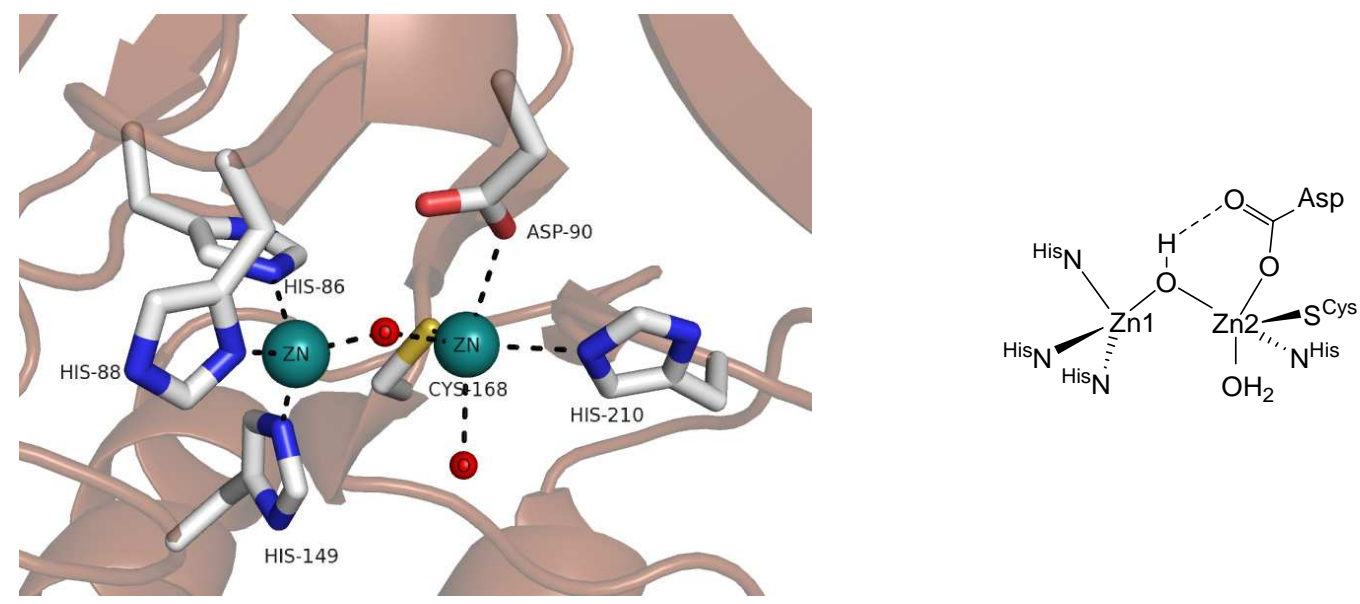

Figure 1.6: Crystal structure of the active site of metallo- $\beta$-lactamase from Bacillus cereus (left, PDB Code: $1 \mathrm{BC} 2$ ) $^{[28 \mathrm{a}]}$ and scheme (right).

In both enzymes, one zinc centre $(\mathrm{Zn} 1)$ is tetrahedrally coordinated by three histidines and a bridging hydroxide ligand (active site of BcII in Figure 1.6). The second zinc ion ( $\mathrm{Zn} 2)$ is penta-coordinated by one histidine, one cysteine, one aspartate and one water molecule. The difference of both active sites is the different affinity of binding zinc ions. While BcII was also found to be present in the mononuclear form due to the weak interaction with $\mathrm{Zn} 2$, both zinc ions are tightly bound in the CcrA enzyme. ${ }^{[29-30]}$ It is reported that the bridging hydroxide, which lies closer to $\mathrm{Zn} 1$, interacts with the aspartate residue that is bound to $\mathrm{Zn} 2$ to bridge the binuclear centre. ${ }^{[28 \mathrm{a}]}$ The functional role of $\mathrm{Zn} 1$ lies in the activation of the substrate during catalysis, while $\mathrm{Zn} 2$ is necessary for stabilisation of the intermediate. ${ }^{[31]}$

Coordination of the substrate to both zinc centres is the initial step in the mechanism (Scheme 1.8). The oxygen atom of the lactam carbonyl moiety binds to $\mathrm{Zn} 1$ polarising the $\mathrm{C}-\mathrm{N}$ bond of the substrate (b). Next step is the nucleophilic attack of the bridging hydroxide resulting in the cleavage of the $\mathrm{C}-\mathrm{N}$ bond. An intermediate with a negatively charged nitrogen atom that is stabilised by $\mathrm{Zn} 2$ was observed by stopped-flow spectroscopic studies (c). Thus, product formation and substrate consumption do not occur simultaneously. Hydrolysis in the next step comprises protonation of the negatively charged nitrogen and ligand exchange at $\mathrm{Zn1}$ (a). The rate-determining step is suggested to be the breakdown of the intermediate. ${ }^{[32]}$ 


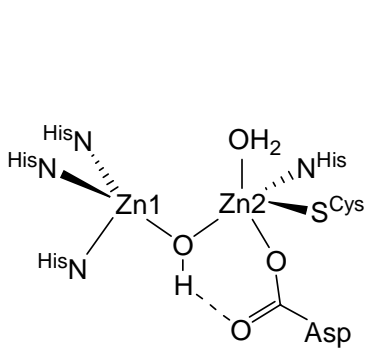

(a)

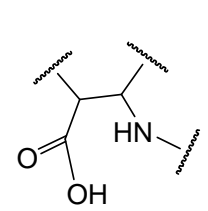

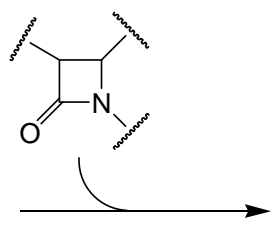

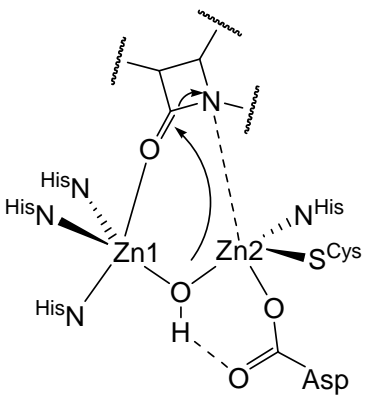

(b)

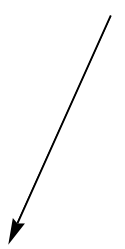

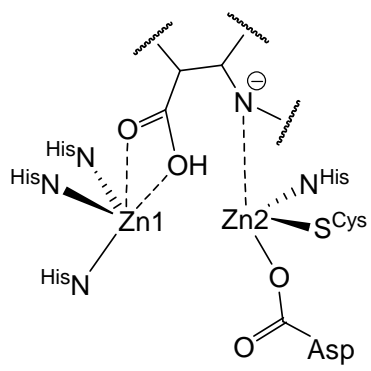

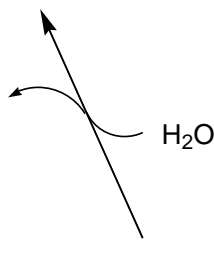

(c)

Scheme 1.8: Proposed mechanism of metallo- $\beta$-lactamases.

Nonetheless, the mechanism of binuclear metallo- $\beta$-lactamase is still controversially discussed in literature. ${ }^{[26 a, 33]}$ Especially the role of the second zinc ion is not fully understood, since mononuclear enzymes showed also activity in hydrolytic reactions. ${ }^{[34]}$ In contrast to this, it is proposed that the "monozinc" species in Bacteroides fragilis enzyme is in fact a mixture of half of the enzyme containing two zinc ions and half having no metal bound into the active site (apoenzyme). ${ }^{[30]}$ Computational studies have contributed significantly to the understanding of $\beta$-lactamase mechanisms. Molecular dynamic simulations and quantum chemical calculations have been carried out to study the function of different amino acid residues in the active sites of enzymes. In addition, possible modes of substrate binding could thus be investigated. ${ }^{[30,35]}$ However, a drawback of most of these studies is the use of simplified model systems, which cannot explain all experimental facts (e.g., influence of $\mathrm{pH}$, kinetic solvent isotope effects, etc.). Another possibility that allows the investigation of hydrolytic reactions in solution is to mimic the active sites of enzymes with synthetic models. These synthetic analogues 
enable the investigations of the catalytic reactions under similar conditions as they are found in nature and support the understanding of the mechanistic pathways of the enzymes.

\subsection{Synthetic Approach to Mimic Metallohydrolases}

The challenge to emulate the active sites of binuclear metallohydrolases is to design suitable ligand systems, which are able to mimic the protein scaffolds and amino acid residues that are present in the active sites of the previously described enzymes. In addition, these ligands should be able to coordinate two metal ions in a predictable way to ensure metal-metal distances as they are found in the enzymes $(3-5 \AA) .{ }^{[12]} \mathrm{A}$ third point that has to be kept in mind is that the binuclear synthetic analogues should provide a hydroxide or metal bound water ligand, which acts as the nucleophile during hydrolytic reactions. Modifications of these synthetic models enable the investigation of necessary conditions that are essential to improve or to inhibit catalysis.

To form binuclear complexes, suitable ligands in most cases bear at least one donor site in the backbone of the ligand scaffold. ${ }^{[23 b]}$ Ligands that feature single-atom bridges and are extensively studied in literature are based on 2,6-substituted phenolates. ${ }^{[36]}$ These ligands are most suitable to form bimetallic complexes, as the $O$-donor atom in the backbone of the ligand and the chelating side chains in positions 2 and 6 ideally fix two zinc ions in close proximity. In addition, modifications of the side chains allow the synthesis of a series of ligands systems, which can be used in complex synthesis.

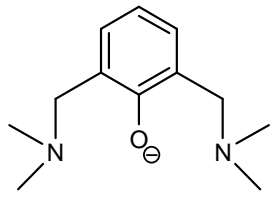

(a)

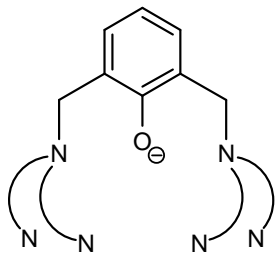

(b)

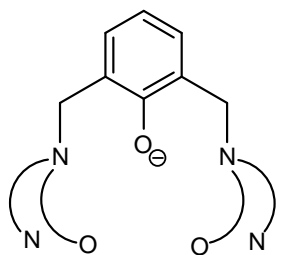

(c)

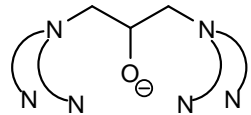

(d)

Scheme 1.9: General overview of ligands based on 2,6-substituted phenolates (a-c) and 1,3-diamino-2-propanols (d). 
On the one hand the phenolate ligand can only be substituted with tertiary amines (Scheme 1.9, a). ${ }^{[37]}$ But additional substitution of the amines with chelating side chains yields a variety of ligands, as it was reported in literature. These side chains can either bear exclusively $N$-donor moieties (Scheme 1.9, b) using aliphatic or aromatic $N$-donor groups ${ }^{[38]}$ or additional $O$-donors (Scheme $\left.1.9, \mathbf{c}\right){ }^{[39]}$ But also the design of asymmetric phenolate based ligands has been reported. ${ }^{[38 \mathrm{~b}, 39 \mathrm{~b}, 40]}$

Another ligand system that features a single $O$-donor bridge is based on 1,3-diamino-2propanols (Scheme 1.9, d). Together with the chelating side chains, two zinc ions can be ideally fixed into the bimetallic pocket yielding suitable models for the active site of zinc containing metallohydrolases. The synthesis of symmetric and asymmetric ligands has been reported, which are substituted with $N$-donor benzimidazole and/or pyridyl moieties. $^{[41]}$

In addition, ligands with two-atom bridges are also common for the synthesis of bimetallic complexes. ${ }^{[36]}$ One example that is based on 1,8-naphtyridine (Scheme 1.10, a) has been developed by the LIPPARD group. ${ }^{[38 c, 42]}$ This ligand bears two nitrogen atoms in the naphtyridine building block and is substituted with secondary amine ligands in positions 2 and 7 of the heterocycle. Working on 3,5-substituted pyrazole ligands (Scheme 1.10, b), MEYER and co-workers were able to design a series of ligands that contain bridges with two adjacent $N$-donor atoms and are well suited to form binuclear complexes. These ligands have been substituted with manifold tertiary amines that bear aliphatic or aromatic $N$-donor groups. ${ }^{[43]}$

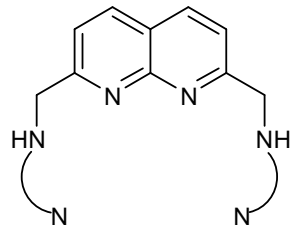

(a)

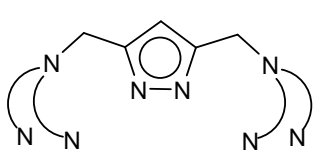

(b)

Scheme 1.10: General schemes of ligands based on 2,7-substituted 1,8-naphtyridine (a) and 3,5-substituted pyrazoles (b). 
The particular feature of this ligand system is the ability to tune the metal to metal distances within the complexes. Using short side chains usually forces the metal atoms to separate, while long side chains allow for shorter metal-metal distances. ${ }^{[43 c, 44]}$

Another generation of ligand systems, which have to be noted, are based on macrocyclic scaffolds. These ligands are also suitable to optimise metal-metal distances depending on the size of the macrocycle. ${ }^{[45]}$ Although the compartments of aza-crown ethers (Scheme 1.11 , a) or macrocyclic diphenolate ligands (Scheme $1.11, \mathbf{b}$ ) are not well suited to emulate the three-dimensional structure of amino acid residues, the binuclear zinc complexes showed activity in the cleavage of phosphate esters (see chapter 2.4.1.). ${ }^{[46]}$

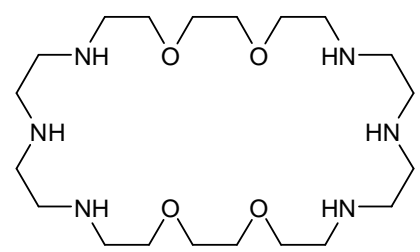

(a)

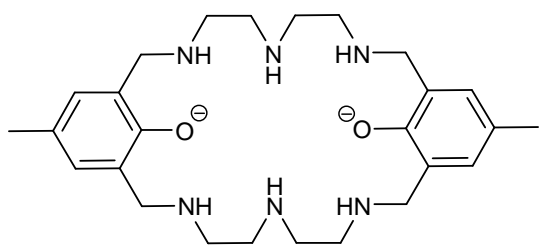

(b)

Scheme 1.11: Ligands based on aza-crown ether (a) and macrocyclic diphenoxide (b).

A suitable ligand that mimics the protein scaffold of the enzymes has been developed using substituted calix[4]arenes (Scheme 1.12). ${ }^{[47]}$ The hydrophobic pocket is similar to the polypeptide backbone of the enzymes and can be modified with multiple catalytic groups to mimic amino acid residues making this system highly suitable to emulate the biological archetypes.

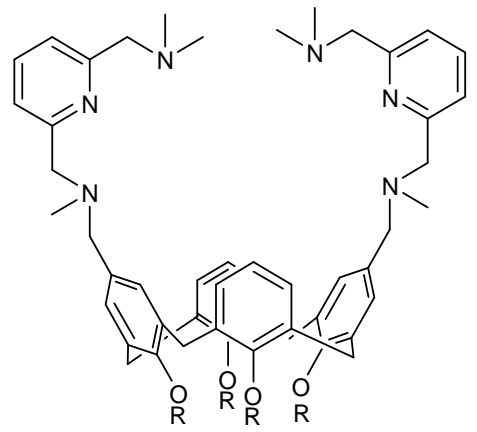

Scheme 1.12: Calix[4] arene based ligand mimicking the protein scaffold of the enzymes $\left[\mathrm{R}=\mathrm{CH}_{2} \mathrm{CH}_{2} \mathrm{OEt}\right]$. 
As mentioned above, the presented ligands have been used in complex synthesis to form bimetallic zinc complexes, which mimic the active sites of zinc containing metallohydrolases. The required nucleophile is generated by the deprotonation of a solvent molecule (e.g. water or methanol). Details of the respective complexes that have been investigated in the cleavage of $\beta$-lactam substrates emulating metallo- $\beta$-lactamases are given in section 2.3.1. In addition, complexes which are active to cleave phosphate diesters and triesters are discussed in section 2.4.1.

\subsection{Aim of this Work}

Based on the above mentioned 3,5-substituted pyrazole ligand, the aim of this work is to design binuclear zinc complexes (Scheme 1.13) that emulate the active sites of zinc containing binuclear metallohydrolases (metallo- $\beta$-lactamases, phosphate diesterases and triestereases).

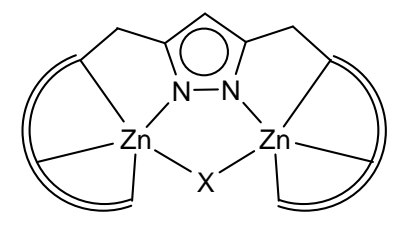

Scheme 1.13: Schematic representation of binuclear zinc complexes based on 3,5-substituted pyrazole ligands, $\mathrm{X}=$ nucleophile.

The chelating side chains of the pyrazole ligands are modified by different donor moieties. Bearing aromatic groups, side chains containing imidazole and benzimidazole moieties are a common motif to mimic histidine. In addition, carboxylate groups are used to emulate aspartate. The characteristics of these binuclear complexes are studied in solid state and in solution. In addition, the complexes are investigated in their hydrolytic activity to cleave Penicillin G and phosphate esters. From previous studies with similar ligand systems it is known that complexes with short zinc-zinc separations are more active in the hydrolysis of Penicillin G, while complexes with long zinc distances show a higher activity in phosphate ester cleavage. ${ }^{[48]}$ Based on these results, the correlation of the zinc distances and their hydrolytic activity in complexes that bear biomimetic donor 
groups is investigated. This work is also focused on the interaction between $\beta$-lactam antibiotic drugs and the zinc atoms of the complexes. The knowledge about the binding motifs of the substrates supports the investigation of the mechanistic pathways of the enzymes. The synthetic analogues can thus be optimised to improve their catalytic efficacy.

As described above, the active site of the mononuclear enzyme carbonic anhydrase consists of three histidine amino acid residues and one water molecule and metabolises $\mathrm{CO}_{2}$. Although the complexes studied in this work are binuclear systems, selected complexes bearing imidazole moieties and a water or hydroxide ligand are investigated with respect to $\mathrm{CO}_{2}$ activation. Transforming $\mathrm{CO}_{2}$ is of great industrial and academic interest, since $\mathrm{CO}_{2}$ is an abundant and nontoxic basic material. The catalytic efficacy of the complex is investigated in the copolymerisation reaction of cyclohexene oxide and in the formation of propylene carbonate. 


\section{Results and Discussion}

\subsection{Ligand Synthesis}

The backbone of all ligand systems used in this work is based on a $1 H$-pyrazole building block, which is substituted with chelating side chains in 3 and 5 positions of the heterocycle. To emulate amino acid residues, the side chains contain biomimetic functional groups. $\mathrm{N}$-donor moieties imidazole and benzimidazole are used to mimic histidine and $O$-donor functions of the carboxylate moieties emulate aspartate. A pyrazole-based ligand that bears imidazole moieties to emulate histidine amino acid residues has already been described in literature. ${ }^{[43 \mathrm{~d}]}$ In addition, three novel ligands, which differ in the length of side chains and in the manner of donor atoms, have been designed and synthesised within this work (Scheme 2.1).

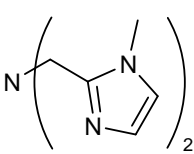

$\mathrm{NR}_{2}$

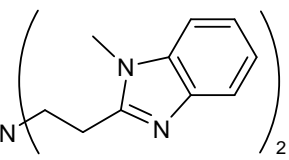

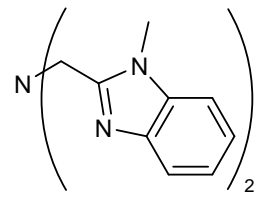<smiles>Cn1ccnc1CNCC(=O)[O-]</smiles>

Scheme 2.1: Overview of ligand systems containing biomimetic $N$-and $O$-donor functions.

Synthesis of the building block 3,5-bis(chloromethyl)- $1 \mathrm{H}$-pyrazole (I) from 3,5-dimethyl$1 H$-pyrazole was carried out in a 4 steps synthesis (Scheme 2.2) as reported in the literature. ${ }^{[49]}$
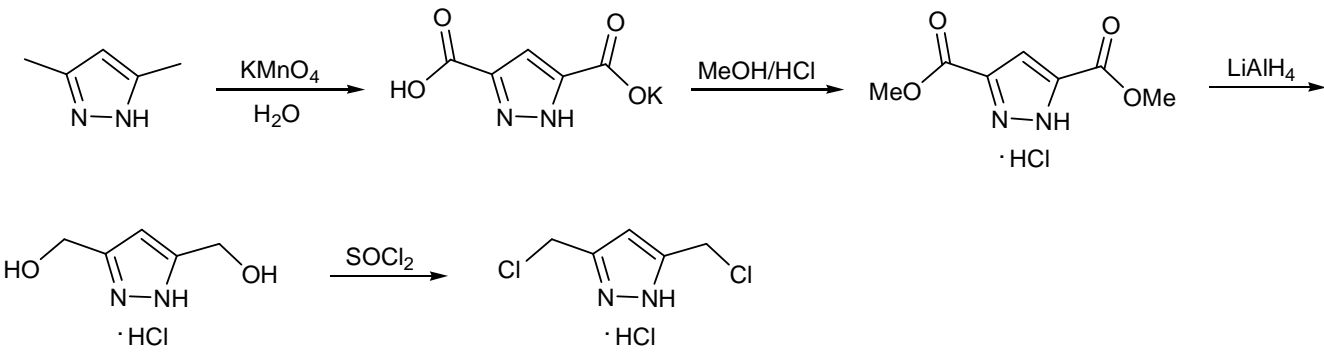
Side chain bis-((1-methyl-1H-imidazol-2-yl)methyl)amine (II) was synthesised as described in litertaure. ${ }^{[50]}$ Bis-((1-methyl-1H-benzimidazol-2-yl)methyl)amine $(\mathbf{V})^{[51]}$ and bis((1-methyl-1H-benzimidazol-2-yl)ethyl)amine (VII $)^{[52]}$ were synthesised according to published procedures and the workup was modified to obtain higher yields. The secondary amine $\mathbf{X}$ was synthesised in 2 steps from $N$-methyl-1H-pyrazole (VIII). Deprotonation with $n$-butyl lithium followed by addition of dimethylformamide yielded $\mathrm{N}$-methyl-1H-imidazole-2-carbaldehyde (IX), which was further treated with glycine ethyl ester and sodium triacetoxyborohydride to obtain ethyl 2-(((1-methyl-1H-imidazol2-yl)methyl)amino)acetate $(\mathbf{X})$. An overview of the side chain syntheses is given in Scheme 2.3.
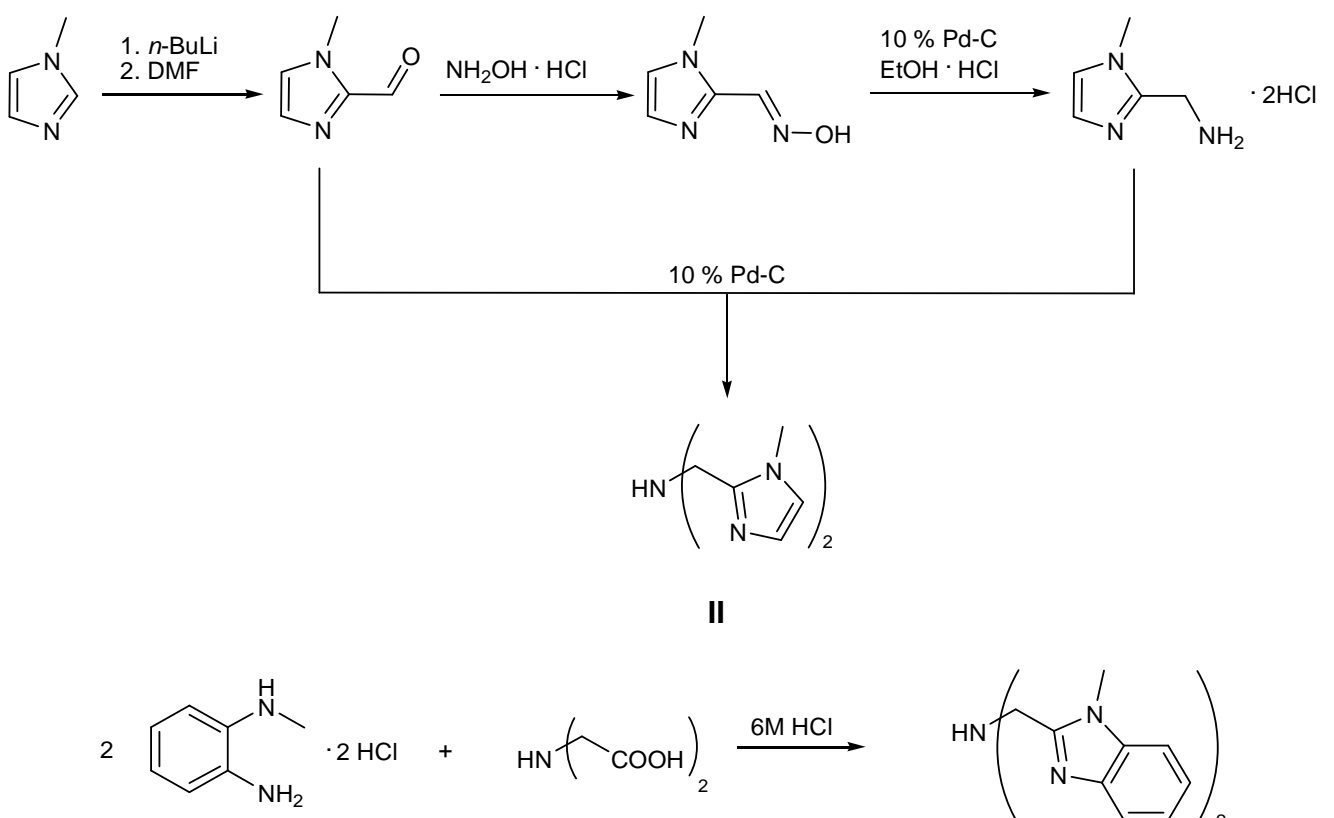

III

IV<smiles>CC(C)c1nc2ccccc2n1C</smiles>

V

2

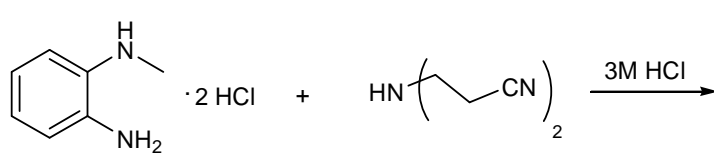

III

VI<smiles>CC(C)NCc1nc2ccccc2n1C</smiles>

VII<smiles>CCOC(=O)CNCc1nccn1C</smiles>

$\mathbf{x}$

Scheme 2.3: Overview of side chain syntheses of II, V, VII and X. 
The desired ligands are synthesised by coupling the secondary amines (II, V, VII and X) with compound I via nucleophilic substitution. It was found that every ligand system has to be treated differently and the reaction conditions have to be optimised for each of them. In general, one equivalent of compound I, two equivalents of secondary amine and ten equivalents of sodium carbonate were used. $\mathbf{L}^{\mathbf{1}}$ (Scheme 2.5) was formed in the presence of acetonitrile under reflux as described in literature. ${ }^{[43 d]}$ Best results for ligands $\mathbf{L}^{2}$ and $\mathbf{L}^{3}$ were obtained using chloroform as solvent (Scheme 2.5). The reaction was carried out under ambient conditions and was monitored by ${ }^{1} \mathrm{H}$ NMR spectroscopy. Although this synthetic route was also performed in different solvents (e.g., methanol, acetonitrile and acetone), products were only obtained in the presence of chloroform. Since compound $\mathbf{X}$ bears a reactive ethyl ester group, synthesis of precursor- $\mathbf{L}^{4}$ was found to be challenging. Although the substitution reaction was performed in a variety of solvents and under different conditions (e.g., different bases and temperatures), no product was obtained. In a similar reaction with ethyl ester side chains, the formation of a heterocycle was observed under harsh conditions (heating or reflux). A nucleophilic attack of the nitrogen atom at the carbon atom led to elimination of ethanol and formation of the 1,4-substituted 2,5-piperazinedione heterocycle. This reaction might also be possible for compound $\mathbf{X}$ (Scheme 2.4). Keeping this in mind, the synthesis of precursor- $\mathbf{L}^{4}$ was optimised under mild conditions. Stirring at room temperature in the presence of ethyl acetate and sodium carbonate led to the formation of precursor- $\mathbf{L}^{4}$ as a colourless sticky oil (Scheme 2.5). To obtain $\mathbf{L}^{\mathbf{4}}$, hydrolysis of the ethyl ester moieties was carried out in aqueous solution using different hydroxides $(\mathrm{NaOH}, \mathrm{KOH}$ and $\mathrm{LiOH})$. Although the ligand was formed, $\mathbf{L}^{4}$ could not be purified due to impurities of inorganic salts (i.e., $\mathrm{NaCl}, \mathrm{KCl}, \mathrm{LiCl}$ ). Therefore, precursor- $\mathbf{L}^{4}$ was used without further purification for the synthesis of the complexes in a one-pot reaction.

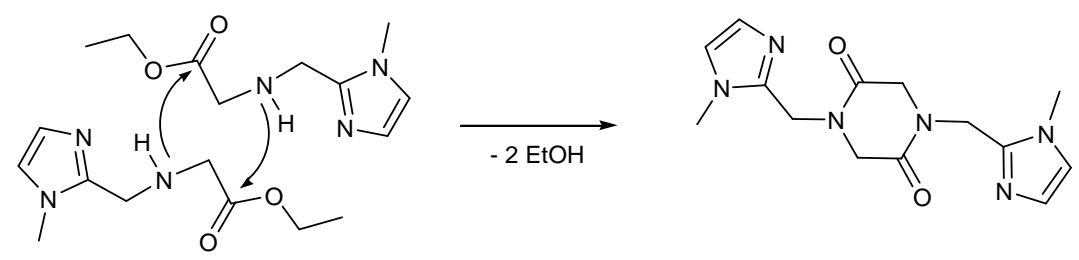

Scheme 2.4: Possible product formation during precursor- $\mathbf{L}^{4}$ synthesis under harsh conditions $(\Delta T)$. 
(

II

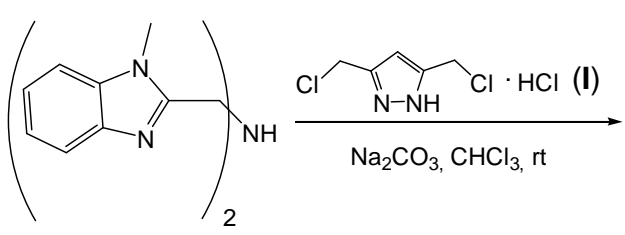

V

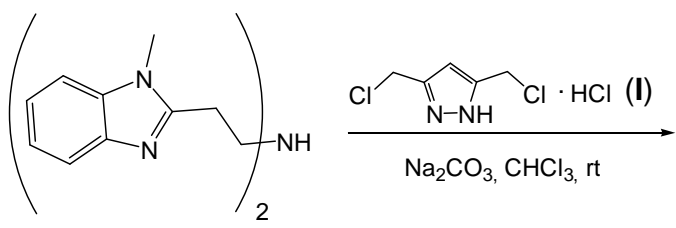

VII

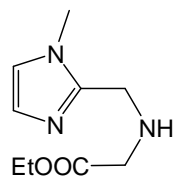

$\underset{\mathrm{Na}_{2} \mathrm{CO}_{3}, \mathrm{EtOAc}, \mathrm{rt}}{\stackrel{\mathrm{N}-\mathrm{NH}}{\mathrm{Cl}} \cdot \mathrm{HCl}(\mathrm{I})}$

$\mathbf{X}$

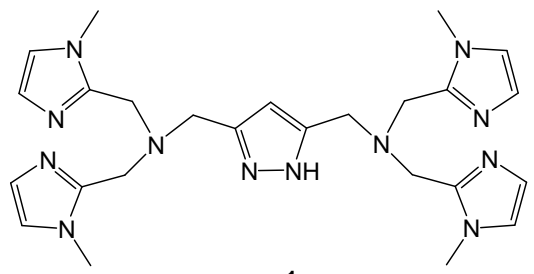

$\mathrm{L}^{1}$

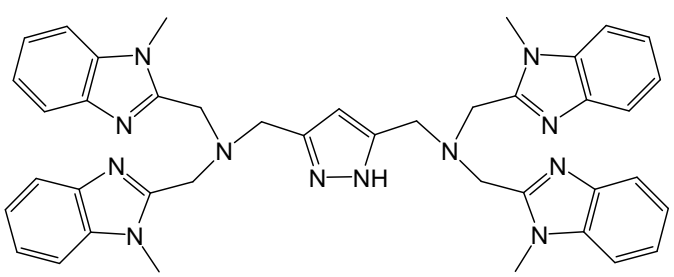

$L^{2}$

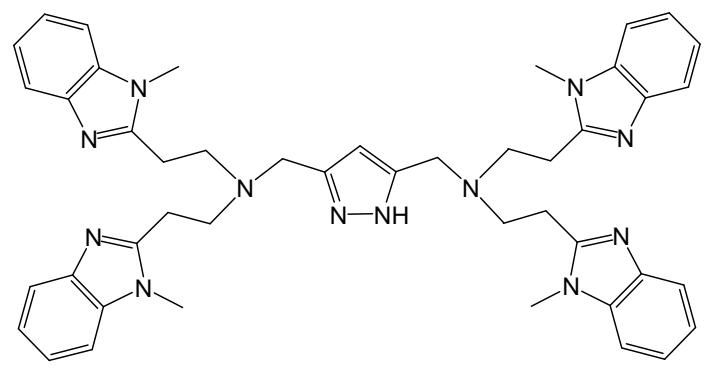

$\mathrm{L}^{3}$

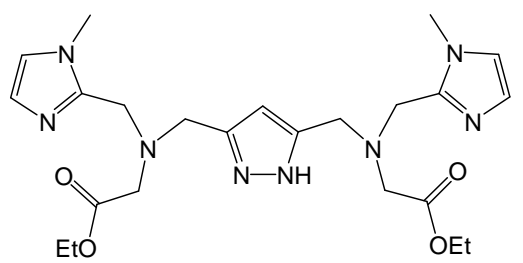

precursor-L ${ }^{4}$

Scheme 2.5: Overview of ligand syntheses. 


\subsection{Complex Synthesis}

As mentioned in the introduction, 3,5-substituted pyrazole ligands are prone to form binuclear metal complexes. For hydrolysis activity, it is necessary that the complex features a nucleophile, which is able to attack. This nucleophile is either a hydroxide or methanolate group (for short metal-metal separations); in the resting state it might be incorporated in a $\mathrm{H}_{3} \mathrm{O}_{2}(\mathrm{HOH} \cdots \mathrm{OH})$ or $\mathrm{Me}_{2} \mathrm{O}_{2} \mathrm{H}(\mathrm{MeOH} \cdots \mathrm{OMe})$ moiety for longer metalmetal distances. In order to ensure formation of a nucleophile, ligands were treated with two equivalents of base $\left(\mathrm{KO}^{t} \mathrm{Bu}\right.$ or alkali metal hydroxides): one equivalent for deprotonation of the pyrazole ligand and the other one for solvent deprotonation $(\mathrm{MeOH}$ or $\left.\mathrm{H}_{2} \mathrm{O}\right)$. In addition, two equivalents of zinc salt $\left(\mathrm{Zn}\left(\mathrm{ClO}_{4}\right)_{2} \cdot 6 \mathrm{H}_{2} \mathrm{O}\right.$ or $\left.\mathrm{Zn}\left(\mathrm{SO}_{3} \mathrm{CF}_{3}\right)_{2}\right)$ were added to form the desired binuclear zinc complexes. Since ligands $\mathbf{L}^{\mathbf{1}}, \mathbf{L}^{\mathbf{2}}$ and $\mathbf{L}^{\mathbf{3}}$ are singly negatively charged when deprotonated, the resulting complexes (with nucleophile) bear two positive charges. Keeping in mind that substrate exchange might be inhibited during hydrolysis due to strong interactions of the negatively charged substrate and the positively charged complex, $\mathbf{L}^{\mathbf{4}}$, a ligand which contains three negative charges when fully deprotonated, was designed. Such solution results in a singly negatively charged complex (without nucleophile) or a neutral complex (with nucleophile) that should allow fast substrate exchange.

\section{Calculation of $\tau_{5}$ parameters:}

In five-coordinated complexes, the coordination polyhedra can be described as trigonal bipyramidal or square pyramidal geometry. The index of the degree of trigonality, within the continuum between both geometries, can be determined by the geometric parameter $\tau_{5}$. This structural index parameter is defined by $(\beta-\alpha) / 60^{\circ}$, whereby $\alpha$ and $\beta$ are the two largest bond angles (Scheme 2.6). ${ }^{[53]}$ This geometric parameter is equal to zero for perfectly tetragonal geometry $\left(\alpha=\beta=180^{\circ}\right)$, while it becomes one for a perfectly trigonal bipyramidal geometry $\left(\alpha=120^{\circ}, \beta=180^{\circ}\right)$. Displacement of $\mathrm{M}$ out of the plane spanned by the equatorial ligands toward A can result in values $\tau_{5}>1$.
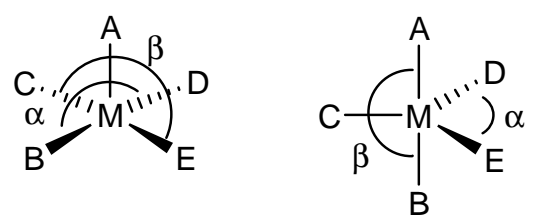

Scheme 2.6: Schematic representation of parameter $\tau_{5}$. 


\subsubsection{Species Distribution of $\mathrm{L}^{1}$ and Complexes}

Potentiometric titrations have been performed by Dr. J. Gałęzowska ${ }^{[54]}$ to determine the $\mathrm{p} K_{\mathrm{a}}$ values of the ligand and to investigate the stoichiometry and stability of zinc complexes containing $\mathbf{L}^{\mathbf{1}}$ at different $\mathrm{pH}$ values. Measurements were carried out in aqueous solution of $0.1 \mathrm{M} \mathrm{KCl}$ to maintain ionic strength and were started at acidic $\mathrm{pH}$. Overall protonation constants $(\log \beta)$ and sequential dissociation constants $\left(\mathrm{p} K_{\mathrm{a}}\right)$ of $\mathbf{L}^{\mathbf{1}}$ and thermodynamic stability constants of complexes formed with $\mathrm{Zn}^{2+}$ are given in Table 2.1 and Table 2.2, respectively.

Table 2.1: Overall Protonation Constants $(\log \beta)$ and Sequential Dissociation Constants (pK $K_{\mathrm{a}}$ ) of $\mathbf{L}^{1}$ at $25^{\circ} \mathrm{C}$ with $I=0.1 \mathrm{M}(\mathrm{KCl})$.

\begin{tabular}{c||cccc}
\hline & {$\left[\mathrm{H}_{4} \mathrm{~L}^{1}\right]^{4+}$} & {$\left[\mathrm{H}_{3} \mathrm{~L}^{1}\right]^{3+}$} & {$\left[\mathrm{H}_{2} \mathrm{~L}^{1}\right]^{2+}$} & {$\left[\mathrm{HL}^{1}\right]^{+}$} \\
\hline \hline $\log \beta$ & $25.81(1)$ & $20.66(1)$ & $14.73(1)$ & $7.86(1)$ \\
$\mathrm{p} K_{\mathrm{a}}$ & 5.15 & 5.94 & 6.87 & 7.86 \\
\hline
\end{tabular}

Table 2.2: Overall Stability Constants $(\log \beta)$ and Dissociation Constants $\left(\mathrm{p} K_{\mathrm{a}}\right)$ for the Complexes formed with $\mathrm{Zn}^{2+}$ at $25{ }^{\circ} \mathrm{C}$ with $I=0.1 \mathrm{M}(\mathrm{KCl})$

\begin{tabular}{c|cccccc}
\hline & {$\left[\mathrm{ZnH}_{2} \mathrm{~L}^{1}\right]^{4+}$} & {$\left[\mathrm{Zn}_{2} \mathrm{~L}^{1}\right]^{4+}$} & {$\left[\mathrm{Zn}_{2} \mathrm{H}_{-1} \mathrm{~L}^{1}\right]^{3+}$} & {$\left[\mathrm{Zn}_{2} \mathrm{H}_{-2} \mathrm{~L}^{1}\right]^{2+}$} & {$\left[\mathrm{Zn}_{4} \mathrm{H}_{-5}\left(\mathrm{~L}^{1}\right)_{2}\right]^{3+}$} & {$\left[\mathrm{Zn}_{4} \mathrm{H}_{-6}\left(\mathrm{~L}^{1}\right)_{2}\right]^{2+}$} \\
\hline $\log \beta$ & $23.66(1)$ & $19.11(1)$ & $14.30(1)$ & $7.94(2)$ & $11.38(6)$ & $2.54(7)$ \\
$\mathrm{p} K_{\mathrm{a}}$ & & & 6.36 & & 8.84 & \\
\hline
\end{tabular}

The ligand behaves under these conditions of titrations $(\mathrm{pH} 2.5-10)$ as a $\left[\mathrm{H}_{4} \mathrm{~L}\right]^{4+}$ acid in which the sequential deprotonation steps correspond to the dissociation of one proton per each protonated imidazole moiety. The very acidic pyrazole proton, which was sometimes reported in similar ligand systems, is out of range of measurements, since it occurs below $\mathrm{pH} 2$ and was not estimated here. ${ }^{[48 \mathrm{a}]}$

As demonstrated in the species distribution pattern (Figure 2.1), the ligand shows a high affinity to bind $\mathrm{Zn}^{2+}$; the coordination process starts already below $\mathrm{pH}$ 2. Although a mononuclear species $\left[\mathrm{ZnH}_{2} \mathrm{~L}^{1}\right]^{4+}$ is observed below $\mathrm{pH} 4$, different binuclear species are formed within $\mathrm{pH} 3.7$ to 7.5. Above $\mathrm{pH} 7.5$, tetranuclear species are present. The broad overlays of species distributions reduce the $\mathrm{pH}$ range, wherein one single species is preferably formed and thus hamper a controlled complex synthesis. The first binuclear 
zinc species, which dominates around $\mathrm{pH} 4$, is $\left[\mathrm{Zn}_{2} \mathrm{~L}^{1}\right]^{4+}$. The heterocycle in this complex is still protonated. We assume that one zinc ion is coordinated by the four nitrogen atoms of the side chain and the pyrazole ring, while the second zinc ion is only ligated by the tripodal imidazole side. The next protonation step results in the formation of $\left[\mathrm{Zn}_{2} \mathrm{H}_{-1} \mathrm{~L}^{1}\right]^{3+}$, the sole species at $\mathrm{pH} 4.8$ to 6.4. This complex is formed, if one equivalent of base is used for the deprotonation of the pyrazole ring during the synthesis of the complexes.

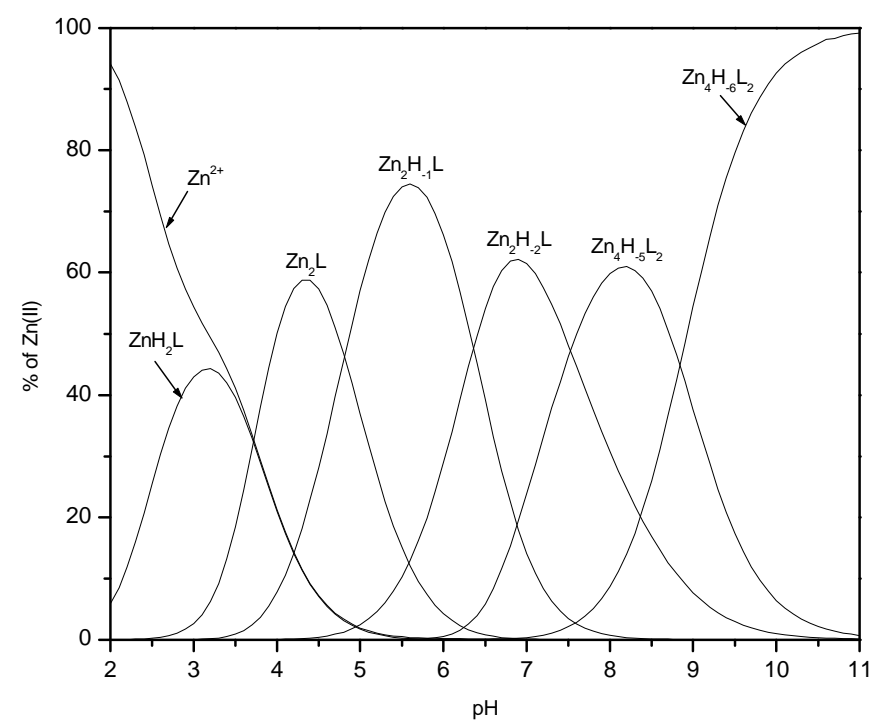

Figure 2.1: Distribution curves of the species formed between $\mathbf{L}^{\mathbf{1}}$ and $\mathrm{Zn}^{2+}$ at a 1:2 ligand to metal ratio.

Under neutral to slightly basic conditions, the major species $\left[\mathrm{Zn}_{2} \mathrm{H}_{-2} \mathrm{~L}^{1}\right]^{2+}$ is observed. This complex is presumably the active one in hydrolysis since it bears a nucleophile $(\mathrm{OH}$ or $\mathrm{H}_{3} \mathrm{O}_{2}$ under aqueous conditions). ${ }^{[48,55]}$ Increasing the $\mathrm{pH}$ results in formation of a tetranuclear complex $\left[\mathrm{Zn}_{4} \mathrm{H}_{-5}\left(\mathrm{~L}^{1}\right)_{2}\right]^{3+}$. This species is preferably formed at $\mathrm{pH} 7.5$ to 8.8 . The next deprotonation step results in the formation of $\left[\mathrm{Zn}_{4} \mathrm{H}_{-6}\left(\mathrm{~L}^{1}\right)_{2}\right]^{2+}$.

Complexes that correspond to species $\left[\mathrm{ZnH}_{2} \mathrm{~L}^{1}\right]^{4+},\left[\mathrm{Zn}_{2} \mathrm{H}_{-1} \mathrm{~L}^{1}\right]^{3+},\left[\mathrm{Zn}_{2} \mathrm{H}_{-2} \mathrm{~L}^{1}\right]^{2+}$ and $\left[\mathrm{Zn}_{4} \mathrm{H}_{-5}\left(\mathrm{~L}^{1}\right)_{2}\right]^{3+}$ are also obtained during synthesis and will be discussed in the following section. 


\subsubsection{Complexes based on $\mathrm{L}^{1}$}

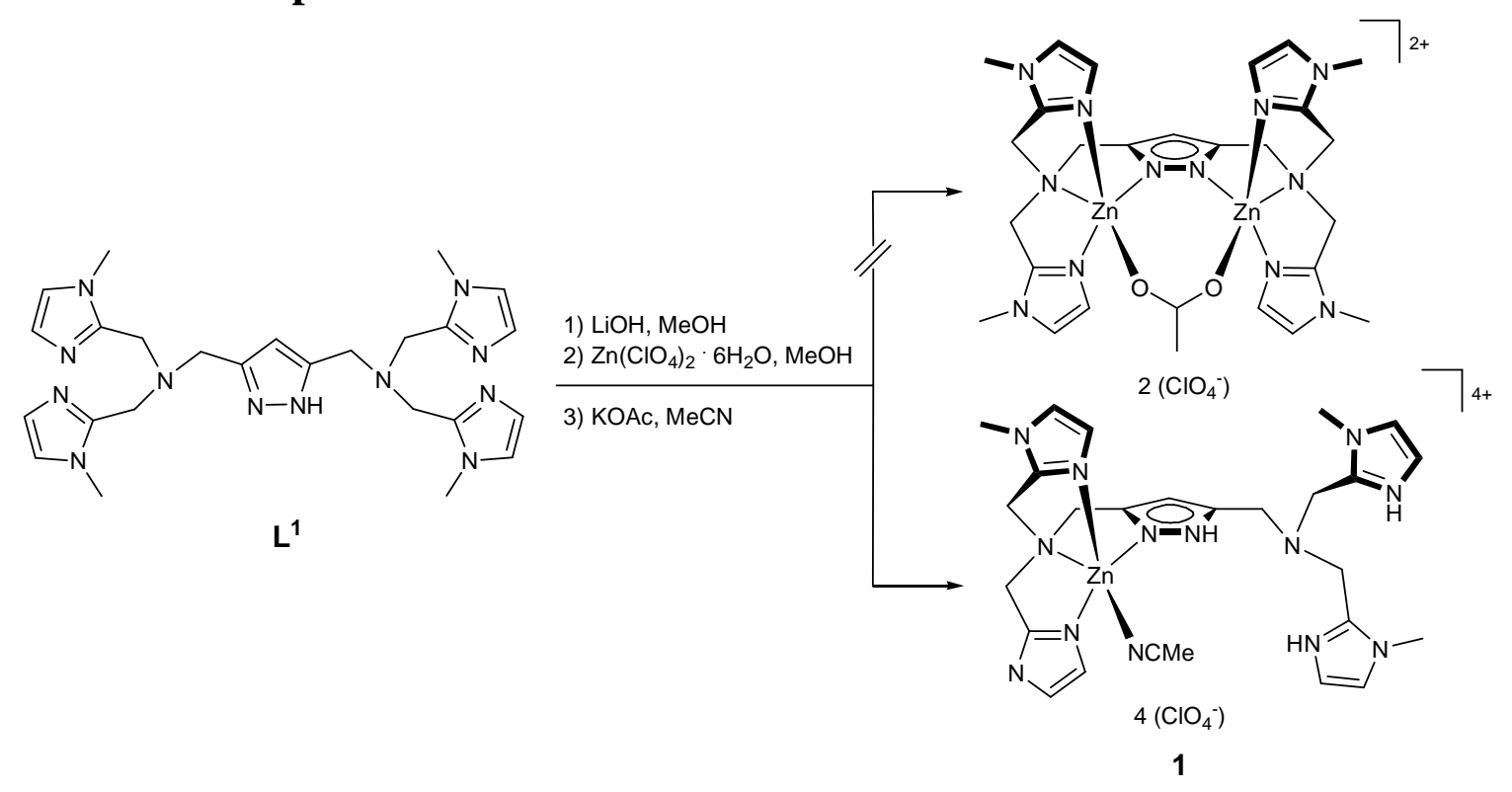

Scheme 2.7: Synthesis of 1 .

The mononuclear complex $\mathbf{1}$ was obtained in the reaction of $\mathbf{L}^{1}$ with $\mathrm{Zn}\left(\mathrm{ClO}_{4}\right)_{2} \cdot 6 \mathrm{H}_{2} \mathrm{O}$ and represents $\left[\mathrm{ZnH}_{2} \mathrm{~L}^{1}\right]^{4+}$. Although the ligand was treated with one equivalent of the respective base, two equivalents of zinc salt and one equivalent of KOAc to obtain an acetate bridged binuclear complex, only a few single crystals of the mononuclear species 1 were obtained. As indicated in Figure 2.1, this complex is present at $\mathrm{pH}<4$ in solution. The isolation of this complex might be by reason of a low quality of the $\mathrm{LiOH}$ or the hydrochloric salt of the ligand $\left(\mathbf{L}^{\mathbf{1}} \cdot \mathrm{xHCl}\right)$ used in the synthesis shown in Scheme 2.7. Within this complex, the $\mathrm{N}$-atom of the heterocycle and the two $\mathrm{N}$-atoms of the imidazoles of one of the side chains are protonated and form hydrogen bonds with oxygen atoms of the perchlorate counter ions. In addition, the zinc ion is nested within the tripodal side chain and the nitrogen atom of the pyrazole ring. Coordination of an additional acetonitrile molecule results in a trigonal bipyramidal coordinated zinc atom $\left(\tau_{5}=0.89\right) .{ }^{[53]}$ As shown in Figure 2.2, one imidazole group of the loosely bound side arm is disordered. Selected bond lengths and angles for $\mathbf{1}$ are given in Table 2.3 and hydrogen bond parameters are listed in Table 2.4. 


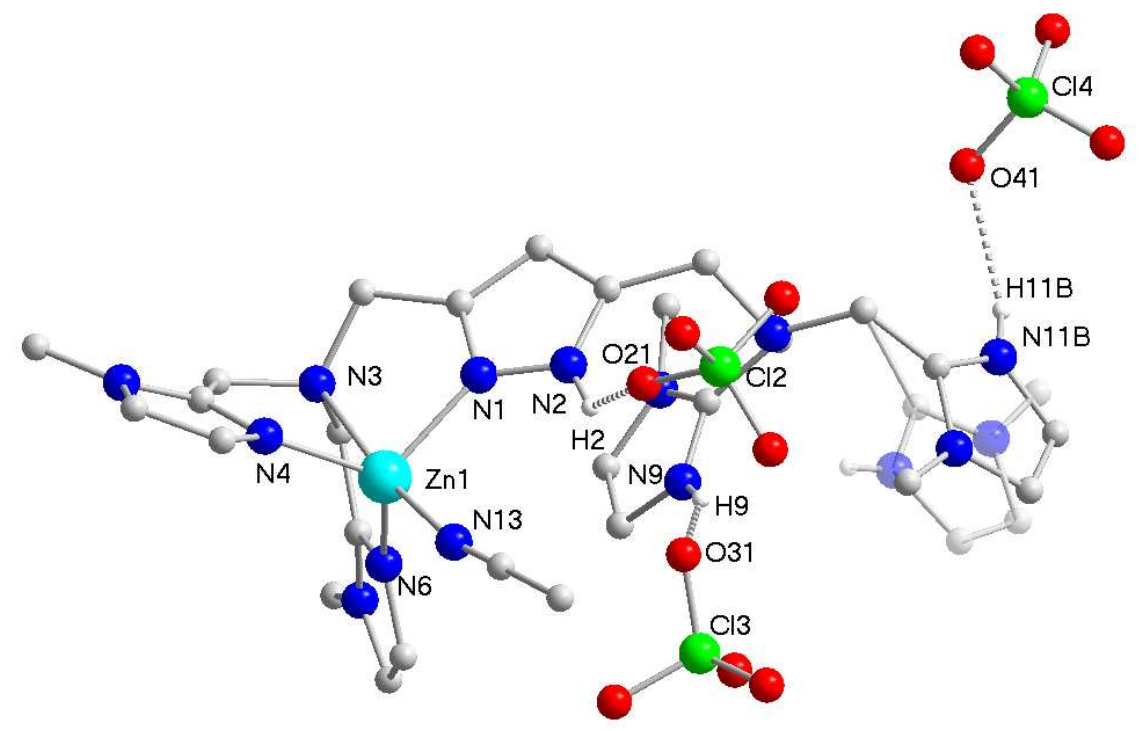

Figure 2.2: Molecular structure of 1, most hydrogen atoms and one counter ion omitted for clarity.

Table 2.3: Selected bond lengths $[\AA]$ and angles $\left[{ }^{\circ}\right]$ of $\mathbf{1}$.

\begin{tabular}{c|cc|c}
\hline Atoms & Bond length & Atoms & Angle \\
\hline \hline Zn1-N1 & $2.026(4)$ & N1-Zn1-N3 & $75.40(13)$ \\
Zn1-N3 & $2.421(3)$ & N1-Zn1-N4 & $115.71(16)$ \\
Zn1-N4 & $1.992(4)$ & N1-Zn1-N6 & $109.23(17)$ \\
Zn1-N6 & $1.992(4)$ & N1-Zn1-N13 & $97.66(15)$ \\
Zn1-N13 & $2.074(4)$ & N3-Zn1-N4 & $77.07(14)$ \\
& & N3-Zn1-N6 & $77.14(14)$ \\
& & N3-Zn1-N13 & $172.69(14)$ \\
& & N4-Zn1-N6 & $119.29(16)$ \\
& & N4-Zn1-N13 & $104.42(16)$ \\
& & N6-Zn1-N13 & $107.77(15)$ \\
\hline
\end{tabular}

Table 2.4: Hydrogen bond parameter; interatomic distances $[\AA ̊]$ and angles $\left[{ }^{\circ}\right]$ for $\mathbf{1}$.

\begin{tabular}{ccccc}
\hline $\mathrm{D}-\mathrm{H} \cdots \mathrm{A}$ & $d(\mathrm{D}-\mathrm{H})$ & $d(\mathrm{H} \cdots \mathrm{A})$ & $d(\mathrm{D} \cdots \mathrm{A})$ & $\angle(\mathrm{D}-\mathrm{H} \cdots \mathrm{A})$ \\
\hline \hline $\mathrm{N} 2-\mathrm{H} 2 \cdots \mathrm{O} 21$ & $0.83(7)$ & $2.39(7)$ & $2.935(6)$ & $124(6)$ \\
$\mathrm{N} 9-\mathrm{H} 9 \cdots \mathrm{O} 31$ & $0.79(7)$ & $2.21(8)$ & $2.945(7)$ & $154(8)$ \\
$\mathrm{N} 11 \mathrm{~B}-\mathrm{H} 11 \mathrm{~B} \cdots \mathrm{O} 41$ & $0.86(1)$ & $2.17(4)$ & $2.941(11)$ & $148.4(7)$ \\
\hline
\end{tabular}


Signals for the protonated pyrazole and the imidazole groups were also found in ${ }^{1} \mathrm{H}$ NMR. A singlet for the two imidazole $\mathrm{NH}$ was observed at $11.8 \mathrm{ppm}$ and the protonated pyrazole $\mathrm{NH}$ gave a signal at $12.0 \mathrm{ppm}$ at room temperature. The ${ }^{1} \mathrm{H}$ NMR spectrum was also measured at low temperatures (253 and $233 \mathrm{~K}$ ). Although chemical shifts did not change significantly, the broad signals for the $\mathrm{CH}_{2}$ groups were split into one singlet for each group. ESI spectra of $\mathbf{1}$ showed various fragments of mononuclear zinc complexes. It seemed that $\mathbf{1}$ was not stable under electrospray conditions, since no fragments have been observed that feature three protonated heterocycles. Under the used conditions, two heterocycles were deprotonated giving a signal at $m / z=665$, which could be assigned to fragment $\left[\mathrm{ZnL}^{1}(\mathrm{ClO})_{4}\right]^{+}$, and $\left[\mathrm{ZnL}^{1}\right]^{2+}$ at $m / z=283$. An additional signal at $m / z=601$ was observed, which matched to $\left[\mathrm{ZnL}^{1}(\mathrm{OH})\left(\mathrm{OH}_{2}\right)\right]^{+}$. However, the protonation state of the heterocycles was additionally confirmed by IR spectroscopy, which revealed two sharp signals at $\tilde{v}=3362$ and $3163 \mathrm{~cm}^{-1}$ for the NH stretching vibrations.

A binuclear species of the type $\left[\mathrm{Zn}_{2} \mathrm{H}_{-1} \mathrm{~L}^{1}\right]^{3+}$ was synthesised by treating $\mathbf{L}^{\mathbf{1}}$ with one equivalent $\mathrm{KO}^{t} \mathrm{Bu}$ and two equivalents of $\mathrm{Zn}\left(\mathrm{ClO}_{4}\right)_{2} \cdot 6 \mathrm{H}_{2} \mathrm{O}$ yielding 2 (Scheme 2.8). The crystal structure is shown in Figure 2.3.

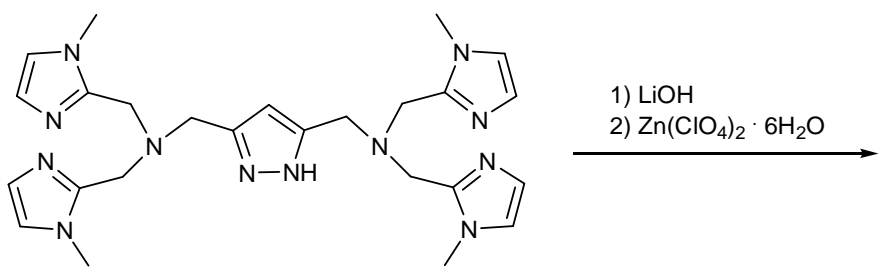

$\mathbf{L}^{1}$

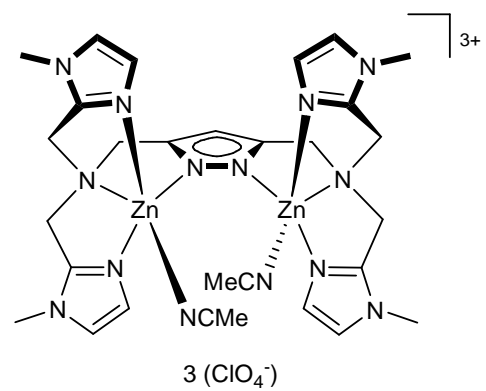

2

Scheme 2.8: Synthesis of complex 2 .

Each zinc atom in $\mathbf{2}$ is coordinated by one pyrazole $\mathrm{N}$-atom, two imidazole $\mathrm{N}$-atoms and the tertiary amine nitrogen atom. In addition, one acetonitrile is bound to each zinc atom. Both zinc atoms are coordinated in a trigonal bipyramidal fashion ( $\mathrm{Zn} 1: \tau_{5}=0.86$, $\left.\mathrm{Zn} 2: \tau_{5}=0.84\right)^{[53]}$ and separated by $4.1028(5) \AA$. The bond lengths of the zinc atom to the aromatic nitrogen atoms are almost equal, although slightly longer for $\mathrm{Zn}-\mathrm{N}^{\text {Imid }}$ (2.00-2.03 $\AA$ ) than $\mathrm{Zn}-\mathrm{N}^{\mathrm{Pz}}(2.00 \AA)$. As expected, bond lengths of the zinc atom to amine 
nitrogen atoms are longer compared to aromatic nitrogen atoms $(\sim 2.4 \AA)$. Selected bond lengths and angles for $\mathbf{2}$ are given in Table 2.5.

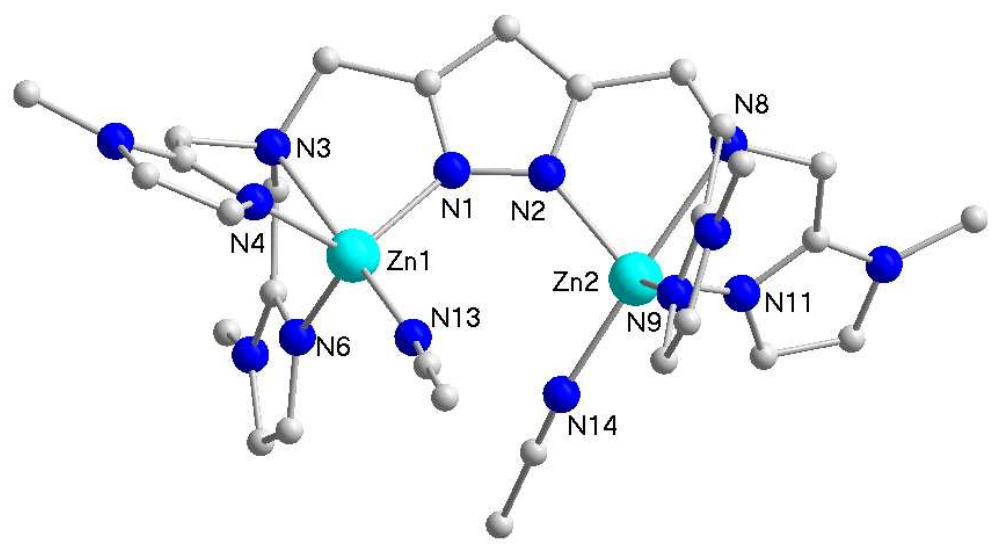

Figure 2.3: Molecular structure of 2, hydrogen atoms and counter ions omitted for clarity.

Table 2.5: Selected bond lengths $[\AA]$ and angles $\left[{ }^{\circ}\right]$ for 2 .

\begin{tabular}{c|c||c|cc|c}
\hline Atoms & Bond length & Atoms & Angle & Atoms & Angle \\
\hline \hline Zn1-N1 & $2.005(3)$ & N1-Zn1-N3 & $75.09(9)$ & N2-Zn2-N8 & $75.56(10)$ \\
Zn1-N3 & $2.376(2)$ & N1-Zn1-N4 & $118.50(10)$ & N2-Zn2-N9 & $109.71(10)$ \\
Zn1-N4 & $2.030(3)$ & N1-Zn1-N6 & $113.15(10)$ & N2-Zn2-N11 & $120.73(10)$ \\
Zn1-N6 & $2.006(3)$ & N3-Zn1-N4 & $75.74(9)$ & N8-Zn2-N9 & $77.05(10)$ \\
Zn1-N13 & $2.066(3)$ & N3-Zn1-N6 & $77.46(10)$ & N8-Zn2-N11 & $76.21(9)$ \\
Zn2-N2 & $1.996(2)$ & N4-Zn1-N6 & $111.48(11)$ & N9-Zn2-N11 & $113.06(10)$ \\
Zn2-N8 & $2.396(3)$ & N1-Zn1-N13 & $107.56(11)$ & N2-Zn2-N14 & $104.81(11)$ \\
Zn2-N9 & $2.002(3)$ & N3-Zn1-N13 & $169.90(11)$ & N8-Zn2-N14 & $171.39(10)$ \\
Zn2-N11 & $2.018(3)$ & N4-Zn1-N13 & $94.67(11)$ & N9-Zn2-N14 & $110.50(12)$ \\
Zn2-N14 & $2.069(3)$ & N6-Zn1-N13 & $109.55(12)$ & N11-Zn2-N14 & $96.59(11)$ \\
Zn1‥Zn2 & $4.1028(5)$ & & & & \\
\hline
\end{tabular}

ESI-MS analysis in the presence of acetonitrile showed the formation of two species: one could be assigned to fragment $\left[\mathrm{Zn}_{2} \mathrm{H}_{-1} \mathrm{~L}^{1}\left(\mathrm{ClO}_{4}\right)_{2}\right]^{+}$at $m / z=827$ and 364 for $\left[\mathrm{Zn}_{2} \mathrm{H}_{-1} \mathrm{~L}^{1}\left(\mathrm{ClO}_{4}\right)\right]^{2+}$. The other species showed fragments at $\mathrm{m} / z=763$ and 332, which fitted to calculated masses of $\left[\mathrm{Zn}_{2} \mathrm{H}_{-1} \mathrm{~L}^{1}\left(\mathrm{H}_{3} \mathrm{O}_{2}\right)\left(\mathrm{ClO}_{4}\right)\right]^{+}$and $\left[\mathrm{Zn}_{2} \mathrm{H}_{-1} \mathrm{~L}^{1}\left(\mathrm{H}_{3} \mathrm{O}_{2}\right)\right]^{2+}$, respectively. The latter species was formed under electrospray conditions. 

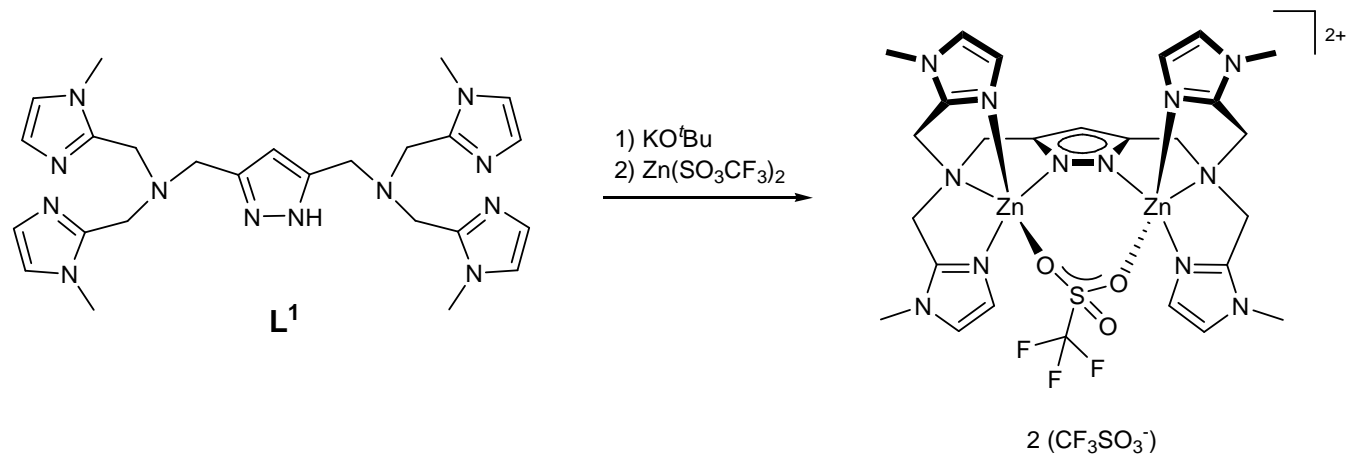

3

Scheme 2.9: Synthesis of 3 .

Using $\mathrm{Zn}\left(\mathrm{SO}_{3} \mathrm{CF}_{3}\right)_{2}$ instead of $\mathrm{Zn}\left(\mathrm{ClO}_{4}\right)_{2} \cdot 6 \mathrm{H}_{2} \mathrm{O}$ in complex synthesis resulted in the formation of 3 (Scheme 2.9). In this complex, the zinc atoms are trigonal bipyramidal coordinated $\left(\mathrm{Zn} 1: \tau_{5}=0.85, \mathrm{Zn} 2: \tau_{5}=0.91\right)^{[53]}$ and are bridged by a triflate counter ion elongating the zinc distance to 4.2484(6) $\AA$ (Figure 2.4), which is the longest $\mathrm{Zn} \cdots \mathrm{Zn}$ separation obtained with $\mathbf{L}^{\mathbf{1}}$. Selected bond lengths $[\AA]$ and angles $\left[^{\circ}\right]$ for $\mathbf{3}$ are listed in Table 2.6.

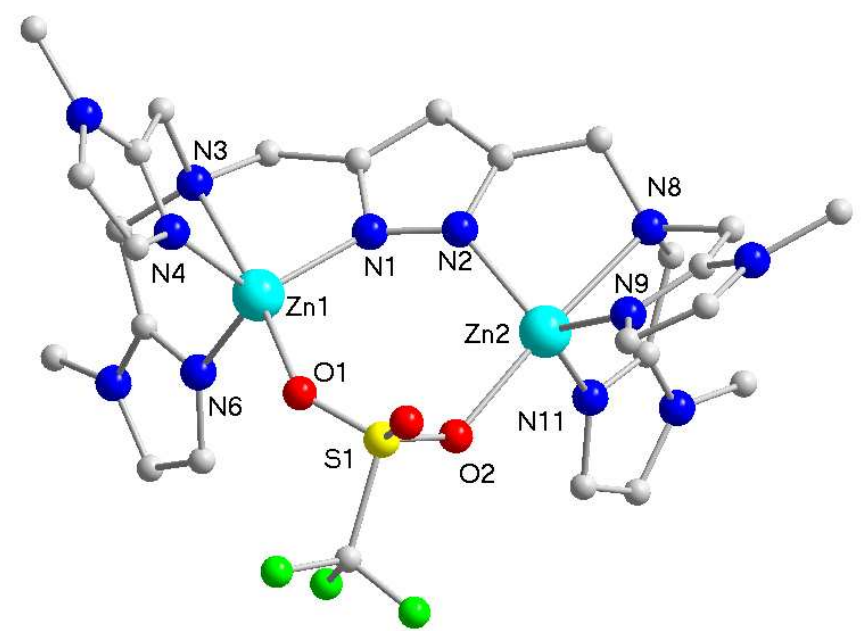

Figure 2.4: Molecular structure of $\mathbf{3}$, hydrogen atoms and counter ions omitted for clarity. 
Table 2.6: Selected bond lengths $[\AA]$ and angles $\left[{ }^{\circ}\right]$ for $\mathbf{3}$.

\begin{tabular}{c|c||c|cc|c}
\hline Atoms & Bond length & Atoms & Angle & Atoms & Angle \\
\hline \hline Zn1-N1 & $1.991(3)$ & N1-Zn1-N3 & $79.32(11)$ & N2-Zn2-N8 & $80.48(11)$ \\
Zn1-N3 & $2.316(3)$ & N1-Zn1-N4 & $120.79(13)$ & N2-Zn2-N9 & $118.32(13)$ \\
Zn1-N4 & $2.013(3)$ & N1-Zn1-N6 & $113.04(12)$ & N2-Zn2-N11 & $112.01(11)$ \\
Zn1-N6 & $2.009(3)$ & N1-Zn1-O1 & $107.25(12)$ & N2-Zn2-O2 & $103.18(11)$ \\
Zn1-O1 & $2.089(3)$ & N3-Zn1-N4 & $77.46(11)$ & N8-Zn2-N9 & $78.93(12)$ \\
Zn2-N2 & $2.009(3)$ & N3-Zn1-N6 & $79.46(11)$ & N8-Zn2-N11 & $78.73(12)$ \\
Zn2-N8 & $2.327(3)$ & N3-Zn1-O1 & $171.89(11)$ & N8-Zn2-O2 & $174.10(10)$ \\
Zn2-N9 & $2.007(3)$ & N4-Zn1-N6 & $114.95(13)$ & N9-Zn2-N11 & $119.65(13)$ \\
Zn2-N11 & $1.996(3)$ & N4-Zn1-O1 & $94.89(11)$ & N9-Zn2-O2 & $103.00(13)$ \\
Zn2-O2 & $2.120(3)$ & N6-Zn1-O1 & $101.72(13)$ & N11-Zn2-O2 & $95.54(12)$ \\
Zn1‥Zn2 & $4.2484(6)$ & & & & \\
\hline
\end{tabular}

ESI-MS analysis of $\mathbf{3}$ was performed in the presence of different solvents, which strongly depend on the variety of species obtained during the measurements. However, not all fragments could be assigned to appropriate species. Measurements have been performed in $\mathrm{H}_{2} \mathrm{O}, \mathrm{MeCN}, \mathrm{MeOH}$ and $\mathrm{MeOH} / \mathrm{H}_{2} \mathrm{O}(1: 1, \mathrm{v} / \mathrm{v})$. In the following, only $[\mathrm{M}]^{2+}$ species are discussed and an overview of species that were assigned is given in Table 2.7. Regardless of the solvent used, all spectra showed fragments at $m / z=389$, which could be assigned to $\left[\mathrm{Zn}_{2} \mathrm{H}_{-1} \mathrm{~L}^{1}\left(\mathrm{SO}_{3} \mathrm{CF}_{3}\right)\right]^{2+}$. In addition, the species $\left[\mathrm{Zn}_{2} \mathrm{H}_{-1} \mathrm{~L}^{1}\left(\mathrm{H}_{3} \mathrm{O}_{2}\right)\right]^{2+}$ was determined, when measurements were performed in $\mathrm{MeCN}$ and $\mathrm{H}_{2} \mathrm{O} / \mathrm{MeOH}$, respectively. Using pure $\mathrm{H}_{2} \mathrm{O}$, fragments matching $\left[\mathrm{Zn}_{2} \mathrm{H}_{-1} \mathrm{~L}^{1}(\mathrm{OH})\right]^{2+}$ were observed. Experiments in $\mathrm{MeOH}$ resulted in the formation of $\left[\mathrm{Zn}_{2} \mathrm{H}_{-1} \mathrm{~L}^{1}(\mathrm{OMe})\right]^{2+}$ and $\left[\mathrm{Zn}_{2} \mathrm{H}_{-1} \mathrm{~L}^{1}(\mathrm{OH})\right]^{2+}$. In summary, this example demonstrates that species formation strongly depends on the used solvent and does not give any reliable information about impurities, which might be present in the sample. 
Table 2.7: ESI-MS fragments of $\mathbf{3}$ in different solvents.

\begin{tabular}{c|c|c|c|c|c}
\hline$m / z$ & Fragment & $\mathrm{MeCN}$ & $\mathrm{H}_{2} \mathrm{O}$ & $\begin{array}{c}\mathrm{H}_{2} \mathrm{O} / \mathrm{MeOH} \\
(1: 1, v / v)\end{array}$ & $\mathrm{MeOH}$ \\
\hline \hline 323 & {$\left[\mathrm{Zn}_{2} \mathrm{H}_{-1} \mathrm{~L}^{1}(\mathrm{OH})\right]^{2+}$} & - & $\checkmark$ & - & $\checkmark$ \\
795 & {$\left[\mathrm{Zn}_{2} \mathrm{H}_{-1} \mathrm{~L}^{1}(\mathrm{OH})\left(\mathrm{SO}_{3} \mathrm{CF}_{3}\right)\right]^{+}$} & - & - & - & $\checkmark$ \\
\hline 330 & {$\left[\mathrm{Zn}_{2} \mathrm{H}_{-1} \mathrm{~L}^{1}(\mathrm{OMe})\right]^{2+}$} & - & - & $\checkmark$ & - \\
\hline 309 & {$\left[\mathrm{Zn}_{2} \mathrm{H}_{-1} \mathrm{~L}^{1}(\mathrm{OMe})\left(\mathrm{SO}_{3} \mathrm{CF}_{3}\right)\right]^{+}$} & & $\checkmark$ & & \\
\hline 389 & {$\left[\mathrm{Zn}_{2} \mathrm{H}_{-1} \mathrm{~L}^{1}\left(\mathrm{H}_{3} \mathrm{O}_{2}\right)\right]^{2+}$} & $\checkmark$ & $\checkmark$ & $\checkmark$ \\
927 & {$\left[\mathrm{Zn}_{2} \mathrm{H}_{-1} \mathrm{~L}^{1}\left(\mathrm{H}_{3} \mathrm{O}_{2}\right)\left(\mathrm{SO}_{3} \mathrm{CF}_{3}\right)\right]^{+}$} & & $\checkmark$ & & \\
\hline
\end{tabular}

Since species $\left[\mathrm{Zn}_{2} \mathrm{H}_{-2} \mathrm{~L}^{1}\right]^{2+}$ bear a nucleophile and are therefore expected to be active in hydrolysis, synthesis of the doubly positively charged complexes was extensively investigated. In general, $\mathbf{L}^{\mathbf{1}}$ was treated with two equivalents of base and two equivalents of the zinc salt.
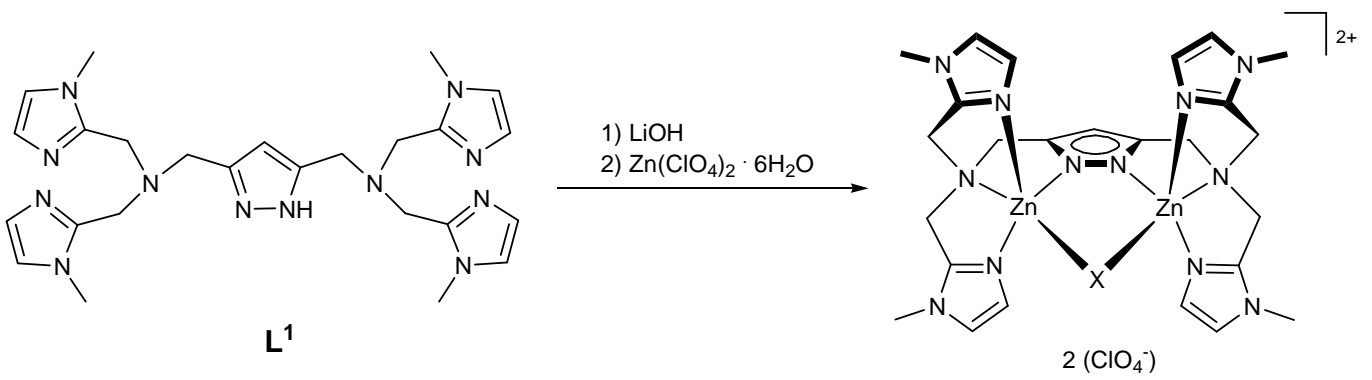

4a $(\mathrm{X}=\mathrm{MeOH} \cdots \mathrm{OMe})$
$\mathbf{4 b}(\mathrm{X}=\mathrm{OMe})$

Scheme 2.10: Synthesis of $4 a$ and $4 b$.

Performing the reaction in MeOH/THF (3:1, v/v) under reflux, very few single crystals of 4a (Scheme 2.10) were obtained by cooling the solution to room temperature. The structure of $4 \mathbf{a}$ is given in Figure 2.5 and shows that the zinc atoms are bridged by a methanol-methanolate $(\mathrm{MeOH} \cdots \mathrm{OMe})$ moiety. The methanolate group additionally forms hydrogen bonds to a second methanol molecule. The zinc atoms are separated by 
4.2113(5) $\AA$ and arranged within the plane of the pyrazole ring. The oxygen atoms of the bridging nucleophile are located barely above $(0.37 \AA$ for $\mathrm{O} 2)$ and below $(0.54 \AA$ for O1) this plane. The zinc atoms are trigonal bipyramidal coordinated $\left(\mathrm{Zn} 1: \tau_{5}=0.92, \mathrm{Zn} 2\right.$ : $\left.\tau_{5}=1.05\right) .{ }^{[53]}$ A geometric parameter $\tau_{5}>1$ for $\mathrm{Zn} 2$ was obtained, because of the location of $\mathrm{Zn} 2$ out of the plane spanned by atoms N2-N9-N11. Selected bond lengths and angles for 4a are given in Table 2.8 and hydrogen bonding parameters are listed in Table 2.9.

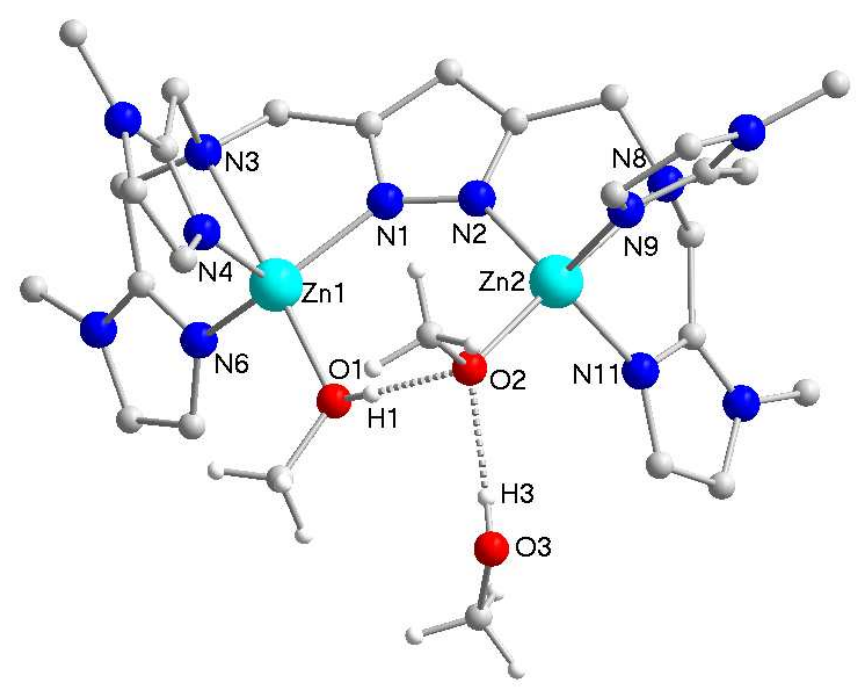

Figure 2.5: Molecular structure of $\mathbf{4 a}$, most hydrogen atoms and counter ions omitted for clarity.

Table 2.8: Selected bond lengths $[\AA]$ and angles $\left[{ }^{\circ}\right]$ for $\mathbf{4 a}$.

\begin{tabular}{c|c||c|cc|c}
\hline Atoms & Bond length & Atoms & Angle & Atoms & Angle \\
\hline \hline Zn1-N1 & $2.020(2)$ & N1-Zn1-N3 & $77.70(9)$ & N2-Zn2-N8 & $74.86(9)$ \\
Zn1-N3 & $2.380(2)$ & N1-Zn1-N4 & $109.56(11)$ & N2-Zn2-N9 & $113.31(10)$ \\
Zn1-N4 & $2.018(3)$ & N1-Zn1-N6 & $120.89(10)$ & N2-Zn2-N11 & $113.55(10)$ \\
Zn1-N6 & $2.032(3)$ & N1-Zn1-O1 & $103.96(9)$ & N2-Zn2-O2 & $106.53(9)$ \\
Zn1-O1 & $1.997(2)$ & N3-Zn1-N4 & $76.92(10)$ & N8-Zn2-N9 & $74.58(9)$ \\
Zn2-N2 & $2.043(2)$ & N3-Zn1-N6 & $76.91(9)$ & N8-Zn2-N11 & $74.61(9)$ \\
Zn2-N8 & $2.420(2)$ & N3-Zn1-O1 & $176.30(10)$ & N8-Zn2-O2 & $176.84(9)$ \\
Zn2-N9 & $2.050(3)$ & N4-Zn1-N6 & $115.12(12)$ & N9-Zn2-N11 & $113.00(10)$ \\
Zn2-N11 & $2.049(3)$ & N4-Zn1-O1 & $105.40(11)$ & N9-Zn2-O2 & $107.15(9)$ \\
Zn2-O2 & $1.982(2)$ & N6-Zn1-O1 & $99.44(10)$ & N11-Zn2-O2 & $102.24(9)$ \\
Zn1․Zn2 & $4.2113(5)$ & & & & \\
\hline
\end{tabular}


Table 2.9: Hydrogen bond parameters for $\mathbf{4 a}$; interatomic distances $[\AA ̊]$ and angles $\left[^{\circ}\right]$.

\begin{tabular}{ccccc}
\hline $\mathrm{D}-\mathrm{H} \cdots \mathrm{A}$ & $d(\mathrm{D}-\mathrm{H})$ & $d(\mathrm{H} \cdots \mathrm{A})$ & $d(\mathrm{D} \cdots \mathrm{A})$ & $\angle(\mathrm{D}-\mathrm{H} \cdots \mathrm{A})$ \\
\hline \hline $\mathrm{O} 1-\mathrm{H} 1 \cdots \mathrm{O} 2$ & $0.77(6)$ & $1.70(6)$ & $2.453(3)$ & $167(7)$ \\
$\mathrm{O} 3-\mathrm{H} 3 \cdots \mathrm{O} 2$ & 0.82 & 1.96 & $2.774(4)$ & 172.3 \\
\hline
\end{tabular}

Experiments to reproduce the complex under similar conditions did not yield $\mathbf{4 a}$, instead 4b was obtained.

Crystallographic data of $\mathbf{4 b}$ show the zinc atoms being bridged by a single methanolate group (see Figure 2.6). The tilt angle between the plane of the pyrazolate ring and the plane through $\mathrm{Zn} 1-\mathrm{O} 1-\mathrm{Zn} 2$ is about $12^{\circ}$. The zinc-zinc distance is $3.3838(12) \AA$, which is far shorter than in $\mathbf{4 a}(4.2113(5) \AA)$. The zinc atoms in $\mathbf{4 b}$ are distorted trigonal bipyramidal coordinated $\left(\mathrm{Zn} 1: \tau_{5}=0.73, \mathrm{Zn} 2: \tau_{5}=0.77\right) .{ }^{[53]}$ Selected bond lengths and angles for $\mathbf{4 b}$ are given in Table 2.10 .

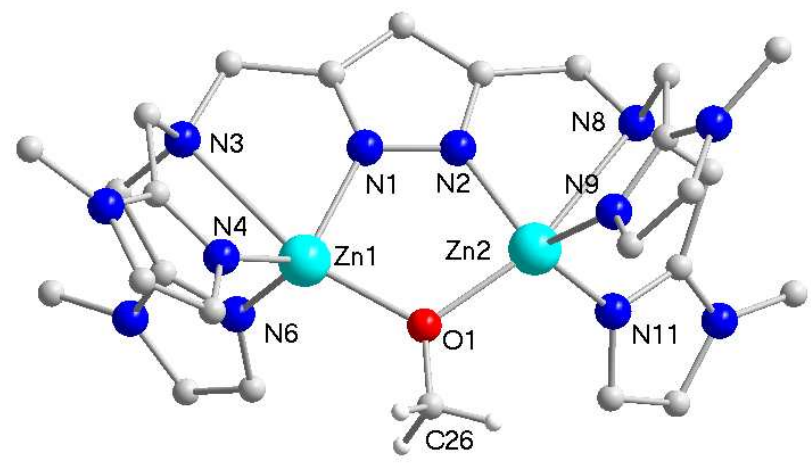

Figure 2.6: Molecular structure of $\mathbf{4 b}$, most hydrogen atoms and counter ions omitted for clarity. 
Table 2.10: Selected bond lengths $[\AA]$ and angles $\left[{ }^{\circ}\right]$ for $\mathbf{4 b}$.

\begin{tabular}{c|c||c|cc|c}
\hline Atoms & Bond length & Atoms & Angle & Atoms & Angle \\
\hline \hline Zn1-N1 & $1.972(4)$ & N1-Zn1-N3 & $70.535(155)$ & N2-Zn2-N8 & $70.653(158)$ \\
Zn1-N3 & $2.5889(45)$ & N1-Zn1-N4 & $119.55(17)$ & N2-Zn2-N9 & $112.05(17)$ \\
Zn1-N4 & $2.013(4)$ & N1-Zn1-N6 & $108.43(16)$ & N2-Zn2-N11 & $116.53(17)$ \\
Zn1-N6 & $2.002(4)$ & N3-Zn1-N4 & $75.035(162)$ & N8-Zn2-N9 & $75.864(171)$ \\
Zn1-O1 & $2.028(4)$ & N3-Zn1-N6 & $75.657(144)$ & N8-Zn2-N11 & $74.849(167)$ \\
Zn2-N2 & $1.969(4)$ & N4-Zn1-N6 & $109.01(17)$ & N9-Zn2-N11 & $108.70(17)$ \\
Zn2-N8 & $2.5544(48)$ & N1-Zn1-O1 & $93.36(17)$ & N2-Zn2-O1 & $92.13(17)$ \\
Zn2-N9 & $2.006(4)$ & N3-Zn1-O1 & $163.803(143)$ & N8-Zn2-O1 & $162.447(145)$ \\
Zn2-N11 & $2.012(4)$ & N4-Zn1-O1 & $113.58(16)$ & N9-Zn2-O1 & $115.31(16)$ \\
Zn2-O1 & $2.032(4)$ & N6-Zn1-O1 & $112.15(16)$ & N11-Zn2-O1 & $111.58(17)$ \\
Zn1‥Zn2 & $3.3838(12)$ & & & Zn1-O1-Zn2 & $112.9(2)$ \\
\hline
\end{tabular}

At the present state, the pyrazole based ligand was reported to be suitable to tune zinczinc separations in the complexes depending on the lengths of the side chains. Ligands bearing long side chains allow for short zinc-zinc distances, which are bridged by a methanolate or hydroxide moiety. Short side chains force the metal atoms to separate requiring an additional solvent molecule to bridge the zinc atoms. ${ }^{[43 c, 44]} \mathrm{A}$ possible equilibrium of $\mathrm{OH} \rightleftarrows \mathrm{H}_{3} \mathrm{O}_{2}$ bridges in aqueous solution was assumed for binuclear zinc complexes with similar ligands, but longer side chains that are more flexible. ${ }^{[48 b]}$ To date, no exchange of nucleophiles with ligands bearing short side chains has been reported in the solid state. A copper(II) complex based on $\mathbf{L}^{\mathbf{1}}$ was obtained that exclusively bears a (MeO $\cdots \mathrm{HOMe}$ ) moiety as bridging group as it was observed for $4 \mathbf{a}^{[43 \mathrm{~d}]}$ The more interesting is the molecular structure of $\mathbf{4 b}$. In this complex the zinc atoms are only bridged by a methanolate group. Compared to $\mathbf{4 a}$, bond lengths of the zinc atoms to the aromatic $N$-donor moieties do not change significantly; the maximum deviation is observed for the bond lengths to the pyrazole nitrogen atoms, which differ about $0.048 \AA$ for Zn1-N1 and $0.074 \AA$ for Zn2-N2. The major difference was observed for the bond lengths to the tertiary nitrogen atoms, which are changed about $0.209 \AA$ for Zn1-N3 and $0.134 \AA$ for Zn2-N8. The flexibility of the system lies thus in the plasticity of the bond lengths of the zinc atoms to the tertiary nitrogen atoms leading to a change in the coordination geometry of the zinc atoms. While the coordination polyhedra of the zinc 
atoms in $\mathbf{4 a}$ are almost perfect trigonal bipyramids $\left(\mathrm{Zn} 1: \tau_{5}=0.92, \mathrm{Zn} 2: \tau_{5}=1.05\right),{ }^{[53]} \mathrm{a}$ significantly distorted trigonal bipyramidal coordination of the zinc atoms is observed in complex 4b $\left(\mathrm{Zn} 1: \tau_{5}=0.73, \mathrm{Zn} 2: \tau_{5}=0.77\right) .{ }^{[53]}$ If one considers that the backside $\mathrm{Zn}-\mathrm{N}$ bonds in $\mathbf{4 b}$ are very long (2.59(1) $\AA$ for $\mathrm{Zn1-Zn3}$ and $2.55(1) \AA$ for Zn2-N8), the coordination in $\mathbf{4 b}$ might be even better described as $\{4+1\}$ approaching tetrahedral. This hemilabile coordination of the zinc atoms allows a shorter zinc-zinc distance in $\mathbf{4 b}$ that enables the zinc atoms to be bridged by a single methanolate moiety only. Conditions, in which either $\mathbf{4 a}$ or $\mathbf{4 b}$ is preferably formed could not be obtained due to the equilibrium of both species (Scheme 2.11).

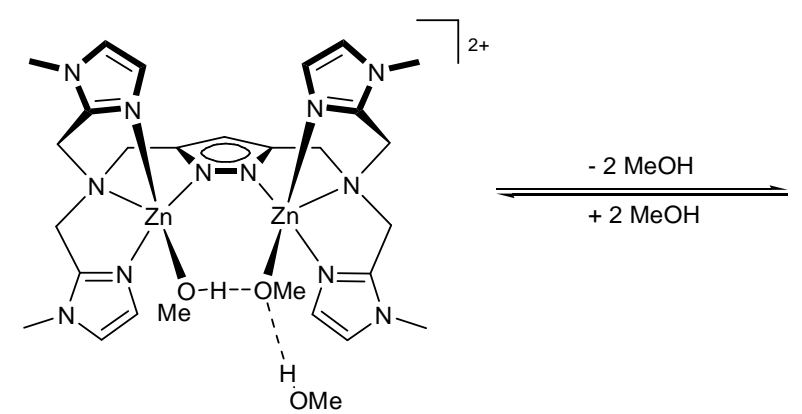

$4 a$

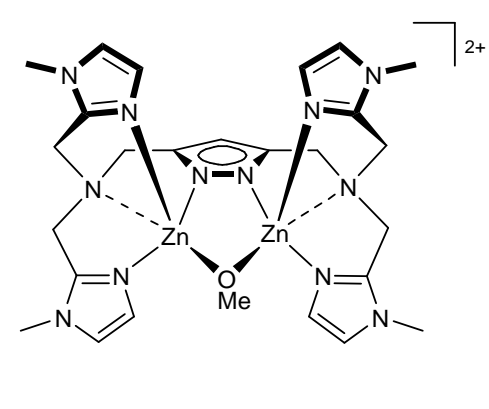

4b

Scheme 2.11: Equilibrium of $4 \mathrm{a}$ and $\mathbf{4 b}$.

ESI-MS analysis of $\mathbf{4 b}$ in the presence of acetonitrile did not reveal appropriate species, but fragments $\left[\mathrm{Zn}_{2} \mathrm{H}_{-1} \mathrm{~L}^{1}(\mathrm{CN})\right]^{2+}$ and $\left[\mathrm{Zn}_{2} \mathrm{H}_{-1} \mathrm{~L}^{1}(\mathrm{CN})\left(\mathrm{ClO}_{4}\right)\right]^{+}$at $\mathrm{m} / \mathrm{z}=328$ and 754 , respectively. Obviously, an exchange of the nucleophiles took place resulting in a cyanospecies, which was formed in acetonitrile. Similar observations have been reported by YANG and co-workers. ${ }^{[56]}$ The authors investigated the activity of cryptate complexes that bear copper or zinc ions to cleave acetonitrile resulting in cyano-bridged complexes. In addition, ${ }^{1} \mathrm{H}$ NMR analysis of $\mathbf{4 b}$ revealed three species in $d_{3}$-MeCN, which might be $\mathbf{4 a}$, 4b and the complex bearing a cyano-ligand. Four different species were obtained when the measurements were performed in $d_{6}$-DMSO indicating strong interactions with the solvent and possible nucleophile exchanges. $4 \mathbf{b}$ was slightly soluble in $d_{4}-\mathrm{MeOD}$, but the obtained spectra showed only two different species, which might be $\mathbf{4 a}$ and $\mathbf{4 b}$ due to the equilibrium as discussed above. Although these findings do not confirm that $\mathbf{4 b}$ is active in acetonitrile cleavage, the observed results most likely indicate such activity as the only species observed in ESI-MS was the cyano-bridged complex. 
<smiles>Cn1ccnc1CN(Cc1cc(CN(Cc2nccn2C)Cc2nccn2C)[nH]n1)Cc1nccn1C</smiles>

$L^{1}$

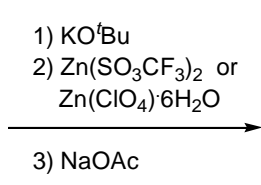

3) $\mathrm{NaOAc}$

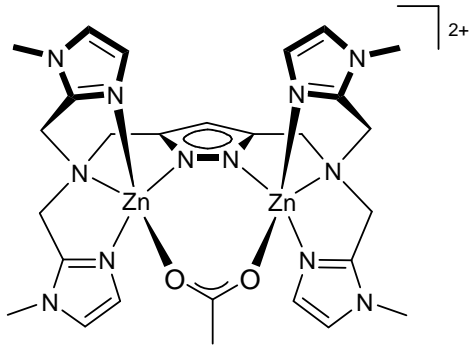

$2\left(X^{-}\right)$

$5 \mathbf{a}\left(\mathrm{X}=\mathrm{CF}_{3} \mathrm{SO}_{3}\right)$

5b $\left(\mathrm{X}=\mathrm{ClO}_{4}\right)$

Scheme 2.12: Synthesis of complexes 5 .

Since the bridging moiety of the complexes representing $\left[\mathrm{Zn}_{2} \mathrm{H}_{-2} \mathrm{~L}^{1}\right]^{2+}$ is difficult to control, acetate was used as co-ligand resulting in the formation of $\mathbf{5 a}$ (Scheme 2.12). The reaction was performed by treating $\mathbf{L}^{\mathbf{1}}$ with $\mathrm{KO}^{t} \mathrm{Bu}, \mathrm{Zn}\left(\mathrm{SO}_{3} \mathrm{CF}_{3}\right)_{2}$ and $\mathrm{NaOAc}$ in acetonitrile. As shown in Figure 2.7, the zinc atoms are bridged by the acetate group in a $\mu_{1,3}$-binding fashion. The zinc-zinc distance is 3.9548(4) $\AA$. In 5a, the bridging acetate moiety is twisted with respect to the pyrazolato plane (angle between the pyrazolato plane and the plane through atoms $\mathrm{O} 1-\mathrm{C} 26-\mathrm{O} 2$ is $\left.41.4(1)^{\circ}\right)$. The zinc atoms are located out of plane with distances of $0.914 \AA$ for $\mathrm{Zn} 1$, which is located above, and $0.402 \AA$ for $\mathrm{Zn} 2$ below the pyrazolato plane. In addition, the carbon atom C26 of the acetate ligand is also arranged out of the pyrazolato plane with a distance of $0.20(1) \AA$, while C27 is located within the plane. Selected bond lengths and angles for $\mathbf{5 a}$ are given in Table 2.11.

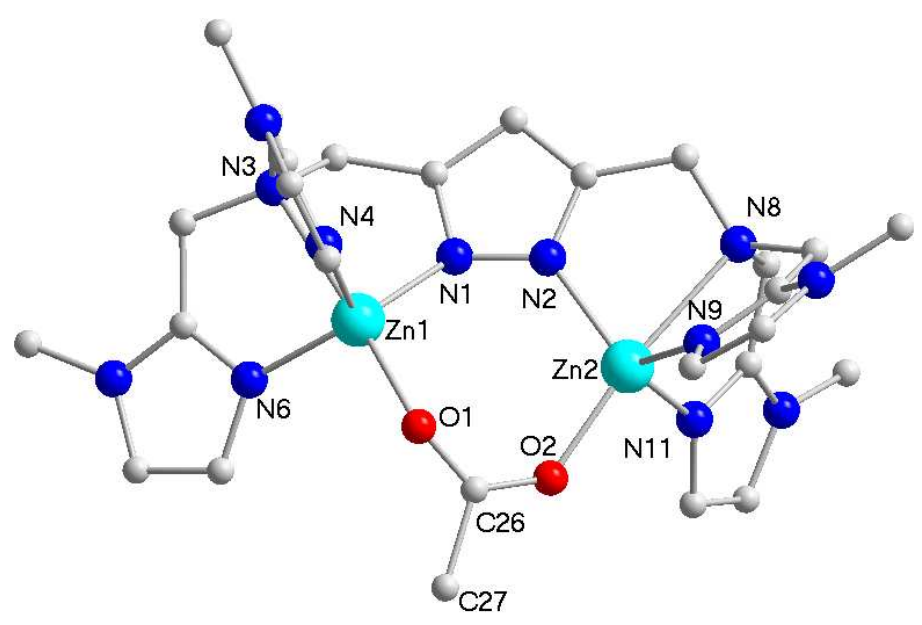

Figure 2.7: Molecular structure of 5a, hydrogen atoms and all counter ions omitted for clarity. 
Table 2.11: Selected bond lengths $[\AA]$ and angles $\left[{ }^{\circ}\right]$ for $\mathbf{5 a}$.

\begin{tabular}{|c|c|c|c|c|c|}
\hline Atoms & Bond length & Atoms & Angle & Atoms & Angle \\
\hline Zn1-N1 & $2.0024(16)$ & N1-Zn1-N3 & $76.72(6)$ & N2-Zn2-N8 & $75.68(6)$ \\
\hline Zn1-N3 & $2.4563(18)$ & N1-Zn1-N4 & $111.89(7)$ & N2-Zn2-N9 & $111.09(7)$ \\
\hline Zn1-N4 & $2.0048(18)$ & N1-Zn1-N6 & $119.00(7)$ & $\mathrm{N} 2-\mathrm{Zn} 2-\mathrm{N} 11$ & $113.21(7)$ \\
\hline Zn1-N6 & $2.0023(17)$ & N1-Zn1-O1 & $107.56(7)$ & $\mathrm{N} 2-\mathrm{Zn} 2-\mathrm{O} 2$ & $110.93(6)$ \\
\hline Zn1-O1 & $1.9823(16)$ & N3-Zn1-N4 & $76.91(6)$ & N8-Zn2-N9 & $76.02(6)$ \\
\hline $\mathrm{Zn2-N2}$ & $1.9890(17)$ & N3-Zn1-N6 & $76.70(7)$ & N8-Zn2-N11 & $75.35(6)$ \\
\hline Zn2-N8 & $2.4636(16)$ & N3-Zn1-O1 & $175.14(6)$ & $\mathrm{N} 8-\mathrm{Zn} 2-\mathrm{O} 2$ & $171.64(6)$ \\
\hline Zn2-N9 & $2.0124(17)$ & N4-Zn1-N6 & $113.84(7)$ & N9-Zn2-N11 & $117.94(7)$ \\
\hline Zn2-N11 & $2.0203(18)$ & N4-Zn1-O1 & $99.10(7)$ & N9-Zn2-O2 & $105.36(7)$ \\
\hline $\mathrm{Zn} 2-\mathrm{O} 2$ & $1.9907(14)$ & N6-Zn1-O1 & $102.71(8)$ & $\mathrm{N} 11-\mathrm{Zn} 2-\mathrm{O} 2$ & $96.98(7)$ \\
\hline $\mathrm{Zn} 1 \cdots \mathrm{Zn} 2$ & $3.9548(4)$ & & & & \\
\hline
\end{tabular}

In a similar reaction using $\mathrm{Zn}\left(\mathrm{ClO}_{4}\right) \cdot 6 \mathrm{H}_{2} \mathrm{O}$ as zinc source, the acetate bridged complex $\mathbf{5 b}$ was obtained. Different to $\mathbf{5 a}$, the zinc atoms in $\mathbf{5 b}$ (see Figure 2.8) are nested within the pyrazolato plane with a zinc-zinc separation of $3.8809(21) \AA$ that is slightly shorter compared to $\mathbf{5 a}(d(\mathrm{Zn} 1 \cdots \mathrm{Zn} 2=3.9548(4) \AA)$. In addition, the acetate group in $\mathbf{5 b}$ is less twisted with respect to the pyrazolato plane with an angle of $27.3(1)^{\circ}$ between the pyrazolato plane and the plane through atoms O1-C14-O1'. The difference between the structures of $\mathbf{5 a}$ and $\mathbf{5 b}$ concerning to the location of the zinc atoms and the twisted acetate moieties is depicted in Figure 2.9 and selected bond lengths and angles for $\mathbf{5 b}$ are listed in Table 2.12. The structure of $\mathbf{5 b}$ is already known in literature. ${ }^{[57]}$ This paper describes the different arrangements of acetate bridged binuclear zinc complexes, which are based on 3,5-substituted pyrazole ligands. Therein, a complex that is based on $\mathbf{L}^{\mathbf{1}}$ has been reported that features out of plane located zinc atoms ( $\mathrm{Zn} 1$ is arranged $0.35 \AA$ above the pyrazolato plane and $\mathrm{Zn} 2$ is $0.26 \AA$ below), as it was observed for $\mathbf{5 a}$, although the zinc atoms are severely more located out of plane in 5a (see values above). The major difference between both structures is that the bridging acetate moiety is arranged within the pyrazolato plane in the reported structure, while a twisted motif was observed for 5a. In addition to this, the authors reported a tilting effect (Scheme 2.13) of the acetate ligand in complexes with similar ligand systems. ${ }^{[57]}$ These findings suggest a high flexibility of the carboxylate binding in the bimetallic pockets. The IR spectrum of 5a shows two strong peaks for the symmetric and asymmetric vibration of the carboxylate moiety with a 
difference of $139 \mathrm{~cm}^{-1}$ that is typical for $\mu_{1,3}$-binding fashion and is in agreement with the reported results $\left(\Delta \tilde{v}=140 \mathrm{~cm}^{-1}\right){ }^{[57]}$

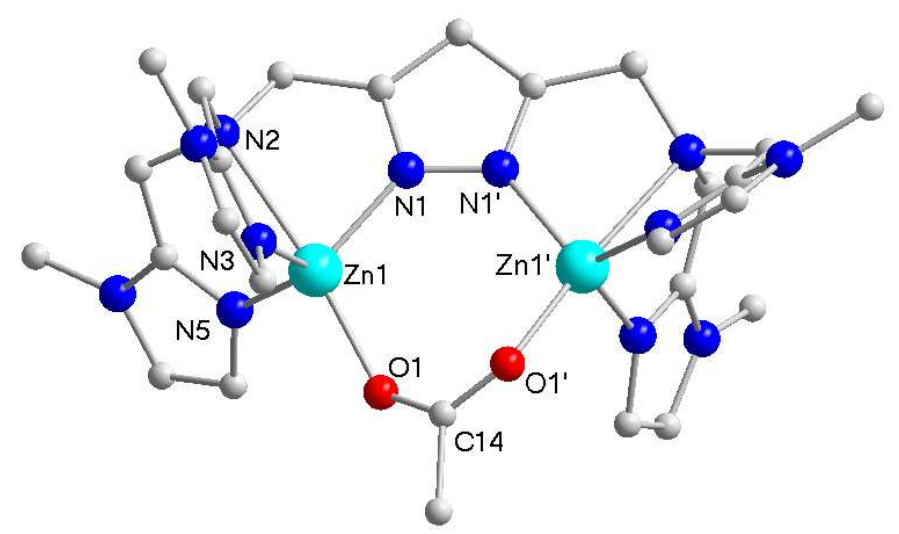

Figure 2.8: Molecular structure of $\mathbf{5 b}$, hydrogen atoms and counter ions omitted for clarity. Symmetry operation used to generate equivalent atoms: (') $-x, y,-z+1 / 2$.

Table 2.12: Selected bond lengths $[\AA ̊]$ and angles $\left[^{\circ}\right]$ for $\mathbf{5 b}$.

\begin{tabular}{c|c||c|cc|c}
\hline Atoms & Bond length & Atoms & Angle & Atoms & Angle \\
\hline \hline Zn1-N1 & $1.984(2)$ & N1-Zn1-N2 & $74.94(8)$ & N2-Zn1-N5 & $76.27(8)$ \\
Zn1-N2 & $2.438(2)$ & N1-Zn1-N3 & $107.16(8)$ & N2-Zn1-O1 & $173.32(8)$ \\
Zn1-N3 & $2.008(2)$ & N1-Zn1-N5 & $116.08(9)$ & N3-Zn1-N5 & $119.79(9)$ \\
Zn1-N5 & $1.995(2)$ & N1-Zn1-O1 & $110.80(9)$ & N3-Zn1-O1 & $103.94(9)$ \\
Zn1-O1 & $2.013(2)$ & N2-Zn1-N3 & $76.91(8)$ & N5-Zn1-O1 & $97.79(9)$ \\
Zn1‥Zn1' & $3.8809(21)$ & & & & \\
\hline
\end{tabular}
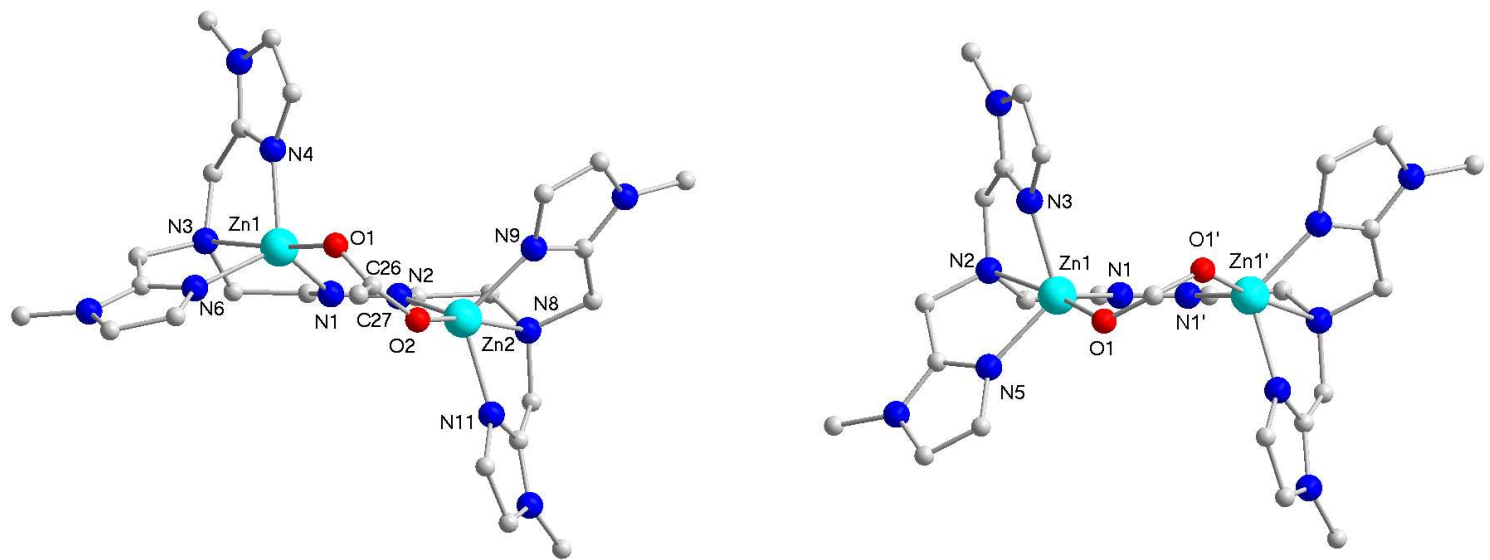

Figure 2.9: Molecular structures of $\mathbf{5 a}$ (left) and $\mathbf{5 b}$ (right) showing the different twisted motifs of the acetate ligand and the out of plane (5a) and in plane (5b) locations of the zinc atoms. 

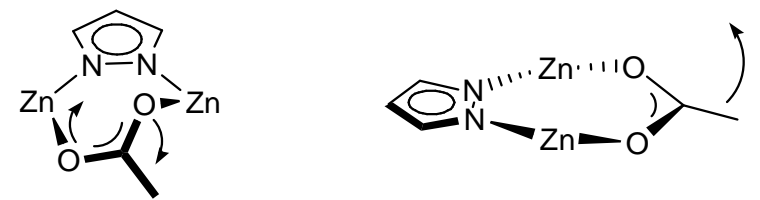

Scheme 2.13: Twisted (left) and tilted (right) binding motifs of the acetate ligand as it is reported in literature. ${ }^{[57]}$

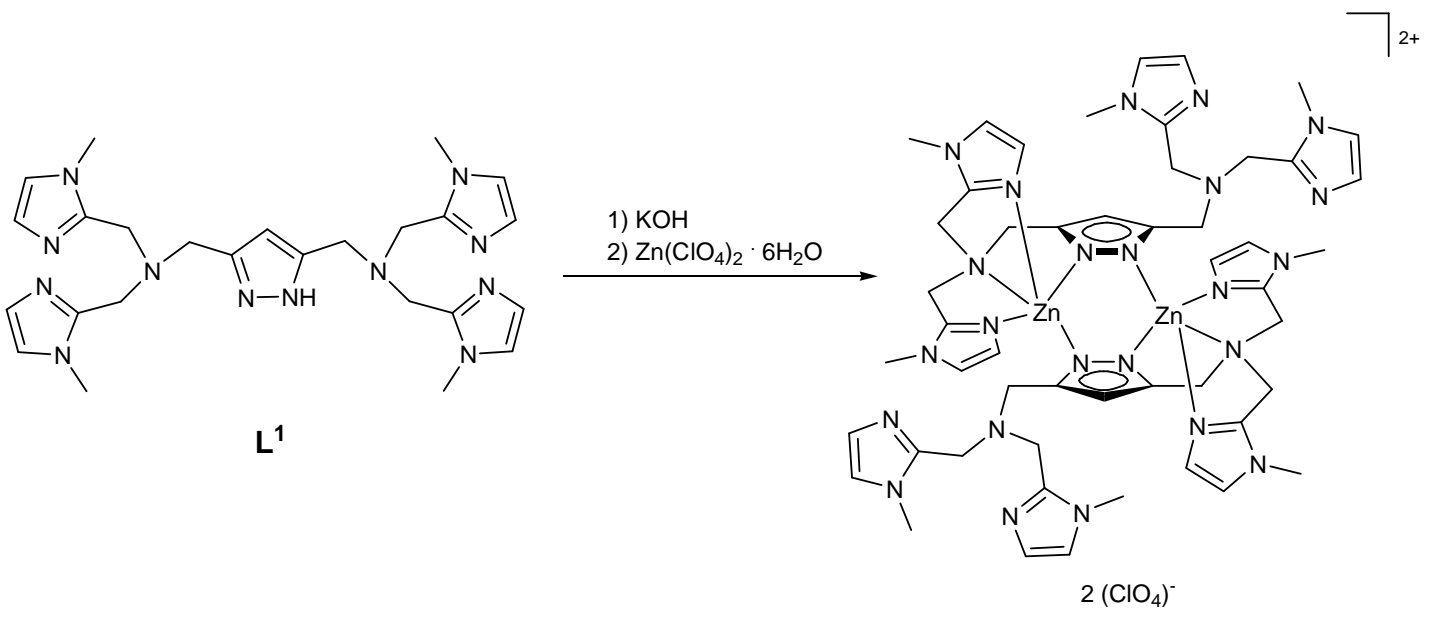

6

Scheme 2.14: Synthesis of complex 6 .

Apart from the discussed complexes, the binuclear zinc complex $\mathbf{6}$ with a metal to ligand ratio of 1:1 was obtained using equimolar amounts of $\mathbf{L}^{\mathbf{1}}$ and $\mathrm{Zn}\left(\mathrm{ClO}_{4}\right)_{2} \cdot 6 \mathrm{H}_{2} \mathrm{O}$ (Scheme 2.14). Complex 6 crystallises in the monoclinic space group $C 2 / c$ with 4 molecules per unit cell. In 6, one zinc atom is coordinated to the tripodal side arm and to one nitrogen atom of the pyrazole ring. The zinc atom additionally binds to the pyrazole nitrogen atom of the second ligand resulting in the structure shown in Figure 2.10. This binding motif reveals two dangling side chains, which are not coordinated. The zinc-zinc distance is found to be 3.7200(4) Å. Selected bond lengths and angles for 7 are listed in Table 2.13. 


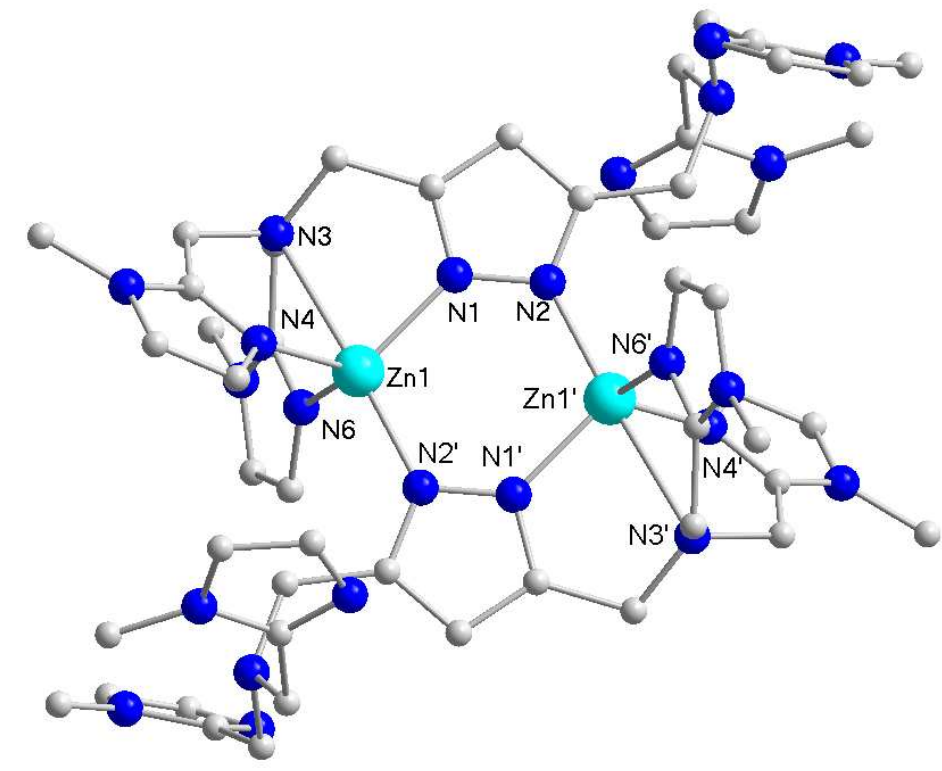

Figure 2.10: Molecular structure of 6, hydrogen atoms and counter ions omitted for clarity. Symmetry operation used to generate equivalent atoms: (') $-x+1,-y+1,-z+1$.

Table 2.13: Selected bond lengths $\left[\AA ̊ \cap\right.$ and angles $\left[{ }^{\circ}\right]$ for $\mathbf{6}$.

\begin{tabular}{|c|c|c|c|}
\hline Atoms & Bond length & Atoms & Angle \\
\hline Zn1-N1 & $2.008(2)$ & N1-Zn1-N3 & $74.67(7)$ \\
\hline Zn1-N3 & $2.496(2)$ & N1-Zn1-N4 & $115.86(8)$ \\
\hline Zn1-N4 & $2.060(2)$ & N1-Zn1-N6 & $111.75(8)$ \\
\hline Zn1-N6 & $2.048(2)$ & N1-Zn1-N2' & $107.94(8)$ \\
\hline Zn1-N2' & $2.014(2)$ & N3-Zn1-N4 & 73.88(7) \\
\hline \multirow[t]{5}{*}{$\mathrm{Zn} 1 \cdots \mathrm{Zn} 1^{\prime}$} & $3.7200(4)$ & N3-Zn1-N6 & $73.76(8)$ \\
\hline & & N3-Zn1-N2' & $175.30(7)$ \\
\hline & & N4-Zn1-N6 & $110.77(8)$ \\
\hline & & N4-Zn1- N2' & $107.86(8)$ \\
\hline & & N6-Zn1- N2' & $101.57(8)$ \\
\hline
\end{tabular}

ESI-MS analysis of 6 revealed a main peak at $m / z=565$ for $\left[\left(\mathrm{ZnH}_{-1} \mathrm{~L}^{1}\right)_{2}\right]^{2+}$. The spectrum showed no other species that gave indication for a high stability of $\mathbf{6}$ in solution. The ${ }^{1} \mathrm{H}$ NMR spectrum in $d_{3}-\mathrm{MeCN}$ at room temperature showed broad peaks for the protons of the $\mathrm{NMe}$ and $\mathrm{CH}_{2}$ groups, which could not be assigned to coordinated or uncoordinated groups. Measurements have therefore been performed at low temperature ( $233 \mathrm{~K}$ ) to obtain sharp singlets for each methylene group and for the $N$-methyl groups of 
the complex. In addition, NMR measurements were carried out by adding defined amounts of $\mathrm{Zn}\left(\mathrm{ClO}_{4}\right)_{2} \cdot 6 \mathrm{H}_{2} \mathrm{O}$ to 6. First, only one equivalent $\mathrm{Zn}\left(\mathrm{ClO}_{4}\right)_{2} \cdot 6 \mathrm{H}_{2} \mathrm{O}$ (dissolved in $d_{3}$-MeCN) was added resulting in a high number of broad signals in the ${ }^{1} \mathrm{H}$ NMR spectrum that indicated the formation of a variety of species. However, addition of the second equivalent revealed sharp and defined signals, which were in accordance with the chemical shifts and intensities as observed for $\mathbf{2}$.

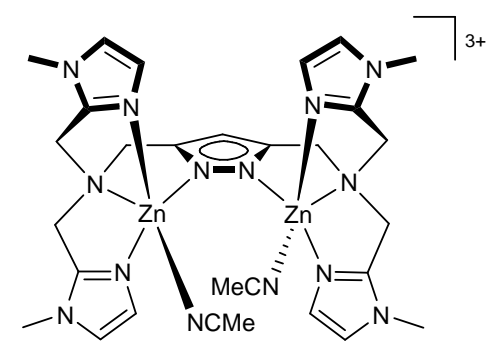

$3\left(\mathrm{ClO}_{4}^{-}\right)$

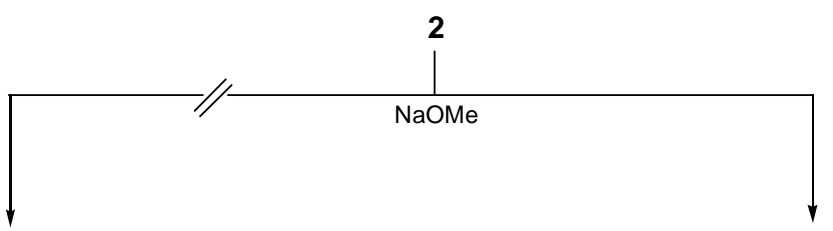

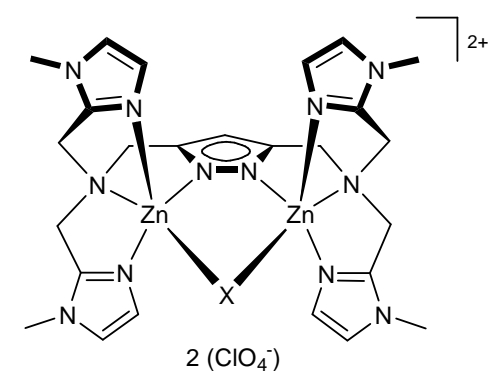

4a $\left(X=\mathrm{MeOH}^{\cdots} \mathrm{OMe}\right)$

4b $(X=O M e)$

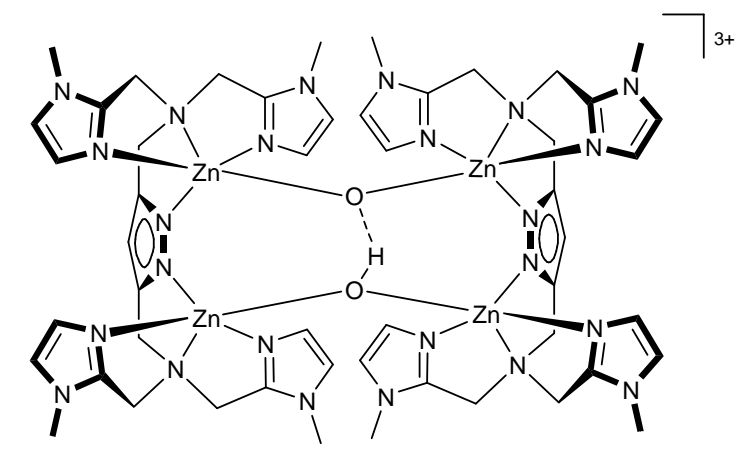

$3\left(\mathrm{ClO}_{4}^{-}\right)$

7

Scheme 2.15: Synthesis of 7 .

In an attempt to reproduce 4, 2 was treated with $\mathrm{NaOMe}$ in methanol (Scheme 2.15). After dissolving 2, a methanol solution of $\mathrm{NaOMe}$ was added dropwise and the mixture was stirred for 12 hours. The longer the reaction was stirred, the more precipitate was formed. After filtration, the colourless precipitate was dried and dissolved in acetonitrile. $\mathrm{Et}_{2} \mathrm{O}$ diffusion into the complex solution afforded colourless crystals suitable for X-ray 
analysis. As shown in Figure 2.11, the tetranuclear complex 7 was formed with a zinczinc separation of $3.9586(11) \AA$ for $\mathrm{Zn} 1 \cdots \mathrm{Zn} 2$ and a distance of $4.1702(12) \AA$ for $\mathrm{Zn} 3 \cdots \mathrm{Zn} 4.7$ represents species $\left[\mathrm{Zn}_{4} \mathrm{H}_{-5}\left(\mathrm{~L}^{1}\right)_{2}\right]^{3+}$ in Figure 2.1 and crystallises in the triclinic space group $\mathrm{P} \overline{1}$ with two formula units per unit cell. The two binuclear units are bridged by a $\mu$-oxo- $\mu$-hydroxo moiety, whereby $\mu$-O2 coordinates to $\mathrm{Zn} 1$ (1.997(4) $\AA$ ) and Zn4 (2.003(4) ̊) and the hydroxide moiety bridges Zn2 (1.934(5) $\mathrm{A})$ and Zn3 (1.957(5) $\AA$ ), respectively. In addition, the zinc atoms of each binuclear complex unit are nested within the pyrazolato plane and both subunits $\left[\mathrm{Zn}_{2} \mathrm{H}_{-1} \mathrm{~L}^{1}\right]$ are twisted about 53.1(4) $)^{\circ}$ relative to each other. The $\mathrm{Zn} 1-\mathrm{O} 2-\mathrm{Zn} 4$ angle is $134.3(3)^{\circ}$ and the angle between atoms $\mathrm{Zn} 2-\mathrm{O} 1-\mathrm{Zn} 3$ is $139.6(3)^{\circ}$. Selected bond lengths and angles for 7 are listed in Table 2.14 and hydrogen bonding parameters are listed in Table 2.15.

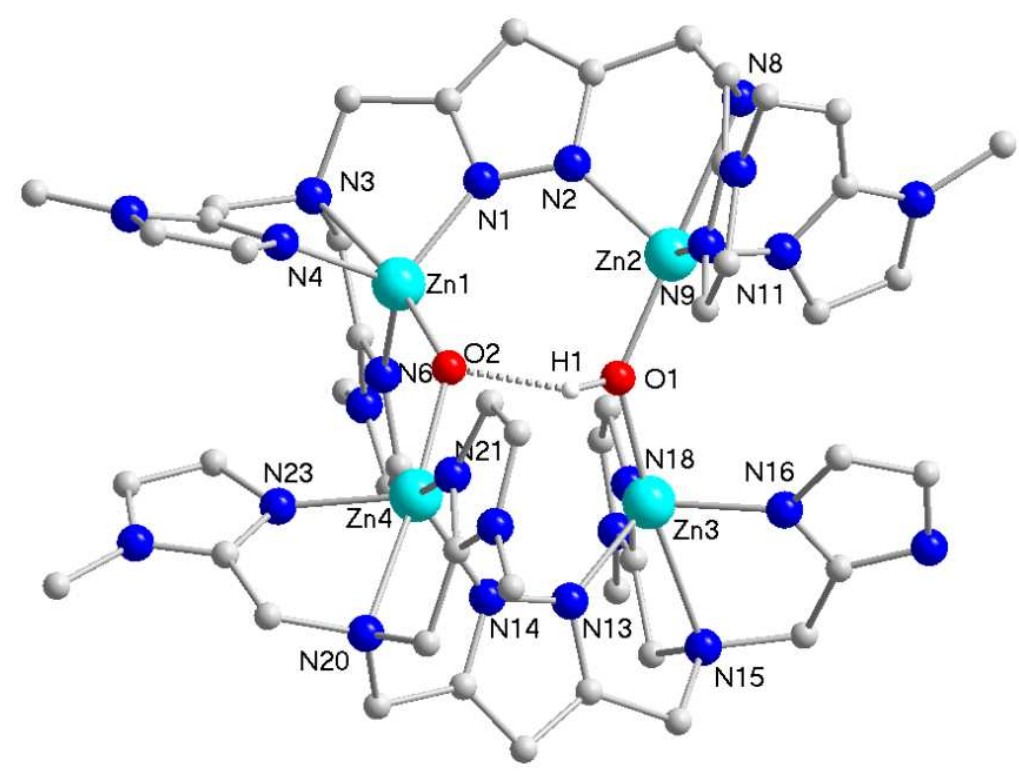

Figure 2.11: Molecular structure of 7, most hydrogen atoms and all counter ions omitted for clarity.

The presence of a $\mu$-oxo- $\mu$-hydroxo bridge is well known for tetranuclear iron complexes and was also described for a manganese complex, but has not been reported for zinc complexes so far. ${ }^{[58]}$

${ }^{1} \mathrm{H}$ NMR analysis revealed two signals for the proton of the pyrazole ring $(6.09 \mathrm{ppm}$ and $6.12 \mathrm{ppm}$ ) giving evidence for two different species. The signal at $6.12 \mathrm{ppm}$ was assigned to 7 . In addition, the spectrum gave a signal at $8.88 \mathrm{ppm}$ that presumably corresponds to the proton of the $\mu-\mathrm{OH}$ ligand. Comparing this spectrum with the ${ }^{1} \mathrm{H}$ NMR spectrum of 
the acetate bridged complex 5 indicated its formation during the reaction, as chemical shifts and intensities were in agreement. The presence of $\mathbf{5 b}$ was also confirmed by ESI-MS analysis giving signals at $m / z=787$ and 344 for fragments $\left[\mathrm{Zn}_{2} \mathrm{H}_{-1} \mathrm{~L}^{1}(\mathrm{OAc})\left(\mathrm{ClO}_{4}\right)\right]^{+}$and $\left[\mathrm{Zn}_{2} \mathrm{H}_{-1} \mathrm{~L}^{1}(\mathrm{OAc})\right]^{2+}$, respectively. Although the reaction was not performed by treating the mixture with acetate salts, the formation of the acetate bridged complex presumably results from impurities of the $\mathrm{NaOMe}$ that was used. A second species was observed under ESI-MS conditions at $m / z=754$ and 328, which matched the calculated masses of $\left[\mathrm{Zn}_{2} \mathrm{H}_{-1} \mathrm{~L}^{1}(\mathrm{CN})\left(\mathrm{ClO}_{4}\right)\right]^{+}$and $\left[\mathrm{Zn}_{2} \mathrm{H}_{-1} \mathrm{~L}^{1}(\mathrm{CN})\right]^{2+}$, respectively, as it was observed in ESI-MS analysis of $\mathbf{4 b}$.

Table 2.14: Selected bond lengths $[\AA]$ and angles $\left[{ }^{\circ}\right]$ for 7 .

\begin{tabular}{|c|c|c|c|c|c|}
\hline Atoms & Bond length & Atoms & Angle & Atoms & Angle \\
\hline Zn1-N1 & $1.974(6)$ & N1-Zn1-N3 & $74.6(2)$ & N2-Zn2-N8 & $73.6(2)$ \\
\hline Zn1-N3 & $2.455(6)$ & N1-Zn1-N4 & $113.7(2)$ & N2-Zn2-N9 & $112.7(2)$ \\
\hline Zn1-N4 & $2.016(6)$ & N1-Zn1-N6 & $110.8(2)$ & N2-Zn2-N11 & $112.4(2)$ \\
\hline Zn1-N6 & $2.026(5)$ & N1-Zn1-O2 & $114.9(2)$ & $\mathrm{N} 2-\mathrm{Zn} 2-\mathrm{O} 1$ & $107.8(2)$ \\
\hline Zn1-O2 & $1.997(4)$ & $\mathrm{N} 3-\mathrm{Zn} 1-\mathrm{N} 4$ & $74.4(2)$ & N8-Zn2-N9 & $74.9(2)$ \\
\hline Zn2-N2 & $2.002(6)$ & N3-Zn1-N6 & $75.6(2)$ & N8-Zn2-N11 & $74.3(2)$ \\
\hline Zn2-N8 & $2.471(6)$ & $\mathrm{N} 3-\mathrm{Zn} 1-\mathrm{O} 2$ & $170.48(19)$ & N8-Zn2-O1 & $176.5(2)$ \\
\hline Zn2-N9 & $2.022(6)$ & N4-Zn1-N6 & $115.7(2)$ & N9-Zn2-N11 & $113.7(3)$ \\
\hline $\mathrm{Zn2-N11}$ & $2.042(5)$ & N4-Zn1-O2 & $99.8(2)$ & N9-Zn2-O1 & $101.6(2)$ \\
\hline Zn2-O1 & $1.934(5)$ & N6-Zn1-O2 & $100.9(2)$ & N11-Zn2-O1 & $107.8(2)$ \\
\hline Zn3-N13 & $1.995(7)$ & N13-Zn3-N15 & $75.7(3)$ & N14-Zn4-N20 & $76.9(2)$ \\
\hline $\mathrm{Zn3-N15}$ & $2.455(7)$ & N13-Zn3-N16 & $116.0(3)$ & N14-Zn4-N21 & $113.8(3)$ \\
\hline Zn3-N16 & 1.992(9) & N13-Zn3-N18 & $114.4(3)$ & N14-Zn4-N23 & 110.7(3) \\
\hline Zn3-N18 & $2.041(6)$ & N13-Zn3-O1 & $112.6(2)$ & N14-Zn4-O2 & $113.6(2)$ \\
\hline Zn3-O1 & $1.957(5)$ & N15-Zn3-N16 & $74.4(4)$ & N20-Zn4-N21 & $74.2(2)$ \\
\hline Zn4-N14 & $2.005(6)$ & N15-Zn3-N18 & $74.5(2)$ & N20-Zn4-N23 & $75.2(2)$ \\
\hline $\mathrm{Zn} 4-\mathrm{N} 20$ & $2.417(6)$ & N15-Zn3-O1 & $171.7(2)$ & $\mathrm{N} 20-\mathrm{Zn} 4-\mathrm{O} 2$ & $168.68(17)$ \\
\hline $\mathrm{Zn} 4-\mathrm{N} 21$ & $2.051(7)$ & N16-Zn3-N18 & $110.0(3)$ & N21-Zn4-N23 & $117.1(2)$ \\
\hline $\mathrm{Zn} 4-\mathrm{N} 23$ & $2.032(6)$ & N16-Zn3-O1 & $101.9(3)$ & $\mathrm{N} 21-\mathrm{Zn} 4-\mathrm{O} 2$ & $96.9(2)$ \\
\hline Zn4-O2 & $2.003(4)$ & N18-Zn3-O1 & $100.3(2)$ & N23-Zn4-O2 & $103.6(2)$ \\
\hline Zn4-N14 & $2.005(6)$ & $\mathrm{Zn} 1-\mathrm{O} 2-\mathrm{Zn} 4$ & $134.3(3)$ & $\mathrm{Zn} 2-\mathrm{O} 1-\mathrm{Zn} 3$ & $139.6(3)$ \\
\hline $\mathrm{Zn} 1 \cdots \mathrm{Zn} 2$ & $3.9586(11)$ & & & & \\
\hline $\mathrm{Zn} 3 \cdots \mathrm{Zn} 4$ & $4.1702(12)$ & & & & \\
\hline
\end{tabular}


Table 2.15: Hydrogen bond parameters for 7; interatomic distances $[\AA]$ and angles $\left[^{\circ}\right]$.

\begin{tabular}{ccccc}
\hline $\mathrm{D}-\mathrm{H} \cdots \mathrm{A}$ & $d(\mathrm{D}-\mathrm{H})$ & $d(\mathrm{H} \cdots \mathrm{A})$ & $d(\mathrm{D} \cdots \mathrm{A})$ & $\angle(\mathrm{D}-\mathrm{H} \cdots \mathrm{A})$ \\
\hline \hline $\mathrm{O} 1-\mathrm{H} 1 \cdots \mathrm{O} 2$ & $0.84(2)$ & $1.91(3)$ & $2.704(6)$ & $157(7)$ \\
\hline
\end{tabular}

\subsubsection{Complexes based on $L^{2}$}
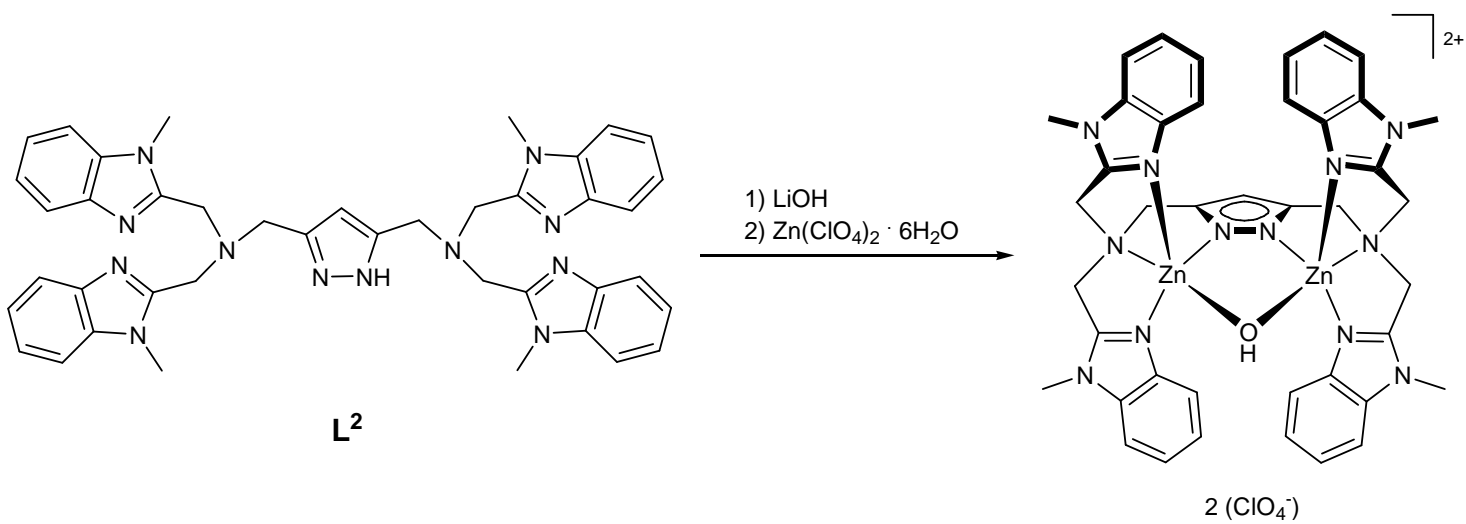

8

Scheme 2.16: Synthesis of 8 .

8 was synthesised in the presence of methanol, treating $\mathbf{L}^{2}$ with two equivalents of LiOH and two equivalents of $\mathrm{Zn}\left(\mathrm{ClO}_{4}\right)_{2} \cdot 6 \mathrm{H}_{2} \mathrm{O}$ (Scheme 2.16). After stirring, the colourless precipitate was collected by filtration and redissolved in acetonitrile. $\mathrm{Et}_{2} \mathrm{O}$ diffusion into the complex solution yielded colourless single crystals that were suitable for X-ray analysis.

8 crystallises in the triclinic space group $P \overline{1}$ with two independent molecules per unit cell. As depicted in Figure 2.12, each zinc atom is coordinated by four $N$-donor groups of the ligand and an additional hydroxide group, which bridges the zinc atoms $(d(\mathrm{Zn} 1 \cdots \mathrm{Zn} 2)=3.3372(12) \AA$ and $3.3374(12) \AA$ for the second independent molecule $)$. Selected bond lengths and angles for $\mathbf{8}$ are listed in Table 2.16. The bridging hydroxide moiety in $\mathbf{8}$ is located within the pyrazolato plane and the zinc atoms are marginally out of plane with distances of $0.34(1) \AA[0.23(1) \AA]$ for Zn1 and 0.24(1) $\AA$ [0.21(1) $\mathrm{A}]$ for $\mathrm{Zn} 2$ (values for independent second molecule in square brackets). The zinc atoms are distorted trigonal bipyramidal coordinated (Zn1: $\tau_{5}=0.77$ [0.72], $\mathrm{Zn} 2: \tau_{5}=0.76$ $[0.70])^{[53]}$ in both molecules. Considering the very long Zn1-N3 and Zn2-N8 bonds the coordination might even be described as $\{4+1\}$ or close to distorted tetrahedral. These 
observations of the distorted coordination polyhedra are in agreement with the results obtained for the methanolate bridged imidazole complex (4b). The bond lengths of the zinc atoms to the tertiary nitrogen atoms in $\mathbf{8}$ are slightly elongated compared to $\mathbf{4 b}$ (Zn1-N3 about $0.04 \AA[0.03 \AA]$ and Zn2-N8 about $0.09 \AA[0.08 \AA]$ ). The plasticity of these $\mathrm{Zn}-\mathrm{N}$ bonds thus results in the distorted coordination geometry of the zinc atoms and allows a short zinc-zinc distance as it was discussed above.

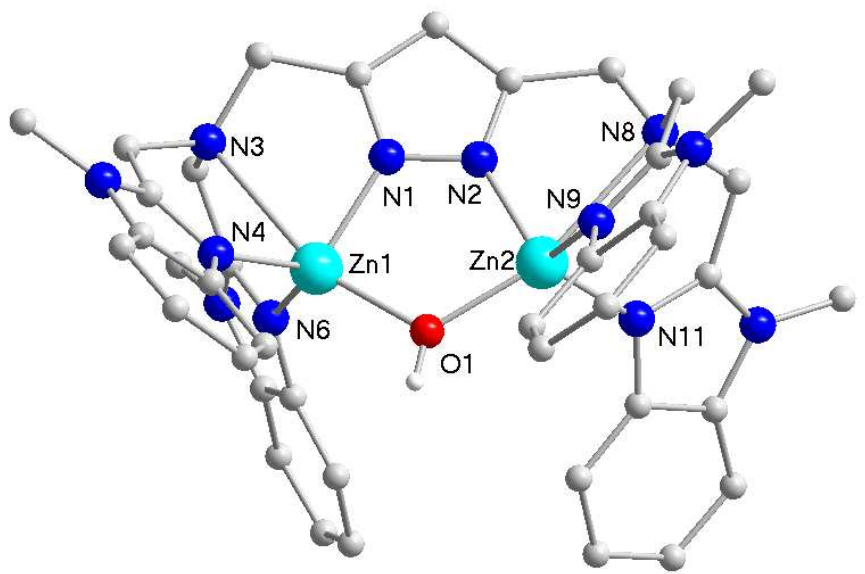

Figure 2.12: Molecular structure of $\mathbf{8}$, most hydrogen atoms and all counter ions omitted for clarity.

Table 2.16: Selected bond lengths $[\AA]$ and angles $\left[{ }^{\circ}\right]$ for $\mathbf{8}$ (values for independent second molecule in square brackets).

\begin{tabular}{|c|c|c|c|c|c|}
\hline Atoms & Bond length & Atoms & Angle & Atoms & Angle \\
\hline Zn1-N1 & $\begin{array}{c}1.974(6) \\
{[1.997(5)]}\end{array}$ & N1-Zn1-N3 & $\begin{array}{c}70.206(204) \\
{[69.510(223)]}\end{array}$ & N2-Zn2-N8 & $\begin{array}{c}69.753(215) \\
{[69.704(225)]}\end{array}$ \\
\hline Zn1-N3 & $\begin{array}{c}2.6279(43) \\
{[2.6165(66)]}\end{array}$ & N1-Zn1-N4 & $\begin{array}{l}115.2(2) \\
{[107.9(2)]}\end{array}$ & N2-Zn2-N9 & $\begin{array}{l}109.3(2) \\
{[113.3(2)]}\end{array}$ \\
\hline Zn1-N4 & $\begin{array}{c}2.014(5) \\
{[2.013(6)]}\end{array}$ & N1-Zn1-N6 & $\begin{array}{c}108.1(2) \\
{[112.9(2)]}\end{array}$ & N2-Zn2-N11 & $\begin{array}{c}112.5(2) \\
{[108.7(2)]}\end{array}$ \\
\hline Zn1-N6 & $\begin{array}{c}2.005(5) \\
{[2.004(6)]}\end{array}$ & N3-Zn1-N4 & $\begin{array}{c}74.357(172) \\
{[74.298(221)]}\end{array}$ & N8-Zn2-N9 & $\begin{array}{c}73.777(179) \\
{[74.443(226)]}\end{array}$ \\
\hline Zn1-O1 & $\begin{array}{c}1.975(4) \\
{[1.961(5)]}\end{array}$ & N3-Zn1-N6 & $\begin{array}{c}74.740(164) \\
{[73.806(221)]}\end{array}$ & N8-Zn2-N11 & $\begin{array}{c}73.233(217) \\
{[74.443(226)]}\end{array}$ \\
\hline Zn2-N2 & $\begin{array}{c}1.966(6) \\
{[1.991(6)]}\end{array}$ & N6-Zn1-N4 & $\begin{array}{c}112.4(2) \\
{[113.3(2)]}\end{array}$ & N11-Zn2-N9 & $\begin{array}{c}111.7(2) \\
{[111.8(2)]}\end{array}$ \\
\hline Zn2-N8 & $\begin{array}{c}2.6426(58) \\
{[2.6312(61)]}\end{array}$ & N1-Zn1-O1 & $\begin{array}{c}91.1(2) \\
{[91.9(2)]}\end{array}$ & $\mathrm{N} 2-\mathrm{Zn} 2-\mathrm{O} 1$ & $\begin{array}{c}92.4(2) \\
{[91.8(2)]}\end{array}$ \\
\hline Zn2-N9 & $\begin{array}{c}2.020(6) \\
{[1.988(6)]}\end{array}$ & $\mathrm{O} 1-\mathrm{Zn} 1-\mathrm{N} 3$ & $\begin{array}{c}161.335(159) \\
{[161.247(218)]}\end{array}$ & $\mathrm{O} 1-\mathrm{Zn} 2-\mathrm{N} 8$ & $\begin{array}{c}162.146(177) \\
{[160.972(188)]}\end{array}$ \\
\hline Zn2-N11 & $\begin{array}{c}2.003(5) \\
{[2.000(6)]}\end{array}$ & O1-Zn1-N4 & $\begin{array}{c}115.2(2) \\
{[110.7(2)]}\end{array}$ & O1-Zn2-N9 & $\begin{array}{c}112.7(2) \\
{[118.9(2)]}\end{array}$ \\
\hline Zn2-O1 & $\begin{array}{c}1.979(5) \\
{[1.981(5)]}\end{array}$ & O1-Zn1-N6 & $\begin{array}{c}113.1(2) \\
{[117.9(2)]}\end{array}$ & $\mathrm{O} 1-\mathrm{Zn} 2-\mathrm{N} 11$ & $\begin{array}{c}116.8(2) \\
{[110.5(2)]}\end{array}$ \\
\hline $\mathrm{Zn} 1 \cdots \mathrm{Zn} 2$ & $\begin{array}{c}3.3372(12) \\
{[3.3374(12)]}\end{array}$ & & & $\mathrm{Zn} 1-\mathrm{O} 1-\mathrm{Zn} 2$ & $\begin{array}{l}115.2(2) \\
{[115.7(2)]}\end{array}$ \\
\hline
\end{tabular}


The proton spectrum of $\mathbf{8}$ in $d_{6}$-DMSO showed a signal at $5.16 \mathrm{ppm}$, which was assigned to $\mu-\mathrm{OH}$. However, no signal for the hydroxide ligand was obtained in $d_{3}-\mathrm{MeCN}$. ESI-MS analysis did not confirm the formation of a hydroxide bridged complex. Instead, signals for the fragments $\left[\mathrm{Zn}_{2} \mathrm{H}_{-1} \mathrm{~L}^{2}\left(\mathrm{H}_{3} \mathrm{O}_{2}\right)\left(\mathrm{ClO}_{4}\right)\right]^{+}$at $m / z=963$ and 432 for $\left[\mathrm{Zn}_{2} \mathrm{H}_{-1} \mathrm{~L}^{2}\left(\mathrm{H}_{3} \mathrm{O}_{2}\right)\right]^{2+}$ were obtained. These findings indicated that the equilibrium, which was found for $\mathbf{4}$, is also present for $\mathbf{8}$ in solution (Scheme 2.17).

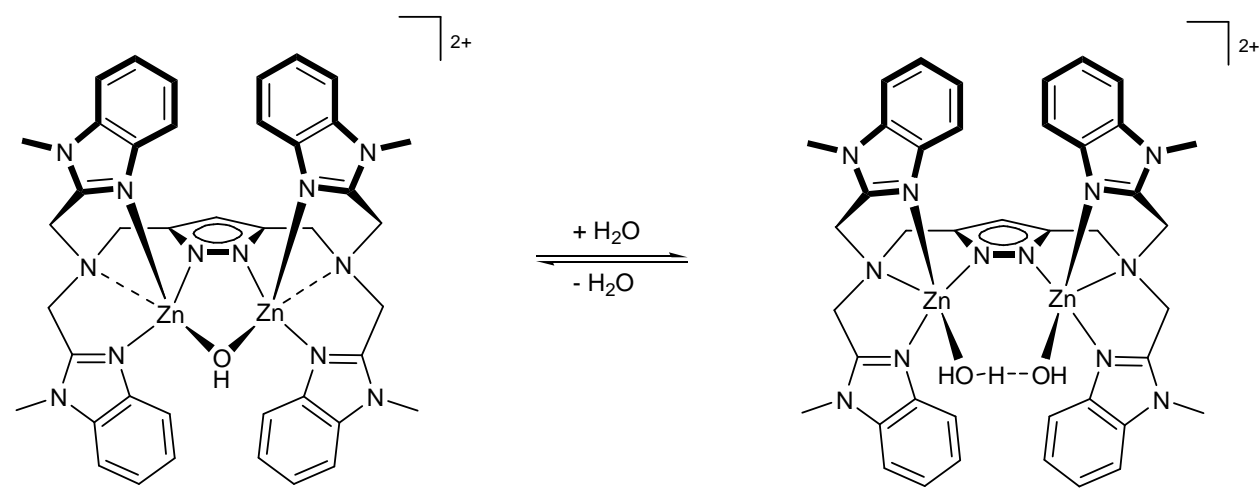

Scheme 2.17: Proposed equilibrium of $\mathbf{8}$; species were found in solid state (left) and in solution (right).

\subsubsection{Complexes based on $L^{3}$}

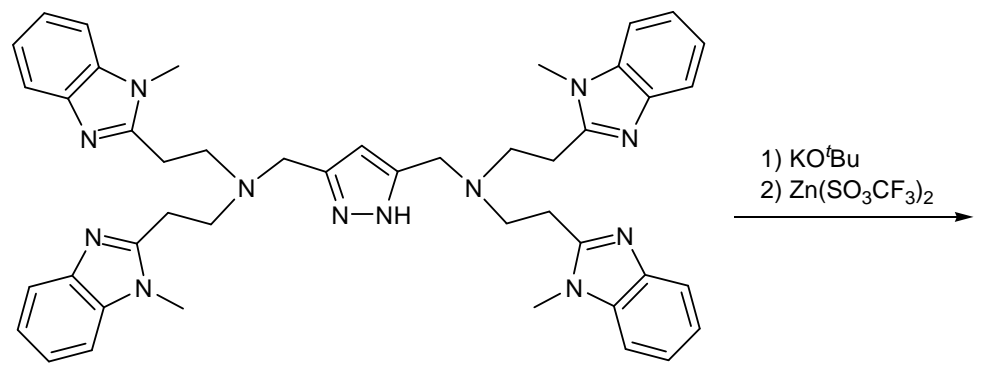

$L^{3}$

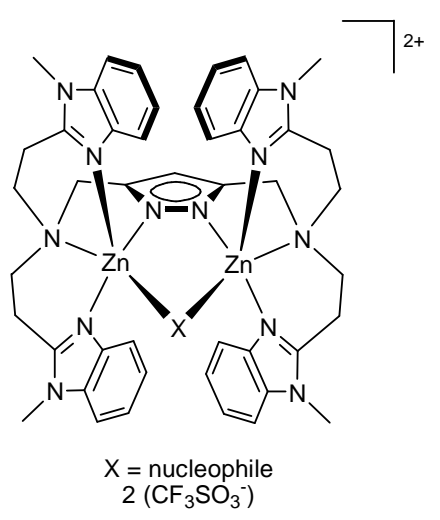

9

Scheme 2.18: Synthesis and proposed structure of 9.

In contrast to the ligands $\mathbf{L}^{1}$ and $\mathbf{L}^{2}$, the usual procedure for complexation was not successful when using $\mathbf{L}^{\mathbf{3}}$ (Scheme 2.18). Treating the ligand with base and $\mathrm{Zn}\left(\mathrm{SO}_{3} \mathrm{CF}_{3}\right)_{2}$ resulted in various species as evidenced by ${ }^{1} \mathrm{H}$ NMR and ESI-MS analysis. The mixture 
of complexes was purified by crystallisation. This purification step resulted in a complex mixture that consists of only two species as the ${ }^{1} \mathrm{H}$ NMR spectrum showed two sharp signals at 5.97 and $6.15 \mathrm{ppm}$ for the aromatic pyrazole protons. Since sharp signals were obtained in the spectrum for all other protons that fitted in intensities, as anticipated for two complexes, the co-existence of two different complexes was assumed. During ESI-MS, fragments $\left[\mathrm{Zn}_{2} \mathrm{H}_{-1} \mathrm{~L}^{3}\left(\mathrm{H}_{3} \mathrm{O}_{2}\right)\right]^{2+}$ at $m / z=460$ and 1069 for $\left[\mathrm{Zn}_{2} \mathrm{H}_{-1} \mathrm{~L}^{3}\left(\mathrm{H}_{3} \mathrm{O}_{2}\right)\left(\mathrm{SO}_{3} \mathrm{CF}_{3}\right)\right]^{+}$were observed. In addition, the signal at $\mathrm{m} / \mathrm{z}=955$ matched the calculated mass of the fragment $\left[\mathrm{Zn}_{2} \mathrm{H}_{-1} \mathrm{~L}^{3}(\mathrm{OH})_{2}\left(\mathrm{H}_{2} \mathrm{O}\right)_{2}\right]^{+}$. However, as demonstrated for the complexes of ligands $\mathbf{L}^{1}$ and $\mathbf{L}^{\mathbf{2}}$, ESI-MS did not confirm the formation of the complexes in bulk solution as different species can be formed under electrospray conditions.

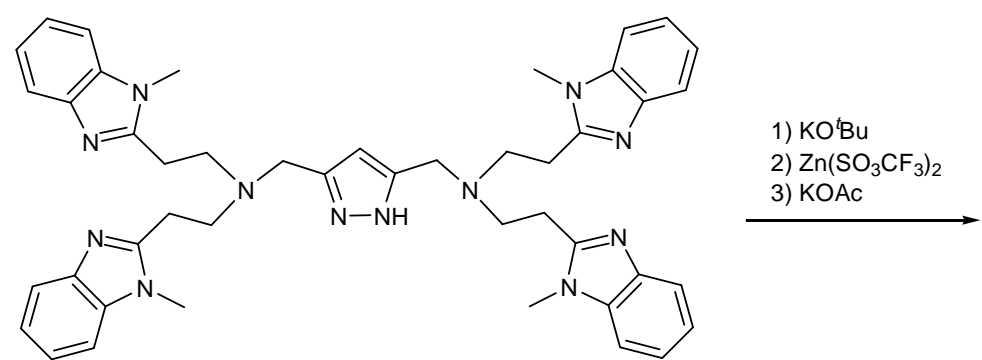

$\mathbf{L}^{3}$

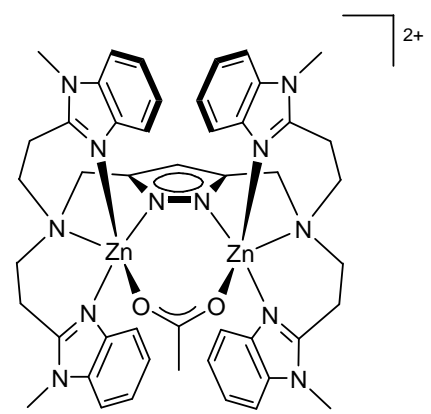

$2\left(\mathrm{CF}_{3} \mathrm{SO}_{3}{ }^{-}\right)$

10

Scheme 2.19: Synthesis and proposed structure of $\mathbf{1 0}$

To obtain a complex that is likely to be stable in solution, acetate was added as co-ligand. The observed signals in the ${ }^{1} \mathrm{H}$ NMR spectrum revealed the formation of one species. The ESI-MS spectrum showed signals at $m / z=1093$ for $\left[\mathrm{Zn}_{2} \mathrm{H}_{-1} \mathrm{~L}^{3}(\mathrm{OAc})\left(\mathrm{SO}_{3} \mathrm{CF}_{3}\right)\right]^{+}$and 472 for $\left[\mathrm{Zn}_{2} \mathrm{H}_{-1} \mathrm{~L}^{3}(\mathrm{OAc})\right]^{2+}$, respectively. In addition, fragments of $\left[\mathrm{Zn}_{2} \mathrm{H}_{-1} \mathrm{~L}^{3}\left(\mathrm{H}_{3} \mathrm{O}_{2}\right)\right]^{2+}$ were observed as for $\mathbf{9}$ without co-ligand. Since $\mathbf{L}^{3}$ bears long side chains that form less stable six-membered chelate rings, structures different from the one shown in Scheme 2.19 might be possible due to the flexible side chains, which are able to dissociate. ${ }^{[44 a, 44 b, 55]}$ 


\subsubsection{Complexes based on $\mathrm{L}^{4}$}
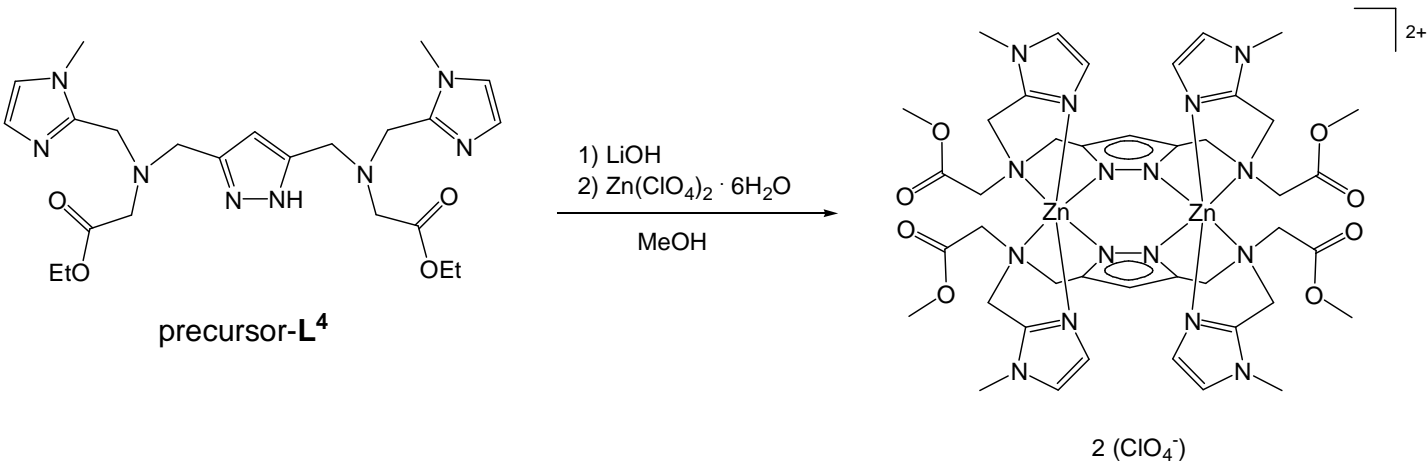

11

Scheme 2.20: Synthesis of 11.

Since ligand $\mathbf{L}^{4}$ could not be separated from inorganic salts (see section 2.1.), precursor- $\mathbf{L}^{\mathbf{4}}$ was used for the synthesis of the complexes. Precursor- $\mathbf{L}^{4}$ and four equivalents of base $(\mathrm{LiOH})$ were stirred in methanol until the solution became clear. Subsequently, $\mathrm{Zn}\left(\mathrm{ClO}_{4}\right)_{2} \cdot 6 \mathrm{H}_{2} \mathrm{O}$ dissolved in methanol was added. In the course of this reaction a colourless precipitate was formed, which dissolved again by stirring. $\mathrm{Et}_{2} \mathrm{O}$ diffusion into the filtered complex solution afforded only few single crystals that were suitable for X-ray analysis. Although a binuclear complex was formed, the structure did not match the expectations of a complex with a metal to ligand ratio of 2:1. Instead, 11 (Figure 2.13) was obtained with a metal to ligand ratio of 1:1. In methanol, a transesterification took place by exchanging ethyl ester into methyl ester groups (Scheme 2.20). Each zinc atom in $\mathbf{1 1}$ is octahedrally coordinated by six nitrogen atoms of the ligands. The methyl ester moieties are dangling and are not involved in the coordination to the zinc ions. Selected bond lengths and angles for $\mathbf{1 1}$ are listed in Table 2.17. 


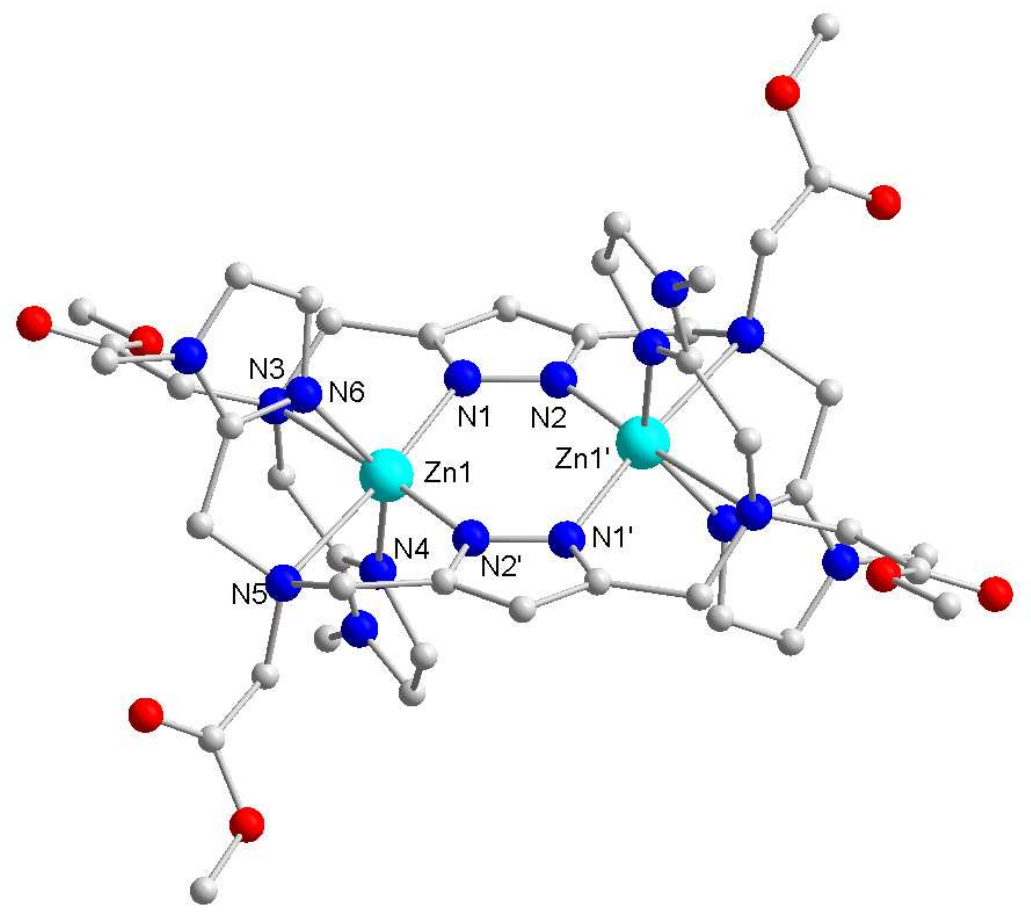

Figure 2.13: Molecular structure of 11, hydrogen atoms and counter ions omitted for clarity. Symmetry operation used to generate equivalent atoms: (') $-x+1,-y,-z+2$.

Table 2.17: Selected bond lengths [̊] and angles $\left[{ }^{\circ}\right]$ for $\mathbf{1 1 .}$

\begin{tabular}{c|c||c|c}
\hline Atoms & Bond length & Atoms & Angle \\
\hline Zn1-N1 & $2.0470(3)$ & N1-Zn1-N3 & $72.461(3)$ \\
Zn1-N3 & $2.7610(2)$ & N1-Zn1-N4 & $97.589(5)$ \\
Zn1-N4 & $2.0228(2)$ & N1-Zn1-N5 & $171.507(5)$ \\
Zn1-N5 & $2.6799(3)$ & N1-Zn1-N6 & $101.859(5)$ \\
Zn1-N6 & $2.0234(2)$ & N3-Zn1-N4 & $71.008(3)$ \\
Zn1‥Zn1' & $3.7318(4)$ & N3-Zn1-N5 & $109.224(3)$ \\
& & N3-Zn1-N6 & $82.367(3)$ \\
& & N4-Zn1-N5 & $90.778(4)$ \\
& & N4-Zn1-N6 & $140.332(5)$ \\
& & N5-Zn1-N6 & $70.464(4)$ \\
\hline
\end{tabular}




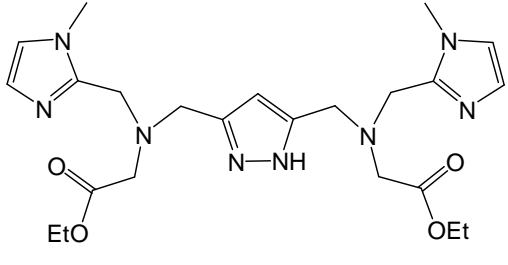

precursor-L ${ }^{4}$
1. $\mathrm{KOH}$

2. $\mathrm{Zn}\left(\mathrm{ClO}_{4}\right)_{2} \cdot 6 \mathrm{H}_{2} \mathrm{O}$

3. KOAC

water, $\mathrm{MeCN}$

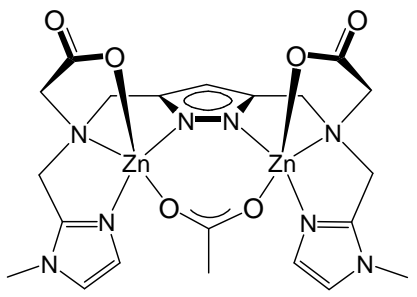

12

Scheme 2.21: Synthesis of 12.

To avoid transesterification, complexation was performed in different solvents (e.g., acetone, acetonitrile), but still showed formation of several species according to NMR analysis. Crystallisation of the complexes always gave colourless oils. Thus, acetate was added as co-ligand to form a complex, which is presumably stable in solution. The reaction was performed in the presence of water using $\mathrm{KOH}$ as base and $\mathrm{Zn}\left(\mathrm{ClO}_{4}\right)_{2} \cdot 6 \mathrm{H}_{2} \mathrm{O}$ (Scheme 2.21). After stirring for several hours, the aqueous solution was filtered from $\mathrm{KClO}_{4}$, evaporated to dryness and the colourless residue was dissolved methanol. Slow diffusion of $\mathrm{Et}_{2} \mathrm{O}$ into the filtered complex solution afforded an amorphous solid, which was collected by filtration. The colourless compound was dried in vacuum and redissolved in acetonitrile. $\mathrm{Et}_{2} \mathrm{O}$ diffusion into the complex solution yielded colourless single crystals that were analysed by X-ray diffraction. The structure of $\mathbf{1 2}$ is given in Figure 2.14 and selected bond lengths and angles are listed in Table 2.18.

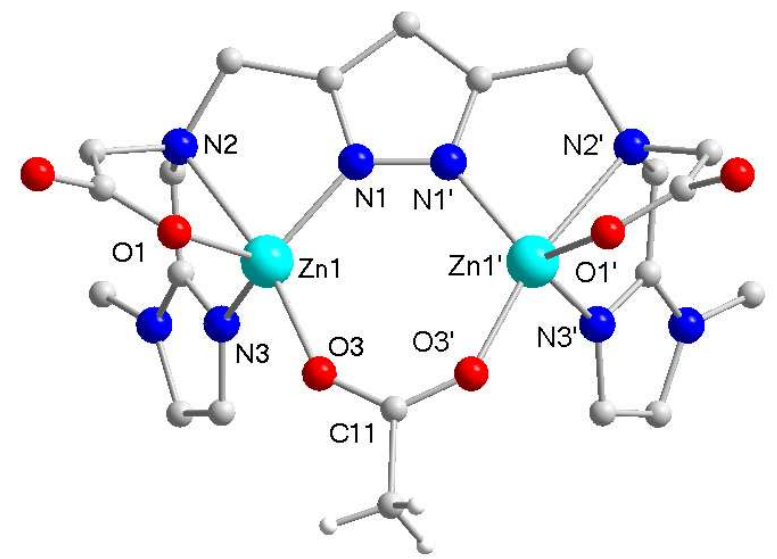

Figure 2.14: Molecular structure of 12, most hydrogen atoms omitted for clarity. Symmetry operation used to generate equivalent atoms: (') $x,-y+1 / 2, z$. 
The neutral complex 12 crystallises in the monoclinic space group $P 2_{1} / m$ with two formula units per unit cell. The zinc atoms are nested within the ligand donor compartments and additionally bridged by the acetate moiety in a $\mu_{1,3}$-binding fashion. Separation of the zinc atoms was found to be 3.9094(4) $\AA$, which lies between the Zn-Zn distances obtained for the acetate bridged complexes $\mathbf{5 a}(3.9548(4) \AA)$ and $\mathbf{5 b}$ (3.8809(21) A). In 12, the zinc atoms and the acetate moiety are almost located within the pyrazolate plane $(d(\mathrm{Zn} 1 \cdots \mathrm{pz})=0.11(1) \AA, d(\mathrm{O} 3 \cdots \mathrm{pz})=0.10(1) \AA, d(\mathrm{C} 11 \cdots \mathrm{pz})=$ $0.21(1) \AA$ ). This is also different from complexes $\mathbf{5 a}$ and $\mathbf{5 b}$, in which the acetate moiety was twisted with respect to the pyrazolato plane.

Table 2.18: Selected bond lengths [ $[\AA]$ and angles $\left[{ }^{\circ}\right]$ for $\mathbf{1 2}$.

\begin{tabular}{c|c||c|c}
\hline Atoms & Bond length & Atoms & Angle \\
\hline \hline Zn1-N1 & $1.9727(18)$ & $\mathrm{N} 1-\mathrm{Zn} 1-\mathrm{N} 2$ & $76.81(7)$ \\
$\mathrm{Zn} 1-\mathrm{N} 2$ & $2.3757(18)$ & $\mathrm{N} 1-\mathrm{Zn} 1-\mathrm{N} 3$ & $116.13(8)$ \\
$\mathrm{Zn} 1-\mathrm{N} 3$ & $2.021(2)$ & $\mathrm{N} 1-\mathrm{Zn} 1-\mathrm{O} 1$ & $112.77(8)$ \\
$\mathrm{Zn} 1-\mathrm{O} 1$ & $1.9819(17)$ & $\mathrm{N} 1-\mathrm{Zn} 1-\mathrm{O} 3$ & $114.31(7)$ \\
$\mathrm{Zn} 1-\mathrm{O} 3$ & $2.0048(16)$ & $\mathrm{N} 2-\mathrm{Zn} 1-\mathrm{N} 3$ & $76.66(7)$ \\
$\mathrm{Zn} 1 \cdots \mathrm{Zn} 11^{\prime}$ & $3.9094(4)$ & $\mathrm{O} 1-\mathrm{Zn} 1-\mathrm{N} 2$ & $77.84(7)$ \\
& & $\mathrm{O} 3-\mathrm{Zn} 1-\mathrm{N} 2$ & $168.74(7)$ \\
& & $\mathrm{O} 1-\mathrm{Zn} 1-\mathrm{N} 3$ & $116.59(8)$ \\
& & O3-Zn1-N3 & $95.97(8)$ \\
& & O1-Zn1-O3 & $98.40(7)$ \\
& & C11-O3-Zn1 & $141.19(17)$ \\
\hline
\end{tabular}

ESI-MS analysis confirmed the formation of $\mathbf{1 2}$ by signals at $m / z=555$ for $\left[\mathrm{ZnH}_{-3} \mathrm{~L}^{4}\right]^{+}$ and 615 for $\left[\mathrm{ZnH}_{-2} \mathrm{~L}^{4}(\mathrm{OAc})\right]^{+}$, respectively. In addition, several fragments were observed that fitted to the composition of $\left[\mathrm{ZnH}_{-3} \mathrm{~L}^{4}\right]^{+}$and additional solvent molecules. A signal at $m / z=1169$ probably reflected the tetranuclear complex $\left[\left(\mathrm{Zn}_{2} \mathrm{H}_{-3} \mathrm{~L}^{4}\right)_{2}(\mathrm{OAc})\right]^{+}$. Strong bands for the asymmetric and symmetric stretching vibration were observed in IR analysis. Bands at 1614 and $1389 \mathrm{~cm}^{-1}$ were assigned to the carboxylate group of the ligand with $\Delta \tilde{v}=226 \mathrm{~cm}^{-1}$ that is characteristic for a monodentate binding fashion. Bands at 1580 and $1424 \mathrm{~cm}^{-1}$ were observed for the acetate group, which is bidentate coordinated as indicated by $\Delta \tilde{v}=156 \mathrm{~cm}^{-1}$. 


\subsection{Investigations on $\beta$-Lactam Substrates}

\subsubsection{Introduction}

Since the germ-killing effect of Penicillin has been found, ${ }^{[59]}$ many diseases, which are caused by bacteria, could be treated with this new kind of antibiotics. The research on related compounds derived from parent penicillins had grown tremendously and various antibiotic drugs have been investigated; ${ }^{[60]}$ nowadays more than $50 \%$ of the worldwide used antibiotics are $\beta$-lactam antibiotics. ${ }^{[24]}$ The acting agent and the characteristic structural motif of this group is the four membered $\beta$-lactam ring. ${ }^{[61]}$ The antibiotic drug inhibits bacterial cell wall biosynthesis, what causes the disruption of the bacteria. ${ }^{[62]}$ Stimulated by the often unnecessary and excessive use of antibiotic drugs, bacteria have increasingly developed resistance against its antagonists. They express an enzyme, which is the so called $\beta$-lactamase. This enzyme binds to the antibiotic substrate, opens the $\beta$-lactam ring by hydrolysis of the $\beta$-lactam $\mathrm{C}-\mathrm{N}$ bond and thus inactivates the medicinal drug (Scheme 2.22). ${ }^{[24]}$ The investigations of mechanistic pathways of these enzymes are of enormous medicinal interest to avoid bacterial epidemics.
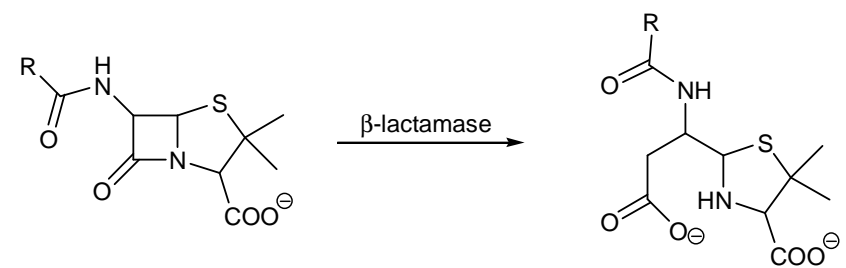

Scheme 2.22: Hydrolysis of $\beta$-lactam antibiotics caused by $\beta$-lactamase enzymes.

Initial studies into the hydrolytic cleavage of $\beta$-lactams were performed with divalent metal ions $\left(\mathrm{Zn}^{2+}, \mathrm{Cu}^{2+}, \mathrm{Co}^{2+}\right.$ and $\left.\mathrm{Ni}^{2+}\right)$. A rate enhancement in the formation of the hydrolytic product was observed in the presence of these transition metals compared to uncatalysed reactions. ${ }^{[63]}$ The mechanistic pathways of these reactions were explored by binding studies of the substrates to the metal ions. Intensive mechanistic studies were carried out by PAGE and co-workers. ${ }^{[63 b, 63 c]}$ The authors hypothesised the coordination of Penicillin $\mathrm{G}$ to the metal ion via the carboxylic acid moiety and the nitrogen atom of the lactam ring. The $\mathrm{C}-\mathrm{N}$ bond is thus polarised and the nucleophilic attack occurs by an external hydroxide group (Scheme 2.23). 


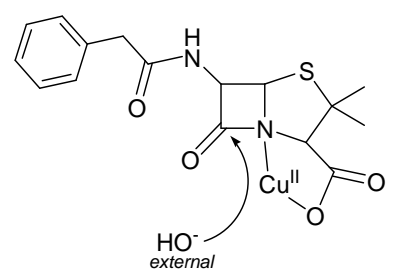

Scheme 2.23: External nucleophilic attack reported by PAGE and co-workers.

In contrast to an external nucleophilic attack, HAY et al. proposed an intramolecular attack by an activated water molecule, which binds to $\mathrm{Cu}^{2+}$. As a result of potentiometric investigations, coordination of the deprotonated amide side chain to $\mathrm{Cu}^{2+}$ was suggested to be the active species (Scheme 2.24, a). In addition, the reaction was observed to be independent from the hydroxide ion concentration above $\mathrm{pH} 6$, which must result from an intramolecular attack of a coordinated hydroxide ion. ${ }^{[64]}$ These studies were supported by FIFE and co-workers (Scheme 2.24, b). ${ }^{[65]}$

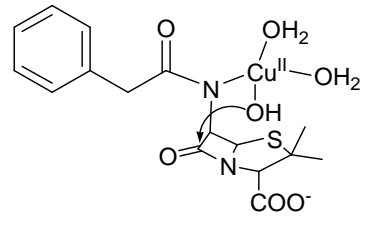

(a)

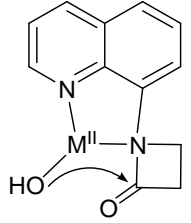

(b)

Scheme 2.24: Intramolecular nucleophilic attack by HAY et al. (a) and FIFE and co-workers $\left[\mathrm{M}^{\mathrm{II}}=\mathrm{Ni}^{2+}, \mathrm{Zn}^{2+}\right](\mathbf{b})$.

Several mononuclear zinc complexes have been investigated with respect to $\beta$-lactam hydrolysis. ${ }^{[42 a, 66]}$ One complex, based on the ligand tris(hydroxymethyl)aminomethane (Tris), showed hydrolytic activity toward a broad range of $\beta$-lactam substrates. The zinc ion acts as a template in the intermediate to bring Tris and the substrate together. Due to coordination to the zinc atom, the $\mathrm{p} K_{\mathrm{a}}$ of the hydroxide group of Tris is lowered and thus internally attacks the carbonyl carbon atom of the substrate (Scheme $2.25, \mathbf{a}){ }^{[66 c, 67]}$ 


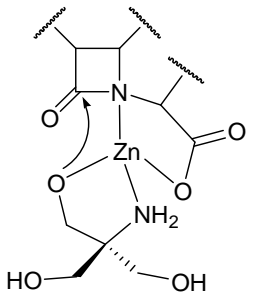

(a)

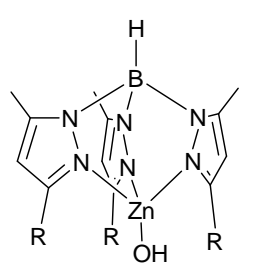

$\mathrm{R}={ }^{\mathrm{t}} \mathrm{Bu}, \mathrm{Ph}, \mathrm{cumol}$

(b)

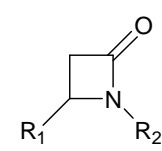

$\mathrm{R}_{1}=\mathrm{H}, \mathrm{Ph}$

$\mathrm{R}_{2}=\mathrm{H}, \mathrm{Me}, \mathrm{Ph}$,

$4-\mathrm{NO}_{2}-\mathrm{Ph}, 2,4-\mathrm{NO}_{2}-\mathrm{Ph}$

(c)

Scheme 2.25: Proposed intermediate of Tris-Zn-substrate template (a), mononuclear zinc complexes by VAHRENKAMP and co-workers (b) and substituted 2-azetidinon substrates (c).

Based on a 3,5-substituted tris(pyrazolylborate) ligand system, VAHRENKAMP and coworkers were able to synthesise suitable mononuclear complexes (Scheme 2.25, b) that were active in the cleavage of 2-azetidinons, which were substituted with electronwithdrawing groups (Scheme 2.25, c). Bearing no substituent at the lactam nitrogen atom, the substrate is deprotonated and coordinates to the zinc complex without cleavage of the four membered ring. To avoid coordination, the nitrogen atom was modified by methylation and phenylation, but this did not improve the hydrolytic cleavage. However, substitution with electron-withdrawing groups (e.g., 4-nitrophenolate and 2,4-nitrophenolate) at the nitrogen atom weakens the $\mathrm{C}-\mathrm{N}$ bond of the lactam ring. These activated substrates are cleaved and the resulting carboxylate group coordinates semibidentate to the zinc atom of the complex. ${ }^{[68]}$

Mono- and binuclear complexes synthesised by MUGESH and co-workers are based on 2,6-substituted phenolate ligands (Scheme 2.26, a). ${ }^{[37 \mathrm{a}]}$ Depending on the zinc salt used during synthesis, mononuclear complexes (with $\mathrm{ZnCl}_{2}$ ) or a binuclear complex (with $\left.\mathrm{Zn}(\mathrm{OAc})_{2} \cdot 6 \mathrm{H}_{2} \mathrm{O}\right)$ were obtained (Scheme 2.26 , b and $\mathbf{c}$ ). 


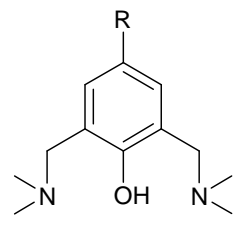

(a)

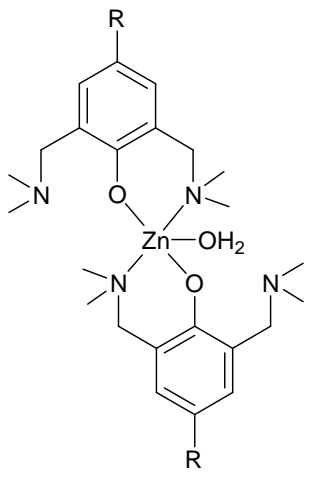

(b)

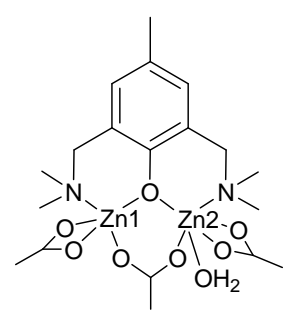

(c)

Scheme 2.26: Ligands and complexes by MUGESH and co-workers $[\mathrm{R}=\mathrm{Me}, \mathrm{Br}]$.

Mononuclear complexes $\mathbf{b}$ and the binuclear complex $\mathbf{c}$ were investigated in their ability to cleave $\beta$-lactam substrates. Although the activity of mononuclear complexes were less compared to the binuclear complex, they were significantly more active than $\mathrm{Zn}(\mathrm{OAc})_{2} \cdot 6 \mathrm{H}_{2} \mathrm{O}$. Thus, the second metal ion is not crucial for hydrolytic activity. The mononuclear complexes are assumed to be active due to the coordinated water molecule, which is strongly hydrogen bound to the uncoordinated tertiary amino groups that serve as an internal base to generate a nucleophile and enhance the catalytic rate. ${ }^{[37 a]}$

Intensive studies towards $\beta$-lactam hydrolysis of binuclear zinc complexes were performed by the LIPPARD group. ${ }^{[38 c, 42 a]}$ The ligand systems were based on 2,7-substituted 1,8-naphthyridine (Scheme 2.27, a) and 2,6-substituted phenolates (Scheme 2.27, b and c).

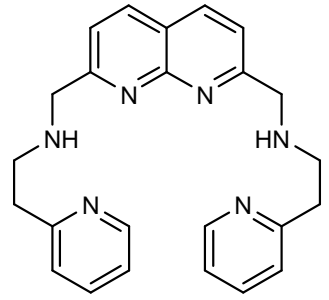

(a)

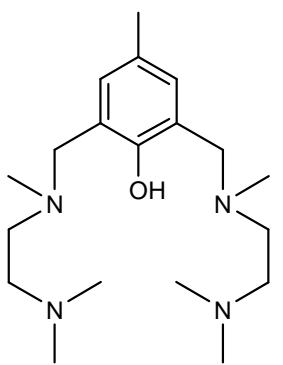

(b)<smiles>CN(C)CCN(C)Cc1cc(Br)cc(CN(C)CCc2ccccn2)c1O</smiles>

(c)

Scheme 2.27: Ligands used by LIPPARD and co-workers. 
Binuclear zinc complexes of these ligands catalysed the hydrolysis of Nitrocefin. Binding studies of the substrates Cephalotin, Nitrocefin and Penicillin G (Scheme 2.28) were performed by ${ }^{13} \mathrm{C}$ NMR and IR spectroscopy.

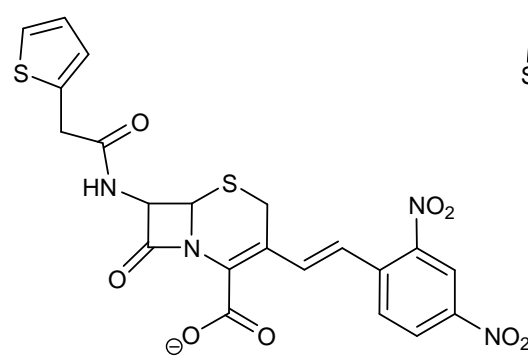

Nitrocefin

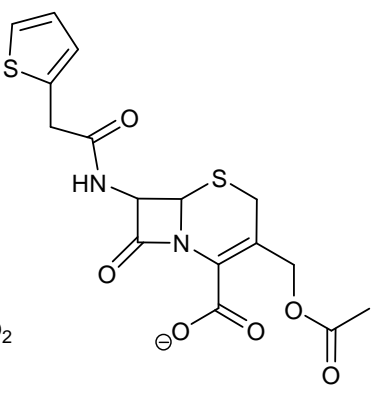

Cephalotin

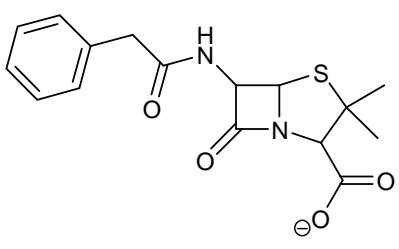

Penicillin G

Scheme 2.28: Substrates used in binding studies by LIPPARD and co-workers.

The results indicated a monodentate coordination of the carboxylate group of the substrate to the zinc ion. This binding was found to be fast and irreversible. Removing the carboxylate group by methylesterification resulted in a significant decrease of the hydrolytic rate. Hence, the carboxylate group plays an important role in substrate coordination.

Working on 3,5-substituted pyrazolate ligands, BAUER-SIEBENLIST et al. designed a series of binuclear zinc complexes, which can be tuned with respect to metal-metal distances. An overview of the complexes is given in Scheme 2.29. Long side chains allow for short zinc-zinc distances (a and $\mathbf{d}$ ), while short side chains force the metal centres to separate (b, $\mathbf{c}$ and $\mathbf{e}$ ). In the latter, an additional solvent molecule is required to bridge the zinc atoms. Catalytic studies of Penicillin G hydrolysis were undertaken using in situ FTIR spectroscopy. The experiments resulted in catalytic activities of $\mathbf{e}<\mathrm{Zn}^{2+}<\mathbf{d}<\mathbf{a}$. Complexes $\mathbf{b}$ and $\mathbf{c}$ showed almost no efficacy. Cleaving three out of four equivalents of Penicillin $\mathrm{G}$ within around 20 minutes, $\mathbf{a}$ was the most active complex. ${ }^{[55]}$ 


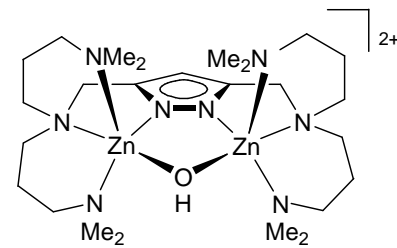

(a)

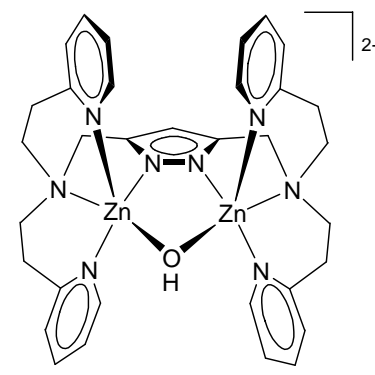

(d)

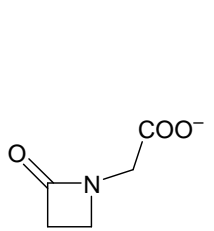

(f)

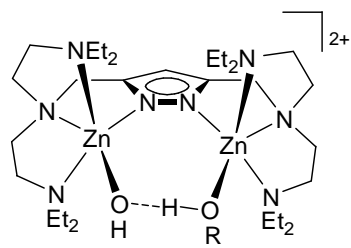

(b) $(\mathrm{R}=\mathrm{H})$

(c) $(\mathrm{R}=\mathrm{Me})$

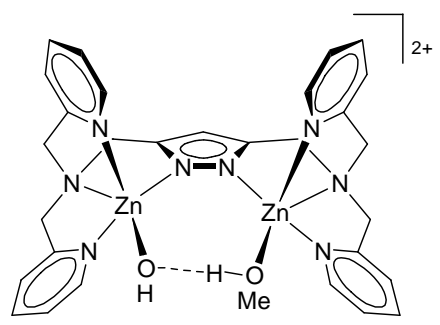

(e)

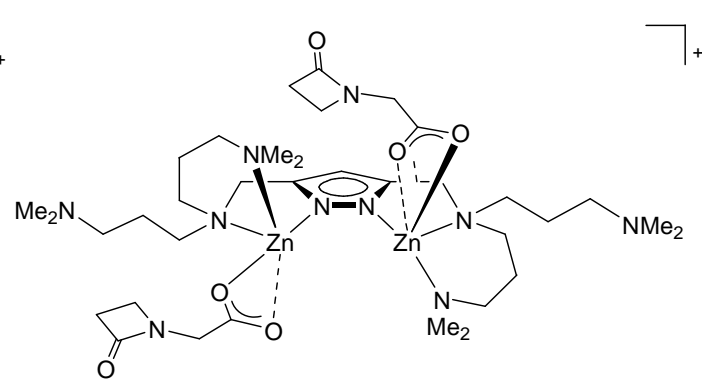

(h)

Scheme 2.29: Complexes by BAUER-SIEBENLIST et al.

In addition, binding of the simple $\beta$-lactam substrate oxazetidinylacetate (Scheme 2.29, f) to the complexes was studied by X-ray diffraction. Complexes $\mathbf{b}, \mathbf{c}$ and $\mathbf{e}$ feature stable five-membered chelate rings that prevent dissociation of the ligands side arms. As the substrate binds to the zinc centres the nucleophile is replaced resulting in an inactive complex (g). The labile six-membered chelate rings in complexes $\mathbf{a}$ and $\mathbf{d}$ are able to dissociate upon substrate coordination generating an accessible coordination site, which allows the binding and activation of a water molecule. In the substrate-complex (h), a semi-bidentate binding fashion of the carboxylate moieties to the zinc atoms was observed displacing two labile coordinated side arms. This explains the higher activity of complexes a and $\mathbf{d}$ in the hydrolysis of Penicillin G compared to complexes that bear short side chains and showed less or no activity in the hydrolytic reactions. ${ }^{[55]}$ 


\subsection{2. $\beta$-Lactam Cleavage}

In the current work, complexes 4,8 and 9 were investigated in their hydrolytic activity to cleave Penicillin G (PenG) (Scheme 2.30). Experiments were performed in $\mathrm{DMSO} / \mathrm{H}_{2} \mathrm{O}$ (9:1, v/v) and were monitored by liquid FTIR spectroscopy. The relevant vibrational bands of PenG are shown in Figure 2.15. The strong band at $1772 \mathrm{~cm}^{-1}$ is assigned to the vibration of the lactam $\mathrm{C}=\mathrm{O}$ group (pink), the band at $1676 \mathrm{~cm}^{-1}$ results from the amide vibration (blue) and the band at $1615 \mathrm{~cm}^{-1}$ is assigned to the vibration of the carboxylate group (yellow). Upon hydrolysis, the $\mathrm{C}-\mathrm{N}$ bond of the lactam ring is cleaved to give a $\beta$-amino acid. As a consequence, the intensity of the strong band at $1772 \mathrm{~cm}^{-1}$ decreases, whereby a new band appears at $\sim 1645 \mathrm{~cm}^{-1}$ (orange).
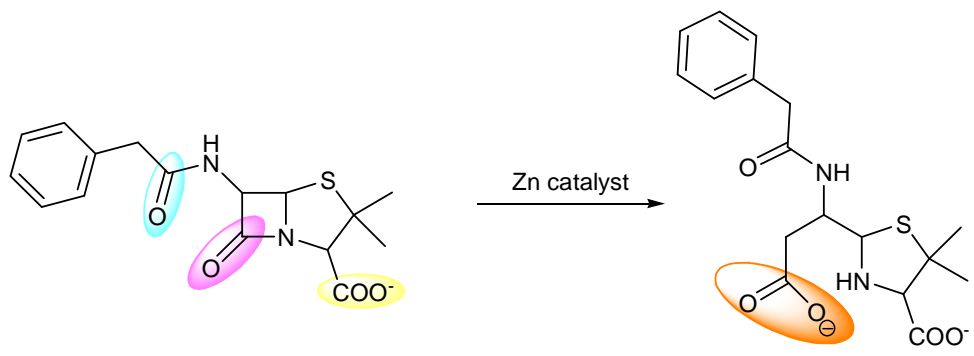

Scheme 2.30: Cleavage reaction of PenG.
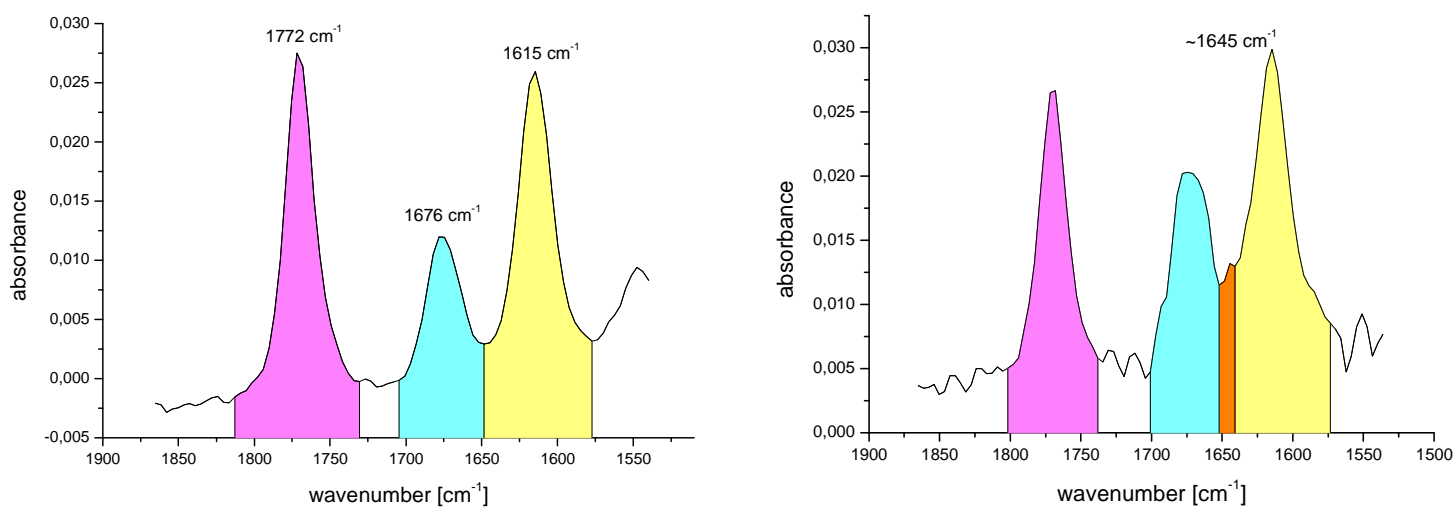

Figure 2.15: Relevant vibration bands of PenG (left) and PenG after partial hydrolysis (right). 
Hydrolytic reactions were carried out in a complex/PenG ratio of 1:4 $([$ complex $]=10.7 \mathrm{mM}, \quad[\mathrm{PenG}]=42.8 \mathrm{mM})$. A pure PenG solution was measured initially, before adding the complex solution. The band at $1772 \mathrm{~cm}^{-1}$ was monitored to investigate the progress of the reaction. Figure 2.16 illustrates the change of intensity of the lactam $\mathrm{C}=\mathrm{O}$ vibration band versus time.

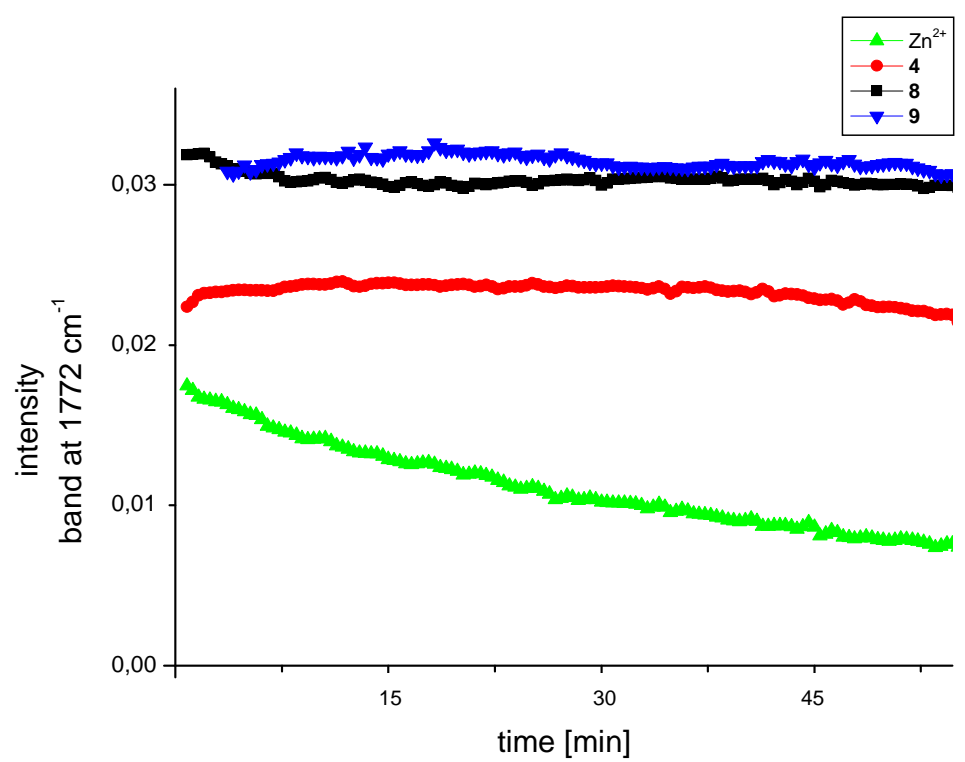

Figure 2.16: Development of lactam $\mathrm{C}=\mathrm{O}$ vibration band versus time.

Apparently, there is no significant impact of 4 (red) and 8 (black) on the intensity. A possible reason might be the stable five-membered chelate rings that fix the zinc ions in a tight binding fashion. If the substrate binds to the complex, a vacant position for the nucleophile is unavailable and the hydrolysis is inhibited. Control reactions with $\mathrm{Zn}\left(\mathrm{ClO}_{4}\right)_{2} \cdot 6 \mathrm{H}_{2} \mathrm{O}$ (green) revealed the decreasing trend of the lactam $\mathrm{C}=\mathrm{O}$ band and thus showed activity in PenG cleavage. As shown in previous studies, a higher hydrolytic activity was observed for complexes with long side chains. These form six-membered chelate rings, which are more labile compared to five-membered rings, and are able to dissociate resulting in a vacant position at the zinc ion that allows a nucleophile to bind ${ }^{[55]}$ It is thus surprising that $\mathbf{9}$, which bears long side chains, did not show any effect on the intensity of the $\mathrm{C}=\mathrm{O}$ lactam vibration band (Figure 2.16, blue). In the hydrolytic reactions, the complex was formed in situ before adding PenG. A different structure of 9 under the used conditions than the proposed one might be a possible reason. 


\subsubsection{Binding Studies of $\beta$-Lactam Substrates}

Considering the poor hydrolytic activity of the complexes, substrate binding studies were undertaken using different $\beta$-lactam substrates (Scheme 2.31).

These $\beta$-lactam antibiotics contain several potential donor groups that are able to coordinate to the zinc ions: (i) carboxylate group, (ii) lactam amide moiety, (iii) thioether group (except Sul), (iv) terminal amide group (except Sul and 6-apa), (v) amine group (6-apa, Amp and Mero) and (vi) hydroxide group (Erta and Mero). These multiple functional groups complicate the determination of the preferred binding to the complexes.

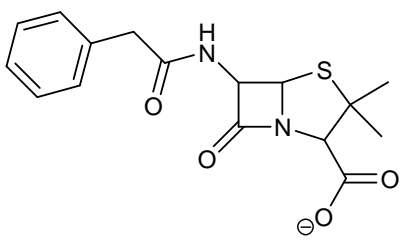

Penicillin G (PenG)<smiles>CC1(C)C(C(=O)[O-])N2C(=O)CC2S1(=O)=O</smiles>

Sulbactam (Sul)<smiles>CC1(C)SC2C(N)C(=O)N2C1C(=O)O</smiles>

6-aminopenicillanic acid (6-apa)<smiles>CC1(C)SC2C(NC(=O)C(N)c3ccccc3)C(=O)N2C1C(=O)[O-]</smiles>

Ampicillin (Amp)<smiles>CC(O)C1C(=O)N2C(C(=O)[O-])=C(SC3CNC(C(=O)Nc4cccc(C(=O)O)c4)C3)C(C)C12</smiles>

Ertapenem (Erta)<smiles>CC(=O)OCC1=C(C(=O)[O-])N2C(=O)C(NC(=O)Cc3cccs3)C2SC1</smiles>

Cephalotin (Ceph)<smiles>CC(O)C1C(=O)N2C(C(=O)O)=C(SC3CNC(C(=O)N(C)C)C3)C(C)C12</smiles>

Meropenem (Mero)

Scheme 2.31: Structures of $\beta$-lactam substrates. 
Several analytical methods have been used: ESI mass spectrometry, IR spectroscopy, ${ }^{1} \mathrm{H}$ and ${ }^{13} \mathrm{C}$ NMR spectroscopy, 2D NMR spectroscopy (HSQC, HMBC and DOSY spectroscopy) and X-ray diffraction. Substrates 6-apa and Mero were available as acids, all other substrates were used as their potassium or sodium salts.

The acetate bridged complexes $\mathbf{5 a}$ and $\mathbf{1 2}$ were not suitable for substrate binding studies. The acetate co-ligand competed with substrate coordination, indicating a high stability due to the bidentate binding fashion of the acetate moiety. However, 2 proved to be a well suited precursor as this complex bears three positive charges that allow strong interaction and coordination of the negatively charged substrate.

ESI-MS was performed to confirm the binding of the substrates to 2. Equimolar amounts of $\mathbf{2}$ and the respective substrate were stirred in acetonitrile and the solution was analysed by ESI-MS. Fragments $\left[\mathrm{Zn}_{2} \mathrm{H}_{-1} \mathrm{~L}^{1}(\mathrm{Lac})\left(\mathrm{ClO}_{4}\right)\right]^{+}$and $\left[\mathrm{Zn}_{2} \mathrm{H}_{-1} \mathrm{~L}^{1}(\mathrm{Lac})\right]^{2+}$ were detected in all spectra (see Table 2.19) with experimental isotopic distributions that were in accordance with those calculated.

Table 2.19: ESI-MS fragments of 2 and $\beta$-lactam substrates.

\begin{tabular}{c||c|c|c|c|c|c|c}
\hline & PenG & Sul & 6-apa & Amp & Ceph & Erta & Mero \\
\hline$m / z\left[\mathrm{Zn}_{2} \mathrm{H}_{-1} \mathrm{~L}^{1}(\mathrm{Lac})\right]^{2+}$ & 481 & 430 & 422 & 489 & 512 & 552 & 506 \\
\hline
\end{tabular}

In addition, adduct formation was observed in reactions of $\mathbf{L}^{\mathbf{1}}, \mathrm{KO}^{t} \mathrm{Bu}, \mathrm{Zn}\left(\mathrm{ClO}_{4}\right)_{2} \cdot 6 \mathrm{H}_{2} \mathrm{O}$ or $\mathrm{Zn}\left(\mathrm{SO}_{3} \mathrm{CF}_{3}\right)_{2}$ and the substrate. The combined compounds were stirred in acetonitrile until all components dissolved. ESI-MS analyses from the solutions demonstrated adduct formation. High resolution ESI-MS was measured for adducts with PenG, Sul, 6-apa and Ceph (see Table 2.20).

Table 2.20: Calculated and experimental masses of $\left[\mathrm{Zn}_{2} \mathrm{H}_{-1} \mathrm{~L}^{1}(\mathrm{Lac})\right]^{2+}$ by HR-MS analysis.

\begin{tabular}{r|c|c|c|c}
\hline Lac & PenG & Sul & 6-apa & Ceph \\
\hline \hline calculated & 481.1216 & 430.5901 & 422.1007 & 512.0947 \\
found & 481.1217 & 430.5903 & 422.1006 & 512.0948 \\
\hline
\end{tabular}


ESI mass spectrometry showed the formation of complex/substrate adducts, but did not give any information about the coordination modes of the substrates to the complex. To investigate, which functional groups are involved in the interaction with the complex, ${ }^{1} \mathrm{H}$ and ${ }^{13} \mathrm{C}$ NMR spectroscopy were used. NMR spectra were measured for solutions of 2 and substrates PenG, Sul, 6-apa, Amp and Ceph. Binding studies with the sterically demanding substrates Erta and Mero were not investigated due to their insolubility in deuterated solvents.

After mixing equimolar amounts of 2 and the respective substrate in $d_{3}-\mathrm{MeCN} / \mathrm{D}_{2} \mathrm{O}$ $(9: 1, v / v)$, spectra were recorded at room temperature $\left(\mathrm{D}_{2} \mathrm{O}\right.$ was necessary for complete dissolution of substrates). For comparison, NMR spectra of pure substrates and pure complex were measured under same conditions.

\subsubsection{Binding Studies of Penicillin G (PenG)}

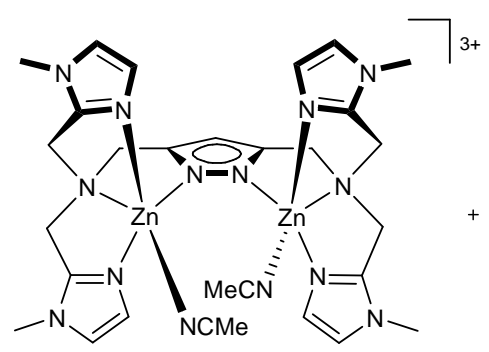

2

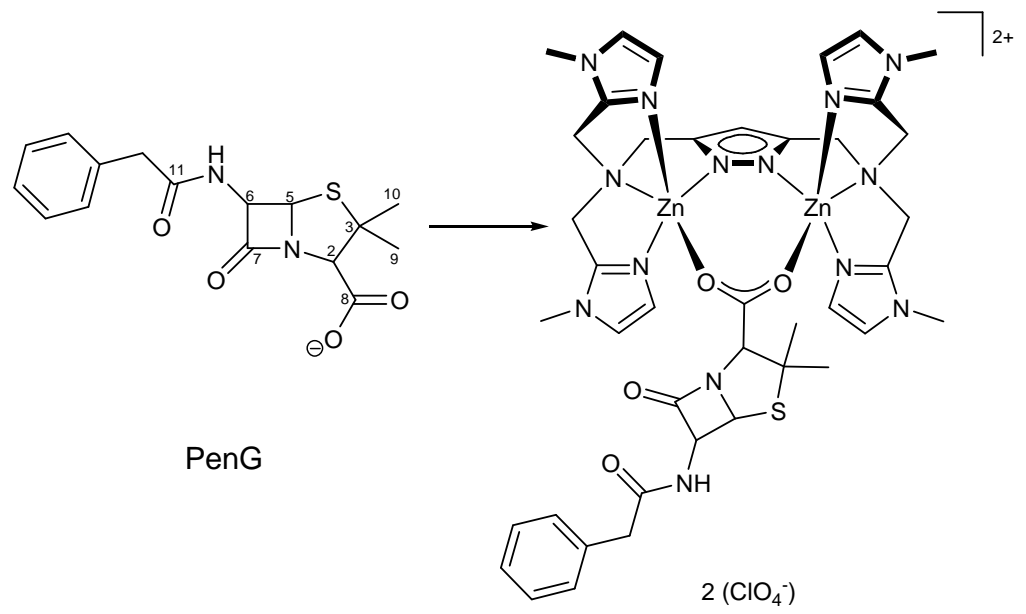

13

Scheme 2.32: Synthesis and proposed structure of 13.

Figure 2.17 shows the ${ }^{1} \mathrm{H}$ NMR spectra of pure PenG potassium salt (bottom row), pure 2 (top row) and an equivalent mixture of both (middle). The most pronounced shift was observed for $\mathrm{H}-2$ changing from $4.07 \mathrm{ppm}$ (pure PenG) to $4.82 \mathrm{ppm}$ (adduct). Protons of the two methyl groups (H-9/10) also underwent a downfield shift from 1.46 and $1.52 \mathrm{ppm}$ 
to 1.68 and $1.80 \mathrm{ppm}$, respectively, while all other signals showed no significant change. In addition, signals did not change in chemical shift and intensity for more than two weeks, indicating the formation of a stable product. The results of the ${ }^{1} \mathrm{H}$ NMR analysis gave evidence for binding by the carboxylate group. To confirm this hypothesis, ${ }^{13} \mathrm{C}$ NMR was carried out. All signals were assigned by 2D HSQC and HMBC spectroscopy. Comparing the HMBC spectrum of pure PenG with the adduct spectrum, a significant shift of the quaternary carbon atom of the carboxylate group $(\mathrm{C}-8)$ to lower field was observed (from 173.3 to $175.5 \mathrm{ppm}$ ). The completeness of the reaction was confirmed by DOSY NMR. Combining equimolar amounts of 2 and PenG in an NMR tube under the same conditions as mentioned above resulted in a spectrum showing the formation of only one species (adduct) without any residual peaks of the starting materials.

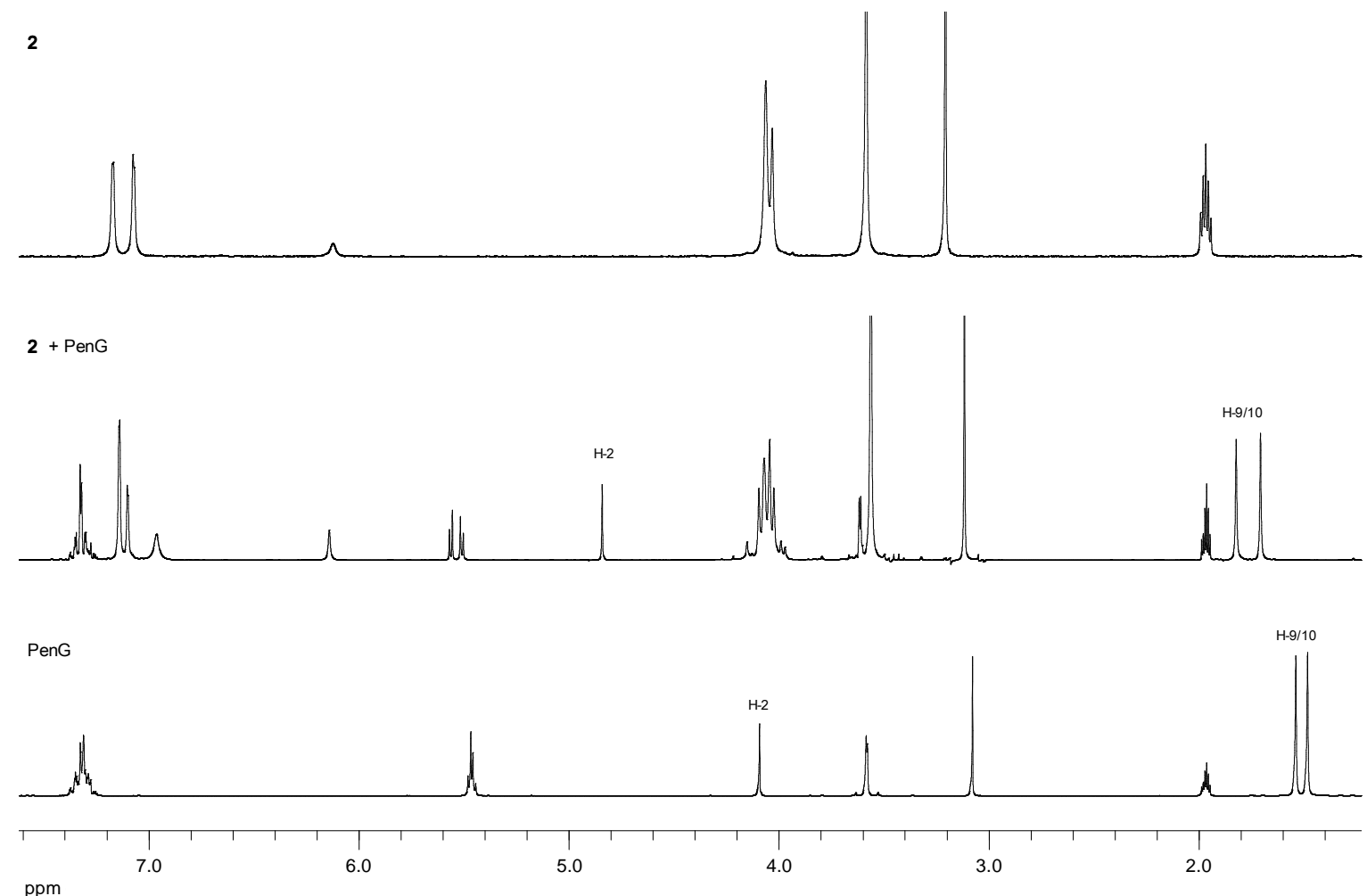

ppm

Figure 2.17: ${ }^{1} \mathrm{H}$ NMR spectra of 2, 2+Penicillin G (PenG) and PenG.

The carboxylate group can coordinate either in a monodentate or bidentate fashion. One of the most suitable method to investigate the binding mode is IR spectroscopy. The relative positions of the antisymmetric $\left(\tilde{v}_{\text {asym }}\right)$ and symmetric $\left(\tilde{v}_{\text {sym }}\right)$ vibration bands are characteristic for the different binding fashions. The wavenumbers of the relevant 
stretching vibrations are listed in Table 2.21. The difference $(\Delta \tilde{v})$ of $191 \mathrm{~cm}^{-1}$ is characteristic for a bidentate binding mode of the carboxylate moiety as it is demonstrated in Scheme 2.32. As seen in Table 2.21, a considerable change was also observed for the amide $\mathrm{C}=\mathrm{O}$ vibration band, which was observed as a broad shoulder in the adduct spectrum. As known from the literature, the position of the amide band differs for PenG salts depending on the cation type $\left(1669 \mathrm{~cm}^{-1}\right.$ for the potassium salt and $1700 \mathrm{~cm}^{-1}$ for the sodium salt). In addition, the amide vibration of penicilloic acid appears at $1645 \mathrm{~cm}^{-1}{ }^{[69]}$ The change of this band is thus not convincing. Due to the lack of a change in chemical shifts in ${ }^{13} \mathrm{C}$ NMR, a complexation of the amide group can be excluded.

Table 2.21: Relevant vibration bands of pure and coordinated substrates, $\tilde{v}$ is given in $\mathrm{cm}^{-1}$.

\begin{tabular}{c|c|c|c|c|c}
\hline Compound & $\begin{array}{c}\tilde{v}(\mathrm{CO}) \\
\text { lactam }\end{array}$ & $\begin{array}{c}\tilde{v}(\mathrm{CO}) \\
\text { amide }\end{array}$ & $\tilde{v}_{\text {asym }}(\mathrm{COO})$ & $\tilde{v}_{\text {sym }}(\mathrm{COO})$ & $\Delta \tilde{v}_{\text {(asym - sym })}$ \\
\hline \hline$[\mathrm{K}(\mathrm{PenG})]$ & 1772 & 1670 & 1613 & 1396 & 217 \\
{$\left[\mathrm{Zn}_{2} \mathrm{H}_{-1} \mathrm{~L}^{1}(\mathrm{PenG})\right]\left(\mathrm{ClO}_{4}\right)_{2}$} & 1776 & $1647^{\text {sh }}$ & 1612 & 1421 & 191 \\
\hline$[\mathrm{Na}(\mathrm{Amp})]$ & 1771 & 1690 & 1604 & 1407 & 197 \\
{$\left[\mathrm{Zn}_{2} \mathrm{H}_{-1} \mathrm{~L}^{1}(\mathrm{Amp})\right]\left(\mathrm{ClO}_{4}\right)_{2}$} & 1775 & 1667 & 1612 & 1426 & 186 \\
\hline $6-\mathrm{apa}$ & 1773 & - & 1624 & 1413 & 211 \\
6 6-apa $+\mathrm{KO}{ }^{t} \mathrm{Bu}$ & 1757 & - & 1613 & 1409 & 204 \\
{$\left[\mathrm{Zn}_{2} \mathrm{H}_{-1} \mathrm{~L}^{1}(6-\mathrm{apa})\right]\left(\mathrm{ClO}_{4}\right)_{2}$} & 1773 & - & 1616 & 1425 & 191 \\
\hline$[\mathrm{Na}(\mathrm{Ceph})]$ & 1732 & 1658 & 1624 & 1408 & 216 \\
{$\left[\mathrm{Zn}_{2} \mathrm{H}_{-1} \mathrm{~L}^{1}(\mathrm{Ceph})\right]\left(\mathrm{ClO}_{4}\right)_{2}$} & 1740 & 1677 & 1608 & 1425 & 183 \\
\hline$[\mathrm{Na}(\mathrm{Sul})]$ & 1773 & - & 1604 & 1399 & 205 \\
{$\left[\mathrm{Zn}_{2} \mathrm{H}_{-1} \mathrm{~L}^{1}(\mathrm{Sul})\right]\left(\mathrm{SO}_{3} \mathrm{CF}_{3}\right)_{2}$} & 1790 & - & 1625 & 1424 & 201 \\
\hline
\end{tabular}




\subsubsection{Binding Studies of Ampicillin (Amp)}
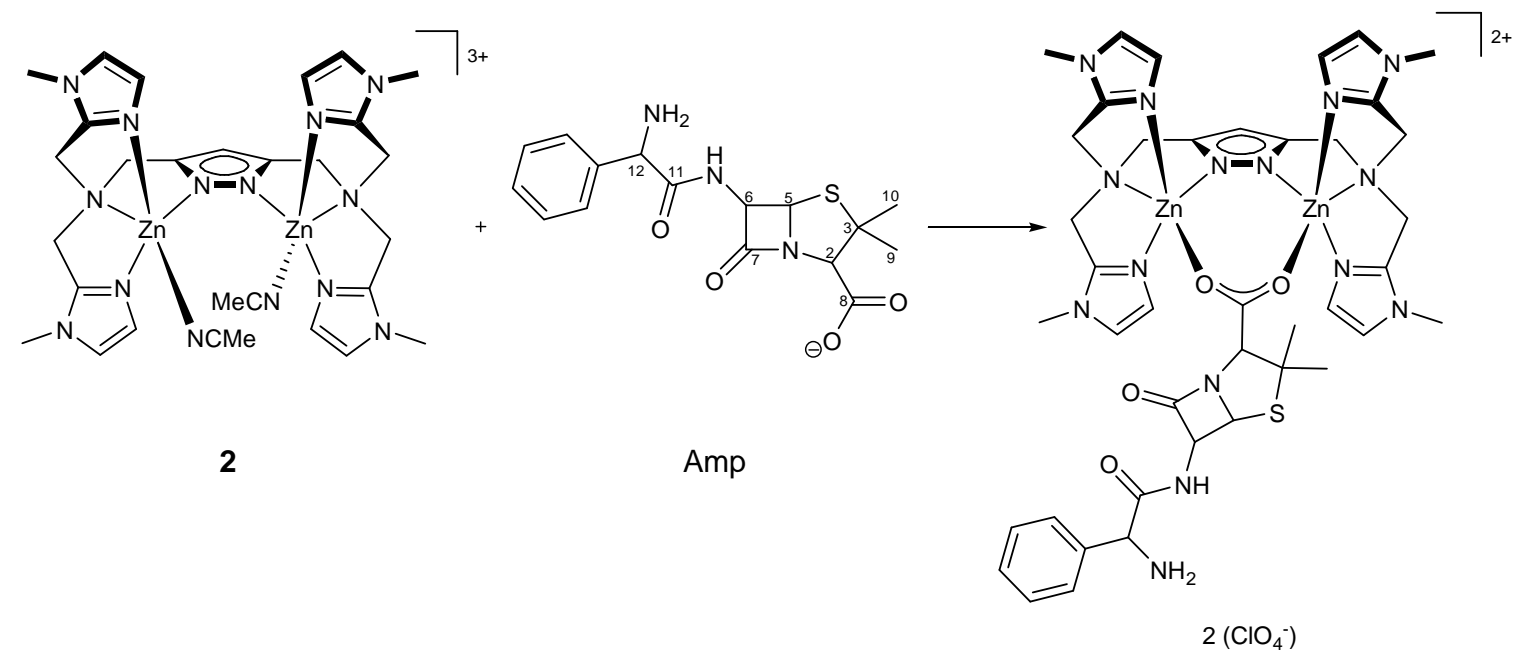

14

Scheme 2.33: Synthesis and proposed structure of 14 .

Analogous results were obtained for the related $\beta$-lactam antibiotic Ampicillin (Amp), which differs from PenG in an additional amine group at the benzylic carbon atom (C-12). Comparing ${ }^{1} \mathrm{H}$ NMR spectra of pure and coordinated Amp (Figure 2.18), a downfield shift of the proton $\mathrm{H}-2$ (from $4.11 \mathrm{ppm}$ to $4.82 \mathrm{ppm}$ ) and of the protons of the methyl groups (1.46 and $1.56 \mathrm{ppm}$ to 1.73 and $1.79 \mathrm{ppm}$ ) were observed.

In ${ }^{13} \mathrm{C}$ NMR analysis, signals of the quaternary carbon atoms of the lactam $(\mathrm{C}-7)$ and the amide group (C-11) were observed in the spectra of pure and coordinated Amp. However, a signal of the quaternary carbon atom of the carboxylate group (C-8) was missing in the complex/substrate spectrum compared to pure substrate. This indicated a considerably change in the chemical surrounding of the carboxylate moiety. As a result from NMR analysis, coordination by the carboxylate group of Amp to $\mathbf{2}$ was assumed. This hypothesis was confirmed by IR spectroscopy (Table 2.21). The difference between the asymmetric and symmetric vibration bands $\left(\Delta \tilde{v}=186 \mathrm{~cm}^{-1}\right)$ indicated a bidentate binding fashion of the carboxylate group to $\mathbf{2}$ as it is shown in Scheme 2.33. 

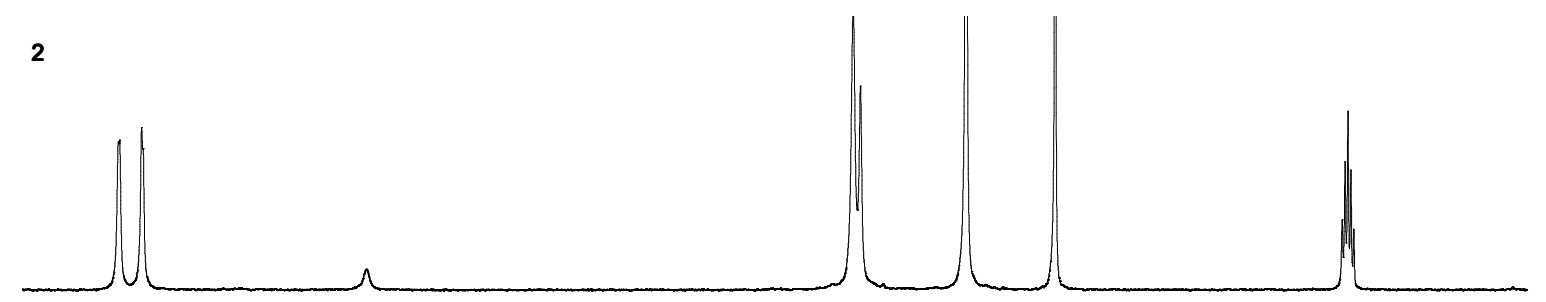

$2+$ Amp
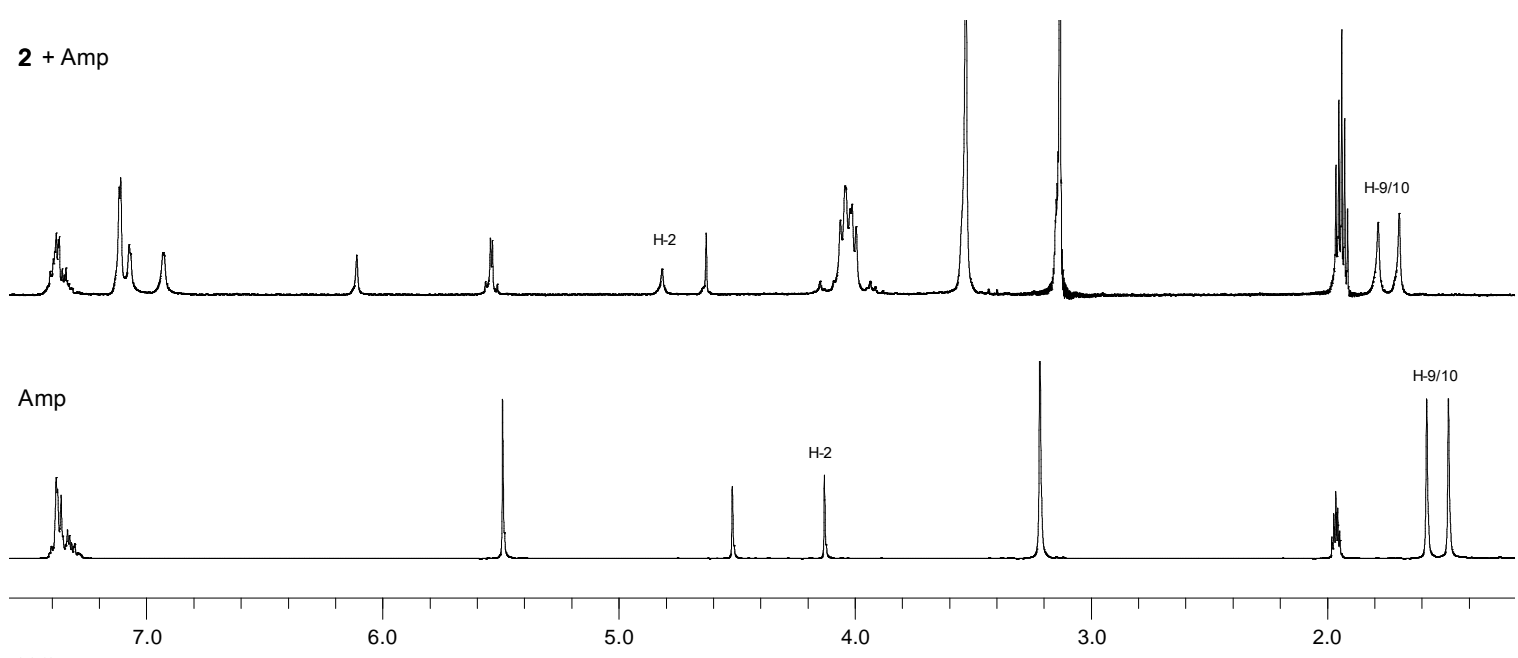

$\mathrm{ppm}$

Figure 2.18: ${ }^{1} \mathrm{H}$ NMR spectra of 2, 2+Ampicillin (Amp) and Amp.

\subsubsection{Binding Studies of 6-Aminopenicillanic Acid (6-Apa)}

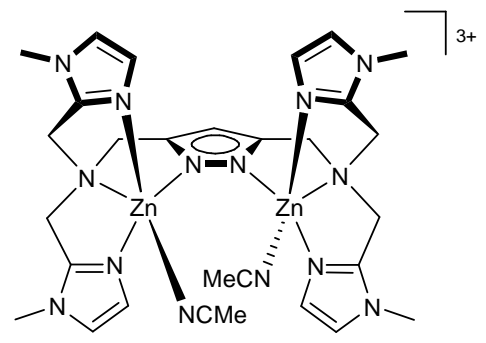

$3\left(\mathrm{ClO}_{4}^{-}\right)$

2

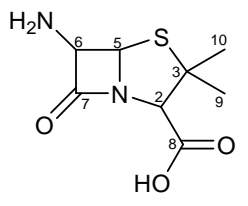

6-apa

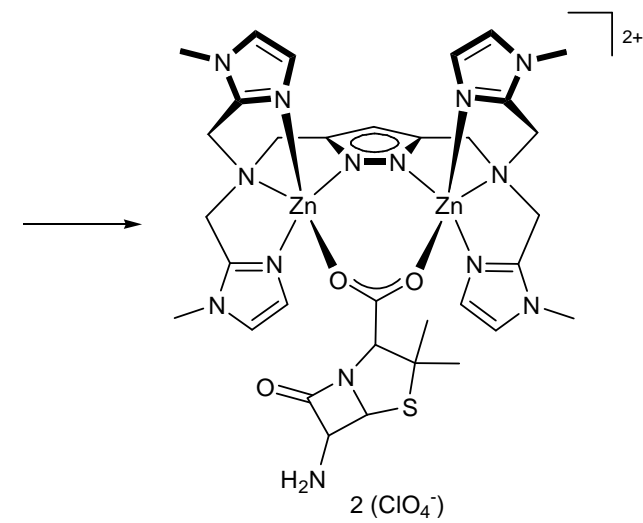

15

Scheme 2.34: Synthesis and proposed structure of $\mathbf{1 5}$.

6-Aminopenicillanic acid (6-apa) was not soluble in deuterated solvents $\left(d_{3}\right.$-MeCN and/or $\mathrm{D}_{2} \mathrm{O}$ ). However, mixing equimolar amounts of $\mathbf{2}$ and 6-apa in an NMR tube $\left(d_{3}-\mathrm{MeCN} / \mathrm{D}_{2} \mathrm{O}=9: 1, \mathrm{v} / \mathrm{v}\right)$ afforded an appropriate spectrum. Although 6-apa did not 
dissolve completely, the suspension became clearer within time and the signals, which were assigned to the substrate, increased in intensity. Adding one equivalent base for deprotonation of the acid resulted in a different ${ }^{1} \mathrm{H}$ NMR spectrum. The signals for protons $\mathrm{H}-2$ and $\mathrm{H}-5$ were shifted about $0.16 \mathrm{ppm}$ and $0.36 \mathrm{ppm}$, respectively, compared to the spectrum without base. In addition, the signals of these two protons were separated under basic conditions, while a multiplet was observed for both protons in the spectrum without base. A possible reason might be the hydrolytic cleavage of the substrate caused by the base. However, NMR and IR analysis of 6-apa and $\mathrm{KO}^{t} \mathrm{Bu}$ revealed only deprotonated and not hydrolysed substrate. ${ }^{[70]}$ In addition, ESI-MS analysis confirmed the formation of 15 under both conditions. Identical IR spectra of the products of both reactions were achieved indicating a bidentate fashion of the carboxylate moiety to 2 $\left(\Delta \tilde{v}=191 \mathrm{~cm}^{-1}\right)$.

\subsubsection{Binding Studies of Cephalotin (Ceph)}

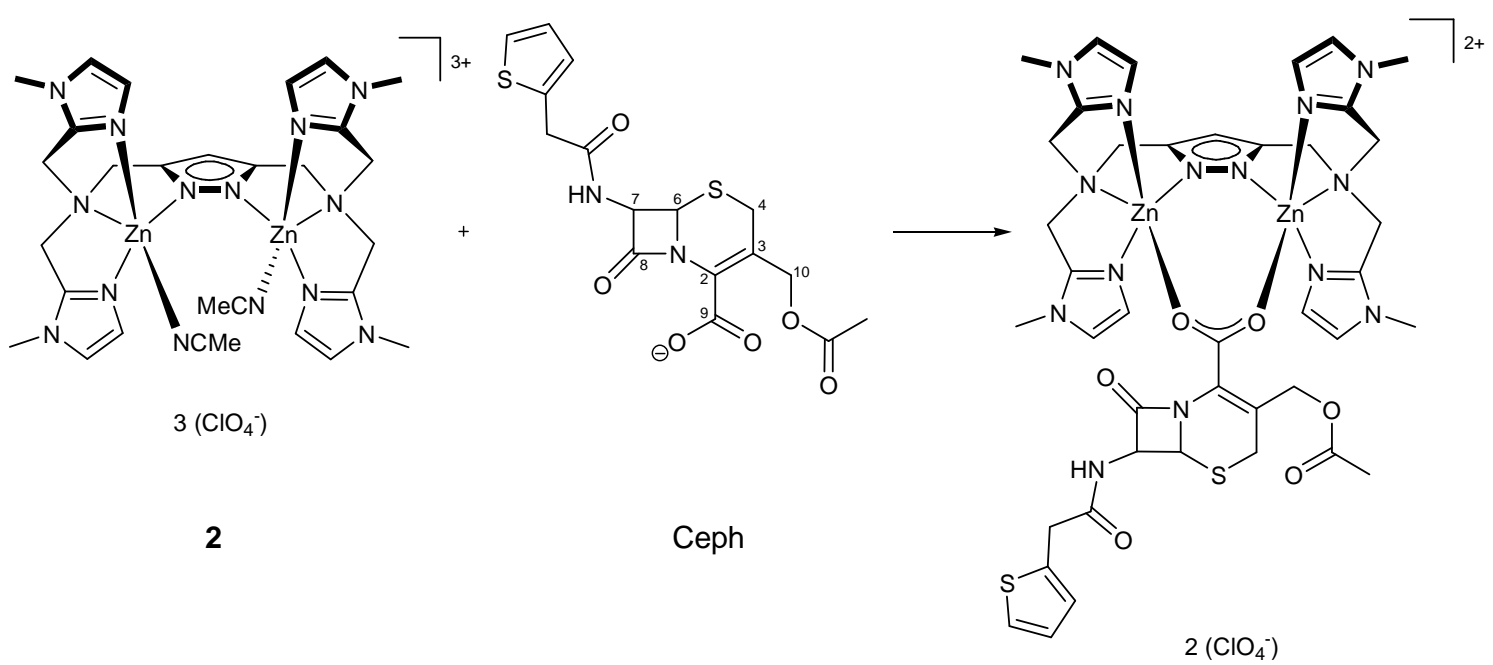

16

Scheme 2.35: Synthesis and proposed structure of $\mathbf{1 6}$.

As depicted in Scheme 2.35, Cephalotin (Ceph) bears multiple functional groups, which can be involved in the interaction with the complex (i.e., (i) carboxylate group, (ii) lactam amide moiety, (iii) thioether group, (iv) terminal amide group, (v) thiophene moiety and (vi) acetoxy group). Mixing equimolar amounts of the respective compounds provided a 
spectrum with sharp signals in NMR analysis, thus indicating fast product formation. As shown in Figure 2.19, a considerably change in chemical shift was observed for protons $\mathrm{H}-10 \mathrm{a}$ and $\mathrm{H}-10 \mathrm{~b}(\Delta \delta=0.50 \mathrm{ppm}$ and $0.17 \mathrm{ppm})$ compared to the spectrum of pure Ceph. In addition, the signal of one proton in the $\mathrm{H}-4$ position of the heterocycle changed about $0.26 \mathrm{ppm}$ and signals of the protons within the lactam ring (H-6 and H-7) were shifted about $0.20 \mathrm{ppm}$ and $0.18 \mathrm{ppm}$, respectively. Signals of the protons of the methyl and the thiophene group did not change significantly, which excluded a binding of the substrate via the acetoxy function nor the thiophene group.

2
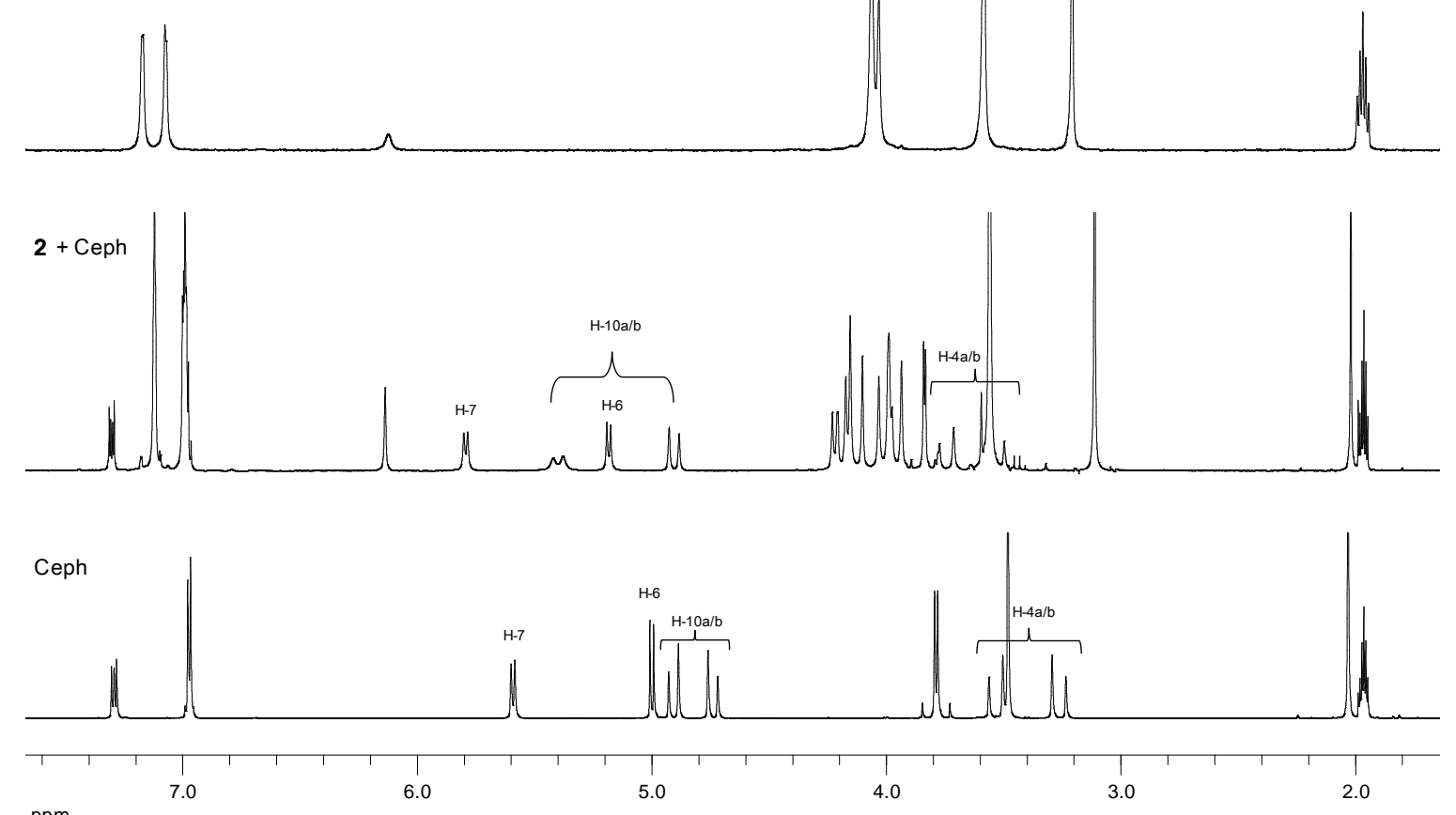

ppm

Figure 2.19: ${ }^{1} \mathrm{H}$ NMR spectra of $\mathbf{2}, \mathbf{2}+$ Cephalotin (Ceph) and Ceph.

Although ${ }^{13} \mathrm{C}$ signals for all quaternary carbon atoms were observed in the spectrum of pure Ceph, no signals were detected in the adduct spectrum for the quaternary carbon atoms C-2, C-3 and C-9. This indicated a considerably change in the chemical surrounding of the carboxylate moiety. IR analysis revealed a bidentate binding fashion of the carboxylate group $\left(\Delta \tilde{v}=183 \mathrm{~cm}^{-1}\right)$. Although the IR band of the terminal amide function was also shifted, coordination by this group could be excluded due to the lack in shift in the ${ }^{13} \mathrm{C}$ NMR analysis. The sterically demanding substrate was assumed to bind bidentate by the carboxylate function to the zinc centres, as it was demonstrated for the less bulky $\beta$-lactam substrates. 


\subsubsection{Binding Studies of Sulbactam (Sul)}
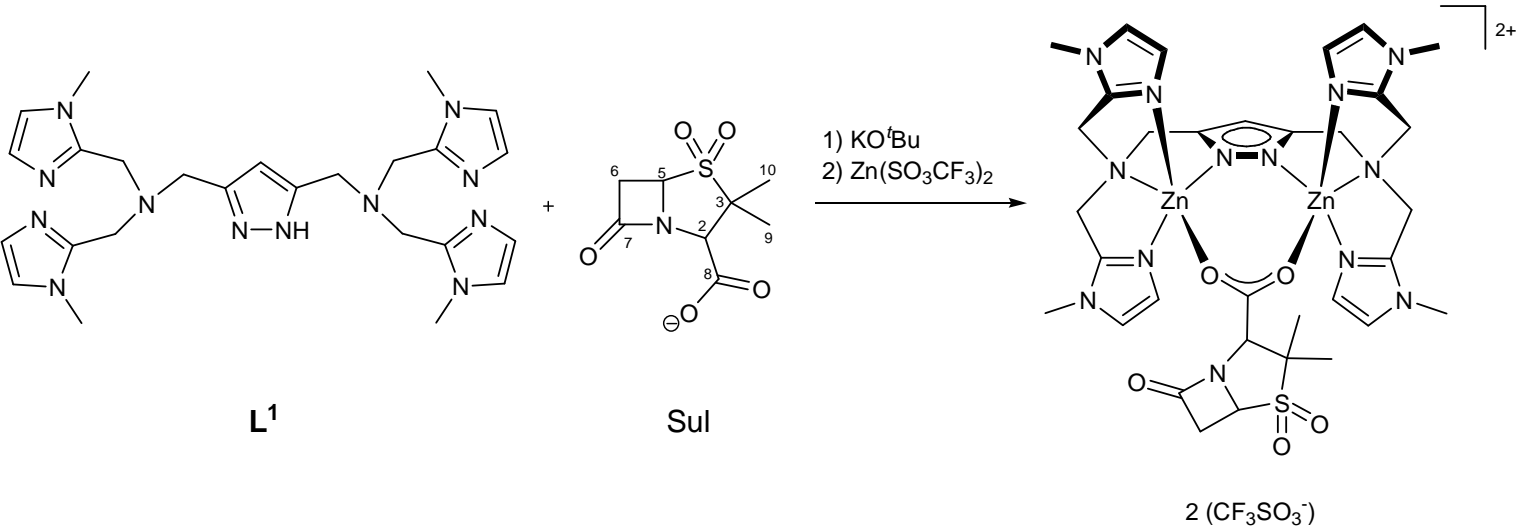

17

Scheme 2.36: Synthesis of $\mathbf{1 7}$.

Sulbactam (Sul) also bears the structural motif of a thia-azabicycloheptanone like various $\beta$-lactam antibiotics, but it has no bactericidal function in medicine. It irreversibly binds to the active sites of most lactamase enzymes and thus inhibits their hydrolytic activity to cleave the medicinal drugs. Due to its hydrolytic stability towards lactamases, it is a suitable substrate for binding studies.

A suspension of $\mathbf{L}^{1}, \mathrm{KO}{ }^{t} \mathrm{Bu}, \mathrm{Zn}\left(\mathrm{SO}_{3} \mathrm{CF}_{3}\right)_{2}$ and Sulbactam sodium salt in the presence of acetonitrile (Scheme 2.36) was stirred until the solution became clear. Slow diffusion of $\mathrm{Et}_{2} \mathrm{O}$ into the filtered acetonitrile solution afforded single crystals, which were suitable for X-ray analysis. As depicted in Figure 2.20, the carboxylate moiety of Sulbactam binds to the zinc atoms of the complex in a $\mu_{1,3}$-binding fashion. 17 crystallises in the monoclinic space group $P 2_{1}$ with two formula units per unit cell. The $\mathrm{Zn} \cdots \mathrm{Zn}$ separation is 3.901(1) $\AA$ that lies in between the zinc-zinc separations found for the acetate bridged complexes $\mathbf{5 a}$ (3.9548(4) $\AA$ ) and $\mathbf{5 b}(3.8809(21) \AA)$. The zinc atoms in $\mathbf{1 7}$ are located within the pyrazolato plane. The carboxylate moiety of Sulbactam is arranged slightly out of this plane $(d(\mathrm{O} 1 \cdots \mathrm{pz})=0.17(1) \AA, d(\mathrm{O} 2 \cdots \mathrm{pz})=0.31(1) \AA$ and $d(\mathrm{C} 26 \cdots \mathrm{pz})=0.41(1) \AA)$, but shows no twisted arrangement as it was observed for $\mathbf{5 a}$ and $\mathbf{5 b}$. This almost planar arrangement of the carboxylate moiety in $\mathbf{1 7}$ might be due to the sterically demanding substrate. The sulfonyl group of the substrate is disordered (not shown in Figure 2.20) and 
is not involved in the coordination to the zinc atoms. Selected bond lengths and angles of $\mathbf{1 7}$ are listed in Table 2.22.

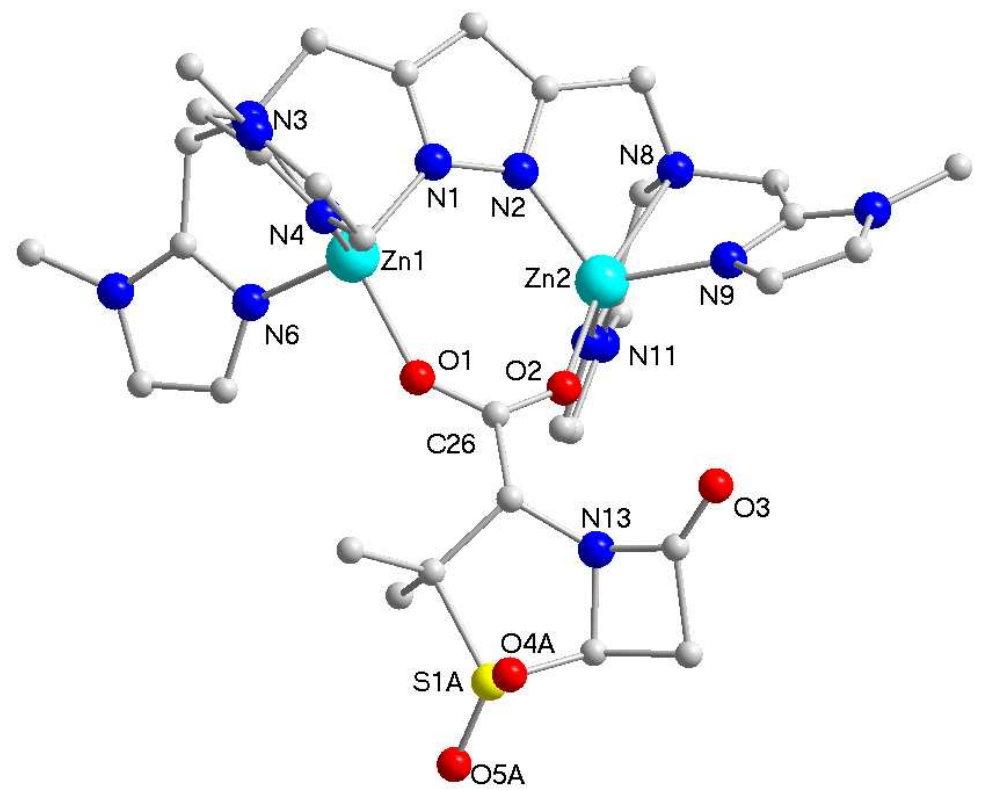

Figure 2.20: Molecular structure of 17, hydrogen atoms and counter ions omitted for clarity.

Table 2.22: Selected bond lengths $[\AA]$ and angles $\left[{ }^{\circ}\right]$ for 17 .

\begin{tabular}{c|c||c|cc|c}
\hline Atoms & Bond length & Atoms & Angle & Atoms & Angle \\
\hline \hline Zn1-N1 & $1.981(3)$ & N1-Zn1-N3 & $76.24(12)$ & N2-Zn2-N8 & $76.26(12)$ \\
Zn1-N3 & $2.471(3)$ & N1-Zn1-N4 & $109.70(14)$ & N2-Zn2-N9 & $113.17(13)$ \\
Zn1-N4 & $1.998(4)$ & N1-Zn1-N6 & $113.72(14)$ & N2-Zn2-N11 & $109.93(13)$ \\
Zn1-N6 & $1.995(3)$ & N3-Zn1-N4 & $75.58(13)$ & N8-Zn2-N9 & $75.35(12)$ \\
Zn1-O1 & $2.027(3)$ & N3-Zn1-N6 & $76.16(12)$ & N8-Zn2-N11 & $76.40(12)$ \\
Zn2-N2 & $1.981(3)$ & N4-Zn1-N6 & $119.50(15)$ & N9-Zn2-N11 & $119.81(14)$ \\
Zn2-N8 & $2.440(3)$ & N1-Zn1-O1 & $114.13(12)$ & N2-Zn2-O2 & $114.60(13)$ \\
Zn2-N9 & $2.011(4)$ & N3-Zn1-O1 & $169.55(12)$ & N8-Zn2-O2 & $168.95(12)$ \\
Zn2-N11 & $2.014(3)$ & N4-Zn1-O1 & $98.77(13)$ & N9-Zn2-O2 & $97.55(13)$ \\
Zn2-O2 & $2.011(3)$ & N6-Zn1-O1 & $99.69(12)$ & N11-Zn2-O2 & $100.59(13)$ \\
Zn1-Zn2 & $3.901(1)$ & C26-O1-Zn1 & $140.8(3)$ & C26-O2-Zn2 & $139.7(3)$ \\
\hline
\end{tabular}


Comparing the ${ }^{1} \mathrm{H}$ NMR spectra of pure Sulbactam sodium salt and 17 (Figure 2.21), the most pronounced downfield shift was observed for the proton $\mathrm{H}-2$ from 4.00 to $4.73 \mathrm{ppm}$. The signals of the methyl protons (H-9/10) were also shifted to lower field (from 1.37 and $1.50 \mathrm{ppm}$ to 1.73 and $1.76 \mathrm{ppm}$ ) and $\mathrm{H}-5$ changed about $0.19 \mathrm{ppm}$ to lower field. In addition, the ${ }^{13} \mathrm{C}$ NMR signal of C-8 was shifted from 172.5 to $175.3 \mathrm{ppm}$. These changes of the chemical shifts were in accordance with the results obtained with the substrates discussed above. These findings confirmed the coordination of all $\beta$-lactam substrates investigated here by the $\mu_{1,3}$-binding fashion of the carboxylate moiety to the zinc atoms of the complex, as it was shown by X-ray analysis in the Sulbactam case. In addition, this coordination explained the inactivity in the hydrolytic reactions. As the substrate was binding to the complex, a vacant position was unavailable for the nucleophile resulting in the inhibition of the complex.

In contrast to the IR spectroscopy results obtained so far for all other substrates, IR analysis of $\mathbf{1 7}$ gave no exact information about the binding fashion. Although the relevant bands were shifted (see Table 2.21), the relative positions of the antisymmetric and symmetric vibration bands did not change $\left(205 \mathrm{~cm}^{-1}\right.$ for the Sulbactam sodium salt and $201 \mathrm{~cm}^{-1}$ for 17). However, the bidentate binding fashion was proven by X-ray analysis.
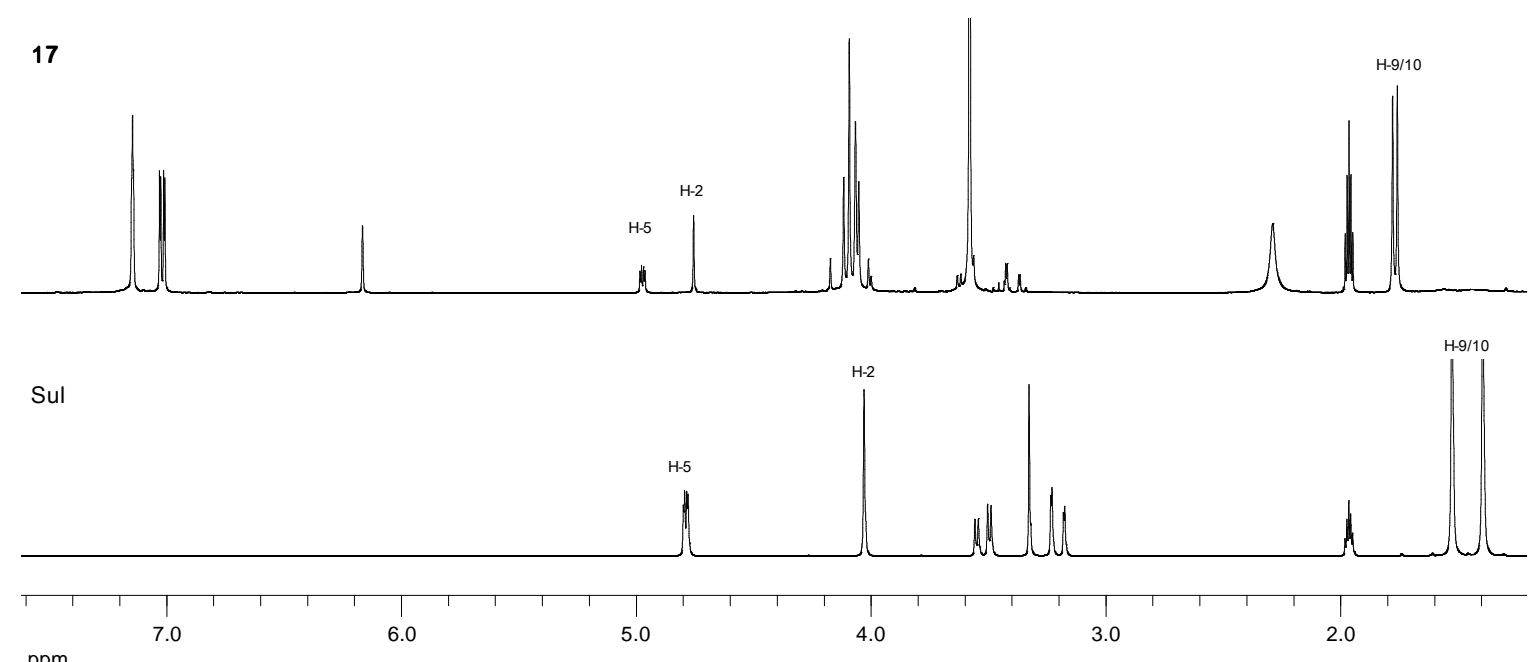

Figure 2.21: ${ }^{1} \mathrm{H}$ NMR spectra of $\mathbf{1 7}$ and Sulbactam (Sul). 
Within the MEYER group, sulphate bridging complexes were obtained in reactions of the Sulbactam sodium salt with several dizinc complexes. The sulphate can either bridge two complexes $^{[71]}$ or it is bidentately coordinated to one complex unit. ${ }^{[54]}$ To investigate the ability of the complex to cleave Sulbactam, mixtures of $\mathbf{L}^{\mathbf{1}}, \mathrm{KO}^{t} \mathrm{Bu}$, zinc salts $\left(\mathrm{Zn}\left(\mathrm{ClO}_{4}\right)_{2} \cdot 6 \mathrm{H}_{2} \mathrm{O}\right.$ or $\left.\mathrm{Zn}\left(\mathrm{SO}_{3} \mathrm{CF}_{3}\right)_{2}\right)$ and Sulbactam sodium salt were stirred under reflux in the presence of acetonitrile. Monitoring this process by ESI-MS, did not confirm decomposition of the substrate. The sulphate source for the bridged complexes was most probably due to impurities in the used reagents. In addition, decomposition of $\mathbf{1 7}$ was also not observed according to ESI-MS analysis.

In conclusion, NMR and IR spectroscopy have been proven to be suitable analytical methods to investigate the binding of $\beta$-lactam substrates. For each substrate, similar changes in chemical shifts were obtained for pure and coordinated antibiotics. In addition, IR spectroscopy revealed a bidentate binding fashion of the carboxylate moiety of all substrates. Moreover, confirming all analytical results obtained by NMR and IR spectroscopy, the $\mu_{1,3}$-binding fashion of the carboxylate group of Sulbactam was proven by X-ray analysis. At the present state, $\mathbf{1 7}$ is the first complex of a bound $\beta$-lactam substrate, which was obtained in synthesis and analysed by X-ray diffraction according to CSD search. 


\subsection{Phosphate Ester Cleavage}

\subsubsection{Introduction}

Phosphodiesters DNA and RNA are extremely resistant to hydrolytic cleavage. The estimated half-life time of DNA is $10-100$ billion years (at $25^{\circ} \mathrm{C}, \mathrm{pH}=7$ ), while RNA is less resistant to hydrolysis with a half-life time of 110 years. ${ }^{[45]}$ This difference in hydrolytic rates results from the different structures of DNA and RNA. Although both are built up from nucleosides that are connected by phosphate groups in 3 ' and 5' positions of the ribose, RNA contains an additional hydroxyl group at the 2 ' position of the nucleotide. ${ }^{[72]}$ Scheme 2.37 illustrates the two step process in the mechanism of RNA cleavage. At first, the 2'-OH acts as an intramolecular nucleophile and attacks the phosphorous atom (transesterification, a) resulting in a trigonal bipyramidal phosphorane (b). The second step is the cleavage of the $\mathrm{P}-\mathrm{O}$ bond that leads to the 2',3'-cyclic phosphate (c) and the 5'-terminal hydroxyl group (d). The intramolecular attack thus accelerates the hydrolysis of RNA compared to DNA, which requires an intermolecular nucleophile. ${ }^{[38 \mathrm{a}, 45,73]}$

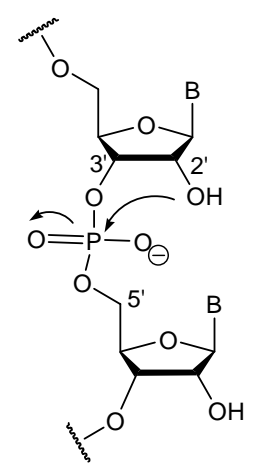

(a)

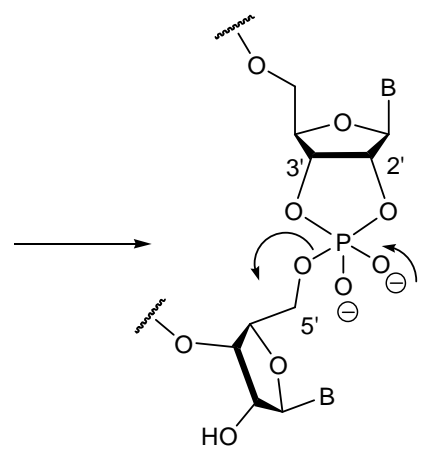

(b)

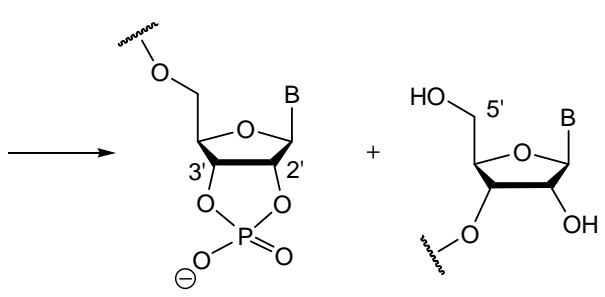

(c)

(d)
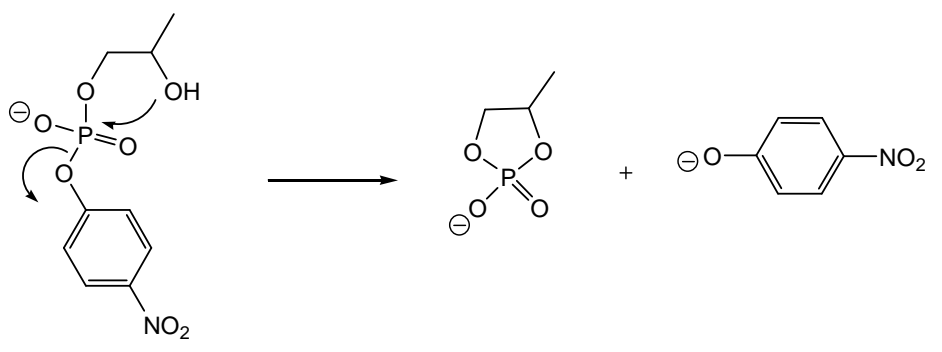

HPNP

Scheme 2.37: Mechanism of RNA and HPNP cleavage. 
Due to the high hydrolytic resistance of DNA and RNA, activated model substrates are used in kinetic studies. A suitable substrate that emulates RNA is 2-hydroxypropyl-pnitrophenyl phosphate (HPNP in Scheme 2.37). In addition, bis(4-nitrophenyl)phosphate (BNPP in Scheme 2.38) is used to mimic natural phosphodiesters (e.g., DNA). In kinetic studies of phosphotriester cleavage, $p$-nitrophenyl diphenylphosphate (PNPDPP) and diethyl 4-nitrophenyl phosphate (Paraoxon) are most common. All these substrates (Scheme 2.38) are p-nitrophenolate derivatives. Once cleaved, $p$-nitrophenolate can be detected by UV-Vis spectroscopy. A second useful analytic method monitoring the cleavage of phosphate esters is ${ }^{31} \mathrm{P}$ NMR spectroscopy.

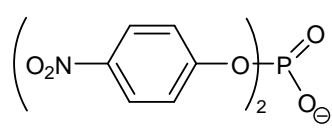

BNPP

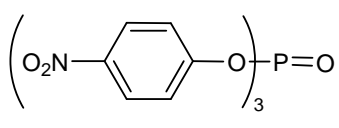

TNPP

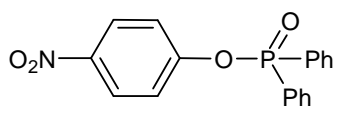

PNPDPP

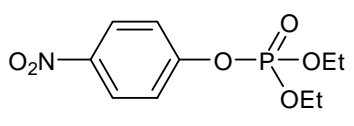

Paraoxon

Scheme 2.38: Substrates used within phosphate ester cleavage.

Various mono- and multinuclear complexes have been investigated to improve hydrolytic activity. KOMIYAMA and co-workers developed a ligand system that can be tuned to bind up to three metals (Scheme 2.39). ${ }^{[4 \mathrm{a}, 41 \mathrm{~b}]}$ These ligands are based on pyridyl-donor moieties. Depending on the number of donor atoms, complexes with one, two or three metal ions can be synthesised and compared in their catalytic activities. A significantly higher hydrolytic activity of the binuclear complex was detected compared to the mononuclear analogue. The trinuclear complex was even more active than the binuclear one. These results confirm the promoting effects of two or more metal ions on Lewis acidity, nucleophile activation, stabilisation of the intermediate and activation of the leaving group. ${ }^{[74]}$
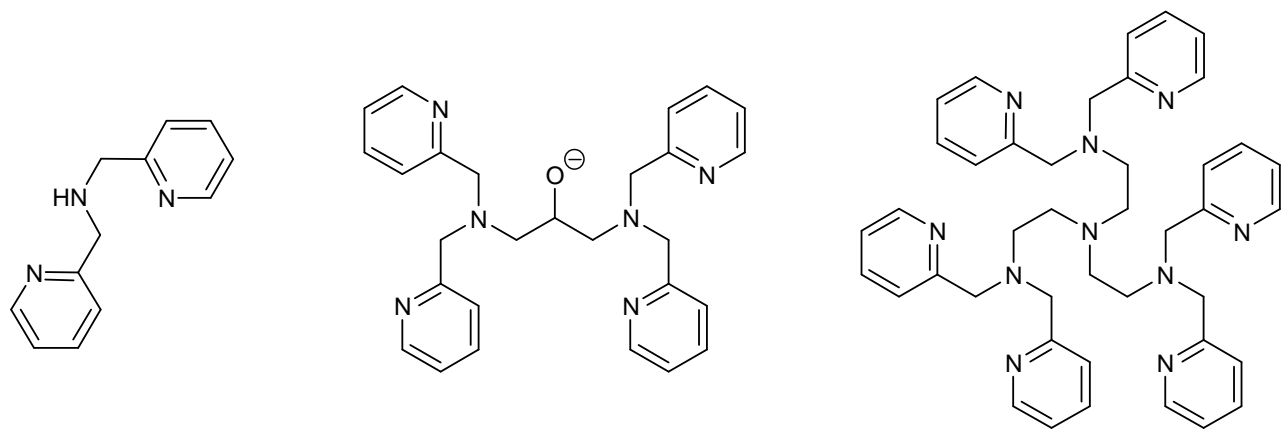

Scheme 2.39: Ligand systems to form mono and multinuclear zinc complexes used by KOMIYAMA and co-workers. 
Similar to the ligands developed by KOMIYAMA and co-workers and based on substituted 1,3-diamino-2-propanols, KREBS and co-workers investigated the activity of symmetric and asymmetric binuclear zinc complexes in HPNP transesterification cleavage (Scheme 2.40). The authors observed a higher activity of the asymmetric complex compared to the symmetric one. This was suggested to be due to the bulky benzimidazole residues of the symmetric ligand, which lowered the binding ability of the substrate to the metal atoms. ${ }^{[41 \mathrm{c}]}$
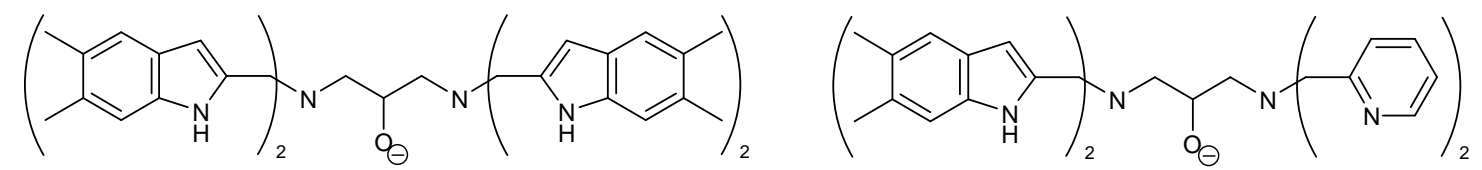

Scheme 2.40: Symmetric and asymmetric ligands used by KREBS and co-workers.

As mentioned in the introduction, binuclear complexes with substituted phenolate ligands are very popular. CHEN et al. reported the synthesis of a bimetallic zinc complex with hydroxylethyl moieties as chelating side chains (Scheme 2.41, a). The obtained crystal structure revealed the formation of an asymmetric zinc complex with one protonated and one deprotonated ethoxy group. This complex efficiently catalysed the cleavage of BNPP with a $10^{5}$-fold higher rate compared to the uncatalysed reaction. ${ }^{[39 a]}$ In addition, a $10^{4}$-fold rate enhancement in the transesterification cleavage of HPNP was observed by BELLE and co-workers with a complex based on a pyridyl-substituted phenolate ligand (Scheme 2.41, b). This complex undergoes a $\mathrm{pH}$ dependent interconversion of $\left[\mathrm{Zn}_{2} \mathrm{~L}(\mathrm{OH})\right]^{2+} \leftrightarrows\left[\mathrm{Zn}_{2} \mathrm{~L}\left(\mathrm{H}_{2} \mathrm{O}\right)_{2}\right]^{3+}$. Activity was only observed for complex $\left[\mathrm{Zn}_{2} \mathrm{~L}(\mathrm{OH})\right]^{2+}$ bearing a coordinated hydroxide group, which acts as the nucleophile. Complex $\left[\mathrm{Zn}_{2} \mathrm{~L}\left(\mathrm{H}_{2} \mathrm{O}\right)_{2}\right]^{3+}$ was not active, because of the irreversible coordination of the substrate to the zinc atoms that was detected by ${ }^{31} \mathrm{P}$ NMR. ${ }^{[38 a]}$ Complexes of symmetric and asymmetric substituted phenolate ligands with carboxylate moieties as chelating side chains were investigated by the NORDLANDER group (Scheme 2.41, c and d). ${ }^{[39 b, 40]}$ Kinetic studies in the transesterification of HPNP revealed a higher activity of the asymmetric zinc complex compared to its symmetric analogue. 


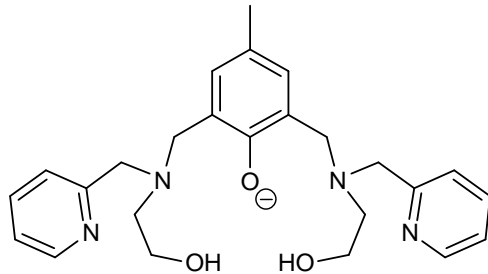

(a)

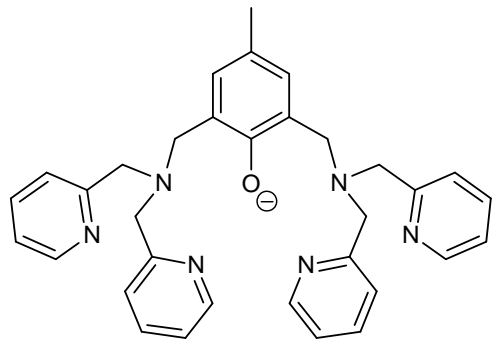

(b)

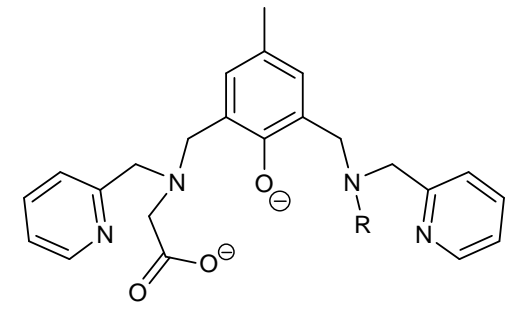

(c) $\left(\mathrm{R}=\mathrm{CH}_{2} \mathrm{COO}^{-}\right)$

(d) $\left(\mathrm{R}={ }^{i} \mathrm{Pr}\right)$

Scheme 2.41: Phenolate based ligands.

A complex based on a 2,7-substituted 1,8-naphthyridine ligand, which was synthesised by LIPPARD and co-workers and was active in $\beta$-lactam cleavage (Scheme 2.27), was additionally tested towards activity in the transesterification cleavage of HPNP. This complex showed a 6.4-fold higher activity compared to the mononuclear reference compound. The authors suggested a significant decrease of the $\mathrm{p} K_{\mathrm{a}}$ of the zinc bound water in the bimetallic system that allowed the formation of a hydroxide group under neutral aqueous conditions. This bridging hydroxide ligand was presumably the reactive base in the transesterification cleavage of HPNP. ${ }^{[42 \mathrm{~b}]}$

In addition, complexes that were studied in $\beta$-lactam hydrolysis, were also tested towards BNPP cleavage by BAUER-SIEBENLIST et al. (Scheme 2.29). ${ }^{[48]}$ Although complex e was initially more active than complex $\mathbf{d}$, the activities of both catalysts were limited by a saturation effect upon hydrolysis of BNPP due to the fixation of the hydrolytic product to the zinc atoms.

But not all models that mimic metallo- $\beta$-lactamases are suitable in the cleavage of phosphate esters. Complexes b and $\mathbf{c}$ (Scheme 2.26) synthesised by MUGESH and coworkers showed high activity in $\beta$-lactam hydrolysis, but were poor catalysts to hydrolyse the phosphortriester PNPDPP (Scheme 2.38). ${ }^{[37 b]}$

Binuclear complexes based on 3,5-substituted pyrazole ligands were tested in HPNP and Paraoxon hydrolysis by PENKova et al. (Scheme 2.42). ${ }^{[75]}$ Although both complexes were active in phosphodiester and phosphotriester cleavage, complex a was more active in 
Paraoxon hydrolysis compared to complex $\mathbf{b}$, which was more active in HPNP transesterification cleavage.

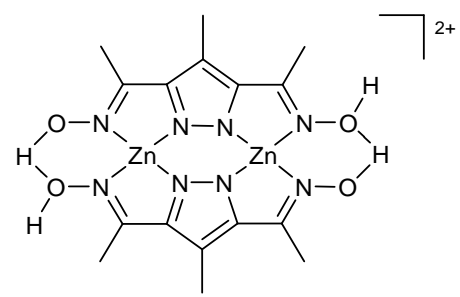

(a)

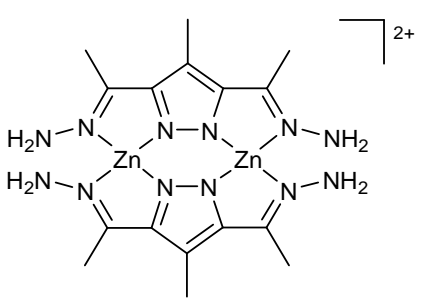

(b)

Scheme 2.42: Complexes synthesised by PENKOVA et al. and active in Paraoxon and HPNP cleavage.

As mentioned in the introduction, bimetallic complexes with macrocyclic ligand scaffolds have been reported to be active in the cleavage of phosphate esters. BAZZICALUPI et al. discovered the reactivity of zinc complexes on the basis of the macrocyclic ligand [30] $\mathrm{aneN}_{6} \mathrm{O}_{4}$ (Scheme 2.43, left). ${ }^{[46 \mathrm{a}]}$ The authors revealed a higher activity of the binuclear complex compared to its mononuclear analogue in BNPP hydrolysis. This fact was suggested to be due to the interaction of the substrate with two electrophilic centres that improved reactivity and enabled the nucleophilic attack of the zinc bound hydroxide ligand.
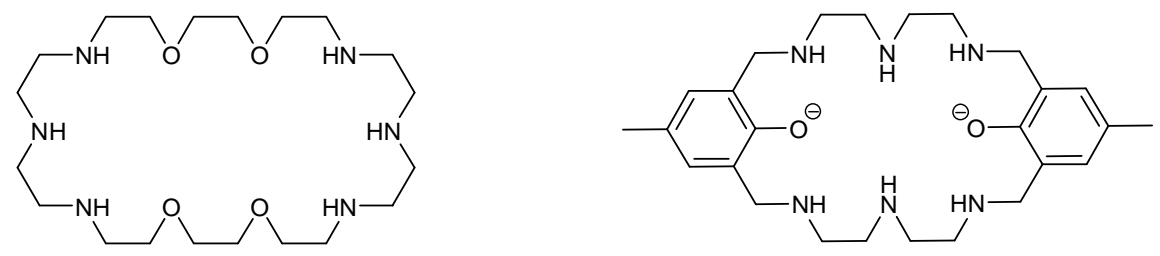

Scheme 2.43: Macrocyclic ligands developed by BAZZICALUPI $e$ t al. (left) and MARTELL and co-workers (right).

In addition, a ligand system based on two phenolate scaffolds connected with amine atom moieties to form a macrocyclic diphenolate ligand was investigated by MARTELL and coworkers (Scheme 2.43, right). ${ }^{[46 b]}$ The binuclear zinc complex was active in TNPP (Scheme 2.38) hydrolysis due to the bidentate binding of the substrate that promoted hydrolysis as mentioned above. To mimic the protein scaffolds of enzymes, the group of REINHOUDT modified a calix[4]arene building block that can either bind one, two or three 
metal ions dependent on the number of substituents (bimetallic complex in Scheme $2.44) .{ }^{[47]}$

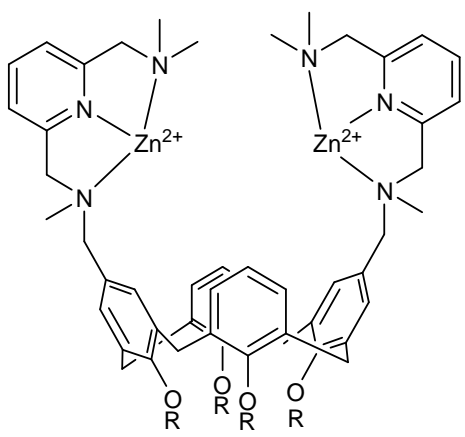

Scheme 2.44: Bincuclear zinc complex synthesised by REINHOUDT and co-workers $\left[\mathrm{R}=\mathrm{CH}_{2} \mathrm{CH}_{2} \mathrm{OEt}\right]$.

The binuclear complex was 50 times more active in HPNP transesterification than the corresponding mononuclear model due to synergetic action of the two zinc centres. The trinuclear complex was the most active catalyst with 32000-fold rate acceleration compared to the uncatalysed reaction. At high HPNP concentrations, however, the trinuclear complex underwent saturation effects presumably due to the binding of more than one HPNP molecule, which resulted in inhibition and decrease of the catalytic activity. The calix[4]arene system is a suitable building block since it bears a hydrophobic pocket similar to the polypeptide backbone of enzymes that can be modified with multiple catalytic groups to mimic amino acid residues. The flexibility of this system during catalysis plays an important role since a lower catalytic rate was observed for the rigid analogue. ${ }^{[47 \mathrm{c}]}$

\subsubsection{General Considerations}

Selected complexes, which were obtained as part of this work (section 2.2), were analysed in their ability to cleave phosphate ester bonds. Substrate HPNP, a phosphodiester, was used to investigate the catalytic activity of $\mathbf{4}$ applying UV-Vis spectroscopy for analysis. Complexes 2, 4, 5a and 12 were studied in phosphotriester hydrolysis of Paraoxon and the catalytic reactions were followed by ${ }^{31} \mathrm{P}$ NMR spectroscopy. Measurements have been performed in buffered solutions, when indicated. Sulfonic acid buffers were used as shown in Table 2.23 and $\mathrm{pH}$ values were adjusted with perchloric acid and sodium hydroxide. 
Table 2.23: Sulfonic acid buffers and $\mathrm{pH}$ ranges.

\begin{tabular}{r|l|c}
\hline Buffer & \multicolumn{1}{|c|}{ Name } & pH range \\
\hline \hline Mes & 2-(N-morpholino)ethanesulfonic acid & $5.0-6.5$ \\
Mops & 3-(N-morpholino)propanesulfonic acid & $7.0-7.5$ \\
Epps & 4-(2-hydroxyethyl)piperazine-1-propanesulfonic acid & $8.0-8.5$ \\
Ches & 2-(cyclohexylamino)-1-ethanesulfonic acid & $9.0-9.5$ \\
Caps & 3-(cyclohexylamino)-1-propanesulfonic acid & $10.0-10.5$ \\
\hline
\end{tabular}

\subsubsection{Cleavage of 2-Hydroxypropyl-p-nitrophenyl Phosphate (HPNP)}

As described above, HPNP is an activated substrate model to mimic RNA. During transesterification/hydrolysis, $p$-nitrophenolate is released (Scheme 2.37) and its formation was monitored by UV-Vis spectroscopy. The absorbance was measured at $400 \mathrm{~nm}\left(\varepsilon=18500 \mathrm{M}^{-1} \cdot \mathrm{cm}^{-1}, \mathrm{p} K_{\mathrm{a}}=7.15\right)$ and $25^{\circ} \mathrm{C}$. The total concentration of p-nitrophenolate was calculated according to (ii) the Beer-Lambert law and (iii) the Henderson-Hasselbalch equation. Initial rates were determined by plotting total concentrations versus time. The experiments were performed in buffered $\mathrm{H}_{2} \mathrm{O} / \mathrm{MeCN}$ $(1: 1, \mathrm{v} / \mathrm{v})$ at $\mathrm{pH}$ ranges of 5.0 to 10.5 . Initial rates were calculated for $\mathbf{L}^{\mathbf{1}}$, $\mathrm{Zn}\left(\mathrm{ClO}_{4}\right)_{2} \cdot 6 \mathrm{H}_{2} \mathrm{O}$, a control and 4 , which was prepared in situ prior to use.

$$
\begin{gathered}
\mathrm{A}=\varepsilon \cdot \mathrm{c} \cdot \mathrm{d} \\
p H=\mathrm{pK}_{\mathrm{a}}+\lg \frac{\mathrm{c}\left(\mathrm{A}^{-}\right)}{\mathrm{c}(\mathrm{HA})}
\end{gathered}
$$

As demonstrated in Figure 2.22, 4 promoted the transesterification/hydrolysis reaction of HPNP at pH 8.0-8.5 compared to $\mathbf{L}^{\mathbf{1}}, \mathrm{Zn}^{2+}$ and the uncatalysed reaction (control). With respect to the uncatalysed reaction, 4 enhanced the rate by a factor of 21 at $\mathrm{pH} 8.0$ and a 12-fold acceleration was observed at $\mathrm{pH}$ 8.5. From potentiometric titration experiments it was known, that the species, which is present at $\mathrm{pH} 8-8.5$, is $\left[\mathrm{Zn}_{4} \mathrm{H}_{-5}\left(\mathrm{~L}^{1}\right)_{2}\right]^{3+}$ (Figure 2.1). Since this species was also obtained in synthesis (7), it might be the active species in 
hydrolysis, although the use of different solvent systems in the potentiometric and kinetic studies hampered a direct comparison. The hypothesis that $\left[\mathrm{Zn}_{2} \mathrm{H}_{-2} \mathrm{~L}^{1}\right]^{2+}$ was the active complex in this reaction is also reasonable, as this species is also present at $\mathrm{pH} 8.0$ to 8.5 and has been reported to be the active one in phosphate ester cleavage with similar complexes. ${ }^{[48]}$ Since the rate enhancement for HPNP cleavage by $\mathbf{4}$ was not impressive, it was not investigated any further.

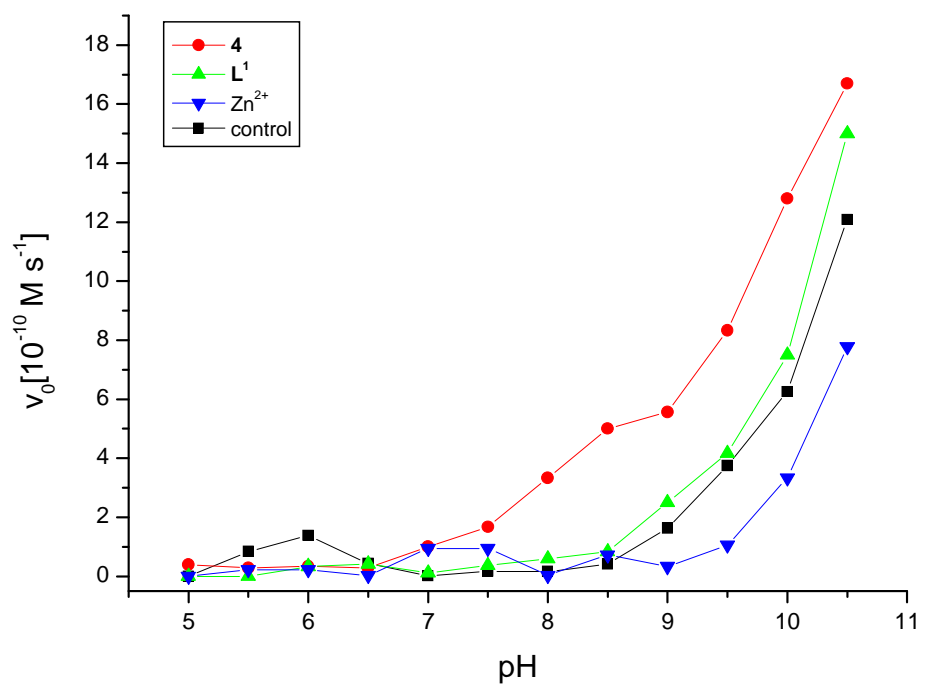

Figure 2.22: Initial rates in 2-hydroxypropyl-p-nitrophenyl phosphate (HPNP) transesterification/hydrolysis of $\mathbf{4}, \mathbf{L}^{\mathbf{1}}$, $\mathrm{Zn}^{2+}$ and a control.

\subsubsection{Cleavage of Paraoxon}

Organophosphate triesters are highly toxic compounds, which have been used as insecticides and warfare agents. The degradation of these compounds is necessary to decrease their toxicity. Paraoxon is a phosphate triester that has been used as insecticide. This substrate can be defanged by the cleavage of the $\mathrm{P}-\mathrm{O}$ bond to form diethyl phosphate and $p$-nitrophenolate (Scheme 2.45).

The activity of 2, 4, 5a and $\mathbf{1 2}$ to cleave Paraoxon was investigated applying ${ }^{31} \mathrm{P}$ NMR spectroscopy. The experiments were performed under different conditions as summarised in Table 2.24. 


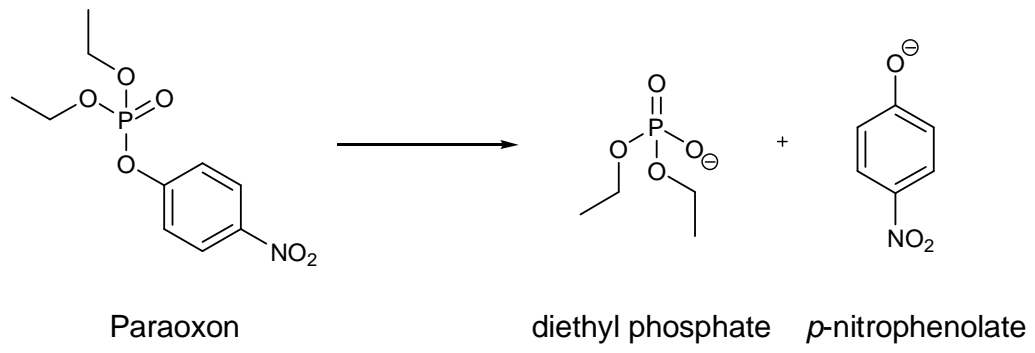

Scheme 2.45: Degradation reaction of Paraoxon resulting in diethyl phosphate and $p$-nitrophenolate.

Table 2.24: Overview of complexes and conditions during Paraoxon cleavage.

\begin{tabular}{c|c|c|c}
\hline Complex & $p$ independent & $p$ Hependent & Equivalents Paraoxon \\
\hline \hline $\mathbf{2}$ & $\checkmark$ & $\checkmark$ & $1.0,2.0$ \\
$\mathbf{4}$ & - & $\checkmark$ & 1.0 \\
$\mathbf{5 a}$ & $\checkmark$ & $\checkmark$ & 1.0 \\
$\mathbf{1 2}$ & $\checkmark$ & - & 1.0 \\
\hline
\end{tabular}

Hydrolytic experiments of 2, 5a and 12 were performed in $d_{3}-\mathrm{MeCN} / \mathrm{D}_{2} \mathrm{O}(9: 1, \mathrm{v} / \mathrm{v})$. Equimolar amounts of each complex and Paraoxon were combined in a NMR tube and measured initially. The reaction was followed in time intervals of one hour. A signal at $7.29 \mathrm{ppm}$ was observed in all spectra, which did not change in chemical shift for more than 31 hours. As a control, pure substrate was analysed under the same conditions revealing a signal at $7.29 \mathrm{ppm}$. These results ended up in the conclusion that the substrate was not hydrolysed under these conditions. A reason might be the acetate co-ligands in $\mathbf{5 a}$ and 12, which are tightly bound to the zinc atoms and do not allow coordination of the substrate. 2 does not bear any co-ligand, but also lacks a nucleophile that is required to mediate substrate cleavage.

In addition to $\mathrm{pH}$ independent experiments, compounds 2, 4 and 5a were studied towards hydrolytic activity within a pH range of 5 to 11 (buffers are listed in Table 2.23). NMR measurements were carried out in buffered $\mathrm{H}_{2} \mathrm{O} / d_{6}$-DMSO $(8: 2, \mathrm{v} / \mathrm{v})$ to maintain a stable $\mathrm{pH}$ and good solubility of the complexes. Spectra were recorded initially after mixing equimolar amounts of complex and Paraoxon and followed at hourly intervals for eight hours, later in 12 hour intervals for three to five days. Between the measurements, the NMR tubes were stored at $40{ }^{\circ} \mathrm{C}$ (water bath) to promote the catalytic reaction. The signal 
of pure Paraoxon was obtained at $6.85 \mathrm{ppm}$ and did not change within the mentioned $\mathrm{pH}$ range. However, after three days of incubation, an additional signal appeared at $0.34 \mathrm{ppm}$ at $\mathrm{pH} 10$ and 11 probably due to background hydrolysis caused by the strongly basic conditions.

The experiments with $\mathbf{2}$ and $\mathbf{4}$ have been monitored for five days. It was surprising that addition of $\mathbf{2}$ and $\mathbf{4}$ did not influence the chemical shift at $6.85 \mathrm{ppm}$, which was the only signal obtained in the spectra. After three days, the signal at $0.34 \mathrm{ppm}$ was also observed at high $\mathrm{pH}$ values in both experiments, which resulted from the background hydrolysis. The formed diethyl phosphate did probably not coordinate to the complexes. If so, a chemical shift from $0.34 \mathrm{ppm}$ would be reasonably expected. Using an excessive amount of substrate (ratio 1:2) did not reveal other signals than $6.85 \mathrm{ppm}$ and $0.34 \mathrm{ppm}$.

A possible reason might be the coordination of the sulfonic acid buffers to the complexes that can inhibit the binding of the phosphate group. In addition, 5a did also not show activity in the hydrolysis of Paraoxon at different $\mathrm{pH}$. This might be due to the bridging acetate group that inhibits the reaction, as discussed above.

To investigate the influence of the used buffer system, an additional experiment was performed in $\mathrm{H}_{2} \mathrm{O} / d_{6}$-DMSO (8:2, v/v). Equimolar amounts of 2, $\mathrm{KO}^{t} \mathrm{Bu}$ and Paraoxon were mixed and the spectra were recorded in regular intervals (12 hours). In addition to the resonance at $6.85 \mathrm{ppm}$ (not hydrolysed substrate) a new signal was observed at $0.82 \mathrm{ppm}$ after three days of incubation at $40^{\circ} \mathrm{C}$. This signal presumably resulted from the hydrolysed substrate (diethyl phosphate), which coordinates to the complex.

In addition to hydrolytic experiments, a suspension containing $\mathbf{L}^{\mathbf{1}}, \mathrm{KO}^{t} \mathrm{Bu}, \mathrm{Zn}\left(\mathrm{SO}_{3} \mathrm{CF}_{3}\right)_{2}$ and Paraoxon was stirred in the presence of acetonitrile (Scheme 2.46) until the solution became clear. ESI-MS analysis of the reaction solution showed fragments that matched the calculated masses of $\left[\mathrm{Zn}_{2} \mathrm{H}_{-1} \mathrm{~L}^{1}\left(\mathrm{OP}(\mathrm{O})(\mathrm{OEt})_{2}\right)\left(\mathrm{SO}_{3} \mathrm{CF}_{3}\right)\right]^{+}$at $\mathrm{m} / z=931$ and $\left[\mathrm{Zn}_{2} \mathrm{H}_{-1} \mathrm{~L}^{1}\left(\mathrm{OP}(\mathrm{O})(\mathrm{OEt})_{2}\right)\right]^{2+}$ at $m / z=391$. Signals in $d_{3}-\mathrm{MeCN}$ were observed at $0.87 \mathrm{ppm}$ (product) and 7.34 ppm (Paraoxon) in ${ }^{31} \mathrm{P}$ NMR. 


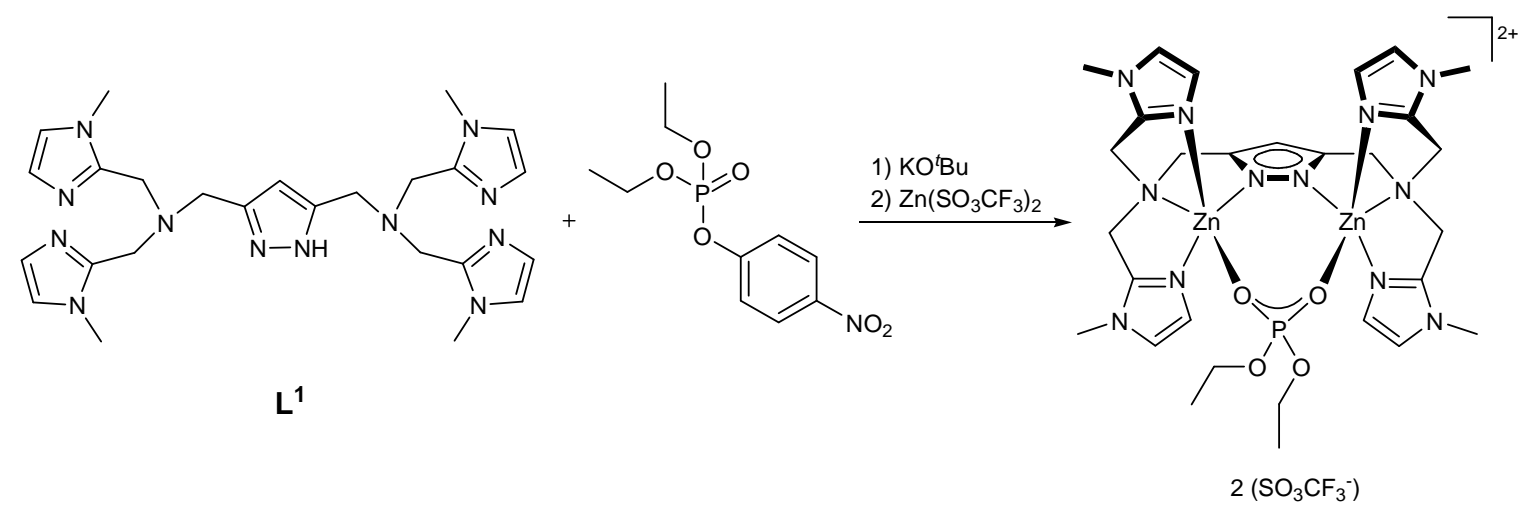

18

Scheme 2.46: Synthesis of 18.

Few single crystals, which were suitable for X-ray analysis, were obtained by slow diffusion of $\mathrm{Et}_{2} \mathrm{O}$ into the filtered acetonitrile solution. 18 crystallises in the monoclinic space group $P 2_{1} / n$ with four molecules per unit cell. As shown in Figure 2.23, each zinc atom is found in trigonal bipyramidal environment $\left(\mathrm{Zn} 1: \tau_{5}=0.91 \text { and } \mathrm{Zn} 2: \tau_{5}=0.88\right)^{[53]}$ by four $N$-donor moieties of the ligand and one oxygen atom of the phosphate group. The zinc atoms and P1 are located within the pyrazolato plane. The oxygen atoms $\mathrm{O} 1$ and $\mathrm{O} 2$ are arranged above this plane $(d(\mathrm{O} 1 \cdots \mathrm{pz})=0.34(1) \AA)$ and below $(d(\mathrm{O} 2 \cdots \mathrm{pz})=$ $0.44(6) \AA)$. The zinc atoms are separated by $4.1086(9) \AA$, which is comparable to 2 $(d(\mathrm{Zn} 1 \cdots \mathrm{Zn} 2)=4.1028(5) \AA)$ and might explain the twisted arrangement of the phosphate. Selected bond lengths and angles for $\mathbf{1 8}$ are listed in Table 2.25.

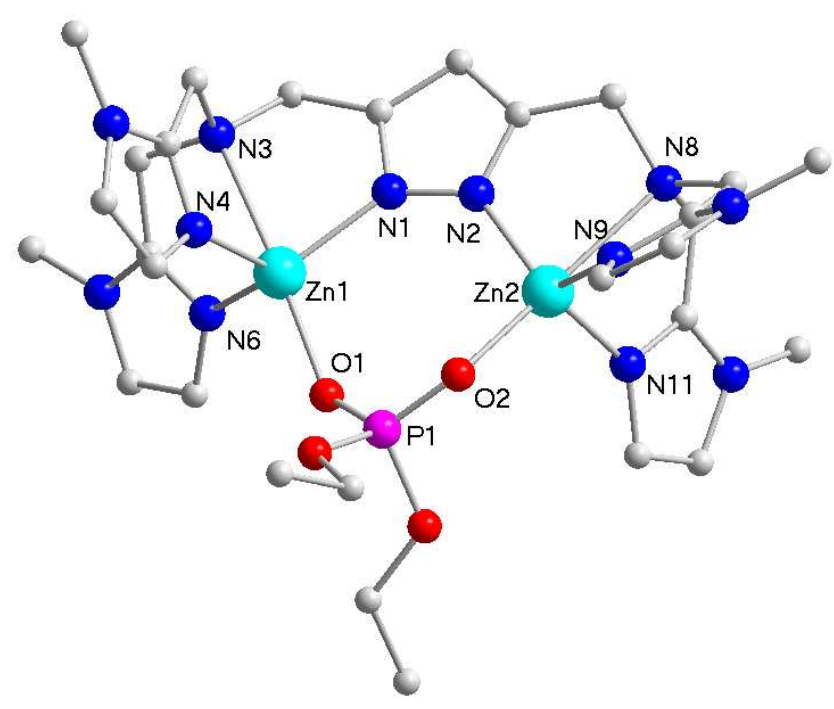

Figure 2.23: Molecular structure of 18, hydrogen atoms and counter ions omitted for clarity. 
Table 2.25: Selected bond lengths $[\AA]$ and angles $\left[{ }^{\circ}\right]$ of $\mathbf{1 8}$.

\begin{tabular}{c|c||c|cc|c}
\hline Atoms & Bond length & Atoms & Angle & Atoms & Angle \\
\hline \hline Zn1-N1 & $2.021(5)$ & N1-Zn1-N3 & $76.1(2)$ & N2-Zn2-N8 & $76.5(2)$ \\
Zn1-N3 & $2.378(5)$ & N1-Zn1-N4 & $113.8(2)$ & N2-Zn2-N9 & $118.9(2)$ \\
Zn1-N4 & $2.041(6)$ & N1-Zn1-N6 & $119.2(2)$ & N2-Zn2-N11 & $112.5(2)$ \\
Zn1-N6 & $2.026(6)$ & N1-Zn1-O1 & $106.9(2)$ & N2-Zn2-O2 & $106.9(2)$ \\
Zn1-O1 & $1.991(5)$ & N3-Zn1-N4 & $75.6(2)$ & N8-Zn2-N9 & $75.8(2)$ \\
Zn2-N2 & $2.005(5)$ & N3-Zn1-N6 & $76.6(2)$ & N8-Zn2-N11 & $75.9(2)$ \\
Zn2-N8 & $2.429(5)$ & N3-Zn1-O1 & $173.9(2)$ & N8-Zn2-O2 & $171.7(2)$ \\
Zn2-N9 & $2.023(6)$ & N4-Zn1-N6 & $110.2(2)$ & N9-Zn2-N11 & $111.8(2)$ \\
Zn2-N11 & $2.031(6)$ & N4-Zn1-O1 & $107.4(3)$ & N9-Zn2-O2 & $96.0(2)$ \\
Zn2-O2 & $1.983(5)$ & N6-Zn1-O1 & $97.4(2)$ & N11-Zn2-O2 & $108.9(3)$ \\
Zn1‥Zn2 & $4.1086(9)$ & & & & \\
\hline
\end{tabular}

${ }^{31} \mathrm{P}$ NMR analysis of $\mathbf{1 8}$ in $d_{3}-\mathrm{MeCN}$ solution revealed one signal at $0.87 \mathrm{ppm}$. This confirmed the hypothesis that the signal at $0.82 \mathrm{ppm}$, which was observed in hydrolytic reactions without buffer, was the hydrolysed substrate (diethyl phosphate) that coordinated to the complex. In addition, it could be demonstrated that the used buffer inhibits the binding of the hydrolysed substrate to the complex as only the free (and not coordinated) diethyl phosphate and Paraoxon were present in the experiments in buffered solutions. Performing the hydrolytic experiments in other buffer systems, which do not interact with the complex, might increase the activity to cleave the $\mathrm{P}-\mathrm{O}$ bond of Paraoxon. 


\section{5. $\mathrm{CO}_{2}$ Activation}

Carbon dioxide is abundant, nontoxic and a bio renewable $\mathrm{C} 1$ feedstock. However, it is thermodynamically stable and needs highly reactive reagents to overcome kinetic barriers to generate useful chemicals. Its activation is of academic and industrial interest and was investigated extensively within the last decades. Utilisation of $\mathrm{CO}_{2}$ as a basic material is often considered as green chemistry. However, the quantity that is used within these processes is rather small compared to the worldwide production of $\mathrm{CO}_{2} \cdot{ }^{[76]}$

\subsection{1. $\mathrm{CO}_{2}$ Copolymerisation}

\subsubsection{Introduction}

One way to leverage the high potential of this resource is the copolymerisation of $\mathrm{CO}_{2}$ and epoxides, mostly propylene oxide (Scheme 2.47) and cyclohexene oxide. The formed polycarbonates are of great industrial interest due to their outstanding properties (e.g., durability, lightness, heat resistance, good electrical insulation). ${ }^{[76]}$

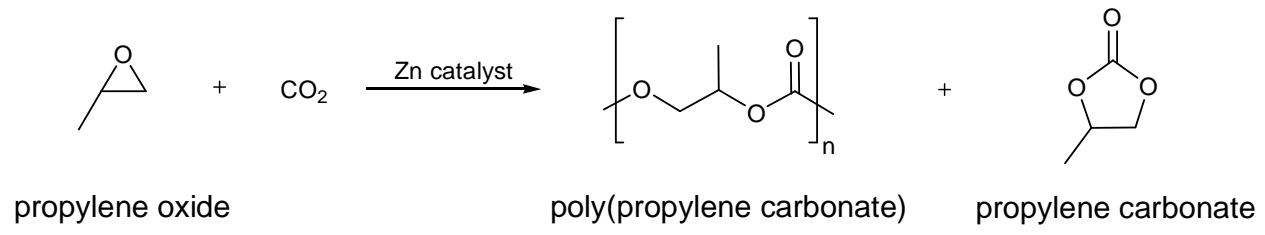

Scheme 2.47: Copolymerisation of propylene oxide and $\mathrm{CO}_{2}$ to form poly- and cyclic propoylene carbonates.

A second product obtained in this synthetic process is a cyclic alkyl carbonate (e.g., propylene carbonate from propylene oxide, Scheme 2.47). This thermodynamically favoured product is preferably formed at high temperatures, while copolymerisation is dominant at low temperatures. ${ }^{[77]}$ Cyclic carbonates are commercially important and are used as electrolytes in lithium batteries and as aprotic polar solvents due to their high boiling points and low toxicity. ${ }^{[76 b, 78]}$ Since both products have important industrial applications, the challenge is to preferably form only one product in the reaction by variation of catalysts, $\mathrm{CO}_{2}$ pressure, temperature and epoxide concentration. ${ }^{\text {[76a] }}$ 
Initial experiments in the copolymerisation reaction of propylene oxide and $\mathrm{CO}_{2}$ were performed by INOUE et al. in 1969. ${ }^{[79]}$ The active species was found to be a $\mathrm{Et}_{2} \mathrm{Zn}$-water (1:1) catalyst forming poly(propylene carbonate). Based on the investigations of INOUE et $a l$., many further developments in the area of copolymerisation were achieved. Air stable metal acetates $\mathrm{Cr}(\mathrm{OAc})_{3}, \mathrm{Co}(\mathrm{OAc})_{2}, \mathrm{Zn}(\mathrm{OAc})_{2}$ and $\mathrm{Ni}(\mathrm{OAc})_{2}$ were studied by SoGA et al . in the copolymerisation of propylene oxide and $\mathrm{CO}_{2}{ }^{[80]}$ Catalytic activity was also observed for complexes (2,6-diphenylphenoxide) ${ }_{2} \mathrm{Zn}(\mathrm{X})_{2} \quad\left(\mathrm{X}=\mathrm{THF}, \mathrm{Et}_{2} \mathrm{O}\right)$ by DARENSBOURG and HoltCAMP (Scheme $2.48, \mathbf{a}) .{ }^{[81]}$ COATES and co-workers developed zinc complexes containing bulky $\beta$-diketiminato ligands (BDI) that are highly active in the copolymerisation of cyclohexene oxide and $\mathrm{CO}_{2}($ Scheme $2.48, \mathbf{b}){ }^{[82]}$

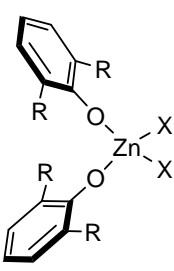

$\mathrm{R}=\mathrm{Ph},{ }^{\mathrm{i}} \mathrm{Pr},{ }^{\mathrm{t}} \mathrm{Bu}$ $\mathrm{X}=\mathrm{THF}, \mathrm{Et}_{2} \mathrm{O}$

(a)

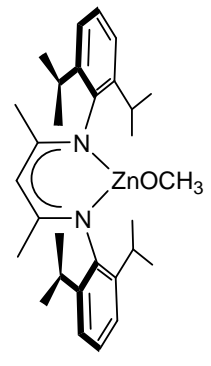

(b)

Scheme 2.48: Zinc complexes synthesised by Darensbourg and Holtcamp (a) and CoATeS and co-workers (b).

The mechanisms of these processes are not fully understood so far. $\mathrm{CO}_{2}$ insertion is proposed to be the first step followed by the coordination of the epoxide and ring opening. ${ }^{[82]}$ Using sterically demanding ligands (e.g., substituted phenoxides), the initial step is assumed to be the coordination of the epoxide to the electrophilic zinc atom followed by ring opening and insertion of $\mathrm{CO}_{2}{ }^{[83]}$ Theoretical calculations of the zinc complex (BDI) $\mathrm{ZnOCH}_{3}$ with a bulky $\beta$-diketiminato ligand revealed an alternating repetition of $\mathrm{CO}_{2}$ insertion into the $\mathrm{Zn}$-alkoxyl bond (Scheme 2.49) and the epoxide insertion into the $\mathrm{Zn}$-carbonate bond being favoured. The rate-determining step is the ring opening of the epoxide during insertion. ${ }^{[84]}$ 


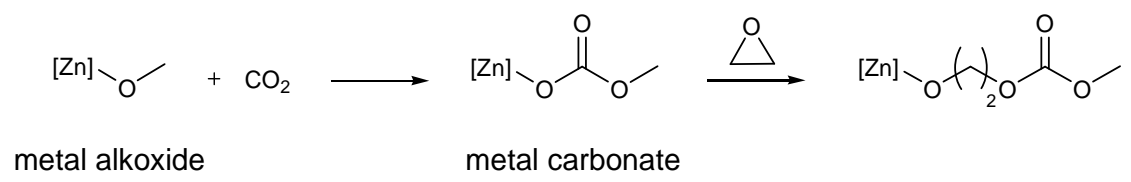

Scheme 2.49: Proposed mechanism resulting from theoretical calculations.

One of the first investigations utilising binuclear zinc complexes in the copolymerisation process were performed by DARENSBOURG et al. ${ }^{[85]}$ Ligand systems based on phenolates, which are substituted in 2 and 6 positions with less bulky and electron-withdrawing fluoride ligands, afforded complexes (Scheme 2.50, a) that are effective catalysts for the copolymerisation of cyclohexene oxide and $\mathrm{CO}_{2}$. The first example for asymmetric copolymerisation of meso-epoxides and $\mathrm{CO}_{2}$ was reported by NOZAKI and co-workers using an equimolar mixture of $\mathrm{Et}_{2} \mathrm{Zn}$ and a chiral amino alcohol $((S)$-diphenyl(pyrrolidin2-yl)methanol) as chiral catalyst. ${ }^{[86]}$ Later, the active species could be isolated and characterised, showing a binuclear structure formed from $\mathrm{Et}_{2} \mathrm{Zn}$ and the chiral amino alcohol (Scheme 2.50, b). ${ }^{[87]}$

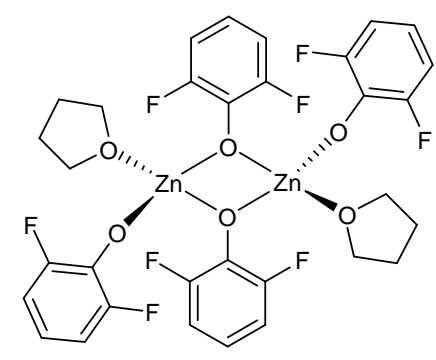

(a)

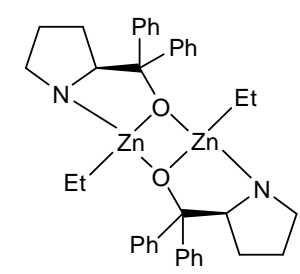

(b)

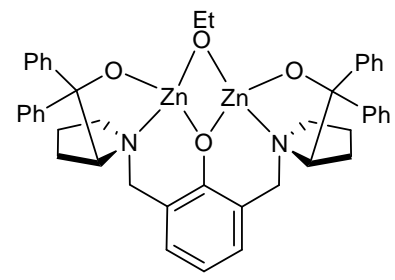

(c)

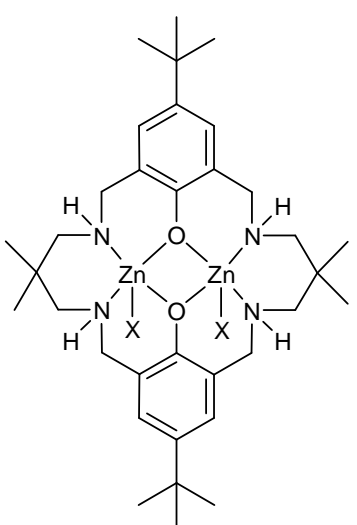

(d)

Scheme 2.50: Binuclear zinc catalysts used in the copolymerisation reaction with $\mathrm{CO}_{2}$ by DARENSBOURG et al. (a), NOZAKI and co-workers (b), XIAO et al. (c) and KEMBER et al. $(\mathbf{d}, \mathrm{X}=\mathrm{OAc})$.

Due to a higher catalytic activity under milder conditions, binuclear zinc complexes have been intensively studied. XIAO et al. carried out experiments using a zinc complex based on a phenolate ligand, which is substituted with diphenyl-2-pyrrolidinemethanol side chains (Scheme 2.50, c) ${ }^{[88]}$ Based on a macrocyclic ligand system (Scheme 2.50, d), KEMBER et al. were able to design a bimetallic zinc complex that showed high activity in $\mathrm{CO}_{2}$ copolymerisation, was air stable and even active under aerobic conditions. ${ }^{[89]}$ 
The optimisation of zinc catalysts, which require low $\mathrm{CO}_{2}$ pressure, gains a significant contribution with respect to the economical and environmental factors of the copolymerisation process.

\subsubsection{Activity of 2 in $\mathrm{CO}_{2}$ Copolymerisation}

Inspired by the high activity of binuclear complexes under mild conditions, $\mathbf{2}$ was studied towards its activity in $\mathrm{CO}_{2}$ copolymerisation of cyclohexene oxide. Stoichiometric amounts of $\mathbf{2}$ and $\mathrm{KO}^{t} \mathrm{Bu}$ were dissolved in cyclohexene oxide under inert conditions (0.04 mol\% of 2). The mixture was heated to $80{ }^{\circ} \mathrm{C}$ and predried $\mathrm{CO}_{2}(1 \mathrm{~atm})$ was gently bubbled through the mixture (16 hours), whereby most of the epoxide evaporated. The residue was dried in vacuum and the resulting colourless solid was suspended in dichloromethane. After filtration, the polymer precipitated by adding methanol to the solution. The colourless product was collected by filtration and dried in vacuum.

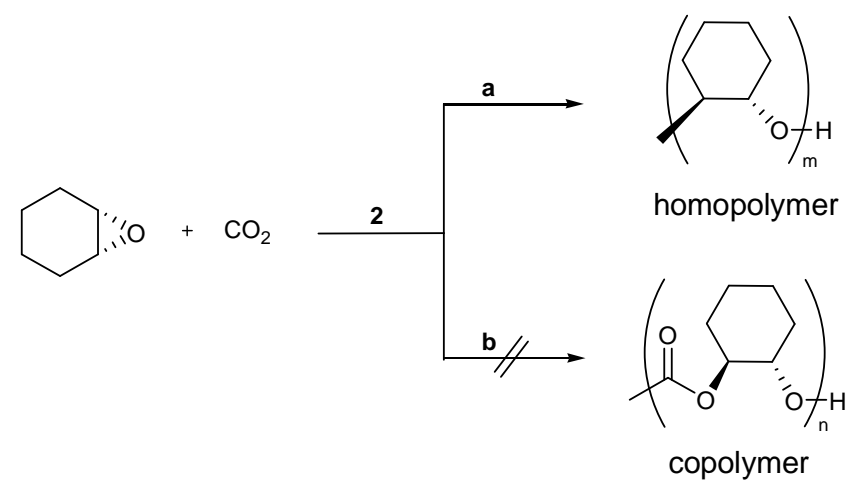

Scheme 2.51: Polymerisation reaction with 2 as catalyst.

The polymerisation product was analysed by ${ }^{1} \mathrm{H}$ NMR spectroscopy. The spectrum showed a broad signal at a chemical shift of $3.40 \mathrm{ppm}$ indicating the formation of the polyether (Scheme 2.51 , a). A signal at $4.63 \mathrm{ppm}$ would confirm the formation of the copolymer product (Scheme $2.51, \mathbf{b}) .{ }^{[88]}$ This was not observed. Increasing the catalyst concentration $(0.1 \mathrm{~mol} \%)$ also revealed the formation of the homopolymer as it was observed with less amount of catalyst. Possible reasons might be the used conditions during the copolymerisation reaction. Since the reaction was performed under $1 \mathrm{~atm} \mathrm{CO}_{2}$ pressure, investigations at high $\mathrm{CO}_{2}$ pressure would be of interest. In addition, higher amounts of catalysts might also improve the formation of the copolymer product. 


\subsubsection{Cyclic Carbonates}

\subsubsection{Introduction}

As mentioned above, cyclic carbonates are of great industrial interest. The technical synthetic process is the reaction of epoxides and carbon dioxide (Scheme 2.52, a). ${ }^{[90]}$ During the copolymerisation reaction, they are formed by the back-biting of a metal alkoxide into an adjacent carbonate linkage. ${ }^{[76 a, 77 b]}$ A useful application of cyclic carbonates (e.g., ethylene carbonate and propylene carbonate) is the transesterification with methanol to form dimethyl carbonate (DMC) and corresponding glycols. ${ }^{[78,91]}$ DMC is a non-toxic liquid and can be used as methylating or methoxycarbonylating reagent making it attractive to replace toxic compounds like dimethyl sulfoxide or phosgene. ${ }^{[92]}$ It is no longer produced by the formerly established method, which required phosgene. DMC formation by catalytic oxidative carbonylation of methanol and oxygen can either be catalysed by copper chloride and carbon monoxide or by a palladium catalyst and methyl nitrite. ${ }^{[91-92]} \mathrm{A}$ new and convenient catalytic route would be achieved, if cyclic carbonates can be synthesised by the reaction of $\mathrm{CO}_{2}$ and glycols (Scheme 2.52, c). $\mathrm{CO}_{2}$ as a bio renewable source and glycols, which are formed during the transesterification of methanol and DMC (Scheme 2.52, b), make the formation of cyclic carbonates from environmental friendly starting materials highly attractive.

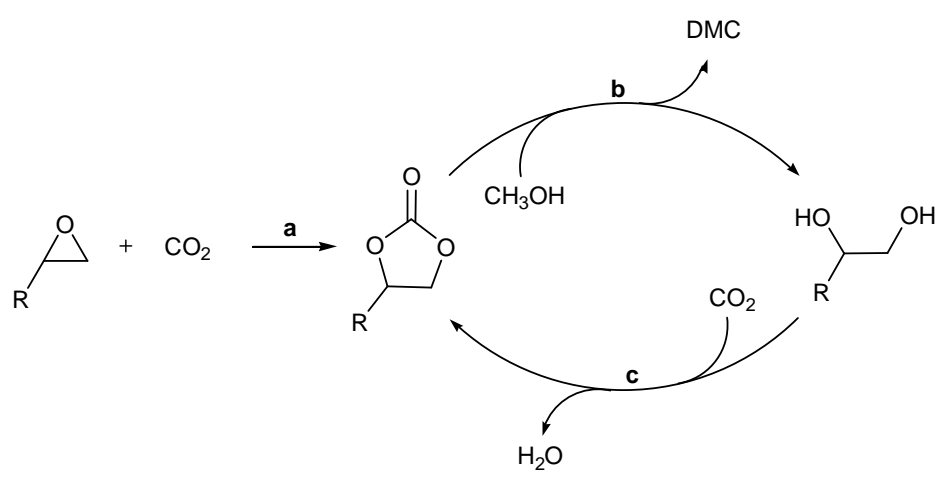

Scheme 2.52: Common syntheses of cyclic carbonates (a) and dimethyl carbonate (DMC, b), worthwhile catalysis to form cyclic carbonates $(\mathbf{c})$.

Only few examples of reactions of $\mathrm{CO}_{2}$ with glycols are known in literature. The first synthesis of a cyclic carbonate from a ketal and catalysed by transition metals was reported by ARESTA et al. in 2003. ${ }^{[93]}$ They investigated the activity of several metal oxides, metal halides and copper or iron complexes based on a perfluorinated diketone 
ligand system. Since no product formation was observed in organic solvents, reactions were performed in supercritical $\mathrm{CO}_{2}\left(\mathrm{SC}-\mathrm{CO}_{2}\right)$, which was suitable as reagent and solvent, yielding cyclic carbonates. Experiments with a hetergeneous $\mathrm{CeO}_{2}-\mathrm{ZrO}_{2}$ catalyst by TOMISHIGE and co-workers and catalysts $\mathrm{Bu}_{2} \mathrm{SnO}, \mathrm{Bu}_{2} \mathrm{Sn}(\mathrm{OMe})_{2}$ and $\mathrm{Ti}(\mathrm{OPr})_{4}$ used by DUE et al. revealed activity in the formation of cyclic carbonates with high selectivity, but low yield $(\sim 2-4 \%) .{ }^{[91,94]}$ The reason was suggested to be a reaction equilibrium (Scheme 2.52 , c). If the formed water is not removed, the reaction is limited. Starting materials were thus dehydrated, which resulted in higher yields. ${ }^{[94 \mathrm{~b}]}$ In 2007 HUANG et al. were able to catalyse the cyclisation of propylene glycol and $\mathrm{CO}_{2}$ under high pressure using $\mathrm{ZnO}$ modified with $\mathrm{KI}$ as catalyst. ${ }^{[78]}$ Under optimised conditions, yields up to $26 \%$ were achieved. The reaction was performed in the presence of acetonitrile, which served as the dehydrating agent. ZHAO and co-workers studied the activity of a series of metal acetate salts in the reaction of propylene glycol and $\mathrm{CO}_{2}$. The most active catalyst was found to be zinc acetate. ${ }^{[95]}$ Under optimised conditions, selectivity and yield were tuned to $12.3 \%$ and $64.1 \%$, respectively.

\subsubsection{Activity of 2 to Form Cyclic Carbonates}

As shown above, zinc compounds have a great potential in the catalytic synthesis of cyclic carbonates compared to other transition metals. The optimisation of catalysts supports economical and environmental factors in the synthetic process of cyclic carbonates, which have a wide variety in industrial applications. In this respect, 2 was investigated to catalyse the reaction of 1,2-propylene glycol and $\mathrm{CO}_{2}$ to form propylene carbonate (Scheme 2.53).

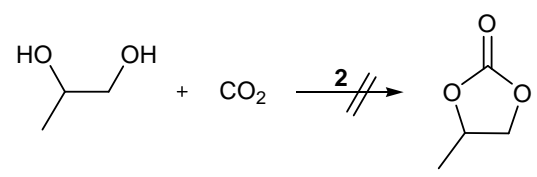

Scheme 2.53: Reaction of 1,2-propylene glycol and $\mathrm{CO}_{2}$ with 2 as catalyst.

$2(1 \mathrm{~mol} \%)$ and 1,2-propylene glycol were stirred in acetonitrile under inert conditions and molecular sieve ( $3 \AA$ ) was added as dehydrating agent. The mixture was heated to 
reflux and $\mathrm{CO}_{2}$ was gently bubbled into the solution. Samples for GC-MS analysis were taken every hour to monitor propylene carbonate formation, but this was not observed under the used conditions. A second reaction was performed at room temperature due to a higher saturation concentration of carbon dioxide compared to high temperature. Since most acetonitrile evaporated during the first reaction, 1,2-propylene glycol was used as reagent and solvent. 2 and an equimolar amount of $\mathrm{KO}^{t} \mathrm{Bu}$ were dried in a Schlenk flask, followed by addition of 1,2-propylene glycol. The mixture was stirred for 3 hours before adding molecular sieve to remove water. $\mathrm{CO}_{2}$ was bubbled through the reaction mixture for 3 days (9 hours each). GC-MS analysis did not confirm the formation of propylene carbonate. Although the experiments gave no indication for any conversion of propylene glycol (the only peak in GC-MS), the reason must not be the inactivity of the complex, but may rather be found in the used conditions. Since the experiments were performed under low $\mathrm{CO}_{2}$ pressure (1 atm) working under high $\mathrm{CO}_{2}$ pressure would be of interest.

\subsubsection{Reaction with $\mathrm{CO}_{2}$}

In addition to the catalytic reactions to activate $\mathrm{CO}_{2}$, a carbonate bridged tetranuclear complex was obtained in synthesis by diffusion of atmospheric $\mathrm{CO}_{2}$ into the complex solution.
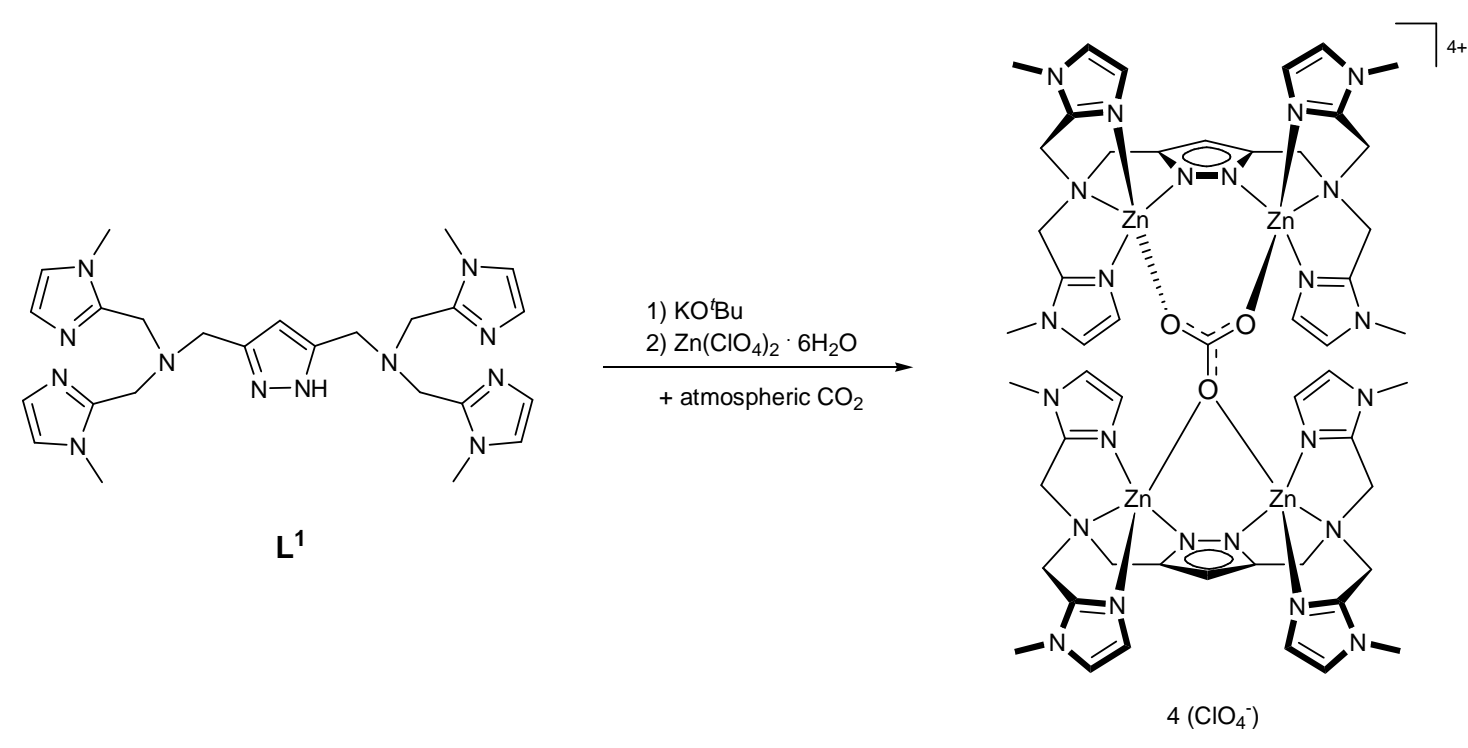
This reaction was performed by treating $\mathbf{L}^{1}$ with $\mathrm{KO}^{\mathrm{t}} \mathrm{Bu}$ and $\mathrm{Zn}\left(\mathrm{ClO}_{4}\right)_{2} \cdot 6 \mathrm{H}_{2} \mathrm{O}$ in methanol (Scheme 2.54). During crystallisation, atmospheric carbon dioxide was able to diffuse into the methanol solution resulting in few single crystals, which were suitable for X-ray analysis. The complex crystallises in the monoclinic space group $C 2 / c$ with four formula units per unit cell. This tetranuclear complex (Figure 2.24) consists of two dizinc complexes that are bridged by a carbonate anion, which is disordered and binds in a $\mu_{4}-\eta^{2}: \eta^{1}: \eta^{1}$ fashion. The bond lengths of the zinc atoms to the oxygen atoms of the carbonate group differ in lengths: 2.025(9) $\AA$ and 2.213(9) $\AA$ to the $\eta^{2}-\mathrm{O} 3$ atom of the carbonate group and 2.059(8) $\AA$ for Zn1-O1 and 1.976(8) $\AA$ for Zn2-O2. The latter is the shortest $\mathrm{Zn}-\mathrm{O}$ bond length found in the complex. This binding mode is unusual for zinc complexes and was recently reported for the first time. ${ }^{[96]}$ The distance of $\mathrm{Zn} 1 \cdots \mathrm{Zn} 2$ is 3.6595(15) A. An overview of selected bond lengths and angles is given in Table 2.26.

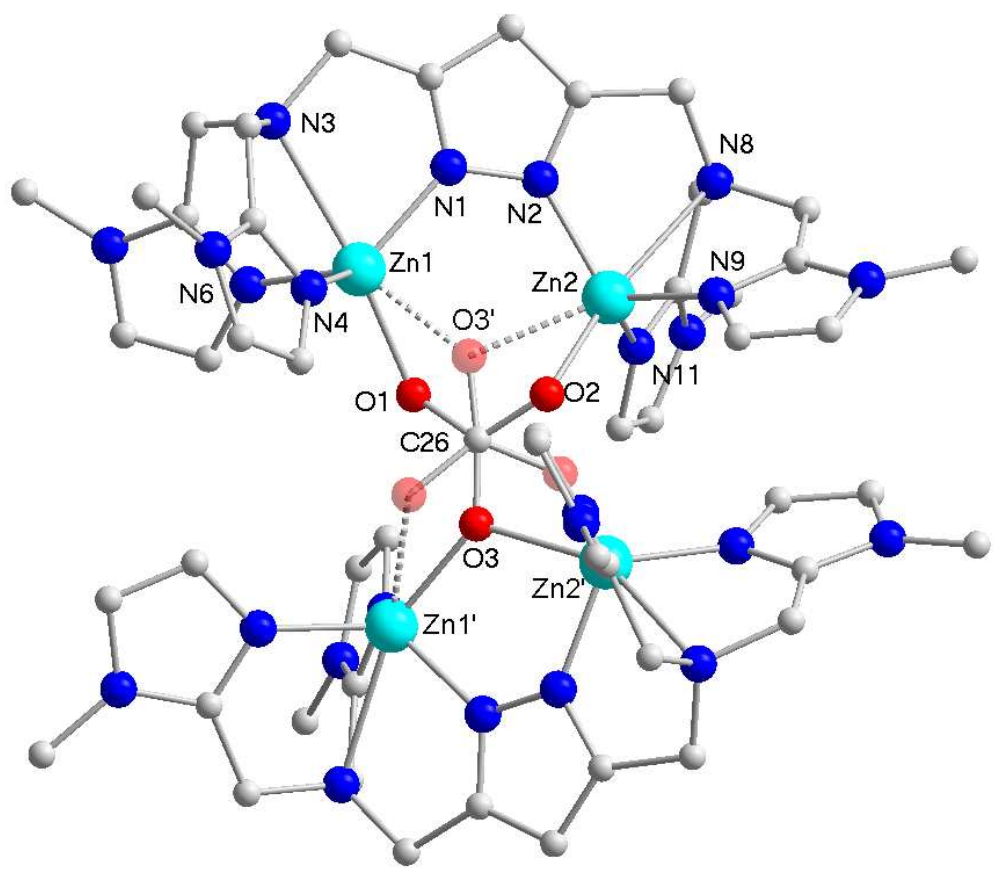

Figure 2.24: Molecular structure of 19, hydrogen atoms and counter ions omitted for clarity. Symmetry operation used to generate equivalent atoms: (') $-x+1, y,-z+1 / 2$. 
Table 2.26: Selected bond lenghts $[\AA]$ and angles $\left[{ }^{\circ}\right]$ for 19 .

\begin{tabular}{c|c||c|cc|c}
\hline Atoms & Bond length & Atoms & Angle & Atoms & Angle \\
\hline \hline Zn1-N1 & $1.978(5)$ & N1-Zn1-O1 & $111.0(3)$ & N2-Zn2-O2 & $113.4(3)$ \\
Zn1-N3 & $2.493(5)$ & N3-Zn1-O1 & $168.8(3)$ & N8-Zn2-O2 & $166.6(3)$ \\
Zn1-N4 & $1.995(6)$ & N4-Zn1-O1 & $107.1(3)$ & N9-Zn2-O2 & $90.4(3)$ \\
Zn1-N6 & $1.993(6)$ & N6-Zn1-O1 & $91.7(3)$ & N11-Zn2-O2 & $110.5(3)$ \\
Zn1-O1 & $2.059(8)$ & N1-Zn1-N3 & $73.2(2)$ & N2-Zn2-N8 & $73.4(2)$ \\
Zn2-N2 & $1.964(5)$ & N1-Zn1-N4 & $118.1(2)$ & N2-Zn2-N9 & $113.1(2)$ \\
Zn2-N8 & $2.469(5)$ & N1-Zn1-N6 & $121.4(2)$ & N2-Zn2-N11 & $112.3(2)$ \\
Zn2-N9 & $2.003(7)$ & N3-Zn1-N4 & $78.61(19)$ & N8-Zn2-N9 & $76.2(2)$ \\
Zn2-N11 & $2.024(6)$ & N3-Zn1-N6 & $77.5(2)$ & N8-Zn2-N11 & $75.5(2)$ \\
Zn2-O2 & $1.976(8)$ & N4-Zn1-N6 & $103.9(2)$ & N9-Zn2-N11 & $115.4(2)$ \\
Zn1-O3' & $2.025(9)$ & N1-Zn1-O3' & $86.2(3)$ & N2-Zn2-O3' & $83.0(3)$ \\
Zn2-O3' & $2.213(9)$ & N3-Zn1-O3' & $158.4(3)$ & N8-Zn2-O3' & $152.8(3)$ \\
Zn1‥Zn2 & $3.6595(15)$ & N4-Zn1-O3' & $106.2(3)$ & N9-Zn2-O3' & $126.8(3)$ \\
& & N6-Zn1-O3' & $120.3(4)$ & N11-Zn2-O3' & $102.0(3)$ \\
& & C26-O1-Zn1 & $123.6(6)$ & C26-O2-Zn2 & $119.8(5)$ \\
& & C26-O3'-Zn1 & $131.7(7)$ & C26-O3'-Zn2 & $108.3(7)$ \\
\hline
\end{tabular}

NMR and ESI-MS analyses of the crystalline material did not confirm the formation of 19. The signal for the carbonate group, which would be expected around $170 \mathrm{ppm},{ }^{[97]}$ was not observed. In addition, 19 was not stable under electrospray conditions. Fragments at $m / z=681,359$ and 337, which showed isotopic distributions for two $\mathrm{Zn}^{2+}$, could not be assigned to fragments of $\mathbf{1 9}$ indicating the decomposition of the complex under ESI-MS conditions. However, formation of $\mathbf{1 9}$ could be confirmed by IR analysis. Two peaks at 1493 and $1393 \mathrm{~cm}^{-1}$ were observed that are characteristic for coordinated carbonate. ${ }^{[97]}$

In order to investigate the formation of complexes being directly exposed to $\mathrm{CO}_{2}$, carbon dioxide was bubbled into a methanol solution containing $\mathbf{L}^{\mathbf{1}}, \mathrm{KO}^{t} \mathrm{Bu}$ and $\mathrm{Zn}\left(\mathrm{SO}_{3} \mathrm{CF}_{3}\right)_{2}$. Although no differences in the species formation was determined by ESI-MS before and after $\mathrm{CO}_{2}$ exposure (due to the instability of complex), $\mathrm{Et}_{2} \mathrm{O}$ diffusion into the complex solution afforded crystals, which were suitable for X-ray diffraction. Crystallographic analysis confirmed the same binding fashion of a disordered carbonate moiety bridging two complexes as discussed above. The complex was present in a different modification due to the different counter ions compared to 19. 


\subsection{Conclusion and Outlook}

This work was based on the synthesis of new binuclear zinc complexes that mimic the active centres of zinc containing enzymes. In addition to the imidazole containing and literature known ligand $\mathbf{L}^{\mathbf{1}}{ }^{[43 \mathrm{~d}]}$ three novel ligands were designed, which bear biomimetic functional groups, like benzimidazole, imidazole and carboxylate $\left(\mathbf{L}^{2}-\mathbf{L}^{4}\right)$. In addition, the length of the side chains of the ligands containing benzimidazole moieties was modified $\left(\mathbf{L}^{2}\right.$ and $\left.\mathbf{L}^{3}\right)$ to obtain zinc complexes, which vary in their zinc-zinc separations (8 and 9).

Two complexes (4a and $\mathbf{4 b}$ ) were obtained that differ considerably in their $\mathrm{Zn} \cdots \mathrm{Zn}$ distances, although based on the same ligand $\left(\mathbf{L}^{\mathbf{1}}\right)$. This is due to the different nucleophiles that bridge the zinc atoms: a methanol-methanolate moiety in case of $\mathbf{4 a}$ and a methanol group in $\mathbf{4 b}$. In addition, a $\mu-\mathrm{OH}$ bridged complex (8) was obtained in solid state with the benzimidazole containing ligand $\mathbf{L}^{2}$. ESI-MS analysis of $\mathbf{8}$ revealed the formation of a $\left(\mathrm{H}_{3} \mathrm{O}_{2}\right)$-bridged complex, which was the only species in solution. These results indicated the flexibility of the pyrazole ligand scaffold, which is substituted in 3 and 5 positions with aromatic $N$-donor moieties. In addition, complex $\mathbf{4 b}$ is most likely active towards the cleavage of acetonitrile, as $\left[\mathrm{Zn}_{2} \mathrm{H}_{-1} \mathrm{~L}^{1}(\mathrm{CN})\right]\left(\mathrm{ClO}_{4}\right)_{2}$ was the only species found in ESI-MS.

In accordance with potentiometric investigations, various complexes were obtained in the synthesis and characterised: $\left[\mathrm{ZnH}_{2} \mathrm{~L}^{1}\right]^{4+}(\mathbf{1}),\left[\mathrm{Zn}_{2} \mathrm{H}_{-1} \mathrm{~L}^{1}\right]^{3+}(\mathbf{2}, \mathbf{3}),\left[\mathrm{Zn}_{2} \mathrm{H}_{-2} \mathrm{~L}^{1}\right]^{2+}(\mathbf{4 a}, \mathbf{4 b}$ and 5a) and $\left[\mathrm{Zn}_{4} \mathrm{H}_{-5}\left(\mathrm{~L}^{1}\right)_{2}\right]^{3+}(\mathbf{7})$. The $\mathrm{Zn} \cdots \mathrm{Zn}$ separations for these complexes differ between

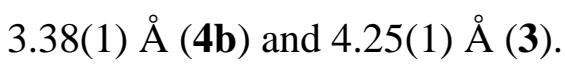

In addition to the binuclear complexes (2-5), a tetranuclear complex (19) was obtained by diffusion of atmospheric $\mathrm{CO}_{2}$ into the complex solution. The resulting carbonate moiety bridges two binuclear subunits in a $\mu_{4}-\eta^{2}: \eta^{1}: \eta^{1}$ binding fashion. The same binding motif was observed when the complex solution was exposed directly to $\mathrm{CO}_{2}$. A second tetranuclear complex (7) was obtained that represented species $\left[\mathrm{Zn}_{4} \mathrm{H}_{-5}\left(\mathrm{~L}^{1}\right)_{2}\right]^{3+}$. This complex bears a $\mu$-oxo- $\mu$-hydroxo bridge, which is uncommon for zinc and has not been reported so far for zinc containing complexes. 
The synthesised complexes were furthermore investigated in catalytic reactions to activate $\mathrm{CO}_{2}$ or to cleave chemical bonds (i.e., $\mathrm{P}-\mathrm{O}$ bond of phosphate diesters and phosphate triesters and the $\mathrm{C}-\mathrm{N}$ bond of $\beta$-lactam antibiotic drugs).

Activation of $\mathrm{CO}_{2}$ was studied in the copolymerisation reaction with cyclohexene oxide and in the formation of propylene oxide with 1,2-propylene glycol. In these reactions 2 was used as catalyst. Since this complex bears no nucleophile, an additional equivalent of base was added to ensure nucleophilicity that is necessary for activity. Although $\mathbf{2}$ did not catalyse both reactions, the reason might be not due to the inactivity of the complex rather than the used conditions. Since both experiments were performed at $1 \mathrm{~atm} \mathrm{CO}_{2}$ pressure, additional experiments under high $\mathrm{CO}_{2}$ pressure might increase the efficacy of $\mathbf{2}$ to activate $\mathrm{CO}_{2}$. In addition, increasing the catalyst concentration might also provide a higher activity.

The activity of the complexes to cleave chemical bonds was investigated by means of phosphate esters. 4 was found to be slightly active in the hydrolysis/transesterification reaction of 2-hydroxypropyl-p-nitrophenyl phosphate (HPNP). Compared to the uncatalysed reaction, a 21-fold rate enhancement was observed at $\mathrm{pH} 8.0$ and a 12-fold acceleration at $\mathrm{pH}$ 8.5. In addition to this, complexes 2, 4, 5a and 12 were explored in hydrolytic experiments to cleave Paraoxon, a phosphate triester. Due to the co-ligand acetate, which strongly binds to the zinc atoms and does not allow coordination of the substrate, 5a and $\mathbf{1 2}$ were not active to hydrolyse Paraoxon. The hydrolytic activity of $\mathbf{2}$ and 4 was examined in buffered solutions. As demonstrated by ${ }^{31} \mathrm{P}$ NMR spectroscopy, the substrate was cleaved after several days (probably due to background hydrolysis) and the free diethyl phosphate was present in solution. Different results were obtained in unbuffered solutions. In these reactions, the hydrolysed diethyl phosphate coordinated to the zinc atoms of the complexes as it was demonstrated by ${ }^{31} \mathrm{P}$ NMR and X-ray analysis. It could thus be proven that the used sulfonic acid buffers inhibit the complexes in the coordination of the substrate. Further experiments in other buffer systems, which do not interact with the complexes, would be of interest to explore the activity of the complexes to cleave the $\mathrm{P}-\mathrm{O}$ bond of Paraoxon. 
In addition to $\mathrm{P}-\mathrm{O}$ bond cleavage, complexes 4,8 and 9 were investigated to cleave the $\mathrm{C}-\mathrm{N}$ bond of the $\beta$-lactam antibiotic Penicillin G. As 9 bears long side chains, this complex was expected to be the most active. It was thus surprising that none of these complexes showed any activity to cleave the $\beta$-lactam ring of Penicillin $\mathrm{G}$. The reason for this was investigated by binding studies of the $\beta$-lactam substrates Penicillin G, Ampicillin, 6-aminopenicillanic acid, Cephalotin and Sulbactam to 2 . It was demonstrated by ESI-MS, NMR and IR spectroscopy that all substrates coordinated to the zinc atoms of the complex in a $\mu_{1,3}$-binding fashion of the carboxylate group that is present in all substrates. In addition, X-ray analysis confirmed these studies as suitable single crystals were obtained in a reaction with the substrate Sulbactam (17). This complex is the first example of a $\beta$-lactam antibiotic drug, which coordinates to a complex, and is analysed by X-ray diffraction. The $\mu_{1,3}$-binding fashion of the carboxylate groups of the substrates thus explains the inactivity of the complexes to cleave Penicillin G.

To design complexes that might be active, the $\mathrm{Zn} \cdots \mathrm{Zn}$ separations can be increased, so that the zinc atoms cannot be bridged by the carboxylate moiety. This might result in a vacant position for the nucleophile and thus in the activity to cleave the substrates. Another possibility is to design ligands, which bear less donor functions. This would result in a complex that can even be active if the substrate coordinates to the zinc atoms as it was demonstrated. A further vacant position for the nucleophile would thus be available and might increase the activity of the complexes. 


\section{Experimental Part}

\subsection{General Considerations}

All manipulations have been carried out in air using p. A. quality solvents, if not otherwise noted. Moisture and air sensitive reactions have been performed under an anaerobic atmosphere of argon using standard Schlenk techniques. $\mathrm{Et}_{2} \mathrm{O}$ was dried over sodium and $\mathrm{MeCN}$ over calcium hydride.

${ }^{1} \mathrm{H}$ NMR, ${ }^{13} \mathrm{C}$ NMR and ${ }^{31} \mathrm{P}$ NMR spectra have been recorded on a Bruker Avance $200 \mathrm{MHz}, 300 \mathrm{MHz}$ or $500 \mathrm{MHz}$ spectrometer. ${ }^{1} \mathrm{H},{ }^{13} \mathrm{C}$ and ${ }^{31} \mathrm{P}$ chemical shifts are reported in ppm relative to residual solvent signals of $\mathrm{CDCl}_{3}(7.26 \mathrm{ppm}$ and $77.2 \mathrm{ppm})$, $d_{3}-\mathrm{MeCN}$ (1.94 ppm and $\left.118.3 \mathrm{ppm}\right), \mathrm{D}_{2} \mathrm{O}(4.79 \mathrm{ppm}), d_{4}-\mathrm{MeOD}$ (3.31 ppm and $49.0 \mathrm{ppm})$ or $d_{6}$-DMSO (2.50 ppm and $\left.39.5 \mathrm{ppm}\right)$. ESI-MS spectra were recorded on a Bruker HCT Ultra spectrometer. High resolution ESI-MS spectra and GC-MS analyses were performed by the service department 'Zentrale Analytik - Massenspektrometrie des Instituts für Organische und Biomolekulare Chemie der Universität Göttingen'. Melting points were determined using a SRS OptiMelt apparatus. Microanalysis were performed by the 'Analytisches Labor des Instituts für Anorganische Chemie der Universität Göttingen'. Infrared spectra ( $\mathrm{KBr}$ pellet) were recorded on a Digilab Excalibur spectrometer; in solution a FTIR Mettler-Toledo ReactIR iC10 spectrometer was used. UV-Vis spectra were determined using a Cary 300 Bio spectrometer equipped with a 12 position thermostated cell changer. Buffers were adjusted by a calibrated Metrohm 780 $\mathrm{pH}$ meter.

Compounds 3,5-bis(chloromethyl)-1H-pyrazole (I) ${ }^{[49]}$ bis-((1-methyl-1H-imidazol-2-yl)methyl)amine $\quad(\mathbf{I I}),{ }^{[50]} \quad 3,5$-bis[bis-((1-methyl-1H-imidazol-2-yl)-methyl)amine]-1Hpyrazole $\left(\mathbf{L}^{\mathbf{1}}\right)^{[43 \mathrm{~d}]}$ and $\left[\mathrm{Zn}_{2} \mathrm{H}_{-1} \mathrm{~L}^{1}(\mathrm{OAc})\right]\left(\mathrm{ClO}_{4}\right)_{2}(\mathbf{5 b})^{[57]}$ were synthesised according to published procedures. The syntheses of bis-((1-methyl-1H-benzimidazol-2-yl)methyl)amine $(\mathbf{V})^{[51]}$ and bis((1-methyl-1H-benzimidazol-2-yl)ethyl)amine (VII) ${ }^{[52]}$ were performed as described in literature and the workup has been optimised to obtain higher yields. All other chemicals were used as purchased. 


\subsection{Synthesis of Ligand Precursors and Ligands}

\section{Bis-((1-methyl-1H-benzimidazol-2-yl)methyl)amine (V)}

A suspension of iminodiacetic acid (IV) $(1.90 \mathrm{~g}, 14.3 \mathrm{mmol})$ and $N$-methyl- $o$ phenylenediamine dihydrochloride (III) $(5.64 \mathrm{~g}, 28.9 \mathrm{mmol})$ in aqueous $\mathrm{HCl}(6 \mathrm{M}$, $15 \mathrm{ml}$ ) was heated to reflux for $4 \mathrm{~d}$. After cooling, pure hydrochloric salt of $\mathbf{V}$ precipitated. This was collected by filtration. Acetone was added to the filtrate solution yielding more precipitate of the crude product. ${ }^{[51]}$ The combined solids have either been re-crystallised from $\mathrm{MeOH}$ yielding pure hydrochloric salt of $\mathbf{V}$ or the solids were solved in a minimum amount of warm water. Addition of aqueous ammonia solution afforded precipitation of the free base of $\mathbf{V}$, which was filtrated and dried in vacuum (1.88 $\mathrm{g}$, $6.2 \mathrm{mmol}, 43 \%)$.

${ }^{1} \mathrm{H}$ NMR $\left(300 \mathrm{MHz}, d_{4}-\mathrm{MeOD}\right): \delta=3.82(\mathrm{~s}, 6 \mathrm{H}, \mathrm{NMe}), 4.16\left(\mathrm{~s}, 4 \mathrm{H}, \mathrm{CH}_{2}\right), 7.20-7.30(\mathrm{~m}$, $\left.4 \mathrm{H}, \mathrm{CH}^{\text {BenzImid }}\right), 7.42-7.45\left(\mathrm{~m}, 2 \mathrm{H}, \mathrm{CH}^{\text {BenzImid }}\right), 7.57-7.60\left(\mathrm{~m}, 2 \mathrm{H}, \mathrm{CH}^{\text {BenzImid }}\right)$.

${ }^{13} \mathrm{C}$ NMR (75 MHz, $\left.d_{4}-\mathrm{MeOD}\right): \delta=30.3(\mathrm{NMe}), 45.8\left(\mathrm{CH}_{2}\right), 110.9\left(\mathrm{CH}^{\text {BenzImid }}\right), 119.3$ $\left(\mathrm{CH}^{\text {BenzImid }}\right), 123.4\left(\mathrm{CH}^{\text {BenzImid }}\right), 124.0\left(\mathrm{CH}^{\text {BenzImid }}\right), 137.2\left(\mathrm{C}_{\mathrm{q}}^{\text {BenzImid }}\right), 142.4\left(\mathrm{C}_{\mathrm{q}}^{\text {BenzImid }}\right)$, $154.0\left(\mathrm{C}_{\mathrm{q}}^{\text {BenzImid }}\right)$.

MS (ESI+): $m / z=306[\mathrm{M}+\mathrm{H}]^{+}, 328[\mathrm{M}+\mathrm{Na}]^{+}$.

\section{Bis((1-methyl-1H-benzimidazol-2-yl)ethyl)amine (VII)}

A suspension of 3,3'-iminodipropionitrile (VI) (3.06 g. $24.9 \mathrm{mmol})$ and $N$-methyl-ophenylenediamine dihydrochloride (III) $(9.70 \mathrm{~g}, 49.7 \mathrm{mmol})$ in aqueous $\mathrm{HCl}(3 \mathrm{M}$, $130 \mathrm{ml}$ ) was heated to reflux for $5 \mathrm{~d}$. After cooling to $0{ }^{\circ} \mathrm{C}$, the formed precipitate was collected by filtration yielding pure hydrochloric salt of VII $(2.71 \mathrm{~g}, 6.1 \mathrm{mmol}, 25 \%)$. To obtain higher yields, ammonia solution was added to the filtrate, whereby the free base of VII precipitated. ${ }^{[52]}$ After filtration, acetone was added to the filtrated solution yielding additional crude product. The combined solids were re-crystallised in EtOH/ $\mathrm{H}_{2} \mathrm{O}$ $(1: 1, \mathrm{v} / \mathrm{v})$ to obtain VII as colourless solid $(2.69 \mathrm{~g}, 8.1 \mathrm{mmol}, 33 \%)$. Overall yield of the reaction resulting from the hydrochloric salt and the free base of VIII was $58 \%$.

${ }^{1} \mathrm{H}$ NMR (300 MHz, $\left.\mathrm{D}_{2} \mathrm{O}\right): \delta=3.81\left(\mathrm{~s}, 8 \mathrm{H}, \mathrm{CH}_{2}\right), 4.07(\mathrm{~s}, 6 \mathrm{H}, \mathrm{NMe}), 7.61-7.70(\mathrm{~m}, 4 \mathrm{H}$, $\left.\mathrm{CH}^{\text {BenzImid }}\right), 7.76-7.85\left(\mathrm{~m}, 4 \mathrm{H}, \mathrm{CH}^{\text {BenzImid }}\right)$. 
${ }^{13} \mathrm{C}$ NMR $\left(75 \mathrm{MHz}, \mathrm{D}_{2} \mathrm{O}\right): \delta=22.4\left(\mathrm{CH}_{2}\right), 31.2(\mathrm{NMe}), 44.0\left(\mathrm{CH}_{2}\right), 112.5\left(\mathrm{CH}^{\text {BenzImid }}\right)$, $113.9\left(\mathrm{CH}^{\text {BenzImid }}\right), 126.4\left(\mathrm{CH}^{\text {BenzImid }}\right), 126.9\left(\mathrm{CH}^{\text {BenzImid }}\right), 129.8\left(\mathrm{C}_{\mathrm{q}}^{\text {BenzImid }}\right), 132.5$ $\left(\mathrm{C}_{\mathrm{q}}^{\text {BenzImid }}\right), 147.7\left(\mathrm{C}_{\mathrm{q}}^{\text {BenzImid }}\right)$.

MS (ESI+): $m / z=334[\mathrm{M}+\mathrm{H}]^{+}, 356[\mathrm{M}+\mathrm{Na}]^{+}$.

\section{Ethyl 2-(((1-methyl-1H-imidazol-2-yl)methyl)amino)acetate (X)}

$N$-methylimidazole (VIII) $(7.25 \mathrm{~g}, 88.2 \mathrm{mmol})$ was dissolved in $80 \mathrm{ml}$ THF under inert conditions and cooled to $-50{ }^{\circ} \mathrm{C}$ (EtOH/dry ice). $n$-BuLi $(35.3 \mathrm{ml}, 2.5 \mathrm{M}$ solution in $n$-hexane, $88.2 \mathrm{mmol}$ ) was added dropwise and the resulting pale yellow solution was stirred for $1 \mathrm{~h}$. Then, DMF $(6.85 \mathrm{ml}, 89.0 \mathrm{mmol})$ was added and the resulting colourless suspension was stirred for $16 \mathrm{~h}$ while warming to $\mathrm{rt}$. The mixture was quenched by addition of water $(15 \mathrm{ml})$, the phases were separated and the aqueous phase was extracted with $\mathrm{CHCl}_{3}(6 \times 20 \mathrm{ml})$. The organic layers were combined and dried over $\mathrm{Na}_{2} \mathrm{SO}_{4}$. After evaporation of the solvent the raw material of 1-methyl- $1 H$-imidazole-2-carbaldehyde (IX) was obtained as a sticky and oily residue $(7.30 \mathrm{~g}, 66.3 \mathrm{mmol}, 75 \%)$ and used without further purification in the next step.

Under inert atmosphere, (IX) $(0.50 \mathrm{~g}, 4.5 \mathrm{mmol})$ and glycine ethyl ester hydrochloride $(0.64 \mathrm{~g}, 4.5 \mathrm{mmol})$ were suspended in 1,2-dichloroethane $(15 \mathrm{ml})$ and stirred for $3 \mathrm{~h}$ at $\mathrm{rt}$. Then, $\mathrm{NaBH}(\mathrm{OAc})_{3}(1.35 \mathrm{~g}, 6.4 \mathrm{mmol})$ was added in small portions and the mixture was stirred for $16 \mathrm{~h}$ at $\mathrm{rt}$. After adding saturated $\mathrm{Na}_{2} \mathrm{CO}_{3}$ solution $(20 \mathrm{ml})$, the phases were separated and the aqueous layer was extracted 7 times with methylenchloride $(10 \mathrm{ml}$ each). The combined organic phases were dried over $\mathrm{Na}_{2} \mathrm{SO}_{4}$ and the solvent was evaporated. $\mathrm{HCl}$ in ethanol $(6.4 \mathrm{M}, 7 \mathrm{ml})$ was added to the oily residue and stirred until a colourless precipitate was formed. The mixture was put into the fridge for complete precipitation of the raw material. The solid was filtered and re-crystallised in ethanol to afford colourless solid (0.62 g, $2.6 \mathrm{mmol}, 58 \%)$.

mp (uncorrected) $198^{\circ} \mathrm{C}$.

${ }^{1} \mathrm{H}$ NMR (300 MHz, $d_{6}$-DMSO): $\delta=1.23\left(\mathrm{t}, 3 \mathrm{H},{ }^{3} J_{\mathrm{H}, \mathrm{H}}=7.2 \mathrm{~Hz}, \mathrm{Me}\right), 3.96(\mathrm{~s}, 3 \mathrm{H}, \mathrm{NMe})$, $4.13\left(\mathrm{~s}, 2 \mathrm{H}, \mathrm{CH}_{2}\right), 4.19$ (q, $\left.2 \mathrm{H},{ }^{3} \mathrm{~J}_{\mathrm{H}, \mathrm{H}}=7.2 \mathrm{~Hz}, \mathbf{C H}_{2} \mathrm{CH}_{3}\right), 4.60$ (s, 2H, $\left.\mathrm{CH}_{2}\right), 7.74(\mathrm{~d}, 1 \mathrm{H}$, $\left.{ }^{3} J_{\mathrm{H}, \mathrm{H}}=1.8 \mathrm{~Hz}, \mathrm{CH}^{\text {Imid }}\right), 7.79\left(\mathrm{~d}, 1 \mathrm{H},{ }^{3} J_{\mathrm{H}, \mathrm{H}}=1.8 \mathrm{~Hz}, \mathrm{CH}^{\text {Imid }}\right)$.

${ }^{13} \mathrm{C} \mathrm{NMR}\left(75 \mathrm{MHz}, d_{6}\right.$-DMSO): $\delta=13.9(\mathrm{Me}), 35.0(\mathrm{NMe}), 38.0\left(\mathrm{CH}_{2}\right), 46.8\left(\mathrm{CH}_{2}\right), 61.7$ $\left(\mathbf{C H}_{2} \mathrm{CH}_{3}\right), 119.6\left(\mathrm{CH}^{\mathrm{Imid}}\right), 124.6\left(\mathrm{CH}^{\mathrm{Imid}}\right), 138.1\left(\mathrm{C}_{\mathrm{q}}^{\mathrm{Imid}}\right), 166.5(\mathrm{COO})$. 
MS (ESI+): $m / z=198[\mathrm{M}+\mathrm{H}]^{+}, 220[\mathrm{M}+\mathrm{Na}]^{+}$.

IR (KBr): $\tilde{v}\left(\mathrm{~cm}^{-1}\right)=3146$ (s), 2974 (s), 2701 (s), 2587 (s), 2390 (s), 1738 (vs), 1600 (m), 1528 (m), 1460 (m), 1427 (s), 1409 (s), 1337 (s), 1240 (vs), 1107 (w), 1087 (w), 1068 (m), 1020 (m), 877 (w), 860 (w), 774 (m), 762 (m), $718(w), 676(w), 497(w)$.

Elemental analysis: Calcd. (\%) for $\mathrm{C}_{9} \mathrm{H}_{17} \mathrm{Cl}_{2} \mathrm{~N}_{3} \mathrm{O}_{2}\left(\mathrm{C}_{9} \mathrm{H}_{15} \mathrm{~N}_{3} \mathrm{O}_{2} \cdot 2 \mathrm{HCl}\right): \mathrm{C} 40.01, \mathrm{H} 6.34$, N 15.55. Found: C 39.12, H 6.41, N 15.68.

\section{3,5-Bis[bis-((1-methyl-1H-benzimidazol-2-yl)methyl)amine]-1H-pyrazole $\left(\mathrm{L}^{2}\right)$}

A suspension of $\mathbf{V}(2.07 \mathrm{~g}, 5.0 \mathrm{mmol}), \mathbf{I}(0.50 \mathrm{~g}, 2.5 \mathrm{mmol})$ and dried $\mathrm{Na}_{2} \mathrm{CO}_{3}(2.70 \mathrm{~g}$, $24.8 \mathrm{mmol})$ was stirred in $\mathrm{CHCl}_{3}(50 \mathrm{ml})$ for $3 \mathrm{~d}$ and the reaction was followed by ${ }^{1} \mathrm{H}$ NMR spectroscopy. After filtration, the solvent was evaporated to dryness to afford crude product. The beige solid was suspended in methanol and filtrated to obtain colourless solid (0.79 g, $1.1 \mathrm{mmol}, 45 \%)$.

mp (uncorrected) $215^{\circ} \mathrm{C}$.

${ }^{1} \mathrm{H}$ NMR $\left(300 \mathrm{MHz}, \mathrm{CDCl}_{3}\right): \delta=3.68(\mathrm{~s}, 12 \mathrm{H}, \mathrm{NMe}), 3.85\left(\mathrm{~s}, 4 \mathrm{H}, \mathrm{CH}_{2}\right), 4.06(\mathrm{~s}, 8 \mathrm{H}$, $\left.\mathrm{CH}_{2}\right), 6.31$ (s, $\left.1 \mathrm{H}, \mathrm{CH}^{\mathrm{Pz}}\right), 7.21-7.30\left(\mathrm{~m}, 12 \mathrm{H}, \mathrm{CH}^{\text {BenzImid }}\right), 7.74-7.75\left(\mathrm{~m}, 4 \mathrm{H}, \mathrm{CH}^{\text {BenzImid }}\right)$.

${ }^{13} \mathrm{C}$ NMR (75 MHz, $\left.\mathrm{CDCl}_{3}\right): \delta=30.1(\mathrm{NMe}), 50.5\left(\mathrm{CH}_{2}\right), 107.0\left(\mathrm{CH}^{\mathrm{Pz}}\right), 109.5$ $\left(\mathrm{CH}^{\text {BenzImid }}\right), 119.2\left(\mathrm{CH}^{\text {BenzImid }}\right), 122.6\left(\mathrm{CH}^{\text {BenzImid }}\right), 123.2\left(\mathrm{CH}^{\text {BenzImid }}\right), 135.8\left(\mathrm{C}_{\mathrm{q}}^{\text {BenzImid }}\right)$, 141.1 $\left(\mathrm{C}_{\mathrm{q}}{ }^{\text {Pz }}\right), 151.2\left(\mathrm{C}_{\mathrm{q}}^{\text {BenzImid }}-\mathrm{CH}_{2}\right)$.

MS (ESI+): $m / z=703[\mathrm{M}+\mathrm{H}]^{+}$.

IR (KBr): $\tilde{v}\left(\mathrm{~cm}^{-1}\right)=3054(\mathrm{w}), 2928(\mathrm{w}), 1615(\mathrm{w}), 1512$ (m), 1473 (vs), 1443 (s), 1403 (s), 1332 (s), 1284 (m), 1240 (m), 1104 (s), 995 (m), 854 (m), 745 (vs).

Elemental analysis: Calcd. (\%) for $\mathrm{C}_{41} \mathrm{H}_{43} \mathrm{ClN}_{12}\left(\mathrm{C}_{41} \mathrm{H}_{42} \mathrm{~N}_{12} \cdot \mathrm{HCl}\right)$ : C 66.61, H 5.86, N 22.73. Found: C 66.16, H 6.08, N 22.75.

\section{3,5-Bis[bis((1-methyl-1H-benzimidazol-2-yl)ethyl)amine]-1H-pyrazole $\left(\mathrm{L}^{3}\right)$}

A suspension of VII $(1.85 \mathrm{~g}, 7.9 \mathrm{mmol}), \mathbf{I}(0.80 \mathrm{~g}, 4.0 \mathrm{mmol})$ and dried $\mathrm{Na}_{2} \mathrm{CO}_{3}(2.30 \mathrm{~g}$, $21.7 \mathrm{mmol})$ was stirred in $\mathrm{CHCl}_{3}(50 \mathrm{ml})$ and the reaction monitored by ${ }^{1} \mathrm{H} \mathrm{NMR}$ spectroscopy. After 7 days the mixture was filtrated and the solvent was evaporated. The fluffy residue was redissolved in $\mathrm{CHCl}_{3}$. Adding $\mathrm{Et}_{2} \mathrm{O}$ and leaving the mixture in the fridge over night afforded $\mathbf{L}^{3}$ as beige solid (0.63 g, $0.8 \mathrm{mmol}, 21 \%$ ). 
${ }^{1} \mathrm{H}$ NMR $\left(300 \mathrm{MHz}, d_{3}-\mathrm{MeCN}\right): \delta=2.82-2.86\left(\mathrm{~m}, 8 \mathrm{H}, \mathrm{CH}_{2}\right), 3.01-3.06\left(\mathrm{~m}, 8 \mathrm{H}, \mathrm{CH}_{2}\right)$, $3.28(\mathrm{~s}, 12 \mathrm{H}, \mathrm{NMe}), 3.84\left(\mathrm{~s}, 4 \mathrm{H}, \mathrm{CH}_{2}\right), 5.96\left(\mathrm{~s}, 1 \mathrm{H}, \mathrm{CH}^{\mathrm{Pz}}\right), 6.82\left(\mathrm{~d}, 4 \mathrm{H},{ }^{3} J_{\mathrm{H}, \mathrm{H}}=8.1 \mathrm{~Hz}\right.$, $\left.\mathrm{CH}^{\text {BenzImid }}\right), 7.01-7.18\left(\mathrm{~m}, 8 \mathrm{H}, \mathrm{CH}^{\text {BenzImid }}\right), 7.65\left(\mathrm{~d}, 4 \mathrm{H},{ }^{3} J_{\mathrm{H}, \mathrm{H}}=8.1 \mathrm{~Hz}, \mathrm{CH}^{\text {BenzImid }}\right)$.

${ }^{13} \mathrm{C}$ NMR $\left(75 \mathrm{MHz}, d_{3}-\mathrm{MeCN}\right): \delta=26.4\left(\mathrm{CH}_{2}\right), 30.2(\mathrm{NMe}), 52.6\left(\mathrm{CH}_{2}\right), 110.4$ $\left(\mathrm{CH}^{\text {BenzImid }}\right), 119.0\left(\mathrm{CH}^{\text {BenzImid }}\right), 122.2\left(\mathrm{CH}^{\text {BenzImid }}\right), 122.5\left(\mathrm{CH}^{\text {BenzImid }}\right)$.

$\mathrm{MS}(\mathrm{ESI}+): m / z=760[\mathrm{M}+\mathrm{H}]^{+}, 781[\mathrm{M}+\mathrm{Na}]^{+}$.

IR (KBr): $\tilde{v}\left(\mathrm{~cm}^{-1}\right)=2929$ (s), 2845 (s), 1617 (m), 1508 (s), 1466 (vs), 1443 (vs), 1401 (s), 1327 (m), 1281 (m), 1238 (m), 1123 (m), 1008 (m), 744 (vs), 572 (w).

\section{3,5-Bis $[N-(($ ethoxycarbonyl)methyl)- $N$-((1-methyl-1H-imidazol-2-yl)methyl)amino- methyl]-1H-pyrazole (precursor- $\mathrm{L}^{4}$ )}

A colourless suspension of $\mathbf{X}(0.67 \mathrm{~g}, 2.9 \mathrm{mmol}), \mathbf{I}(0.25 \mathrm{~g}, 1.2 \mathrm{mmol})$ and dried $\mathrm{Na}_{2} \mathrm{CO}_{3}$ $(1.40 \mathrm{~g}, 12.5 \mathrm{mmol})$ in ethyl acetate $(40 \mathrm{ml})$ was stirred for $6 \mathrm{~d}$ (monitored by ${ }^{1} \mathrm{H} \mathrm{NMR}$ spectroscopy). The mixture was filtrated over celite and the filter cake washed intensively with ethyl acetate. The filtrate was dried over $\mathrm{Na}_{2} \mathrm{SO}_{4}$ and the solvent evaporated. Precursor- $\mathbf{L}^{4}$ was obtained as colourless and sticky oil and used without further purification $(0.45 \mathrm{~g}, 0.9 \mathrm{mmol}, 74 \%)$.

${ }^{1} \mathrm{H}$ NMR (300 MHz, $d_{6}$-DMSO): $\delta=1.17\left(\mathrm{t}, 6 \mathrm{H},{ }^{3} J_{\mathrm{H}, \mathrm{H}}=7.2 \mathrm{~Hz}, \mathrm{Me}\right), 3.23\left(\mathrm{~s}, 4 \mathrm{H}, \mathrm{CH}_{2}\right)$, 3.61 (s, 6H, NMe), 3.70 (s, 4H, $\mathrm{CH}_{2}$ ), $3.76\left(\mathrm{~s}, 4 \mathrm{H}, \mathrm{CH}_{2}\right), 4.05$ (q, 4H, ${ }^{3} J_{\mathrm{H}, \mathrm{H}}=7.2 \mathrm{~Hz}$, $\left.\mathbf{C H}_{2} \mathrm{CH}_{3}\right), 6.09\left(\mathrm{~s}, 1 \mathrm{H}, \mathrm{CH}^{\mathrm{Pz}}\right), 6.76\left(\mathrm{~s}, 2 \mathrm{H}, \mathrm{CH}^{\mathrm{Imid}}\right), 7.08\left(\mathrm{~s}, 2 \mathrm{H}, \mathrm{CH}^{\text {Imid }}\right)$.

${ }^{13} \mathrm{C}$ NMR $\left(75 \mathrm{MHz}, d_{6}\right.$-DMSO): $\delta=14.0(\mathrm{Me}), 32.3(\mathrm{NMe}), 49.1\left(\mathrm{CH}_{2}\right), 53.0\left(\mathrm{CH}_{2}\right), 59.8$ $\left(\mathbf{C H}_{2} \mathrm{CH}_{3}\right), 104.9\left(\mathrm{CH}^{\mathrm{Pz}}\right), 122.1\left(\mathrm{CH}^{\text {Imid }}\right), 126.2\left(\mathrm{CH}^{\text {Imid }}\right), 144.4\left(\mathrm{C}_{\mathrm{q}}^{\text {Imid }}\right), 170.3(\mathrm{COO})$.

MS (ESI+): $m / z=487[\mathrm{M}+\mathrm{H}]^{+}, 509[\mathrm{M}+\mathrm{Na}]^{+}$.

MS (ESI-): $m / z=485[\mathrm{M}-\mathrm{H}]^{-}$.

IR (KBr): $\tilde{v}\left(\mathrm{~cm}^{-1}\right)=3191$ (s), 3124 (s), 2982 (s), 2931 (s), 2855 (s), 1737 (vs), 1656 (w), 1501 (m), 1453 (m), 1416 (m), 1373 (m), 1283 (m), 1194 (vs), 1154 (s), 1115 (m), $1026(\mathrm{~m}), 970(\mathrm{w}), 848(\mathrm{w}), 804(\mathrm{w}), 749(\mathrm{w}), 705(\mathrm{w}), 666(\mathrm{w})$. 


\subsection{Synthesis of Complexes}

\section{Synthesis of $\left[\mathrm{ZnH}_{2} \mathrm{~L}^{1}\right]\left(\mathrm{ClO}_{4}\right)_{4}(1)$}

$\mathbf{L}^{\mathbf{1}}$ (502 $\left.\mathrm{mg}, 1.00 \mathrm{mmol}\right)$ was suspended in $\mathrm{MeOH}(50 \mathrm{ml})$ at $33^{\circ} \mathrm{C}$ and $\mathrm{LiOH}(24 \mathrm{mg}$, $1.00 \mathrm{mmol})$ was added. After 30 minutes, $\mathrm{Zn}\left(\mathrm{ClO}_{4}\right)_{2} \cdot 6 \mathrm{H}_{2} \mathrm{O}(750 \mathrm{mg}, 2.01 \mathrm{mmol})$ in $\mathrm{MeOH}$ (40 ml) was added dropwise, whereby a colourless precipitate was formed. The suspension was filtrated and the solution was evaporated to dryness. The colourless residue was redissolved in $\mathrm{MeCN}$ (30 ml). After filtration, slow diffusion of $\mathrm{Et}_{2} \mathrm{O}$ into the complex solution did not result in crystals. Thus, the solvent was evaporated and the colourless solid (177 mg, $0.17 \mathrm{mmol})$ was suspended with KOAc (17 mg, $0.17 \mathrm{mmol})$ in $\mathrm{MeCN}(10 \mathrm{ml})$ and stirred for $4 \mathrm{~h}$. The suspension was filtrated and $\mathrm{Et}_{2} \mathrm{O}$ diffusion into the solution afforded colourless single crystals (26 mg, $25 \mu \mathrm{mol}, 3 \%)$.

${ }^{1} \mathrm{H}$ NMR (500 MHz, $d_{3}-\mathrm{MeCN}, 273 \mathrm{~K}$ ): $\delta=3.60$ (s, 6H, NMe), 3.73 (s, 6H, NMe), 4.01 (s, 2H, $\left.\mathrm{CH}_{2}\right), 4.10\left(\mathrm{~s}, 2 \mathrm{H}, \mathrm{CH}_{2}\right), 4.11-4.13\left(\mathrm{~m}, 8 \mathrm{H}, \mathrm{CH}_{2}\right), 6.47$ (s, 1H, $\mathrm{CH}^{\mathrm{Pz}}$ ), 7.14 (bs, 2H, $\left.\mathrm{CH}^{\text {Imid }}\right), 7.20\left(\mathrm{~s}, 2 \mathrm{H}, \mathrm{CH}^{\text {Imid }}\right), 7.24-7.25\left(\mathrm{~m}, 2 \mathrm{H}, \mathrm{CH}^{\text {Imid }}\right), 7.27$ (bs, 2H, $\left.\mathrm{CH}^{\text {Imid }}\right), 11.8$ (bs, 2H, NH $\left.{ }^{\mathrm{Imid}}\right), 12.0\left(\mathrm{bs}, 1 \mathrm{H}, \mathrm{NH}^{\mathrm{Pz}}\right.$ ).

${ }^{1} \mathrm{H}$ NMR (500 MHz, $d_{3}-\mathrm{MeCN}, 233 \mathrm{~K}$ ): $\delta=3.55$ (s, 6H, NMe), 3.66 (s, 6H, NMe), 3.94 (bs, 2H, $\mathrm{CH}_{2}$ ), 4.01 (bs, 4H, $\mathrm{CH}_{2}$ ), 4.06 (bs, 2H, $\mathrm{CH}_{2}$ ), 4.07 (bs, 2H, $\mathrm{CH}_{2}$ ), 4.08 (bs, 2H, $\left.\mathrm{CH}_{2}\right), 6.44\left(\mathrm{bs}, 1 \mathrm{H}, \mathrm{CH}^{\mathrm{Pz}}\right), 7.13\left(\mathrm{~d}, 2 \mathrm{H},{ }^{3} \mathrm{~J}_{\mathrm{H}, \mathrm{H}}=1.5 \mathrm{~Hz}, \mathrm{CH}^{\mathrm{Imid}}\right), 7.20\left(\mathrm{~d}, 2 \mathrm{H},{ }^{3} J_{\mathrm{H}, \mathrm{H}}=\right.$ $1.5 \mathrm{~Hz}, \mathrm{CH}^{\mathrm{Imid}}$ ), 7.22-7.23 (m, 2H, $\left.\mathrm{CH}^{\mathrm{Imid}}\right), 7.27-7.28$ (m, 2H, $\left.\mathrm{CH}^{\mathrm{Imid}}\right), 12.0$ (bs, 2H, $\left.\mathrm{NH}^{\text {Imid }}\right), 12.1$ (bs, $1 \mathrm{H}, \mathrm{NH}^{\mathrm{Pz}}$ ).

${ }^{13} \mathrm{C}$ NMR $\left(75 \mathrm{MHz}, d_{3}-\mathrm{MeCN}, 273 \mathrm{~K}\right): \delta=33.7(\mathrm{NMe}), 35.5(\mathrm{NMe}), 49.3\left(\mathrm{CH}_{2}\right), 50.0$ $\left(\mathrm{CH}_{2}\right), 51.9\left(\mathrm{CH}_{2}\right), 53.4\left(\mathrm{CH}_{2}\right), 106.5\left(\mathrm{CH}^{\mathrm{Pz}}\right), 119.8\left(\mathrm{CH}^{\mathrm{Imid}}\right), 125.3\left(\mathrm{CH}^{\mathrm{Imid}}\right), 144.2$ $\left(\mathrm{C}_{\mathrm{q}}^{\text {Imid }}\right), 148.4\left(\mathrm{C}_{\mathrm{q}}^{\text {Imid }}\right), 152.9\left(\mathrm{C}_{\mathrm{q}}{ }^{\mathrm{Pz}}\right)$.

MS (ESI+): $m / z=665\left[\mathrm{ZnL}^{1}\left(\mathrm{ClO}_{4}\right)\right]^{+}, 601\left[\mathrm{ZnL}^{1}\left(\mathrm{H}_{3} \mathrm{O}_{2}\right)\right]^{+}, 283\left[\mathrm{ZnL}^{1}\right]^{2+}$.

IR (KBr): $\tilde{v}\left(\mathrm{~cm}^{-1}\right)=3362(\mathrm{~m}), 3163(\mathrm{~m}), 2307(\mathrm{w}), 2280(\mathrm{w}), 2019(\mathrm{w}), 1608(\mathrm{~m})$, 1538 (m), 1510 (m), 1450 (m), 1364 (m), 1285 (m), 1095 (vs), 957 (m), 930 (m), 880 (w), $833(\mathrm{w}), 757(\mathrm{~s}), 676(\mathrm{w}), 657(\mathrm{w}), 624(\mathrm{vs})$. 


\section{Synthesis of $\left[\mathrm{Zn}_{2} \mathrm{H}_{-1} \mathrm{~L}^{1}(\mathrm{MeCN})_{2}\right]\left(\mathrm{ClO}_{4}\right)_{3}(2)$}

To a suspension of $\mathbf{L}^{\mathbf{1}}$ (200 mg, $0.40 \mathrm{mmol}$ ) in $\mathrm{MeOH}$ (20 ml) was added $\mathrm{LiOH}$ (10 mg, $0.42 \mathrm{mmol})$ and the mixture was stirred at $33{ }^{\circ} \mathrm{C}$ until the solution became clear $(\sim 2 \mathrm{~h})$. $\mathrm{Zn}\left(\mathrm{ClO}_{4}\right)_{2} \cdot 6 \mathrm{H}_{2} \mathrm{O}(298 \mathrm{mg}, 0.80 \mathrm{mmol})$ was dissolved in $\mathrm{MeOH}(20 \mathrm{ml})$ and added dropwise to the ligand solution via a filter-pipette, whereby a colourless precipitate was formed. The mixture was stirred for $2 \mathrm{~h}$. After filtration, the solvent was evaporated and the residue dissolved in $\mathrm{MeCN}(8 \mathrm{ml})$. Slow diffusion of $\mathrm{Et}_{2} \mathrm{O}$ into the complex solution at rt afforded colourless crystals suitable for X-ray analysis (274 mg, $0.27 \mathrm{mmol}, 68 \%$ ). $\mathrm{mp}$ (uncorrected) $240{ }^{\circ} \mathrm{C}$ (decomposition).

${ }^{1} \mathrm{H}$ NMR $\left(400 \mathrm{MHz}, d_{3}-\mathrm{MeCN}\right): \delta=1.95$ (s, 6H, MeCN), 3.59 (s, 12H, NMe), 4.05 (s, $\left.8 \mathrm{H}, \mathrm{CH}_{2}\right), 4.06\left(\mathrm{~s}, 4 \mathrm{H}, \mathrm{CH}_{2}\right), 6.06\left(\mathrm{~s}, 1 \mathrm{H}, \mathrm{CH}^{\mathrm{Pz}}\right), 7.10\left(\mathrm{~d}, 4 \mathrm{H},{ }^{3} J_{\mathrm{H}, \mathrm{H}}=1.6 \mathrm{~Hz}, \mathrm{CH}^{\text {Imid }}\right), 7.18$ $\left(\mathrm{d}, 4 \mathrm{H},{ }^{3} J_{\mathrm{H}, \mathrm{H}}=1.6 \mathrm{~Hz}, \mathrm{CH}^{\mathrm{Imid}}\right)$.

${ }^{13} \mathrm{C} \mathrm{NMR}\left(100 \mathrm{MHz}, d_{3}-\mathrm{MeCN}\right): \delta=33.7(\mathrm{NMe}), 51.0\left(\mathrm{CH}_{2}\right), 53.2\left(\mathrm{CH}_{2}\right), 100.9\left(\mathrm{CH}^{\mathrm{Pz}}\right)$, $125.3\left(\mathrm{CH}^{\text {Imid }}\right), 148.6\left(\mathrm{C}_{\mathrm{q}}{ }^{\text {Imid }}\right), 154.1\left(\mathrm{C}_{\mathrm{q}}{ }^{\mathrm{Pz}}\right)$.

MS (ESI+): $m / z=827 \quad\left[\mathrm{Zn}_{2} \mathrm{H}_{-1} \mathrm{~L}^{1}\left(\mathrm{ClO}_{4}\right)_{2}\right]^{+}, \quad 763 \quad\left[\mathrm{Zn}_{2} \mathrm{H}_{-1} \mathrm{~L}^{1}\left(\mathrm{H}_{3} \mathrm{O}_{2}\right)\left(\mathrm{ClO}_{4}\right)\right]^{+}, \quad 364$ $\left[\mathrm{Zn}_{2} \mathrm{H}_{-1} \mathrm{~L}^{1}\left(\mathrm{ClO}_{4}\right)\right]^{2+}, 332\left[\mathrm{Zn}_{2} \mathrm{H}_{-1} \mathrm{~L}^{1}\left(\mathrm{H}_{3} \mathrm{O}_{2}\right)\right]^{2+}$.

IR (KBr): $\tilde{v}\left(\mathrm{~cm}^{-1}\right)=3144(\mathrm{w}), 2915(\mathrm{w}), 2020(\mathrm{w}), 1635(\mathrm{~m}), 1546(\mathrm{~m}), 1509$ (s), 1447 (m), 1362 (m), 1281 (m), 1108 (vs), 960 (m), 876 (m), 751 (m), 656 (w), 626 (s).

Elemental analysis: Due to co-crystallisation of $\mathrm{KClO}_{4}$ values are given for $\mathrm{C}_{29} \mathrm{H}_{39} \mathrm{Cl}_{3} \mathrm{~N}_{14} \mathrm{O}_{12} \mathrm{Zn}_{2} \cdot \mathrm{KClO}_{4}$. Calcd. (\%) for $\mathrm{C}_{29} \mathrm{H}_{39} \mathrm{Cl}_{4} \mathrm{KN}_{14} \mathrm{O}_{16} \mathrm{Zn}_{2}$ : C 30.25, H 3.41, N 17.03. Found: C 30.70, H 3.52, N 17.19.

\section{Synthesis of $\left[\mathrm{Zn}_{2} \mathrm{H}_{-1} \mathrm{~L}^{1}\right]\left(\mathrm{SO}_{3} \mathrm{CF}_{3}\right)_{3}(3)$}

To a solution of $\mathbf{L}^{1}$ (300 mg, $\left.0.60 \mathrm{mmol}\right)$ in $\mathrm{MeCN}$ (25 ml) was added $\mathrm{KO}^{t} \mathrm{Bu}(67 \mathrm{mg}$, $0.60 \mathrm{mmol})$ and the mixture was stirred for $1 \mathrm{~h}$. Subsequently, $\mathrm{Zn}\left(\mathrm{SO}_{3} \mathrm{CF}_{3}\right)_{2}(434 \mathrm{mg}$, $1.2 \mathrm{mmol})$ dissolved in $\mathrm{MeCN}(10 \mathrm{ml})$ was added dropwise to the ligand solution. After stirring for $2 \mathrm{~h}$, the solvent was evaporated to dryness. The colourless residue was redissolved in $\mathrm{MeCN}$ (12 ml). Slow diffusion of $\mathrm{Et}_{2} \mathrm{O}$ into the filtrated complex solution afforded colourless single crystals that were suitable for X-ray analysis (445 mg, $0.44 \mathrm{mmol}, 64 \%)$.

${ }^{1} \mathrm{H}$ NMR (300 MHz, $\left.d_{3}-\mathrm{MeCN}\right): \delta=3.57(\mathrm{~s}, 12 \mathrm{H}, \mathrm{NMe}), 4.07-4.11\left(\mathrm{~m}, 12 \mathrm{H}, \mathrm{CH}_{2}\right), 6.17$ $\left(\mathrm{s}, 1 \mathrm{H}, \mathrm{CH}^{\mathrm{Pz}}\right), 7.05\left(\mathrm{bs}, 4 \mathrm{H}, \mathrm{CH}^{\mathrm{Imid}}\right), 7.16$ (bs, 4H, $\mathrm{CH}^{\text {Imid }}$ ). 
${ }^{13} \mathrm{C}$ NMR $\left(75 \mathrm{MHz}, d_{3}-\mathrm{MeCN}\right): \delta=33.6(\mathrm{NMe}), 51.6\left(\mathrm{CH}_{2}\right), 53.8\left(\mathrm{CH}_{2}\right), 102.4\left(\mathrm{CH}^{\mathrm{Pz}}\right)$, $125.2\left(\mathrm{CH}^{\text {Imid }}\right), 125.4\left(\mathrm{CH}^{\text {Imid }}\right), 148.6\left(\mathrm{C}_{\mathrm{q}}^{\text {Imid }}\right), 153.6\left(\mathrm{C}_{\mathrm{q}}{ }^{\mathrm{Pz}}\right)$.

MS (ESI+, MeCN): $m / z=927\left[\mathrm{Zn}_{2} \mathrm{H}_{-1} \mathrm{~L}^{1}\left(\mathrm{SO}_{3} \mathrm{CF}_{3}\right)_{2}\right]^{+}, 813\left[\mathrm{Zn}_{2} \mathrm{H}_{-1} \mathrm{~L}^{1}\left(\mathrm{H}_{3} \mathrm{O}_{2}\right)\left(\mathrm{SO}_{3} \mathrm{CF}_{3}\right)\right]^{+}$, $389\left[\mathrm{Zn}_{2} \mathrm{H}_{-1} \mathrm{~L}^{1}\left(\mathrm{SO}_{3} \mathrm{CF}_{3}\right)\right]^{2+}, 332\left[\mathrm{Zn}_{2} \mathrm{H}_{-1} \mathrm{~L}^{1}\left(\mathrm{H}_{3} \mathrm{O}_{2}\right)\right]^{2+}$.

MS (ESI+, $\left.\mathrm{H}_{2} \mathrm{O}\right): m / z=927\left[\mathrm{Zn}_{2} \mathrm{H}_{-1} \mathrm{~L}^{1}\left(\mathrm{SO}_{3} \mathrm{CF}_{3}\right)_{2}\right]^{+}, 795\left[\mathrm{Zn}_{2} \mathrm{H}_{-1} \mathrm{~L}^{1}(\mathrm{OH})\left(\mathrm{SO}_{3} \mathrm{CF}_{3}\right)\right]^{+}, 389$ $\left[\mathrm{Zn}_{2} \mathrm{H}_{-1} \mathrm{~L}^{1}\left(\mathrm{SO}_{3} \mathrm{CF}_{3}\right)\right]^{2+}, 323\left[\mathrm{Zn}_{2} \mathrm{H}_{-1} \mathrm{~L}^{1}(\mathrm{OH})\right]^{2+}$.

MS (ESI+, $\left.\mathrm{H}_{2} \mathrm{O} / \mathrm{MeOH}(1: 1 / \mathrm{v}, \mathrm{v})\right): m / z=927 \quad\left[\mathrm{Zn}_{2} \mathrm{H}_{-1} \mathrm{~L}^{1}\left(\mathrm{SO}_{3} \mathrm{CF}_{3}\right)_{2}\right]^{+}, \quad 813$ $\left[\mathrm{Zn}_{2} \mathrm{H}_{-1} \mathrm{~L}^{1}\left(\mathrm{H}_{3} \mathrm{O}_{2}\right)\left(\mathrm{SO}_{3} \mathrm{CF}_{3}\right)\right]^{+}, 389\left[\mathrm{Zn}_{2} \mathrm{H}_{-1} \mathrm{~L}^{1}\left(\mathrm{SO}_{3} \mathrm{CF}_{3}\right)\right]^{2+}, 332\left[\mathrm{Zn}_{2} \mathrm{H}_{-1} \mathrm{~L}^{1}\left(\mathrm{H}_{3} \mathrm{O}_{2}\right)\right]^{2+}$. MS (ESI+, MeOH): $m / z=927\left[\mathrm{Zn}_{2} \mathrm{H}_{-1} \mathrm{~L}^{1}\left(\mathrm{SO}_{3} \mathrm{CF}_{3}\right)_{2}\right]^{+}, 809\left[\mathrm{Zn}_{2} \mathrm{H}_{-1} \mathrm{~L}^{1}(\mathrm{OMe})\left(\mathrm{SO}_{3} \mathrm{CF}_{3}\right)\right]^{+}$, $795\left[\mathrm{Zn}_{2} \mathrm{H}_{-1} \mathrm{~L}^{1}(\mathrm{OH})\left(\mathrm{SO}_{3} \mathrm{CF}_{3}\right)\right]^{+}, 389\left[\mathrm{Zn}_{2} \mathrm{H}_{-1} \mathrm{~L}^{1}\left(\mathrm{SO}_{3} \mathrm{CF}_{3}\right)\right]^{2+}, 330\left[\mathrm{Zn}_{2} \mathrm{H}_{-1} \mathrm{~L}^{1}(\mathrm{OMe})\right]^{2+}, 323$ $\left[\mathrm{Zn}_{2} \mathrm{H}_{-1} \mathrm{~L}^{1}(\mathrm{OH})\right]^{2+}$.

IR (KBr): $\tilde{v}\left(\mathrm{~cm}^{-1}\right)=3476(\mathrm{~m}), 3141(\mathrm{w}), 2951(\mathrm{w}), 1628(\mathrm{w}), 1550(\mathrm{~m}), 1511$ (s), 1452 (m), 1362 (m), 1266 (vs), 1225 (vs), 1163 (vs), 1092 (w), 1031 (vs), 983 (m), 961 (s), $879(\mathrm{~m}), 818(\mathrm{~m}), 770$ (s), 753 (s), 639 (vs), 574 (s), 517 (s), 453 (m).

\section{Synthesis of $\left[\mathrm{Zn}_{2} \mathrm{H}_{-1} \mathrm{~L}^{1}\left(\mathrm{Me}_{2} \mathrm{O}_{2} \mathrm{H}\right)\right]\left(\mathrm{ClO}_{4}\right)_{2}(4 a)$}

$\mathbf{L}^{1}$ (100 mg, $0.20 \mathrm{mmol}$ ) and $\mathrm{LiOH}(12 \mathrm{mg}, 0.50 \mathrm{mmol}$ ) were dissolved in MeOH/THFmixture (20 ml, 3:1 v/v) and heated to reflux. $\mathrm{Zn}\left(\mathrm{ClO}_{4}\right)_{2} \cdot 6 \mathrm{H}_{2} \mathrm{O}(156 \mathrm{mg}, 0.42 \mathrm{mmol})$ in $\mathrm{MeOH}(2 \mathrm{ml})$ were added dropwise to the colourless solution. After $1.5 \mathrm{~h}$, heating was removed and the mixture was allowed to cool down slowly in the oil bath. Very few single crystals were formed by cooling to $\mathrm{rt}$ that were suitable for X-ray analysis. Attempts to reproduce complex $\mathbf{4 a}$ resulted in $\mathbf{4 b}$. For this reason, no other analytical methods than X-ray analysis were performed for $\mathbf{4 a}$.

\section{Synthesis of $\left[\mathrm{Zn}_{2} \mathrm{H}_{-1} \mathrm{~L}^{1}(\mathrm{OMe})\right]\left(\mathrm{ClO}_{4}\right)_{2}(4 \mathrm{~b})$}

$\mathbf{L}^{1}$ (100 mg, $\left.0.20 \mathrm{mmol}\right)$ and $\mathrm{LiOH}(12 \mathrm{mg}, 0.50 \mathrm{mmol})$ were stirred at $35{ }^{\circ} \mathrm{C}$ in $\mathrm{MeOH} / \mathrm{THF}-m i x t u r e(20 \mathrm{ml}, 3: 1 \mathrm{v} / \mathrm{v})$ until the solution became clear. Then, $\mathrm{Zn}\left(\mathrm{ClO}_{4}\right)_{2} \cdot 6 \mathrm{H}_{2} \mathrm{O}(156 \mathrm{mg}, 0.42 \mathrm{mmol})$ dissolved in $\mathrm{MeOH}(3 \mathrm{ml})$ was added dropwise. The resulting suspension was stirred for $30 \mathrm{~min}$ and filtrated. Colourless crystals suitable 
for X-ray analysis were obtained by slow $\mathrm{Et}_{2} \mathrm{O}$ diffusion into the complex solution (28 mg, $33 \mu \mathrm{mol}, 16 \%$ ).

Since NMR data indicate formation of three different complexes due to signals at 6.10, 6.12 and $6.16 \mathrm{ppm}$ for $\mathrm{CH}^{\mathrm{Pz}}$, chemical shifts and relative intensities are listed for all of them.

${ }^{1} \mathrm{H}$ NMR (300 MHz, $\left.d_{3}-\mathrm{MeCN}\right): \delta=3.50-3.66(\mathrm{~m}, 27 \mathrm{H}), 3.71-3.84(\mathrm{~m}, 6 \mathrm{H}), 4.08-4.36$ $(\mathrm{m}, 20 \mathrm{H}), 6.10\left(\mathrm{~s}, 0.6 \mathrm{H}, \mathrm{CH}^{\mathrm{Pz}}\right), 6.12\left(\mathrm{~s}, 1 \mathrm{H}, \mathrm{CH}^{\mathrm{Pz}}\right), 6.16\left(\mathrm{bs}, 1.7 \mathrm{H}, \mathrm{CH}^{\mathrm{Pz}}\right), 6.64-6.65(\mathrm{bs}$, 3.6H, $\left.\mathrm{CH}^{\text {Imid }}\right), 6.79-6.80\left(\mathrm{~m}, 2.5 \mathrm{H}, \mathrm{CH}^{\text {Imid }}\right), 6.89-6.90\left(\mathrm{~m}, 4.3 \mathrm{H}, \mathrm{CH}^{\text {Imid }}\right), 7.08-7.14(\mathrm{~m}$, 3.4 $\left.\mathrm{H}, \mathrm{CH}^{\mathrm{Imid}}\right)$.

MS (ESI+): $m / z=754\left[\mathrm{Zn}_{2} \mathrm{H}_{-1} \mathrm{~L}^{1}(\mathrm{CN})\left(\mathrm{ClO}_{4}\right)\right]^{+}, 328\left[\mathrm{Zn}_{2} \mathrm{H}_{-1} \mathrm{~L}^{1}(\mathrm{CN})\right]^{2+}$.

IR (KBr): $\tilde{v}\left(\mathrm{~cm}^{-1}\right)=3153(\mathrm{w}), 3132(\mathrm{w}), 2916(\mathrm{w}), 2854(\mathrm{w}), 1628(\mathrm{~m}), 1545(\mathrm{w})$, 1508 (s), 1447 (w), 1363 (w), 1286 (m), 1096 (vs), 961 (m), 872 (w), 764 (m), 676 (w), $652(\mathrm{w}), 623(\mathrm{~s}), 444(\mathrm{w})$.

\section{Synthesis of $\left[\mathrm{Zn}_{2} \mathrm{H}_{-1} \mathrm{~L}^{1}(\mathrm{OAc})\right]\left(\mathrm{SO}_{3} \mathrm{CF}_{3}\right)_{2}(5 \mathrm{a})$}

$\mathbf{L}^{1}$ (200 mg, $0.40 \mathrm{mmol}$ ), KO ${ }^{t} \mathrm{Bu}(45 \mathrm{mg}, 0.40 \mathrm{mmol}), \mathrm{Zn}\left(\mathrm{SO}_{3} \mathrm{CF}_{3}\right)_{2}(289 \mathrm{mg}, 0.80 \mathrm{mmol})$ and $\mathrm{NaOAc}$ (33 mg, $0.40 \mathrm{mmol}$ ) were dried in vacuum. Dry MeCN (12 ml) was added and the suspension was stirred until the solution became clear. After filtration, colourless crystals were obtained by slow diffusion of $\mathrm{Et}_{2} \mathrm{O}$ into the complex solution (264 mg, $27 \mu \mathrm{mol}, 67 \%)$.

${ }^{1} \mathrm{H}$ NMR $\left(300 \mathrm{MHz}, d_{3}-\mathrm{MeCN}\right): \delta=2.42(\mathrm{~s}, 3 \mathrm{H}, \mathrm{Me}), 3.55$ (s, 12H, NMe), $4.02(\mathrm{~s}, 4 \mathrm{H}$, $\mathrm{CH}_{2}$ ), 4.06-4.07 (m, 8H, $\left.\mathrm{CH}_{2}\right), 6.10\left(\mathrm{~s}, 1 \mathrm{H}, \mathrm{CH}^{\mathrm{Pz}}\right), 6.99$ (bs, 4H, $\left.\mathrm{CH}^{\mathrm{Imid}}\right), 7.11$ (bs, 4H, $\left.\mathrm{CH}^{\text {Imid }}\right)$.

${ }^{13} \mathrm{C}$ NMR $\left(75 \mathrm{MHz}, d_{3}-\mathrm{MeCN}\right): \delta=24.3(\mathrm{Me}), 33.5(\mathrm{NMe}), 51.8\left(\mathrm{CH}_{2}\right), 53.9\left(\mathrm{CH}_{2}\right)$, $101.8\left(\mathrm{CH}^{\mathrm{Pz}}\right), 124.9\left(\mathrm{CH}^{\mathrm{Imid}}\right), 125.2\left(\mathrm{CH}^{\text {Imid }}\right), 148.7\left(\mathrm{C}_{\mathrm{q}}^{\text {Imid }}\right), 152.4(\mathrm{COO})$.

MS (ESI+): $m / z=837\left[\mathrm{Zn}_{2} \mathrm{H}_{-1} \mathrm{~L}^{1}(\mathrm{OAc})\left(\mathrm{SO}_{3} \mathrm{CF}_{3}\right)\right]^{+}, 344\left[\mathrm{Zn}_{2} \mathrm{H}_{-1} \mathrm{~L}^{1}(\mathrm{OAc})\right]^{2+}$.

IR (KBr): $\tilde{v}\left(\mathrm{~cm}^{-1}\right)=3131(\mathrm{w}), 2917(\mathrm{w}), 1582$ (s), 1510 (s), 1442 (s), 1358 (m), 1265 (vs), 1224 (m), 1162 (vs), 1090 (w), 1030 (vs), 979 (m), 959 (m), 872 (w), 815 (w), $790(\mathrm{w}), 757(\mathrm{~s}), 638(\mathrm{vs}), 573(\mathrm{w}), 518(\mathrm{~m}), 448(\mathrm{w})$. 
Elemental analysis: Due to co-crystallisation of $\mathrm{KSO}_{3} \mathrm{CF}_{3}$ values are given for $\mathrm{C}_{29} \mathrm{H}_{36} \mathrm{~F}_{6} \mathrm{~N}_{12} \mathrm{O}_{8} \mathrm{~S}_{2} \mathrm{Zn}_{2} \cdot \mathrm{CH}_{3} \mathrm{CN} \cdot \mathrm{KSO}_{3} \mathrm{CF}_{3}$. Calcd. (\%) for $\mathrm{C}_{32} \mathrm{H}_{39} \mathrm{~F}_{9} \mathrm{KN}_{13} \mathrm{O}_{11} \mathrm{~S}_{3} \mathrm{Zn}_{2}: \mathrm{C}$ 31.53, H 3.23, N 14.94, S 7.89. Found: C 31.51, H 3.17, N 14.75, S 8.04.

\section{Synthesis of $\left[\left(\mathrm{ZnH}_{-1} \mathrm{~L}^{1}\right)_{2}\right]\left(\mathrm{ClO}_{4}\right)_{2}(6)$}

$\mathbf{L}^{1}$ (107 mg, $\left.0.21 \mathrm{mmol}\right)$ and $\mathrm{Zn}\left(\mathrm{ClO}_{4}\right)_{2} \cdot 6 \mathrm{H}_{2} \mathrm{O}(80 \mathrm{mg}, 0.21 \mathrm{mmol})$ were suspended in $\mathrm{MeOH}(30 \mathrm{ml})$. An aqueous solution of $\mathrm{KOH}(12 \mathrm{mg}, 0.21 \mathrm{mmol}$ in $140 \mu \mathrm{l}$ water) was added. The solution became clear and was further stirred for $16 \mathrm{~h}$ at $\mathrm{rt}$, whereby a fine precipitate was formed. The suspension was filtrated and slow $\mathrm{Et}_{2} \mathrm{O}$ diffusion into the complex solution afforded colourless crystals, which were suitable for X-ray analysis (79 mg, $60 \mu \mathrm{mol}, 28 \%$ ).

${ }^{1} \mathrm{H}$ NMR $\left(500 \mathrm{MHz}, d_{3}-\mathrm{MeCN}, 273 \mathrm{~K}\right): \delta=3.48$ (s, 24H, NMe), $3.82\left(\mathrm{~s}, 24 \mathrm{H}, \mathrm{CH}_{2}\right.$ ), 6.24 $\left(\mathrm{s}, 2 \mathrm{H}, \mathrm{CH}^{\mathrm{Pz}}\right), 6.57\left(\mathrm{~s}, 8 \mathrm{H}, \mathrm{CH}^{\text {Imid }}\right), 6.91\left(\mathrm{~s}, 8 \mathrm{H}, \mathrm{CH}^{\text {Imid }}\right)$.

${ }^{1} \mathrm{H}$ NMR (500 MHz, $\left.d_{3}-\mathrm{MeCN}, 233 \mathrm{~K}\right): \delta=3.33$ (s, 12H, NMe), 3.50 (s, 8H, $\mathrm{CH}_{2}$ ), 3.53 (s, 12H, NMe), 3.57 (s, 4H, $\left.\mathrm{CH}_{2}\right), 3.90\left(\mathrm{~s}, 4 \mathrm{H}, \mathrm{CH}_{2}\right), 4.02\left(\mathrm{~s}, 8 \mathrm{H}, \mathrm{CH}_{2}\right), 6.27(\mathrm{~s}, 2 \mathrm{H}$, $\left.\mathrm{CH}^{\mathrm{Pz}}\right), 6.41\left(\mathrm{~s}, 4 \mathrm{H}, \mathrm{CH}^{\mathrm{Imid}}\right), 6.61\left(\mathrm{~s}, 4 \mathrm{H}, \mathrm{CH}^{\mathrm{Imid}}\right), 6.88\left(\mathrm{~s}, 4 \mathrm{H}, \mathrm{CH}^{\mathrm{Imid}}\right), 6.98(\mathrm{~s}, 4 \mathrm{H}$, $\mathrm{CH}^{\text {Imid }}$ ).

${ }^{13} \mathrm{C}$ NMR $\left(75 \mathrm{MHz}, d_{3}-\mathrm{MeCN}, 273 \mathrm{~K}\right): \delta=33.3(\mathrm{NMe}), 50.7\left(\mathrm{CH}_{2}\right), 52.9\left(\mathrm{CH}_{2}\right), 103.4$ $\left(\mathrm{CH}^{\mathrm{Pz}}\right), 123.5\left(\mathrm{CH}^{\mathrm{Imid}}\right), 126.6\left(\mathrm{CH}^{\mathrm{Imid}}\right)$.

MS (ESI+): $m / z=1229\left[\left(\mathrm{ZnH}_{-1} \mathrm{~L}^{1}\right)_{2}\left(\mathrm{ClO}_{4}\right)\right]^{+}, 565\left[\left(\mathrm{ZnH}_{-1} \mathrm{~L}^{1}\right)_{2}\right]^{2+}$.

IR (KBr): $\tilde{v}\left(\mathrm{~cm}^{-1}\right)=3127(\mathrm{w}), 2933(\mathrm{w}), 2912(\mathrm{w}), 1654(\mathrm{w}), 1546(\mathrm{w}), 1504(\mathrm{~s})$, 1452 (m), 1358 (m), 1285 (m), 1247 (w), 1137 (s), 1096 (vs), 990 (m), 959 (m), 876 (w), $782(\mathrm{~m}), 753(\mathrm{~s}), 697(\mathrm{w}), 675(\mathrm{w}), 625(\mathrm{~s}), 523(\mathrm{w})$.

\section{Synthesis of $\left[\left(\mathrm{Zn}_{2} \mathrm{H}_{-1} \mathrm{~L}^{1}\right)_{2}(\mu-\mathrm{O})(\mu-\mathrm{OH})\right]\left(\mathrm{ClO}_{4}\right)_{3}(7)$}

To a solution of 2 (47 mg, $0.05 \mathrm{mmol})$ in $\mathrm{MeOH}(12 \mathrm{ml})$ was added dropwise $\mathrm{NaOMe}$ (3 $\mathrm{mg}, 0.05 \mathrm{mmol}$ ) dissolved in $\mathrm{MeOH}(2 \mathrm{ml})$. After $2 \mathrm{~d}$, the colourless suspension was filtrated and the solid was dried in vacuum. The solid was dissolved in $\operatorname{MeCN}(8 \mathrm{ml})$. Colourless crystals, which were suitable for X-ray analysis, were obtained by slow diffusion of $\mathrm{Et}_{2} \mathrm{O}$ into the filtrated complex solution $(7 \mathrm{mg}, 3.83 \mathrm{mmol}, 8 \%)$. As indicated by ${ }^{1} \mathrm{H}$ NMR and ESI-MS analysis a mixture of $\mathbf{5 b}$ and $\mathbf{7}$ has been formed. To 
distinguish the signals of both complexes, the signals and intensities of $\mathbf{7}$ are written in italics.

${ }^{1} \mathrm{H}$ NMR (300 MHz, $\left.d_{3}-\mathrm{MeCN}\right): \delta=2.42$ (s, 3H, OAc), 3.55 (s, 12H+6H, NMe), 4.02 (s, $\left.4 \mathrm{H}, \mathrm{CH}_{2}\right), 4.03\left(s, 2 \mathrm{H}, \mathrm{CH}_{2}\right)$ 4.05-4.07 (m, 8H+4H, $\left.\mathrm{CH}_{2}\right), 6.09\left(\mathrm{~s}, 1 \mathrm{H}, \mathrm{CH}^{\mathrm{Pz}}\right), 6.12(s$, $\left.0.5 H, \mathrm{CH}^{P z}\right), 6.98-6.99\left(\mathrm{~m}, 4 \mathrm{H}+2 \mathrm{H}, \mathrm{CH}^{\mathrm{Imid}}\right), 7.11\left(\mathrm{bs}, 4 \mathrm{H}+2 \mathrm{H}, \mathrm{CH}^{\mathrm{Imid}}\right), 8.88(\mathrm{~s}, 0.5 \mathrm{H}$, $\mu-O H)$.

MS (ESI+): $m / z=787\left[\mathrm{Zn}_{2} \mathrm{H}_{-1} \mathrm{~L}^{1}(\mathrm{OAc})\left(\mathrm{ClO}_{4}\right)\right]^{+}, 754\left[\mathrm{Zn}_{2} \mathrm{H}_{-1} \mathrm{~L}^{1}(\mathrm{CN})\left(\mathrm{ClO}_{4}\right)\right]^{+}, 344$ $\left[\mathrm{Zn}_{2} \mathrm{H}_{-1} \mathrm{~L}^{1}(\mathrm{OAc})\right]^{2+}, 328\left[\mathrm{Zn}_{2} \mathrm{H}_{-1} \mathrm{~L}^{1}(\mathrm{CN})\right]^{2+}$.

\section{Synthesis of $\left[\mathrm{Zn}_{2} \mathrm{H}_{-1} \mathrm{~L}^{2}(\mathrm{OH})\right]\left(\mathrm{ClO}_{4}\right)_{2}(8)$}

To a stirred suspension of $\mathbf{L}^{2}(100 \mathrm{mg}, 14.2 \mathrm{mmol})$ and $\mathrm{LiOH}(7 \mathrm{mg}, 29.2 \mathrm{mmol})$ in $\mathrm{MeOH}(10 \mathrm{ml})$ was added $\mathrm{Zn}(\mathrm{ClO})_{4} \cdot 6 \mathrm{H}_{2} \mathrm{O}(106 \mathrm{mg}, 28.4 \mathrm{mmol})$ and stirred for $16 \mathrm{~h}$. The suspension was filtrated and the colourless solid dissolved in $\mathrm{MeCN}$. Diffusion of $\mathrm{Et}_{2} \mathrm{O}$ into the solution afforded colourless crystals suitable for X-ray analysis.

${ }^{1} \mathrm{H}$ NMR $\left(300 \mathrm{MHz}, d_{3}-\mathrm{MeCN}\right): \delta=3.71(\mathrm{~s}, 12 \mathrm{H}, \mathrm{Me}), 4.22\left(\mathrm{~s}, 4 \mathrm{H}, \mathrm{CH}_{2}\right), 4.40-4.55(\mathrm{~m}$, $\left.8 \mathrm{H}, \mathrm{CH}_{2}\right), 5.98\left(\mathrm{~s}, 1 \mathrm{H}, \mathrm{CH}^{\mathrm{Pz}}\right), 7.36-7.50\left(\mathrm{~m}, 8 \mathrm{H}, \mathrm{CH}^{\text {BenzImid }}\right), 7.53-7.57(\mathrm{~m}, 4 \mathrm{H}$, $\left.\mathrm{CH}^{\text {BenzImid }}\right), 8.28-8.29\left(\mathrm{~m}, 2 \mathrm{H}, \mathrm{CH}^{\text {BenzImid }}\right), 8.31-8.32\left(\mathrm{~m}, 2 \mathrm{H}, \mathrm{CH}^{\text {BenzImid }}\right)$.

${ }^{1} \mathrm{H}$ NMR (500 MHz, $d_{6}$-DMSO): $\delta=3.75$ (s, 12H, NMe), 4.25 (s, 4H, $\left.\mathrm{CH}_{2}\right), 4.55(\mathrm{~d}, 4 \mathrm{H}$, $\left.{ }^{2} J_{\mathrm{H}, \mathrm{H}}=18 \mathrm{~Hz}, \mathrm{CH}_{2}\right), 4.70\left(\mathrm{~d}, 4 \mathrm{H},{ }^{2} J_{\mathrm{H}, \mathrm{H}}=18 \mathrm{~Hz}, \mathrm{CH}_{2}\right), 5.16(\mathrm{~s}, 1 \mathrm{H}, \mu-\mathrm{OH}), 5.98(\mathrm{~s}, 1 \mathrm{H}$, $\left.\mathrm{CH}^{\mathrm{Pz}}\right), 7.40\left(\mathrm{t}, 4 \mathrm{H},{ }^{3} J_{\mathrm{H}, \mathrm{H}}=7.5 \mathrm{~Hz}, \mathrm{CH}^{\text {BenzImid }}\right), 7.48\left(\mathrm{t}, 4 \mathrm{H},{ }^{3} \mathrm{~J}_{\mathrm{H}, \mathrm{H}}=8 \mathrm{~Hz}, \mathrm{CH}^{\text {BenzImid }}\right), 7.69$ $\left(\mathrm{d}, 4 \mathrm{H},{ }^{3} J_{\mathrm{H}, \mathrm{H}}=8 \mathrm{~Hz}, \mathrm{CH}^{\text {BenzImid }}\right), 8.45\left(\mathrm{~d}, 4 \mathrm{H},{ }^{3} J_{\mathrm{H}, \mathrm{H}}=8.5 \mathrm{~Hz}, \mathrm{CH}^{\text {BenzImid }}\right)$.

${ }^{13} \mathrm{C}$ NMR $\left(75 \mathrm{MHz}, d_{3}-\mathrm{MeCN}\right): \delta=31.0(\mathrm{NMe}), 54.3\left(\mathrm{CH}_{2}\right), 56.6\left(\mathrm{CH}_{2}\right), 112.1$ $\left(\mathrm{CH}^{\text {BenzImid }}\right), 124.8\left(\mathrm{CH}^{\text {BenzImid }}\right), 125.2\left(\mathrm{CH}^{\text {BenzImid }}\right), 136.6\left(\mathrm{C}_{\mathrm{q}}\right), 139.1\left(\mathrm{C}_{\mathrm{q}}\right), 150.7\left(\mathrm{C}_{\mathrm{q}}\right)$, $156.5\left(\mathrm{C}_{\mathrm{q}}\right)$.

MS (ESI+): $m / z=963\left[\mathrm{Zn}_{2} \mathrm{H}_{-1} \mathrm{~L}^{2}\left(\mathrm{H}_{3} \mathrm{O}_{2}\right)\left(\mathrm{ClO}_{4}\right)\right]^{+}, 432\left[\mathrm{Zn}_{2} \mathrm{H}_{-1} \mathrm{~L}^{2}\left(\mathrm{H}_{3} \mathrm{O}_{2}\right)\right]^{2+}$.

Synthesis of $\left[\mathrm{Zn}_{2} \mathrm{H}_{-1} \mathrm{~L}^{3}(\mathrm{X})\right]\left(\mathrm{SO}_{3} \mathrm{CF}_{3}\right)_{2}(9)$ (X = nucleophile)

To a stirred suspension of $\mathbf{L}^{3}(100 \mathrm{mg}, 0.13 \mathrm{mmol})$ and $\mathrm{KO}^{t} \mathrm{Bu}(30 \mathrm{mg}, 0.27 \mathrm{mmol})$ in $\mathrm{MeCN}(10 \mathrm{ml})$, was added $\mathrm{Zn}\left(\mathrm{SO}_{3} \mathrm{CF}_{3}\right)_{2}(96 \mathrm{mg}, 0.26 \mathrm{mmol})$. This mixture was further stirred for $12 \mathrm{~h}$ resulting in a clear solution that was filtrated. Slow diffusion of $\mathrm{Et}_{2} \mathrm{O}$ into the complex solution afforded colourless crystals. Due to the low quality of the crystals, 
no crystallographic data was obtained. In addition, ${ }^{1} \mathrm{H}$ NMR revealed the formation of two complexes due to two signals for $\mathrm{CH}^{\mathrm{Pz}}$ at 5.97 and $6.15 \mathrm{ppm}$. Although DOSY NMR was applied, it was not possible to assign the signals to the respective complexes. For this reason, NMR data is listed for the mixture of both.

${ }^{1} \mathrm{H}$ NMR $\left(300 \mathrm{MHz}, d_{3}-\mathrm{MeCN}\right): \delta=2.75-2.79\left(\mathrm{~m}, 8 \mathrm{H}, \mathrm{CH}_{2}\right), 2.86-2.92\left(\mathrm{~m}, 8 \mathrm{H}, \mathrm{CH}_{2}\right)$, 2.96-3.05 (m, 8H, $\left.\mathrm{CH}_{2}\right), 3.10-3.14\left(\mathrm{~m}, 8 \mathrm{H}, \mathrm{CH}_{2}\right), 3.76(\mathrm{~s}, 12 \mathrm{H}, \mathrm{NMe}), 3.78(\mathrm{~s}, 12 \mathrm{H}$, $\mathrm{NMe}), 3.93\left(\mathrm{~s}, 4 \mathrm{H}, \mathrm{CH}_{2}\right), 4.01\left(\mathrm{~s}, 4 \mathrm{H}, \mathrm{CH}_{2}\right), 5.97\left(\mathrm{~s}, 1 \mathrm{H}, \mathrm{CH}^{\mathrm{Pz}}\right), 6.15\left(\mathrm{~s}, 1 \mathrm{H}, \mathrm{CH}^{\mathrm{Pz}}\right)$, 6.78-6.84 (m, 4H, $\mathrm{CH}^{\text {BenzImid })}$, 6.93-6.98 (m, 4H, $\mathrm{CH}^{\text {BenzImid }), ~ 7.31-7.38 ~(m, ~ 8 H, ~}$ $\left.\mathrm{CH}^{\text {BenzImid }}\right), 7.56-7.60\left(\mathrm{~m}, 8 \mathrm{H}, \mathrm{CH}^{\text {BenzImid }}\right), 7.85\left(\mathrm{~d}, 4 \mathrm{H},{ }^{3} \mathrm{~J}_{\mathrm{H}, \mathrm{H}}=8.4 \mathrm{~Hz}, \mathrm{CH}^{\text {BenzImid }}\right), 8.11$ $\left(\mathrm{d}, 4 \mathrm{H},{ }^{3} J_{\mathrm{H}, \mathrm{H}}=8.1 \mathrm{~Hz}, \mathrm{CH}^{\text {BenzImid }}\right)$.

MS (ESI+): $m / z=1069\left[\mathrm{Zn}_{2} \mathrm{H}_{-1} \mathrm{~L}^{3}\left(\mathrm{H}_{3} \mathrm{O}_{2}\right)\left(\mathrm{SO}_{3} \mathrm{CF}_{3}\right)\right]^{+}, 955\left[\mathrm{Zn}_{2} \mathrm{H}_{-1} \mathrm{~L}^{3}(\mathrm{OH})_{2}\left(\mathrm{H}_{2} \mathrm{O}\right)_{2}\right]^{+}, 460$ $\left[\mathrm{Zn}_{2} \mathrm{H}_{-1} \mathrm{~L}^{3}\left(\mathrm{H}_{3} \mathrm{O}_{2}\right)\right]^{2+}$.

\section{Synthesis of $\left[\mathrm{Zn}_{2} \mathrm{H}_{-1} \mathrm{~L}^{3}(\mathrm{OAc})\right]\left(\mathrm{SO}_{3} \mathrm{CF}_{3}\right)_{2}(10)$}

A mixture of $\mathbf{L}^{3}$ (100 mg, $\left.0.13 \mathrm{mmol}\right), \mathrm{KO}^{t} \mathrm{Bu}(15 \mathrm{mg}, 0.13 \mathrm{mmol}), \mathrm{Zn}\left(\mathrm{SO}_{3} \mathrm{CF}_{3}\right)_{2}(96 \mathrm{mg}$, $0.26 \mathrm{mmol})$ and $\mathrm{KOAc}(13 \mathrm{mg}, 0.13 \mathrm{mmol})$ was suspended in $\mathrm{MeCN}(10 \mathrm{ml})$ and stirred for $12 \mathrm{~h}$. The resulting clear solution was filtrated. Colourless crystals were obtained by slow diffusion of $\mathrm{Et}_{2} \mathrm{O}$ into the complex solution. These crystals had low quality and were not suitable for X-ray analysis $(36 \mathrm{mg}, 29 \mu \mathrm{mol}, 22 \%)$

${ }^{1} \mathrm{H}$ NMR $\left(300 \mathrm{MHz}, d_{3}-\mathrm{MeCN}\right): \delta=1.75(\mathrm{~s}, 3 \mathrm{H}, \mathrm{OAc}), 2.63-2.72\left(\mathrm{~m}, 4 \mathrm{H}, \mathrm{CH}_{2}\right)$, 2.76-2.86 (m, 4H, $\left.\mathrm{CH}_{2}\right), 2.96-3.00\left(\mathrm{~m}, 8 \mathrm{H}, \mathrm{CH}_{2}\right), 3.71(\mathrm{~s}, 12 \mathrm{H}, \mathrm{NMe}), 3.76\left(\mathrm{~s}, 4 \mathrm{H}, \mathrm{CH}_{2}\right)$, 6.09 (s, 1H, $\left.\mathrm{CH}^{\mathrm{Pz}}\right), 6.89-6.94\left(\mathrm{~m}, 4 \mathrm{H}, \mathrm{CH}^{\text {BenzImid }}\right), 7.32-7.38\left(\mathrm{~m}, 4 \mathrm{H}, \mathrm{CH}^{\text {BenzImid }}\right), 7.57$ (d, $\left.4 \mathrm{H},{ }^{3} J_{\mathrm{H}, \mathrm{H}}=8.4 \mathrm{~Hz}, \mathrm{CH}^{\text {BenzImid }}\right), 7.77\left(\mathrm{~d}, 4 \mathrm{H},{ }^{3} J_{\mathrm{H}, \mathrm{H}}=8.4 \mathrm{~Hz}, \mathrm{CH}^{\text {BenzImid }}\right)$. MS (ESI+): $m / z=1093\left[\mathrm{Zn}_{2} \mathrm{H}_{-1} \mathrm{~L}^{3}(\mathrm{OAc})\left(\mathrm{SO}_{3} \mathrm{CF}_{3}\right)\right]^{+}, 1069\left[\mathrm{Zn}_{2} \mathrm{H}_{-1} \mathrm{~L}^{3}\left(\mathrm{H}_{3} \mathrm{O}_{2}\right)\left(\mathrm{SO}_{3} \mathrm{CF}_{3}\right)\right]^{+}$, $472\left[\mathrm{Zn}_{2} \mathrm{H}_{-1} \mathrm{~L}^{3}(\mathrm{OAc})\right]^{2+}, 460\left[\mathrm{Zn}_{2} \mathrm{H}_{-1} \mathrm{~L}^{3}\left(\mathrm{H}_{3} \mathrm{O}_{2}\right)\right]^{2+}$.

\section{Synthesis of $\left[\left(\mathrm{ZnH}_{-3}(\mathrm{Me})_{2} \mathrm{~L}^{4}\right)_{2}\right]\left(\mathrm{ClO}_{4}\right)_{2}(11)$}

Precursor- $\mathbf{L}^{4}$ (112 mg, $\left.0.23 \mathrm{mmol}\right)$ was dissolved in $\mathrm{MeOH}(7 \mathrm{ml}), \mathrm{LiOH}$ (22 mg, $0.92 \mathrm{mmol})$ was added and the suspension was stirred for 3 hours. $\mathrm{Zn}\left(\mathrm{ClO}_{4}\right)_{2} \cdot 6 \mathrm{H}_{2} \mathrm{O}$ $(173 \mathrm{mg}, 0.46 \mathrm{mmol})$ in $\mathrm{MeOH}(6 \mathrm{ml})$ was added dropwise, whereby a precipitate was formed, which dissolved again by stirring. Slow diffusion of $\mathrm{Et}_{2} \mathrm{O}$ into the filtrated 
complex solution afforded some colourless crystals, which were suitable for X-ray analysis (6 mg, $5 \mu \mathrm{mol}, 2 \%)$.

$\mathbf{1 1}$ was only characterised by $\mathrm{X}$-ray analysis.

\section{Synthesis of $\left[\mathrm{Zn}_{2} \mathrm{H}_{-3} \mathrm{~L}^{4}(\mathrm{OAc})\right](12)$}

Precursor-L $\mathbf{L}^{4}$ (175 mg, $\left.0.36 \mathrm{mmol}\right)$ was dissolved in water $(10 \mathrm{ml})$. KOH $(81 \mathrm{mg}$, $1.44 \mathrm{mmol}$ ) was added and the colourless solution was stirred for $2 \mathrm{~h}$ at $\mathrm{rt}$. $\mathrm{Zn}\left(\mathrm{ClO}_{4}\right)_{2} \cdot 6 \mathrm{H}_{2} \mathrm{O}(268 \mathrm{mg}, 0.72 \mathrm{mmol})$ was dissolved in water $(10 \mathrm{ml})$ and added dropwise to the aqueous ligand solution. After addition of KOAc (35 mg, $0.36 \mathrm{mmol})$ and stirring for $2 \mathrm{~h}$, the suspension was filtrated from $\mathrm{KClO}_{4}$ salt. Water was evaporated and the residue dried in vacuum. The colourless solid was suspended in $\mathrm{MeOH}$. After filtration and slow diffusion of $\mathrm{Et}_{2} \mathrm{O}$ into the complex solution, an amorphous solid was obtained after several days. This was collected by filtration and dried in vacuum. The solid was dissolved in $\mathrm{MeCN}$ (6 ml). Colourless crystals were obtained by slow diffusion of $\mathrm{Et}_{2} \mathrm{O}$ into the complex solution ( $\left.5 \mathrm{mg}, 8 \mu \mathrm{mol}, 3 \%\right)$.

${ }^{1} \mathrm{H}$ NMR $\left(300 \mathrm{MHz}, d_{3}-\mathrm{MeCN}\right): \delta=2.52$ (s, 3H, OAc), 3.20-3.24 (m, 4H, $\mathrm{CH}_{2}$ ), 3.52-3.54 (m, 6H, NMe), 3.81-4.00 (m, 8H, $\left.\mathrm{CH}_{2}\right), 5.98\left(\mathrm{~s}, 1 \mathrm{H}, \mathrm{CH}^{\mathrm{Pz}}\right), 6.96-7.02(\mathrm{~m}, 2 \mathrm{H}$, $\left.\mathrm{CH}^{\mathrm{Imid}}\right), 7.09-7.11\left(\mathrm{~m}, 2 \mathrm{H}, \mathrm{CH}^{\mathrm{Imid}}\right)$.

${ }^{13} \mathrm{C}$ NMR $\left(75 \mathrm{MHz}, d_{3}-\mathrm{MeCN}\right): \delta=33.3(\mathrm{NMe}), 52.0\left(\mathrm{CH}_{2}\right), 54.3\left(\mathrm{CH}_{2}\right), 60.9\left(\mathrm{CH}_{2}\right)$, $124.7\left(\mathrm{CH}^{\text {Imid }}\right)$.

MS (ESI+): $m / z=1169\left[\left(\mathrm{Zn}_{2} \mathrm{H}_{-3} \mathrm{~L}^{4}\right)_{2}(\mathrm{OAc})\right]^{+}, 673\left[\mathrm{ZnH}_{-3} \mathrm{~L}^{4}(\mathrm{MeCN})_{2}\left(\mathrm{H}_{2} \mathrm{O}\right)_{2}\right]^{+}, 637$ $\left[\mathrm{ZnH}_{-3} \mathrm{~L}^{4}(\mathrm{MeCN})_{2}\right]^{+}, 615\left[\mathrm{Zn}_{2} \mathrm{H}_{-2} \mathrm{~L}^{4}(\mathrm{OAc})\right]^{+}, 555\left[\mathrm{Zn}_{2} \mathrm{H}_{-3} \mathrm{~L}^{4}\right]^{+}$,

IR (KBr): $\tilde{v}\left(\mathrm{~cm}^{-1}\right)=2924(\mathrm{w}), 2218$ (w), 1614 (vs), 1580 (vs), 1510 (m), 1424 (m), 1389 (s), 1281 (m), 1164 (m), 1119 (s), 1042 (m), 964 (m), 923 (m), 889 (w), 758 (m), $737(\mathrm{~m}), 655(\mathrm{~m}), 544(\mathrm{w})$. 


\subsection{Binding Studies of $\beta$-Lactam Substrates}

Compound 2 was used in the binding studies of the $\beta$-lactam substrates. Depending on the NMR experiment and on the substrate, amounts of $10.0 \mathrm{mg}(9.9 \mu \mathrm{mol})$ to $24.6 \mathrm{mg}$ $(24.3 \mu \mathrm{mol})$ of 2 were used. NMR experiments were undertaken in $d_{3}-\mathrm{MeCN} / \mathrm{D}_{2} \mathrm{O}$ $(9: 1, \mathrm{v} / \mathrm{v})$ at rt. Equimolar amounts of $\mathbf{2}$ and substrates Penicillin potassium salt (PenG), Ampicillin sodium salt (amp), 6-aminopenicillanic acid (6-apa), Cephalotin sodium salt (Ceph) and Sulbactam sodium salt (Sul) were mixed in a total volume of $600 \mu \mathrm{l}$. In addition, 1 equivalent $\mathrm{KO}^{t} \mathrm{Bu}$ was added in experiments of 6-apa.

ESI-MS and IR analyses were performed from reaction solutions containing $\mathbf{L}^{\mathbf{1}}$ (100 mg, $0.20 \mathrm{mmol}), 1$ equivalent of the corresponding base $\mathrm{KO}^{t} \mathrm{Bu}(22 \mathrm{mg}, 0.20 \mathrm{mmol})$ or $\mathrm{LiOH}$ $(5 \mathrm{mg}, 0.20 \mathrm{mmol})$ and 2 equivalents of $\mathrm{Zn}\left(\mathrm{ClO}_{4}\right)_{2} \cdot 6 \mathrm{H}_{2} \mathrm{O}(149 \mathrm{mg}, 0.40 \mathrm{mmol})$ or $\mathrm{Zn}\left(\mathrm{SO}_{3} \mathrm{CF}_{3}\right)_{2} \quad(146 \mathrm{mg}, 0.40 \mathrm{mmol})$. The solvents used were acetone, methanol or acetonitrile. PenG was used as potassium or as sodium salt. Substrates Amp, Ceph, Sul and Erta were purchased as sodium salts and 6-apa and Mero were available in their acid forms.

ESI-MS analysis of $\left[\mathrm{Zn}_{2} \mathrm{H}_{-1} \mathrm{~L}^{1}(\mathrm{Mero})\right]\left(\mathrm{SO}_{3} \mathrm{CF}_{3}\right)_{2}$

MS (ESI+): $m / z=1160\left[\mathrm{Zn}_{2} \mathrm{H}_{-1} \mathrm{~L}^{1}(\text { Mero })\left(\mathrm{SO}_{3} \mathrm{CF}_{3}\right)\right]^{+}, 506\left[\mathrm{Zn}_{2} \mathrm{H}_{-1} \mathrm{~L}^{1}(\text { Mero })\right]^{2+}$.

\section{ESI-MS analysis of $\left[\mathrm{Zn}_{2} \mathrm{H}_{-1} \mathrm{~L}^{1}(\right.$ Erta $\left.)\right]\left(\mathrm{ClO}_{4}\right)_{2}$}

MS (ESI+): $m / z=1202\left[\mathrm{Zn}_{2} \mathrm{H}_{-1} \mathrm{~L}^{1}(\mathrm{Erta})\left(\mathrm{ClO}_{4}\right)\right]^{+}, 552\left[\mathrm{Zn}_{2} \mathrm{H}_{-1} \mathrm{~L}^{1}(\text { Erta })\right]^{2+}$.

\section{Characterisation of $\left[\mathrm{Zn}_{2} \mathrm{H}_{-1} \mathrm{~L}^{1}(\mathrm{PenG})\right]\left(\mathrm{ClO}_{4}\right)_{2}(13)$}

${ }^{1} \mathrm{H}$ NMR $\left(300 \mathrm{MHz}, d_{3}-\mathrm{MeCN} / \mathrm{D}_{2} \mathrm{O}=9: 1, \mathrm{v} / \mathrm{v}\right): \delta=1.68\left(\mathrm{~s}, 3 \mathrm{H}, \mathrm{Me}^{\mathrm{PenG}}\right), 1.80(\mathrm{~s}, 3 \mathrm{H}$, $\left.\mathrm{Me}^{\mathrm{PenG}}\right), 3.54(\mathrm{~s}, 12 \mathrm{H}, \mathrm{NMe}), 3.59\left(\mathrm{~d}, 2 \mathrm{H},{ }^{4} \mathrm{~J}_{\mathrm{H}, \mathrm{H}}=2.1 \mathrm{~Hz}, \mathrm{CH}_{2}{ }^{\mathrm{PenG}}\right), 4.00-4.07(\mathrm{~m}, 12 \mathrm{H}$, $\left.\mathrm{CH}_{2}\right), 4.82\left(\mathrm{~s}, 1 \mathrm{H}, \mathbf{C H}-\mathrm{COO}^{\mathrm{PenG}}\right), 5.51\left(\mathrm{dd}, 2 \mathrm{H},{ }^{3} J_{\mathrm{H}, \mathrm{H}}=15.3 \mathrm{~Hz},{ }^{4} J_{\mathrm{H}, \mathrm{H}}=4.2 \mathrm{~Hz}\right.$, $\left.\mathrm{NH}-\mathbf{C H}-\mathbf{C H}-\mathrm{S}^{\mathrm{PenG}}\right), 6.12\left(\mathrm{~s}, 1 \mathrm{H}, \mathrm{CH}^{\mathrm{Pz}}\right), 6.94\left(\mathrm{bs}, 2 \mathrm{H}, \mathrm{CH}^{\mathrm{Imid}}\right), 7.08\left(\mathrm{~s}, 2 \mathrm{H}, \mathrm{CH}^{\text {Imid }}\right), 7.12$ (s, 4H, $\left.\mathrm{CH}^{\mathrm{Imid}}\right), 7.30\left(\mathrm{~m}, 5 \mathrm{H}, \mathrm{CH}^{\text {arom,PenG }}\right)$. 
${ }^{13} \mathrm{C}$ NMR $\left(75 \mathrm{MHz}, d_{3}-\mathrm{MeCN} / \mathrm{D}_{2} \mathrm{O}=9: 1, \mathrm{v} / \mathrm{v}\right): \delta=27.4\left(\mathrm{Me}^{\mathrm{PenG}}\right), 33.0\left(\mathrm{Me}^{\mathrm{PenG}}\right), 33.1$ (NMe), $42.6\left(\mathrm{CH}_{2}{ }^{\mathrm{PenG}}\right), 51.1\left(\mathrm{CH}_{2}\right), 53.3\left(\mathrm{CH}_{2}\right), 59.9\left(\mathrm{NH}-\mathbf{C H}-\mathrm{CH}-\mathrm{S}^{\mathrm{PenG}}\right), 64.8$ $\left(\mathrm{S}-\mathrm{C}_{\mathrm{q}}{ }^{\mathrm{PenG}}\right), 68.6\left(\mathrm{NH}-\mathrm{CH}-\mathbf{C H}-\mathrm{S}^{\mathrm{PenG}}\right), \quad 73.7 \quad\left(\mathbf{C H}-\mathrm{COO}^{\mathrm{PenG}}\right), \quad 101.8 \quad\left(\mathrm{CH}^{\mathrm{Pz}}\right), 124.7$ $\left(\mathrm{CH}^{\text {Imid }}\right), 124.8\left(\mathrm{CH}^{\text {Imid }}\right), 125.1\left(\mathrm{CH}^{\text {Imid }}\right), 127.6\left(\mathrm{CH}^{\text {arom,PenG }}\right), 129.2\left(\mathrm{CH}^{\text {arom,PenG }}\right), 129.9$ $\left(\mathrm{CH}^{\text {arom,PenG }}\right), 135.8\left(\mathrm{C}_{\mathrm{q}}^{\text {arom,PenG }}\right), 148.2\left(\mathrm{C}_{\mathrm{q}}^{\text {Imid }}\right), 148.3\left(\mathrm{C}_{\mathrm{q}}^{\text {Imid }}\right), 152.4\left(\mathrm{C}_{\mathrm{q}}{ }^{\mathrm{Pz}}\right), 172.0$ $\left(\mathrm{CH}_{2}-\mathbf{C O}-\mathrm{NH}^{\mathrm{PenG}}\right), 174.0\left(\mathrm{CO}^{\mathrm{Lactam}, \mathrm{PenG}}\right), 175.5\left(\mathrm{COO}^{\mathrm{PenG}}\right)$.

MS (ESI+): $m / z=1061\left[\mathrm{Zn}_{2} \mathrm{H}_{-1} \mathrm{~L}^{1}(\mathrm{PenG})\left(\mathrm{ClO}_{4}\right)\right]^{+}, 481\left[\mathrm{Zn}_{2} \mathrm{H}_{-1} \mathrm{~L}^{1}(\mathrm{PenG})\right]^{2+}$.

HR-MS (ESI+): Calcd. $\left(\mathrm{m} / \mathrm{z}\right.$ ) for $\left[\mathrm{C}_{41} \mathrm{H}_{50} \mathrm{ClN}_{14} \mathrm{O}_{8} \mathrm{SZn}_{2}\right]^{+}:$1061.1923. Found: 1061.1923. Calcd. $(\mathrm{m} / z)$ for $\left[\mathrm{C}_{41} \mathrm{H}_{50} \mathrm{~N}_{14} \mathrm{O}_{4} \mathrm{SZn}_{2}\right]^{2+}: 481.1216$. Found: 481.1217.

IR (KBr): $\tilde{v}\left(\mathrm{~cm}^{-1}\right)=3437(\mathrm{~s}), 3131(\mathrm{w}), 2959(\mathrm{w}), 2926(\mathrm{w}), 1776(\mathrm{~m}), 1647$ (sh), 1612 (m), 1547 (w), 1509 (m), 1441 (sh), 1421 (m), 1361 (w), 1287 (w), 1266 (w), 1091 (vs), 982 (w), 960 (m), $872(\mathrm{w}), 756(\mathrm{~m}), 654(\mathrm{w}), 624(\mathrm{~s})$.

For comparison: chemical shifts of PenG potassium salt under same conditions

${ }^{1} \mathrm{H}$ NMR $\left(300 \mathrm{MHz}, d_{3}-\mathrm{MeCN} / \mathrm{D}_{2} \mathrm{O}=9: 1, \mathrm{v} / \mathrm{v}\right): \delta=1.46$ (s, 3H, Me), 1.52 (s, 3H, Me), 3.51-3.61 (m, 2H, $\mathrm{CH}_{2}$ ), 4.07 (s, 1H, CH-COO), 5.42-5.46 (m, 2H, NH-CH-CH-S), 7.23-7.36 (m, 5H, $\left.\mathrm{CH}^{\text {arom }}\right)$.

${ }^{13} \mathrm{C}$ NMR $\left(75 \mathrm{MHz}, d_{3}-\mathrm{MeCN}\right): \delta=27.4(\mathrm{Me}), 32.1(\mathrm{Me}), 42.7\left(\mathrm{CH}_{2}\right), 58.7$ $(\mathrm{NH}-\mathbf{C H}-\mathrm{CH}-\mathrm{S}), \quad 65.1 \quad\left(\mathrm{~S}-\mathrm{C}_{\mathrm{q}}\right), 67.7 \quad(\mathrm{NH}-\mathrm{CH}-\mathbf{C H}-\mathrm{S}), \quad 74.1 \quad(\mathbf{C H}-\mathrm{COO}), \quad 127.6$ $\left(\mathrm{CH}^{\text {arom }}\right), 129.3\left(\mathrm{CH}^{\text {arom }}\right), 130.0\left(\mathrm{CH}^{\text {arom }}\right), 136.0\left(\mathrm{C}_{\mathrm{q}}^{\text {arom }}\right), 172.2\left(\mathrm{CH}_{2}-\mathbf{C O}-\mathrm{NH}\right), 173.3$ (COO), $174.6\left(\mathrm{CO}^{\text {Lactam }}\right)$.

\section{Characterisation of $\left[\mathrm{Zn}_{2} \mathrm{H}_{-1} \mathrm{~L}^{1}(\mathrm{Amp})\right]\left(\mathrm{ClO}_{4}\right)_{2}(14)$}

${ }^{1} \mathrm{H}$ NMR $\left(300 \mathrm{MHz}, d_{3}-\mathrm{MeCN} / \mathrm{D}_{2} \mathrm{O}=9: 1, \mathrm{v} / \mathrm{v}\right): \delta=1.73\left(\mathrm{~s}, 3 \mathrm{H}, \mathrm{Me}^{\mathrm{Amp}}\right), 1.79(\mathrm{~s}, 3 \mathrm{H}$, $\mathrm{Me}^{\mathrm{Amp}}$ ), 3.54 (s, 12H, NMe), 4.00-4.08 (m, 12H, $\mathrm{CH}_{2}$ ), 4.53 (s, 1H, $\mathrm{NH}_{2}-\mathbf{C H}^{\mathrm{Amp}}$ ), 4.82 (bs, $\left.1 \mathrm{H}, \mathbf{C H}-\mathrm{COO}^{\mathrm{Amp}}\right), 5.53-5.58\left(\mathrm{~m}, 2 \mathrm{H}, \mathrm{NH}-\mathbf{C H}-\mathbf{C H}-\mathrm{S}^{\mathrm{Amp}}\right), 6.12\left(\mathrm{~s}, 1 \mathrm{H}, \mathrm{CH}^{\mathrm{Pz}}\right), 6.93$ (bs, 2H, $\mathrm{CH}^{\mathrm{Imid}}$ ), 7.08 (bs, 2H, $\mathrm{CH}^{\text {Imid }}$ ), 7.12 (bs, 4H, $\mathrm{CH}^{\text {Imid }}$ ), 7.28-7.40 (m, 5H, $\left.\mathrm{CH}^{\text {arom,Amp }}\right)$.

${ }^{13} \mathrm{C}$ NMR $\left(75 \mathrm{MHz}, d_{3}-\mathrm{MeCN} / \mathrm{D}_{2} \mathrm{O}=9: 1, \mathrm{v} / \mathrm{v}\right): \delta=27.3\left(\mathrm{Me}^{\mathrm{Amp}}\right), 32.8\left(\mathrm{Me}^{\mathrm{Amp}}\right), 33.1$ $(\mathrm{NMe}), 51.2\left(\mathrm{CH}_{2}\right), 53.4\left(\mathrm{CH}_{2}\right), 59.2\left(\mathrm{NH}-\mathbf{C H}-\mathrm{CH}-\mathrm{S}^{\mathrm{Amp}}\right), 59.5\left(\mathrm{NH}_{2}-\mathbf{C H}^{\mathrm{Amp}}\right), 64.8$ $\left(\mathrm{S}-\mathrm{C}_{\mathrm{q}}{ }^{\mathrm{Amp}}\right), 68.4\left(\mathrm{NH}-\mathrm{CH}-\mathbf{C H}-\mathrm{S}^{\mathrm{Amp}}\right), 73.7\left(\mathbf{C H}-\mathrm{COO}^{\mathrm{Amp}}\right), 101.8\left(\mathrm{CH}^{\mathrm{Pz}}\right), 124.7\left(\mathrm{CH}^{\mathrm{Imid}}\right)$, 


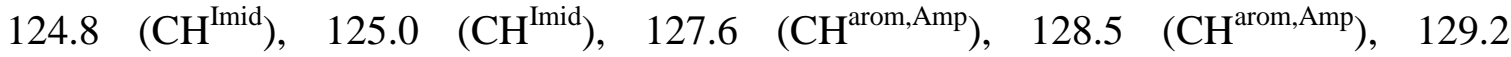
$\left(\mathrm{CH}^{\text {arom,Amp }}\right), 141.5\left(\mathrm{C}_{\mathrm{q}}^{\text {arom,Amp }}\right), 148.2\left(\mathrm{C}_{\mathrm{q}}^{\text {Imid }}\right), 148.3\left(\mathrm{C}_{\mathrm{q}}^{\text {Imid }}\right), 152.3\left(\mathrm{C}_{\mathrm{q}}{ }^{\mathrm{Pz}}\right), 174.2$ $\left(\mathrm{CH}-\mathrm{CO}-\mathrm{NH}^{\mathrm{Amp}}\right), 174.4\left(\mathrm{CO}^{\mathrm{Lactam}, \mathrm{Amp}}\right)$.

MS (ESI+): $m / z=1076\left[\mathrm{Zn}_{2} \mathrm{H}_{-1} \mathrm{~L}^{1}(\mathrm{Amp})\left(\mathrm{ClO}_{4}\right)\right]^{+}, 489\left[\mathrm{Zn}_{2} \mathrm{H}_{-1} \mathrm{~L}^{1}(\mathrm{Amp})\right]^{2+}$.

MS (ESI-): $m / z=1274\left[\mathrm{Zn}_{2} \mathrm{H}_{-1} \mathrm{~L}^{1}(\mathrm{Amp})\left(\mathrm{ClO}_{4}\right)_{3}\right]^{-}$.

IR (KBr): $\tilde{v}\left(\mathrm{~cm}^{-1}\right)=3434(\mathrm{br}), 3131(\mathrm{~m}), 2962$ (w), $2926(\mathrm{w}), 2020(\mathrm{w}), 1775$ (s), 1667 (s), 1612 (vs), 1547 (m), 1509 (vs), 1444 (m), 1426 (m), 1359 (w), 1321 (w), 1287 (m), 1089 (vs), 982 (w), 960 (m), 876 (m), 758 (m), 702 (w), 655 (w), 625 (s), $532(\mathrm{w}), 453(\mathrm{w})$.

For comparison: chemical shifts of Amp sodium salt under same conditions

${ }^{1} \mathrm{H}$ NMR $\left(300 \mathrm{MHz}, d_{3}-\mathrm{MeCN} / \mathrm{D}_{2} \mathrm{O}=9: 1, \mathrm{v} / \mathrm{v}\right): \delta=1.46$ (s, 3H, Me), 1.56 (s, 3H, Me), 4.11 (s, 1H, CH-COO), 4.50 (s, 1H, $\left.\mathrm{NH}_{2}-\mathbf{C H}\right), 5.47$ (s, 2H, NH-CH-CH-S), 7.25-7.39 $\left(\mathrm{m}, 5 \mathrm{H}, \mathrm{CH}^{\text {arom }}\right)$.

${ }^{13} \mathrm{C}$ NMR $\left(75 \mathrm{MHz}, d_{3}-\mathrm{MeCN} / \mathrm{D}_{2} \mathrm{O}=9: 1, \mathrm{v} / \mathrm{v}\right): \delta=27.3(\mathrm{Me}), 31.9(\mathrm{Me}), 58.1$ $(\mathrm{NH}-\mathbf{C H}-\mathrm{CH}-\mathrm{S}), \quad 59.4 \quad\left(\mathrm{NH}_{2}-\mathbf{C H}\right), \quad 65.1 \quad\left(\mathrm{~S}-\mathrm{C}_{\mathrm{q}}\right), \quad 67.5 \quad(\mathrm{NH}-\mathrm{CH}-\mathbf{C H}-\mathrm{S}), \quad 74.0$ (CH-COO $), 127.6\left(\mathrm{CH}^{\text {arom }}\right), 128.4\left(\mathrm{CH}^{\text {arom }}\right), 129.3\left(\mathrm{CH}^{\text {arom }}\right), 141.6\left(\mathrm{C}_{\mathrm{q}}{ }^{\text {arom }}\right), 173.5$ (COO), $174.5(\mathrm{CH}-\mathrm{CO}-\mathrm{NH}), 174.9\left(\mathrm{CO}^{\mathrm{Lactam}}\right)$.

\section{Characterisation of $\left[\mathrm{Zn}_{2} \mathrm{H}_{-1} \mathrm{~L}^{1}(6-\mathrm{apa})\right]\left(\mathrm{ClO}_{4}\right)_{2}(15)$}

Chemical shifts for equivalent amounts of $\mathbf{2}$ and 6-apa:

${ }^{1} \mathrm{H}$ NMR $\left(200 \mathrm{MHz}, d_{3}-\mathrm{MeCN} / \mathrm{D}_{2} \mathrm{O}=9: 1, \mathrm{v} / \mathrm{v}\right): \delta=1.76\left(\mathrm{~s}, 3 \mathrm{H}, \mathrm{Me}^{6-\mathrm{apa}}\right), 1.84(\mathrm{~s}, 3 \mathrm{H}$, $\left.\mathrm{Me}^{6 \text {-apa }}\right), 3.54$ (s, 12H, NMe), 3.94-4.07 (m, 12H, $\left.\mathrm{CH}_{2}\right), 4.87-4.89$ (m, 2H, $\left.\mathrm{NH}_{2}-\mathrm{CH}-\mathbf{C H}-\mathrm{S}^{6-\text { apa }}, \mathbf{C H}-\mathrm{COO}^{6 \text {-apa }}\right), 5.59\left(\mathrm{~d}, 1 \mathrm{H},{ }^{4} J_{\mathrm{H}, \mathrm{H}}=4.2 \mathrm{~Hz}, \mathrm{NH}_{2}-\mathbf{C H}-\mathrm{CH}-\mathrm{S}^{6-\text { apa }}\right)$, $6.13\left(\mathrm{~s}, 1 \mathrm{H}, \mathrm{CH}^{\mathrm{Pz}}\right), 6.92\left(\mathrm{~s}, 2 \mathrm{H}, \mathrm{CH}^{\mathrm{Imid}}\right), 7.07\left(\mathrm{~s}, 2 \mathrm{H}, \mathrm{CH}^{\mathrm{Imid}}\right), 7.12\left(\mathrm{~s}, 4 \mathrm{H}, \mathrm{CH}^{\text {Imid }}\right)$.

${ }^{13} \mathrm{C}$ NMR $\left(75 \mathrm{MHz}, d_{3}-\mathrm{MeCN} / \mathrm{D}_{2} \mathrm{O}=9: 1, \mathrm{v} / \mathrm{v}\right): \delta=27.5\left(\mathrm{Me}^{6 \text {-apa }}\right), 32.6\left(\mathrm{Me}^{6 \text {-apa }}\right), 33.1$ (NMe), $51.1\left(\mathrm{CH}_{2}\right), 53.3\left(\mathrm{CH}_{2}\right), 59.1\left(\mathrm{NH}_{2}-\mathrm{CH}-\mathbf{C H}-\mathrm{S}^{6-\text { apa }}\right), 65.7\left(\mathrm{~S}-\mathrm{C}_{\mathrm{q}}{ }^{6-\text { apa }}\right), 66.2$ $\left(\mathrm{NH}_{2}-\mathbf{C H}-\mathrm{CH}-\mathrm{S}^{6-a p a}\right), \quad 73.5 \quad\left(\mathbf{C H}-\mathrm{COO}^{6-\text { apa }}\right), \quad 101.9\left(\mathrm{CH}^{\mathrm{Pz}}\right), \quad 124.7 \quad\left(\mathrm{CH}^{\text {Imid }}\right), \quad 124.8$ $\left(\mathrm{CH}^{\text {Imid }}\right), 125.0\left(\mathrm{CH}^{\text {Imid }}\right), 148.2\left(\mathrm{C}_{\mathrm{q}}^{\text {Imid }}\right), 148.2\left(\mathrm{C}_{\mathrm{q}}^{\text {Imid }}\right), 152.3\left(\mathrm{C}_{\mathrm{q}}^{\mathrm{Pz}}\right), 170.2\left(\mathrm{CO}^{\text {Lactam,6-apa }}\right)$. 
Chemical shifts for equivalent amounts of 2, 6-apa and $\mathrm{KO}^{t} \mathrm{Bu}$ :

${ }^{1} \mathrm{H}$ NMR $\left(300 \mathrm{MHz}, d_{3}-\mathrm{MeCN} / \mathrm{D}_{2} \mathrm{O}=9: 1, \mathrm{v} / \mathrm{v}\right): \delta=1.15\left(\mathrm{~s}, 9 \mathrm{H},{ }^{t} \mathrm{Bu}\right), 1.71(\mathrm{~s}, 3 \mathrm{H}$, $\left.\mathrm{Me}^{6 \text {-apa }}\right), 1.80$ (s, 3H, Me $\left.{ }^{6 \text {-apa }}\right), 3.54$ (s, 12H, NMe), 4.00-4.07 (m, 12H, $\left.\mathrm{CH}_{2}\right), 4.53$ (d, 1H, $\left.{ }^{4} J_{\mathrm{H}, \mathrm{H}}=4.2 \mathrm{~Hz}, \mathrm{NH}_{2}-\mathrm{CH}-\mathbf{C H}-\mathrm{S}^{6-\mathrm{apa}}\right), 4.72\left(\mathrm{bs}, 1 \mathrm{H}, \mathbf{C H}-\mathrm{COO}^{6-\mathrm{apa}}\right), 5.50\left(\mathrm{~d}, 1 \mathrm{H},{ }^{4} J_{\mathrm{H}, \mathrm{H}}=\right.$ $\left.4.2 \mathrm{~Hz}, \mathrm{NH}_{2}-\mathbf{C H}-\mathrm{CH}-\mathrm{S}^{6-\mathrm{apa}}\right), 6.11\left(\mathrm{~s}, 1 \mathrm{H}, \mathrm{CH}^{\mathrm{Pz}}\right), 6.93$ (s, 2H, $\left.\mathrm{CH}^{\mathrm{Imid}}\right), 7.09$ (s, 2H, $\left.\mathrm{CH}^{\text {Imid }}\right), 7.11$ (s, 4H, $\left.\mathrm{CH}^{\text {Imid }}\right)$.

${ }^{13} \mathrm{C}$ NMR $\left(75 \mathrm{MHz}, d_{3}-\mathrm{MeCN} / \mathrm{D}_{2} \mathrm{O}=9: 1, \mathrm{v} / \mathrm{v}\right): \delta=27.5\left(\mathrm{Me}^{6-\mathrm{apa}}\right), 30.7\left(\mathrm{CH}_{3}{ }^{{ }^{\mathrm{Bu}}}\right), 32.5$ $\left(\mathrm{Me}^{6-\mathrm{apa}}\right), 33.1(\mathrm{NMe}), 51.2\left(\mathrm{CH}_{2}\right), 53.4\left(\mathrm{CH}_{2}\right), 63.0\left(\mathrm{NH}_{2}-\mathrm{CH}-\mathbf{C H}-\mathrm{S}^{6-a p a}\right), 64.0$ $\left(\mathrm{S}-\mathrm{C}_{\mathrm{q}}{ }^{6-\mathrm{apa}}\right), 68.7\left(\mathrm{C}_{\mathrm{q}}{ }^{\mathrm{tBu}}\right), 70.8\left(\mathrm{NH}_{2}-\mathbf{C H}-\mathrm{CH}-\mathrm{S}^{6-\mathrm{apa}}\right), 73.4\left(\mathbf{C H}-\mathrm{COO}^{6-\mathrm{apa}}\right), 101.8\left(\mathrm{CH}^{\mathrm{Pz}}\right)$, $124.7\left(\mathrm{CH}^{\text {Imid }}\right), 124.8\left(\mathrm{CH}^{\text {Imid }}\right), 125.1\left(\mathrm{CH}^{\text {Imid }}\right), 148.2\left(\mathrm{C}_{\mathrm{q}}^{\text {Imid }}\right), 148.3\left(\mathrm{C}_{\mathrm{q}}{ }^{\text {Imid }}\right), 152.3\left(\mathrm{C}_{\mathrm{q}}{ }^{\mathrm{Pz}}\right)$, $175.9\left(\mathrm{COO}^{6-a p a}\right), 179.1\left(\mathrm{CO}^{\text {Lactam,6-apa }}\right)$.

Product formation was observed under basic conditions $\left(\mathrm{KO}^{t} \mathrm{Bu}\right)$, without base and also independent from the counter ions $\left(\mathrm{ClO}_{4}{ }^{-}\right.$or $\left.\mathrm{CF}_{3} \mathrm{SO}_{3}{ }^{-}\right)$.

MS (ESI+): $m / z=993\left[\mathrm{Zn}_{2} \mathrm{H}_{-1} \mathrm{~L}^{1}(6-\mathrm{apa})\left(\mathrm{SO}_{3} \mathrm{CF}_{3}\right)\right]^{+}, 422\left[\mathrm{Zn}_{2} \mathrm{H}_{-1} \mathrm{~L}^{1}(6-\mathrm{apa})\right]^{2+}$.

MS (ESI+): $m / z=943\left[\mathrm{Zn}_{2} \mathrm{H}_{-1} \mathrm{~L}^{1}(6-\mathrm{apa})\left(\mathrm{ClO}_{4}\right)\right]^{+}, 422\left[\mathrm{Zn}_{2} \mathrm{H}_{-1} \mathrm{~L}^{1}(6-\mathrm{apa})\right]^{2+}$.

MS (ESI-): $m / z=1141\left[\mathrm{Zn}_{2} \mathrm{H}_{-1} \mathrm{~L}^{1}(6-\mathrm{apa})\left(\mathrm{ClO}_{4}\right)_{3}\right]^{-}$.

HR-MS (ESI+): Calcd. $(\mathrm{m} / \mathrm{z})$ for $\left[\mathrm{C}_{33} \mathrm{H}_{44} \mathrm{ClN}_{14} \mathrm{O}_{7} \mathrm{SZn}_{2}\right]^{+}$: 943.1504. Found: 943.1496. Calcd. $(\mathrm{m} / z)$ for $\left[\mathrm{C}_{33} \mathrm{H}_{44} \mathrm{~N}_{14} \mathrm{O}_{3} \mathrm{SZn}_{2}\right]^{2+}: 422.1007$. Found: 422.1006.

IR (KBr): $\tilde{v}\left(\mathrm{~cm}^{-1}\right)=3442(\mathrm{br}), 3132(\mathrm{~m}), 2963(\mathrm{w}), 1773(\mathrm{~m}), 1616$ (s), 1549 (w), 1509 (s), 1445 (m), 1425 (w), 1362 (w), 1287 (m), 1091 (vs), 983 (w), 960 (m), 876 (m), $759(\mathrm{~s}), 676(\mathrm{w}), 655(\mathrm{~m}), 625(\mathrm{~s})$.

\section{Characterisation of $\left[\mathrm{Zn}_{2} \mathrm{H}_{-1} \mathrm{~L}^{1}(\mathrm{Ceph})\right]\left(\mathrm{ClO}_{4}\right)_{2}(16)$}

${ }^{1} \mathrm{H}$ NMR $\left(300 \mathrm{MHz}, d_{3}-\mathrm{MeCN} / \mathrm{D}_{2} \mathrm{O}=9: 1, \mathrm{v} / \mathrm{v}\right): \delta=2.00\left(\mathrm{~s}, 3 \mathrm{H}, \mathrm{Me}^{\mathrm{Ceph}}\right), 3.54(\mathrm{~s}, 12 \mathrm{H}$, $\mathrm{NMe}), 3.47-3.69\left(\mathrm{~m}, 2 \mathrm{H}, \mathrm{S}-\mathrm{CH}_{2}{ }^{\mathrm{Ceph}}\right), 3.81\left(\mathrm{~d}, 2 \mathrm{H},{ }^{4} \mathrm{~J}_{\mathrm{H}, \mathrm{H}}=2.4 \mathrm{~Hz}, \mathrm{CH}_{2}-\mathrm{CO}^{\mathrm{Ceph}}\right)$, $3.91-4.21\left(\mathrm{~m}, 12 \mathrm{H}, \mathrm{CH}_{2}\right), 4.88\left(\mathrm{~d}, 1 \mathrm{H},{ }^{2} J_{\mathrm{H}, \mathrm{H}}=12.6 \mathrm{~Hz}, \mathrm{CH}_{2}-\mathrm{O}^{\mathrm{Ceph}}\right), 5.16\left(\mathrm{~d}, 1 \mathrm{H},{ }^{3} J_{\mathrm{H}, \mathrm{H}}=\right.$ $\left.4.8 \mathrm{~Hz}, \mathrm{NH}-\mathrm{CH}-\mathbf{C H}-\mathrm{S}^{\mathrm{Ceph}}\right), 5.37\left(\mathrm{~d}, 1 \mathrm{H},{ }^{2} J_{\mathrm{H}, \mathrm{H}}=12.9 \mathrm{~Hz}, \mathrm{CH}_{2}-\mathrm{O}^{\mathrm{Ceph}}\right), 5.76(\mathrm{~d}, 1 \mathrm{H}$, $\left.{ }^{3} J_{\mathrm{H}, \mathrm{H}}=4.8 \mathrm{~Hz}, \mathrm{NH}-\mathbf{C H}-\mathrm{CH}-\mathrm{S}^{\mathrm{Ceph}}\right), 6.11\left(\mathrm{~s}, 1 \mathrm{H}, \mathrm{CH}^{\mathrm{Pz}}\right), 6.94-6.98\left(\mathrm{~m}, 6 \mathrm{H}, \mathrm{CH}^{\mathrm{Imid}}\right.$, $\left.\mathrm{CH}^{\text {arom,Ceph }}\right), 7.10\left(\mathrm{~s}, 4 \mathrm{H}, \mathrm{CH}^{\text {Imid }}\right), 7.27-7.29\left(\mathrm{~m}, 1 \mathrm{H}, \mathrm{CH}^{\mathrm{arom}, \mathrm{Ceph}}\right)$. 
${ }^{13} \mathrm{C}$ NMR $\left(75 \mathrm{MHz}, d_{3}-\mathrm{MeCN} / \mathrm{D}_{2} \mathrm{O}=9: 1, \mathrm{v} / \mathrm{v}\right): \delta=20.7\left(\mathrm{Me}^{\mathrm{Ceph}}\right), 26.6\left(\mathrm{~S}-\mathrm{CH}_{2}{ }^{\mathrm{Ceph}}\right), 33.1$

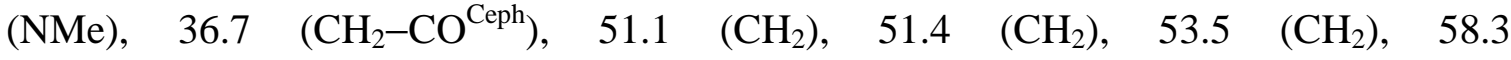
$\left(\mathrm{NH}-\mathrm{CH}-\mathbf{C H}-\mathrm{S}^{\mathrm{Ceph}}\right), 60.0\left(\mathrm{NH}-\mathbf{C H}-\mathrm{CH}-\mathrm{S}^{\mathrm{Ceph}}\right), 64.3\left(\mathrm{CH}_{2}-\mathrm{O}^{\mathrm{Ceph}}\right), 101.6\left(\mathrm{CH}^{\mathrm{Pz}}\right), 124.6$ $\left(\mathrm{CH}^{\mathrm{Imid}}\right), 125.1\left(\mathrm{CH}^{\mathrm{Imid}}\right), 125.8\left(\mathrm{CH}^{\text {arom,Ceph }}\right), 127.6\left(\mathrm{CH}^{\text {arom,Ceph }}\right), 136.9\left(\mathrm{C}_{\mathrm{q}}^{\text {Ceph,Thiophene }}\right)$,

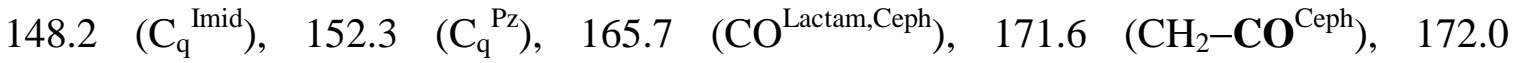
$\left(\mathbf{C O}-\mathrm{CH}_{3}{ }^{\mathrm{Ceph}}\right)$.

MS (ESI+): $m / z=1123\left[\mathrm{Zn}_{2} \mathrm{H}_{-1} \mathrm{~L}^{1}(\mathrm{Ceph})\left(\mathrm{ClO}_{4}\right)_{2}\right]^{+}, 512\left[\mathrm{Zn}_{2} \mathrm{H}_{-1} \mathrm{~L}^{1}(\mathrm{Ceph})\right]^{2+}$.

MS (ESI+): $m / z=1173\left[\mathrm{Zn}_{2} \mathrm{H}_{-1} \mathrm{~L}^{1}(\mathrm{Ceph})\left(\mathrm{SO}_{3} \mathrm{CF}_{3}\right)_{2}\right]^{+}, 512\left[\mathrm{Zn}_{2} \mathrm{H}_{-1} \mathrm{~L}^{1}(\mathrm{Ceph})\right]^{2+}$.

MS (ESI-): $m / z=1321\left[\mathrm{Zn}_{2} \mathrm{H}_{-1} \mathrm{~L}^{1}(\mathrm{Ceph})\left(\mathrm{ClO}_{4}\right)_{3}\right]^{-}$.

HR-MS (ESI+): Calcd. $(\mathrm{m} / z)$ for $\left[\mathrm{C}_{41} \mathrm{H}_{48} \mathrm{ClN}_{14} \mathrm{O}_{10} \mathrm{~S}_{2} \mathrm{Zn}_{2}\right]^{+}:$1123.1385. Found: 1123.1386.

Calcd. $(\mathrm{m} / \mathrm{z})$ for $\left[\mathrm{C}_{41} \mathrm{H}_{48} \mathrm{~N}_{14} \mathrm{O}_{6} \mathrm{~S}_{2} \mathrm{Zn}_{2}\right]^{2+}$ : 512.0947. Found: 512.0948.

IR (KBr): $\tilde{v}\left(\mathrm{~cm}^{-1}\right)=3133(\mathrm{w}), 2960(\mathrm{w}), 1775(\mathrm{~m}), 1740(\mathrm{w}), 1677(\mathrm{w}), 1608$ (s), 1547 (w), 1520 (s), 1425 (m), 1336 (w), 1256 (vs), 1168 (vs), 1036 (vs), 982 (w), $961(\mathrm{w}), 877(\mathrm{w}), 794(\mathrm{w}), 762(\mathrm{~m}), 707(\mathrm{w}), 642(\mathrm{vs}), 578(\mathrm{~m}), 520(\mathrm{~m})$.

For comparison: chemical shifts of Ceph sodium salt under same conditions

${ }^{1} \mathrm{H}$ NMR $\left(300 \mathrm{MHz}, d_{3}-\mathrm{MeCN} / \mathrm{D}_{2} \mathrm{O}=9: 1, \mathrm{v} / \mathrm{v}\right): \delta=2.00(\mathrm{~s}, 3 \mathrm{H}, \mathrm{Me}), 3.24\left(\mathrm{~d}, 1 \mathrm{H},{ }^{2} J_{\mathrm{H}, \mathrm{H}}=\right.$ $\left.17.7 \mathrm{~Hz}, \mathrm{~S}-\mathrm{CH}_{2}\right), 3.51\left(\mathrm{~d}, 1 \mathrm{H},{ }^{2} \mathrm{~J}_{\mathrm{H}, \mathrm{H}}=17.4 \mathrm{~Hz}, \mathrm{~S}-\mathrm{CH}_{2}\right), 3.71-3.82\left(\mathrm{~m}, 2 \mathrm{H}, \mathrm{CH}_{2}-\mathrm{CO}\right)$, $4.72\left(\mathrm{~d}, 1 \mathrm{H},{ }^{2} J_{\mathrm{H}, \mathrm{H}}=12.3 \mathrm{~Hz}, \mathrm{CH}_{2}-\mathrm{O}\right), 4.88\left(\mathrm{~d}, 1 \mathrm{H},{ }^{2} J_{\mathrm{H}, \mathrm{H}}=12.6 \mathrm{~Hz}, \mathrm{CH}_{2}-\mathrm{O}\right), 4.97(\mathrm{~d}, 1 \mathrm{H}$, $\left.{ }^{3} J_{\mathrm{H}, \mathrm{H}}=4.8 \mathrm{~Hz}, \mathrm{NH}-\mathrm{CH}-\mathbf{C H}-\mathrm{S}\right), 5.57\left(\mathrm{~d}, 1 \mathrm{H},{ }^{3} J_{\mathrm{H}, \mathrm{H}}=4.8 \mathrm{~Hz}, \mathrm{NH}-\mathbf{C H}-\mathrm{CH}-\mathrm{S}\right), 6.95(\mathrm{~d}$, $\left.2 \mathrm{H},{ }^{3} \mathrm{~J}_{\mathrm{H}, \mathrm{H}}=3.9 \mathrm{~Hz}, \mathrm{CH}^{\mathrm{arom}}\right), 7.26-7.28\left(\mathrm{~m}, 1 \mathrm{H}, \mathrm{CH}^{\text {arom }}\right)$.

${ }^{13} \mathrm{C}$ NMR $\left(75 \mathrm{MHz}, d_{3}-\mathrm{MeCN} / \mathrm{D}_{2} \mathrm{O}=9: 1, \mathrm{v} / \mathrm{v}\right): \delta=20.6(\mathrm{Me}), 25.8\left(\mathrm{~S}-\mathrm{CH}_{2}\right), 36.5$ $\left(\mathbf{C H}_{2}-\mathrm{CO}\right), 57.7$ (NH-CH-CH-S), $59.4 \quad(\mathrm{NH}-\mathbf{C H}-\mathrm{CH}-\mathrm{S}), 64.6 \quad\left(\mathrm{CH}_{2}-\mathrm{O}\right), \quad 115.8$ $\left(\mathrm{CH}_{2}-\mathrm{C}_{\mathrm{q}}-\mathrm{CH}_{2}\right), 125.6\left(\mathrm{CH}^{\text {arom }}\right), 127.4\left(\mathrm{CH}^{\text {arom }}\right), 133.0\left(\mathrm{C}_{\mathrm{q}}-\mathrm{COO}\right), 136.8\left(\mathrm{C}_{\mathrm{q}}^{\text {Thiophene }}\right)$, $164.6\left(\mathrm{CO}^{\mathrm{Lactam}}\right), 167.3(\mathrm{COO}), 172.0(\mathrm{CO}-\mathrm{NH}), 172.6\left(\mathbf{C O}-\mathrm{CH}_{3}\right)$. 


\section{Synthesis of $\left[\mathrm{Zn}_{2} \mathrm{H}_{-1} \mathrm{~L}^{1}(\mathrm{Sul})\right]\left(\mathrm{SO}_{3} \mathrm{CF}_{3}\right)_{2}(17)$}

$\mathbf{L}^{1}$ (100 mg, $0.20 \mathrm{mmol}$ ), KO ${ }^{t} \mathrm{Bu}(22 \mathrm{mg}, 0.20 \mathrm{mmol}), \mathrm{Zn}\left(\mathrm{SO}_{3} \mathrm{CF}_{3}\right)_{2}$ (145 mg, $0.40 \mathrm{mmol}$ ) and Sulbactam sodium salt (51 mg, $0.20 \mathrm{mmol})$ were dried in vacuum. Dry MeCN (8 ml) was added and the suspension was stirred for $3 \mathrm{~d}$ resulting in an almost clear solution. Filtration via cannula and slow diffusion of $\mathrm{Et}_{2} \mathrm{O}$ into the $\mathrm{MeCN}$ solution afforded colourless crystals, which were suitable for X-ray analysis (36 mg, $31 \mu \mathrm{mol}, 15 \%$ ).

${ }^{1} \mathrm{H}$ NMR $\left(300 \mathrm{MHz}, d_{3}-\mathrm{MeCN}\right): \delta=1.73\left(\mathrm{~s}, 3 \mathrm{H}, \mathrm{Me}^{\mathrm{Sul}}\right), 1.76\left(\mathrm{~s}, 3 \mathrm{H}, \mathrm{Me}^{\mathrm{Sul}}\right), 3.34-3.61$ (m, 14H, NMe, $\left.\mathrm{CH}_{2}{ }^{\mathrm{Sul}}\right), 3.99-4.15\left(\mathrm{~m}, 12 \mathrm{H}, \mathrm{CH}_{2}\right), 4.73\left(\mathrm{~s}, 1 \mathrm{H}, \mathbf{C H}-\mathrm{COO}^{\mathrm{Sul}}\right), 4.94-4.96$ $\left(\mathrm{m}, 1 \mathrm{H}, \mathbf{C H}-\mathrm{CH}_{2}{ }^{\mathrm{Sul}}\right), 6.14\left(\mathrm{~s}, 1 \mathrm{H}, \mathrm{CH}^{\mathrm{Pz}}\right), 6.99\left(\mathrm{dd}, 4 \mathrm{H},{ }^{3} J_{\mathrm{H}, \mathrm{H}}=5.4 \mathrm{~Hz},{ }^{4} J_{\mathrm{H}, \mathrm{H}}=1.5 \mathrm{~Hz}\right.$, $\left.\mathrm{CH}^{\text {Imid }}\right), 7.12$ (bs, 4H, $\mathrm{CH}^{\text {Imid }}$ ).

${ }^{13} \mathrm{C} \mathrm{NMR}\left(75 \mathrm{MHz}, d_{3}-\mathrm{MeCN}\right): \delta=18.9\left(\mathrm{Me}^{\mathrm{Sul}}\right), 21.2\left(\mathrm{Me}^{\mathrm{Sul}}\right), 33.6(\mathrm{NMe}), 38.5\left(\mathrm{CH}_{2}{ }^{\mathrm{Sul}}\right)$, $51.6\left(\mathrm{CH}_{2}\right), 53.8\left(\mathrm{CH}_{2}\right), 62.2\left(\mathbf{C H}-\mathrm{CH}_{2}{ }^{\mathrm{Sul}}\right), 64.0\left(\mathrm{~S}-\mathrm{C}_{\mathrm{q}}{ }^{\mathrm{Sul}}\right), 66.5\left(\mathbf{C H}-\mathrm{COO}^{\mathrm{Sul}}\right), 102.3$ $\left(\mathrm{CH}^{\mathrm{Pz}}\right), 125.0\left(\mathrm{CH}^{\mathrm{Imid}}\right), 125.1\left(\mathrm{CH}^{\text {Imid }}\right), 125.4\left(\mathrm{CH}^{\text {Imid }}\right), 125.5\left(\mathrm{CH}^{\text {Imid }}\right), 148.7\left(\mathrm{C}_{\mathrm{q}}^{\text {Imid }}\right)$, $152.7\left(\mathrm{C}_{\mathrm{q}}^{\mathrm{Pz}}\right), 173.6\left(\mathrm{CO}^{\mathrm{Lactam}, \mathrm{Sul}}\right), 175.3\left(\mathrm{COO}^{\mathrm{Sul}}\right)$.

MS (ESI+): $m / z=1010\left[\mathrm{Zn}_{2} \mathrm{H}_{-1} \mathrm{~L}^{1}(\mathrm{Sul})\left(\mathrm{SO}_{3} \mathrm{CF}_{3}\right)\right]^{+}, 430\left[\mathrm{Zn}_{2} \mathrm{H}_{-1} \mathrm{~L}^{1}(\mathrm{Sul})\right]^{2+}$.

HR-MS (ESI+): Calcd. $(m / z)$ for $\left[\mathrm{C}_{34} \mathrm{H}_{43} \mathrm{~F}_{3} \mathrm{~N}_{13} \mathrm{O}_{8} \mathrm{~S}_{2} \mathrm{Zn}_{2}\right]^{+}:$1010.1329. Found: 1010.1335. Calcd. $(\mathrm{m} / z)$ for $\left[\mathrm{C}_{33} \mathrm{H}_{43} \mathrm{~N}_{13} \mathrm{O}_{5} \mathrm{SZn}_{2}\right]^{2+}: 430.5901$. Found: 430.5903.

IR (KBr): $\tilde{v}\left(\mathrm{~cm}^{-1}\right)=3130(\mathrm{w}), 2923(\mathrm{w}), 2863(\mathrm{w}), 1790(\mathrm{~s}), 1625$ (vs), $1548(\mathrm{w})$, $1510(\mathrm{~s}), 1424$ (s), 1359 (m), 1320 (m), 1264 (vs), 1225 (m), 1160 (s), 1118 (m), $1031(\mathrm{vs}), 983$ (m), 959 (m), 875 (m), 791 (m), $756(\mathrm{~m}), 710(\mathrm{w}), 676(\mathrm{w}), 639$ (s), $571(\mathrm{~m}), 518(\mathrm{~m})$.

For comparison: chemical shifts of Sul sodium salt

${ }^{1} \mathrm{H}$ NMR (300 MHz, $\left.d_{3}-\mathrm{MeCN} / \mathrm{D}_{2} \mathrm{O}=9: 1, \mathrm{v} / \mathrm{v}\right): \delta=1.37$ (s, 3H, Me), 1.50 (s, 3H, Me), $3.18\left(\mathrm{dd}, 1 \mathrm{H},{ }^{2} J_{\mathrm{H}, \mathrm{H}}=16.2 \mathrm{~Hz},{ }^{3} J_{\mathrm{H}, \mathrm{H}}=1.5 \mathrm{~Hz}, \mathrm{CH}_{2}\right), 3.49\left(\mathrm{dd}, 1 \mathrm{H},{ }^{2} J_{\mathrm{H}, \mathrm{H}}=16.2 \mathrm{~Hz},{ }^{3} J_{\mathrm{H}, \mathrm{H}}=\right.$ $\left.4.5 \mathrm{~Hz}, \mathrm{CH}_{2}\right), 4.0(\mathbf{C H}-\mathrm{COO}), 4.75-4.77\left(\mathrm{~m}, 1 \mathrm{H}, \mathrm{CH}_{2}-\mathbf{C H}\right)$.

${ }^{13} \mathrm{C} \mathrm{NMR}\left(75 \mathrm{MHz}, d_{3}-\mathrm{MeCN} / \mathrm{D}_{2} \mathrm{O}=9: 1, \mathrm{v} / \mathrm{v}\right): \delta=18.7(\mathrm{Me}), 20.3(\mathrm{Me}), 37.5\left(\mathrm{CH}_{2}\right)$, $61.5\left(\mathrm{CH}_{2}-\mathbf{C H}\right), 63.7\left(\mathrm{~S}-\mathrm{C}_{\mathrm{q}}\right), 66.1(\mathbf{C H}-\mathrm{COO}), 172.5(\mathrm{COO}), 174.0\left(\mathrm{CO}^{\mathrm{Lactam}}\right)$. 


\subsection{Hydrolytic Activity in Penicillin G Cleavage}

Experiments of the hydrolysis of Penicillin $\mathrm{G}(\mathrm{PenG})$ were performed in $\mathrm{DMSO} / \mathrm{H}_{2} \mathrm{O}$ $(9: 1, \mathrm{v} / \mathrm{v})$ in a total volume of $500 \mu \mathrm{l}$. PenG $(\mathrm{c}=42.8 \mathrm{mM})$ was used in 4-fold excess with respect to the complex $(\mathrm{c}=10.7 \mathrm{mM})$. Complex and substrate were dissolved separately and a spectrum of pure PenG was recorded before adding the complex solution. After mixing, the course of the intensity of the band at $1772 \mathrm{~cm}^{-1}$ was monitored at $\mathrm{rt}$ and plotted versus time.

In case of $\mathbf{9}, \mathbf{L}^{\mathbf{3}}(4.1 \mathrm{mg}, 5.4 \mu \mathrm{mol}), \mathrm{KO}^{t} \mathrm{Bu}(1.2 \mathrm{mg}, 10.7 \mu \mathrm{mol})$ and $\mathrm{Zn}\left(\mathrm{ClO}_{4}\right)_{2} \cdot 6 \mathrm{H}_{2} \mathrm{O}$ (4.0 mg, $10.7 \mu \mathrm{mol})$ were dissolved in $250 \mu \mathrm{DMSO} / \mathrm{H}_{2} \mathrm{O}(9: 1, \mathrm{v} / \mathrm{v})$ and stirred until the solution became clear. To this complex solution PenG $(8.0 \mathrm{mg}, 21.4 \mu \mathrm{mol})$ dissolved in $250 \mu \mathrm{DMSO} / \mathrm{H}_{2} \mathrm{O}(9: 1, \mathrm{v} / \mathrm{v})$ was added and the measurements were started initially. The reaction was followed at the band at $1772 \mathrm{~cm}^{-1}$ in intervals of 1 minute for the first $30 \mathrm{~min}$, later in 4 min intervals.

\subsection{Phosphate Ester Cleavage}

\subsubsection{2-Hydroxypropyl-p-nitrophenyl Phosphate (HPNP)}

In order to investigate the hydrolytic activity towards 2-hydroxypropyl-p-nitrophenyl phosphate (HPNP) transesterification/hydrolysis, the absorbance of $p$-nitrophenolate was followed by UV-Vis spectroscopy at $400 \mathrm{~nm}$. The concentrations used were $0.82 \mathrm{mM}$ HPNP and $0.25 \mathrm{mM}$ complex, in a total volume of $2 \mathrm{ml}$ buffered $\mathrm{H}_{2} \mathrm{O} / \mathrm{MeCN}(1: 1, \mathrm{v} / \mathrm{v})$. Ionic strength was maintained at $0.1 \mathrm{M}$ with $\mathrm{NaClO}_{4}$ and buffers $(\mathrm{c}=0.01 \mathrm{M})$ were used as follows: Mes (pH 5.0-6.5), Mops (pH 7.0-7.5), Epps (pH 8.0-8.5), Ches (pH 9.0-9.5) and Caps (pH 10.0-10.5). Perchloric acid and sodium hydroxide were used to adjust $\mathrm{pH}$ values. The temperature was kept at $25^{\circ} \mathrm{C}$ during measurements by thermostated cell changer. Before adding HPNP, all reagents were mixed in a cuvette due to zero absorbance measurement. The substrate was then added and the measurements were started initially in time intervals of $1 \mathrm{~min}$ for $4 \mathrm{~h}$. The total concentration of $p$-nitrophenolate $\left(\varepsilon=18500 \mathrm{M}^{-1} \cdot \mathrm{cm}^{-1}, \mathrm{p} K_{\mathrm{a}}=7.15\right)$ was calculated utilising the BeerLambert law (ii) and the Henderson-Hasselbalch equation (iii) (section 2.4.3.). Initial 
rates, resulting from the slope of the fitted line, were determined by plotting total concentrations versus time.

\subsubsection{Paraoxon}

The cleavage of Paraoxon was followed applying ${ }^{31} \mathrm{P}$ NMR spectroscopy. A stock solution of Paraoxon (100 mg in $1000 \mu \mathrm{l} \mathrm{MeCN})$ was used for all experiments.

The $\mathrm{pH}$ independent experiments were performed in $d_{3}-\mathrm{MeCN} / \mathrm{D}_{2} \mathrm{O}(9: 1, \mathrm{v} / \mathrm{v})$ :

Paraoxon $(6.60 \mu \mathrm{l}$ stock solution, $2.4 \mu \mathrm{mol})$ was added to an equimolar amount of the respective complex (2 $(2.43 \mathrm{mg}, 2.4 \mu \mathrm{mol}), \mathbf{5 a}(2.38 \mathrm{mg}, 2.4 \mu \mathrm{mol}), \mathbf{1 2}(1.48 \mathrm{mg}$, $2.4 \mu \mathrm{mol}))$ in $534 \mu \mathrm{l} d_{3}$-MeCN. Furthermore, $60 \mu \mathrm{l} \mathrm{D}_{2} \mathrm{O}$ was added and the measurements were started immediately after mixing. Spectra were continuously recorded, in the beginning every 15-30 minutes, later every hour.

${ }^{31} \mathrm{P}$ NMR (121 MHz, $\left.d_{3}-\mathrm{MeCN} / \mathrm{D}_{2} \mathrm{O}=9: 1, \mathrm{v} / \mathrm{v}\right): \delta=7.29$ (Paraoxon).

The $\mathrm{pH}$ dependent experiments were performed in buffered $\mathrm{H}_{2} \mathrm{O} / d_{6}$-DMSO $(8: 2, \mathrm{v} / \mathrm{v})$ : Paraoxon $(6.88 \mu \mathrm{l}$ stock solution, $2.5 \mu \mathrm{mol})$ was added to $480 \mu \mathrm{l}$ buffer solution. Furthermore, 1 equivalent of the respective complex (2 $(2.53 \mathrm{mg}, 2.5 \mu \mathrm{mol}), 4(2.32 \mathrm{mg}$, $2.5 \mu \mathrm{mol})$ or $6(2.48 \mathrm{mg}, 2.5 \mu \mathrm{mol}))$ dissolved in $120 \mu \mathrm{l} d_{6}$-DMSO was added and the measurements recorded initially after mixing. Between the measurements, the NMR tubes were stored at $40{ }^{\circ} \mathrm{C}$ (water bath) to promote the catalytic reaction.

${ }^{31} \mathrm{P}$ NMR $\left(121 \mathrm{MHz}\right.$, buffered $\mathrm{H}_{2} \mathrm{O} / d_{6}$-DMSO $\left.=8: 2, \mathrm{v} / \mathrm{v}\right): \delta=6.85$ (Paraoxon), 0.34 (free $\left.\mathrm{OP}(\mathrm{O})(\mathrm{OEt})_{2}\right)$.

In the experiment to investigate the influence of the sulfonic buffer, Paraoxon $(6.88 \mu \mathrm{l}$ stock solution, $2.5 \mu \mathrm{mol}), 2(2.53 \mathrm{mg}, 2.5 \mu \mathrm{mol})$ and $\mathrm{KO}^{t} \mathrm{Bu}(0.28 \mathrm{mg}, 2.5 \mu \mathrm{mol})$ were mixed in $600 \mu \mathrm{l} \mathrm{H}_{2} \mathrm{O} / d_{6}$-DMSO $(8: 2, \mathrm{v} / \mathrm{v})$. Measurements were recorded in regular intervals (12 hours) and the NMR tube was stored at $40{ }^{\circ} \mathrm{C}$ (water bath) between measurements.

${ }^{31} \mathrm{P}$ NMR $\left(121 \mathrm{MHz}, \mathrm{H}_{2} \mathrm{O} / d_{6}-\mathrm{DMSO}=8: 2, \mathrm{v} / \mathrm{v}\right): \delta=6.85$ (Paraoxon), 0.82 (coordinated $\left.\mathrm{OP}(\mathrm{O})(\mathrm{OEt})_{2}\right)$. 


\subsubsection{Synthesis of $\left[\mathrm{Zn}_{2} \mathrm{H}_{-1} \mathrm{~L}^{1}\left(\mathrm{OP}(\mathrm{O})(\mathrm{OEt})_{2}\right)\right]\left(\mathrm{SO}_{3} \mathrm{CF}_{3}\right)_{2}(18)$}

Under an inert atmosphere, $\mathbf{L}^{\mathbf{1}}(20 \mathrm{mg}, 0.04 \mathrm{mmol}), \mathrm{KO}^{t} \mathrm{Bu}(5 \mathrm{mg}, 0.04 \mathrm{mmol})$ and $\mathrm{Zn}\left(\mathrm{SO}_{3} \mathrm{CF}_{3}\right)_{2}(29 \mathrm{mg}, 0.08 \mathrm{mmol})$ were combined in a flask, before adding $\mathrm{MeCN}(8 \mathrm{ml})$. The mixture was stirred until the suspension became clear. Addition of Paraoxon (11 mg, $0.04 \mathrm{mmol})$ in $\mathrm{MeCN}(110 \mu \mathrm{l})$ was followed by stirring for $16 \mathrm{~h}$. After filtration and diffusion of $\mathrm{Et}_{2} \mathrm{O}$ into the complex solution, colourless crystals were obtained and analysed by X-ray diffraction ( $2 \mathrm{mg}, 2 \mu \mathrm{mol}, 5 \%$ )

${ }^{1} \mathrm{H}$ NMR $\left(300 \mathrm{MHz}, d_{3}-\mathrm{MeCN}\right): \delta=1.44\left(\mathrm{t}, 6 \mathrm{H},{ }^{3} J_{\mathrm{HH}}=7.2 \mathrm{~Hz}, \mathrm{CH}_{2}-\mathbf{C H}_{3}\right), 3.54(\mathrm{~s}, 12 \mathrm{H}$, $\mathrm{NMe}$ ), 3.98-4.04 (m, 12H, $\left.\mathrm{CH}_{2}\right), 4.20-4.25$ (m, 4H, $\left.\mathbf{C H}_{2}-\mathrm{CH}_{3}\right), 6.09\left(\mathrm{~s}, 1 \mathrm{H}, \mathrm{CH}^{\mathrm{Pz}}\right), 6.98$ $\left(\mathrm{d}, 2 \mathrm{H},{ }^{3} J_{\mathrm{H}, \mathrm{H}}=1.5 \mathrm{~Hz}, \mathrm{CH}^{\text {Imid }}\right), 7.08\left(\mathrm{~d}, 2 \mathrm{H},{ }^{3} J_{\mathrm{H}, \mathrm{H}}=1.5 \mathrm{~Hz}, \mathrm{CH}^{\text {Imid }}\right), 7.11\left(\mathrm{bs}, 4 \mathrm{H}, \mathrm{CH}^{\text {Imid }}\right)$. ${ }^{31} \mathrm{P}$ NMR $\left(121 \mathrm{MHz}, d_{3}-\mathrm{MeCN}\right): \delta=0.87\left(\mathrm{OP}(\mathrm{O})(\mathrm{OEt})_{2}\right)$.

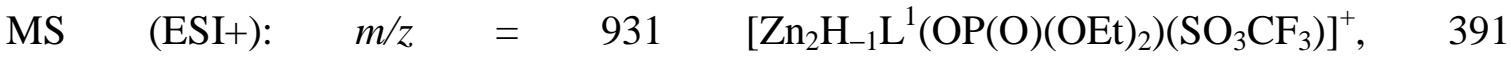
$\left[\mathrm{Zn}_{2} \mathrm{H}_{-1} \mathrm{~L}^{1}\left(\mathrm{OP}(\mathrm{O})(\mathrm{OEt})_{2}\right)\right]^{2+}$.

HR-MS (ESI+): Calcd. $(\mathrm{m} / z)$ for $\left[\mathrm{C}_{30} \mathrm{H}_{43} \mathrm{~F}_{3} \mathrm{~N}_{12} \mathrm{O}_{7} \mathrm{PSZn}_{2}\right]^{+}$: 931.1366. Found: 931.1364. Calcd. $(m / z)$ for $\left[\mathrm{C}_{29} \mathrm{H}_{43} \mathrm{~N}_{12} \mathrm{O}_{4} \mathrm{PZn}_{2}\right]^{2+}: 391.0920$. Found: 391.0919 .

IR (KBr): $\tilde{v}\left(\mathrm{~cm}^{-1}\right)=3435$ (vs), 2926 (w), 1632 (m), 1508 (m), 1442 (w), 1262 (vs), 1157 (m), 1031 (s), $964(\mathrm{w}), 752(\mathrm{w}), 639(\mathrm{~m}), 574(\mathrm{w}), 518(\mathrm{w})$.

\subsection{Activation of $\mathrm{CO}_{2}$}

\subsubsection{Reaction of Cyclohexene Oxide and $\mathrm{CO}_{2}$}

$2(20.6 \mathrm{mg}, 20.3 \mu \mathrm{mol})$ and $\mathrm{KO}^{t} \mathrm{Bu}(2.3 \mathrm{mg}, 20.5 \mu \mathrm{mol})$ were dissolved in cyclohexene oxide $(5.0 \mathrm{ml}, 49.5 \mathrm{mmol})$ under inert conditions. The mixture was heated to $80{ }^{\circ} \mathrm{C}$ and $\mathrm{CO}_{2}(1 \mathrm{~atm})$ was gently bubbled into the mixture $(16 \mathrm{~h})$. The residue was dried in vacuum and the colourless solid was suspended in DCM $(10 \mathrm{ml})$. After filtration, $\mathrm{MeOH}$ was added to the solution, whereby the product precipitated. This was collected by filtration and the colourless polymeric product was dried in vacuum.

The same experiment was performed with $2(49.0 \mathrm{mg}, 48.4 \mu \mathrm{mol})$ and $\mathrm{KO}^{t} \mathrm{Bu}(5.4 \mathrm{mg}$, $48.3 \mu \mathrm{mol})$ in cyclohexene oxide $(5.0 \mathrm{ml}, 49.5 \mathrm{mmol})$. 
${ }^{1} \mathrm{H}$ NMR $\left(200 \mathrm{MHz}, \mathrm{CDCl}_{3}\right): \delta=1.05-1.46$ (bs, 4H), 1.46-1.73 (bs, 2H), 1.73-2.09 (bs, 2H), 3.19-3.60 (bs, 2H).

\subsubsection{Reaction of 1,2-Propylene Glycol and $\mathrm{CO}_{2}$}

$2(100.0 \mathrm{mg}, 0.1 \mathrm{mmol})$ and $\mathrm{KO}^{t} \mathrm{Bu}(11.1 \mathrm{mg}, 0.1 \mathrm{mmol})$ were dried in vacuum. MeCN $(20 \mathrm{ml})$ was added and the suspension was stirred for $30 \mathrm{~min}$. 1,2-Propylene glycol ( $0.73 \mathrm{ml}, 10.0 \mathrm{mmol})$ and molecular sieve $(3 \AA)$ was added and the suspension was stirred for $2 \mathrm{~h}$. The mixture was heated to reflux and $\mathrm{CO}_{2}(1 \mathrm{~atm})$ was bubbled gently into the mixture (18 h). In hourly intervals samples were taken for GC-MS analysis.

The same procedure was carried out for $2(86.0 \mathrm{mg}, 85 \mu \mathrm{mol}), \mathrm{KO}^{t} \mathrm{Bu}(9.5 \mathrm{mg}, 85 \mu \mathrm{mol})$ and 1,2-Propylene glycol (30 ml, $0.4 \mathrm{~mol})$ at $\mathrm{rt}$.

GC-MS: $\mathrm{t}_{\mathrm{R}}=3.45 \mathrm{~min}$ (1,2-propylene glycol).

\subsubsection{Synthesis of $\left[\left(\mathrm{Zn}_{2} \mathrm{H}_{-1} \mathrm{~L}^{1}\right)_{2}\left(\mathrm{CO}_{3}\right)\right]\left(\mathrm{ClO}_{4}\right)_{4}(19)$}

$\mathbf{L}^{\mathbf{1}}$ (100 mg, $0.20 \mathrm{mmol}$ ) was dissolved in $\mathrm{MeOH}(9 \mathrm{~mL})$. To this colourless solution, $\mathrm{KO}^{t} \mathrm{Bu}(45 \mathrm{mg}, 0.40 \mathrm{mmol}$ ) was added and stirred for $30 \mathrm{~min}$. Subsequently, $\mathrm{Zn}\left(\mathrm{ClO}_{4}\right)_{2} \cdot 6 \mathrm{H}_{2} \mathrm{O}(150 \mathrm{mg}, 0.40 \mathrm{mmol})$ was added. After stirring for $12 \mathrm{~h}$, the suspension was filtrated. Diffusion of $\mathrm{Et}_{2} \mathrm{O}$ into the complex solution afforded colourless crystals after several weeks. (6 mg, $3 \mu \mathrm{mol}, 2 \%)$.

${ }^{1} \mathrm{H}$ NMR (300 MHz, $d_{3}-\mathrm{MeCN}$ ): $\delta=3.56$ (s, 24H, NMe), 4.07-4.23 (m, 24H, $\mathrm{CH}_{2}$ ), 6.10 $\left(\mathrm{s}, 2 \mathrm{H}, \mathrm{CH}^{\mathrm{Pz}}\right), 6.80\left(\mathrm{bs}, 8 \mathrm{H}, \mathrm{CH}^{\mathrm{Imid}}\right), 6.90\left(\mathrm{bs}, 8 \mathrm{H}, \mathrm{CH}^{\mathrm{Imid}}\right)$.

${ }^{13} \mathrm{C} \mathrm{NMR}\left(75 \mathrm{MHz}, d_{3}-\mathrm{MeCN}\right): \delta=33.6(\mathrm{NMe}), 52.0\left(\mathrm{CH}_{2}\right), 54.4\left(\mathrm{CH}_{2}\right), 100.8\left(\mathrm{CH}^{\mathrm{Pz}}\right)$, 124.8 $\left(\mathrm{CH}^{\text {Imid }}\right), 125.4\left(\mathrm{CH}^{\text {Imid }}\right), 149.1\left(\mathrm{C}_{\mathrm{q}}^{\text {Imid }}\right), 151.8\left(\mathrm{C}_{\mathrm{q}}{ }^{\mathrm{Pz}}\right)$.

IR (KBr): $\tilde{v}\left(\mathrm{~cm}^{-1}\right)=2922(\mathrm{w}), 2855(\mathrm{w}), 1660(\mathrm{~s}), 1625$ (sh), $1546(\mathrm{w}), 1505$ (m), 1493 (sh), 1443 (w), 1393 (w), 1286 (m), 1165 (m), 1096 (vs), 981 (w), 960 (m), 872 (w), $759(\mathrm{~m}), 621(\mathrm{~s}), 562(\mathrm{w}), 454(\mathrm{w})$. 


\section{Appendix}

\section{Crystallography}

X-ray data were recorded at $133 \mathrm{~K}$ on a STOE IPDS II diffractometer with graphite monochromated Mo-K $\mathrm{K}_{\alpha}$ radiation $(\lambda=0.71073 \AA)$. X-ray crystallographic data of 11 were measured on a Bruker three circle diffractometer equipped with a SMART 6000 $\mathrm{CCD}$ detector using monochromated $\mathrm{Cu}-\mathrm{K}_{\alpha}$ radiation $(\lambda=1.54178 \AA)$ at $100 \mathrm{~K}$. In addition to corrections in terms of Lorentz and polarisations effects, ${ }^{[98]}$ absorption corrections of the crystallographic data were performed. ${ }^{[99]}$ The crystal structures were solved and refined using the programs SHELXS-97 and SHELXL-97. ${ }^{[100]}$ 
Table A.1: Crystal data and refinement details for 1, 2 and $\mathbf{3 .}$

\begin{tabular}{|c|c|c|c|}
\hline & $\mathbf{1}$ & 2 & 3 \\
\hline empirical formula & $\mathrm{C}_{27} \mathrm{H}_{39} \mathrm{Cl}_{4} \mathrm{~N}_{13} \mathrm{O}_{16} \mathrm{Zn}$ & $\mathrm{C}_{33} \mathrm{H}_{45} \mathrm{Cl}_{3} \mathrm{~N}_{16} \mathrm{O}_{12} \mathrm{Zn}_{2}$ & 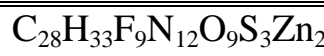 \\
\hline formula weight & 1008.88 & 1094.94 & 1079.58 \\
\hline crystal size $\left[\mathrm{mm}^{3}\right]$ & $0.32 \times 0.09 \times 0.05$ & $0.5 \times 0.25 \times 0.17$ & $0.17 \times 0.11 \times 0.06$ \\
\hline crystal system & Monoclinic & Triclinic & Triclinic \\
\hline space group & $P 2_{1} / c$ & $P \overline{1}$ & $P \overline{1}$ \\
\hline$a[\AA]$ & $13.8475(7)$ & $12.8010(7)$ & $12.2505(6)$ \\
\hline$b[\AA]$ & $12.5262(4)$ & $12.9777(7)$ & $13.1090(7)$ \\
\hline$c[\AA]$ & $23.7268(10)$ & $14.8777(7)$ & $16.6079(9)$ \\
\hline$\alpha\left[^{\circ}\right]$ & 90.00 & $85.234(4)$ & $85.563(4)$ \\
\hline$\beta\left[^{\circ}\right]$ & $94.212(4)$ & $76.122(4)$ & $86.136(4)$ \\
\hline$\gamma\left[^{\circ}\right]$ & 90.00 & $84.947(4)$ & $65.344(4)$ \\
\hline$V\left[\AA^{3}\right]$ & $4104.5(3)$ & $2385.2(2)$ & $2414.9(2)$ \\
\hline$Z$ & 4 & 2 & 2 \\
\hline$\rho\left[\mathrm{g} / \mathrm{cm}^{3}\right]$ & 1.633 & 1.525 & 1.485 \\
\hline$F(000)$ & 2072 & 1124 & 1092 \\
\hline$\mu\left[\mathrm{mm}^{-1}\right]$ & 0.944 & 1.246 & 1.213 \\
\hline$T \min / T \max$ & $0.2934 / 0.6868$ & $0.5267 / 0.8066$ & $0.6452 / 0.9527$ \\
\hline$\theta$ range $\left[{ }^{\circ}\right]$ & $1.47-26.82$ & $1.64-27.04$ & $1.71-27.01$ \\
\hline$h k l$ range & $\pm 17, \pm 15,-30-29$ & $\pm 16,-15-16,-19-18$ & $\pm 15, \pm 16, \pm 21$ \\
\hline measured refl. & 39029 & 21171 & 22761 \\
\hline unique refl. [Rint] & $8739[0.1336]$ & $10284[0.0580]$ & $10436[0.0664]$ \\
\hline observed refl. $(I>2 \sigma(I))$ & 5628 & 7865 & 6635 \\
\hline data / restraints / param. & $8739 / 0$ / 555 & 10284 / 32 / 642 & $10436 / 0$ / 568 \\
\hline goodness-of-fit $\left(F^{2}\right)$ & 1.077 & 0.939 & 1.032 \\
\hline$R 1, w R 2(I>2 \sigma(I))$ & $0.0729,0.1209$ & $0.0448,0.1193$ & $0.0511,0.0712$ \\
\hline$R 1, w R 2$ (all data) & $0.1250,0.1367$ & $0.0641,0.1280$ & $0.0962,0.0775$ \\
\hline resid. el. dens. $\left[\mathrm{e} / \AA^{3}\right]$ & $-0.467 / 0.438$ & $-0.696 / 1.073$ & $-0.528 / 0.489$ \\
\hline
\end{tabular}


Table A.2: Crystal data and refinement details for $\mathbf{4 a}, \mathbf{4 b}$ and $5 \mathbf{a}$.

\begin{tabular}{|c|c|c|c|}
\hline & $4 a$ & $4 \mathrm{~b}$ & $5 \mathbf{a}$ \\
\hline empirical formula & $\mathrm{C}_{28} \mathrm{H}_{44} \mathrm{Cl}_{2} \mathrm{~N}_{12} \mathrm{O}_{11} \mathrm{Zn}_{2}$ & $\overline{\mathrm{C}_{28} \mathrm{H}_{44} \mathrm{Cl}_{2} \mathrm{~N}_{12} \mathrm{O}_{11} \mathrm{Zn}_{2}}$ & $\mathrm{C}_{29} \mathrm{H}_{36} \mathrm{~F}_{6} \mathrm{~N}_{12} \mathrm{O}_{8} \mathrm{~S}_{2} \mathrm{Zn}_{2}$ \\
\hline formula weight & 926.39 & 926.39 & 989.56 \\
\hline crystal size $\left[\mathrm{mm}^{3}\right]$ & $0.50 \times 0.24 \times 0.15$ & $0.25 \times 0.22 \times 0.22$ & $0.34 \times 0.25 \times 0.24$ \\
\hline crystal system & Monoclinic & Monoclinic & Triclinic \\
\hline space group & $C c$ & $P 2_{1} / c$ & $P \overline{1}$ \\
\hline$a[\AA]$ & $18.8465(6)$ & $17.436(4)$ & $11.7590(6)$ \\
\hline$b[\AA]$ & $16.7309(7)$ & $13.988(3)$ & $13.4783(6)$ \\
\hline$c[\AA]$ & $13.1306(5)$ & $16.176(3)$ & $15.0186(7)$ \\
\hline$\alpha\left[^{\circ}\right]$ & 90.00 & 90.00 & $63.680(3)$ \\
\hline$\beta\left[^{\circ}\right]$ & $113.515(2)$ & $104.56(3)$ & $75.883(4)$ \\
\hline$\gamma\left[^{\circ}\right]$ & 90.00 & 90.00 & $66.229(3)$ \\
\hline$V\left[\AA^{3}\right]$ & $3796.5(2)$ & $3818.6(13)$ & $1946.38(16)$ \\
\hline$Z$ & 4 & 4 & 2 \\
\hline$\rho\left[\mathrm{g} / \mathrm{cm}^{3}\right]$ & 1.621 & 1.611 & 1.688 \\
\hline$F(000)$ & 1912 & 1912 & 1008 \\
\hline$\mu\left[\mathrm{mm}^{-1}\right]$ & 1.477 & 1.468 & 1.433 \\
\hline$T \min / T \max$ & $0.6878 / 0.4245$ & $0.6211 / 0.7698$ & $0.5983 / 0.7747$ \\
\hline$\theta$ range $\left[{ }^{\circ}\right]$ & $1.69-26.96$ & $1.89-26.83$ & $1.52-26.75$ \\
\hline$h k l$ range & $\pm 23, \pm 21, \pm 16$ & $\pm 22, \pm 17,-16-20$ & $-12-14, \pm 17,-19-18$ \\
\hline measured refl. & 16814 & 34391 & 18205 \\
\hline unique refl. [Rint] & $7555[0.0396]$ & 7938 [0.0649] & $8194[0.0341]$ \\
\hline observed refl. $(I>2 \sigma(I))$ & 7006 & 5753 & 6435 \\
\hline data / restraints / param. & $7555 / 2 / 508$ & 7938 / 0 / 500 & 8194 / 0 / 532 \\
\hline goodness-of-fit $\left(F^{2}\right)$ & 1.010 & 1.052 & 0.927 \\
\hline$R 1, w R 2(I>2 \sigma(I))$ & $0.0291,0.0668$ & $0.0634,0.1402$ & $0.0285,0.0611$ \\
\hline$R 1, w R 2$ (all data) & $0.0326,0.0677$ & $0.0966,0.1528$ & $0.0433,0.0640$ \\
\hline resid. el. dens. $\left[\mathrm{e} / \AA^{3}\right]$ & $-0.377 / 0.441$ & $-0.657 / 0.947$ & $-0.587 / 0.337$ \\
\hline
\end{tabular}


Table A.3: Crystal data and refinement details for $\mathbf{5 b}, \mathbf{6}$ and $\mathbf{7 .}$

\begin{tabular}{|c|c|c|c|}
\hline & $5 \mathbf{b}$ & 6 & 7 \\
\hline empirical formula & $\mathrm{C}_{31} \mathrm{H}_{42} \mathrm{Cl}_{2} \mathrm{~N}_{14} \mathrm{O}_{10} \mathrm{Zn}_{2}$ & $\mathrm{C}_{52} \mathrm{H}_{76} \mathrm{Cl}_{2} \mathrm{~N}_{24} \mathrm{O}_{11} \mathrm{Zn}_{2}$ & 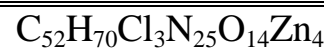 \\
\hline formula weight & 972.43 & 1415.01 & 1637.16 \\
\hline crystal size $\left[\mathrm{mm}^{3}\right]$ & $0.24 \times 0.18 \times 0.14$ & $0.5 \times 0.35 \times 0.27$ & $0.5 \times 0.1 \times 0.09$ \\
\hline crystal system & Monoclinic & Monoclinic & Triclinic \\
\hline space group & $C 2 / c$ & $C 2 / c$ & $P \overline{1}$ \\
\hline$a[\AA]$ & $26.763(5)$ & $23.7716(12)$ & $13.0416(8)$ \\
\hline$b[\AA]$ & $11.028(2)$ & $13.7956(4)$ & $15.4255(9)$ \\
\hline$c[\AA]$ & $17.519(4)$ & $19.3180(10)$ & $23.1438(14)$ \\
\hline$\alpha\left[^{\circ}\right]$ & 90.00 & 90.00 & $90.586(5)$ \\
\hline$\beta\left[{ }^{\circ}\right]$ & $127.76(3)$ & $101.937(4)$ & $93.478(5)$ \\
\hline$\gamma\left[{ }^{\circ}\right]$ & 90.00 & 90.00 & $93.129(5)$ \\
\hline$V\left[\AA^{3}\right]$ & $4087.7(14)$ & $6198.2(5)$ & $4640.0(5)$ \\
\hline$Z$ & 4 & 4 & 2 \\
\hline$\rho\left[\mathrm{g} / \mathrm{cm}^{3}\right]$ & 1.580 & 1.516 & 1.172 \\
\hline$F(000)$ & 2000 & 2952 & 1680 \\
\hline$\mu\left[\mathrm{mm}^{-1}\right]$ & 1.376 & 0.939 & 1.166 \\
\hline$T \min / T \max$ & $0.5763 / 0.8380$ & 0.6504 / 0.7902 & - \\
\hline$\theta$ range $\left[{ }^{\circ}\right]$ & $1.93-26.74$ & $1.72-25.67$ & $1.32-25.71$ \\
\hline$h k l$ range & $\pm 33, \pm 13, \pm 22$ & $\pm 28,-15-16, \pm 23$ & $-15-13, \pm 18, \pm 28$ \\
\hline measured refl. & 17467 & 24344 & 39157 \\
\hline unique refl. [Rint] & $4324[0.0330]$ & 5857 [0.0439] & $17435[0.0966]$ \\
\hline observed refl. $(I>2 \sigma(I))$ & 3752 & 4421 & 6764 \\
\hline data / restraints / param. & 4324 / 0 / 269 & $5857 / 2 / 418$ & $17435 / 59 / 873$ \\
\hline goodness-of-fit $\left(F^{2}\right)$ & 1.044 & 0.935 & 0.772 \\
\hline$R 1, w R 2(I>2 \sigma(I))$ & $0.0381,0.0996$ & $0.0352,0.0815$ & $0.0689,0.1573$ \\
\hline$R 1, w R 2$ (all data) & $0.0451,0.1032$ & $0.0543,0.0857$ & $0.1456,0.1822$ \\
\hline resid. el. dens. [e/ $\left.\AA^{3}\right]$ & $-0.642 / 0.745$ & $-0.541 / 0.789$ & $-0.811 / 0.967$ \\
\hline
\end{tabular}


Table A.4: Crystal data and refinement details for $\mathbf{8 , 1 1}$ and 12 .

\begin{tabular}{|c|c|c|c|}
\hline & 8 & 11 & 12 \\
\hline empirical formula & $\mathrm{C}_{88} \mathrm{H}_{93} \mathrm{Cl}_{4} \mathrm{~N}_{27} \mathrm{O}_{18} \mathrm{Zn}_{4}$ & $\mathrm{C}_{42} \mathrm{H}_{58} \mathrm{Cl}_{2} \mathrm{~N}_{16} \mathrm{O}_{16} \mathrm{Zn}_{2}$ & $\mathrm{C}_{21} \mathrm{H}_{26} \mathrm{~N}_{8} \mathrm{O}_{6} \mathrm{Zn}_{2}$ \\
\hline formula weight & 2220.17 & 1244.68 & 617.24 \\
\hline crystal size $\left[\mathrm{mm}^{3}\right]$ & $0.29 \times 0.14 \times 0.08$ & $0.05 \times 0.05 \times 0.03$ & $0.25 \times 0.1 \times 0.06$ \\
\hline crystal system & Triclinic & Monoclinic & Monoclinic \\
\hline space group & $P \overline{1}$ & $P 2_{1} / c$ & $P 2_{1} / m$ \\
\hline$a[\AA]$ & $14.4687(5)$ & $10.1050(10)$ & $6.5307(4)$ \\
\hline$b[\AA]$ & $16.1003(6)$ & $16.793(2)$ & $23.6427(10)$ \\
\hline$c[\AA]$ & $20.8574(8)$ & $15.332(2)$ & $9.0163(5)$ \\
\hline$\alpha\left[^{\circ}\right]$ & $90.420(3)$ & 90.00 & 90.00 \\
\hline$\beta\left[^{\circ}\right]$ & $93.688(3)$ & $100.989(10)$ & $109.478(4)$ \\
\hline$\gamma\left[^{\circ}\right]$ & $103.994(3)$ & 90.00 & 90.00 \\
\hline$V\left[\AA^{3}\right]$ & $4703.5(3)$ & $2554.0(5)$ & $1312.47(12)$ \\
\hline$Z$ & 2 & 2 & 2 \\
\hline$\rho\left[\mathrm{g} / \mathrm{cm}^{3}\right]$ & 1.568 & 1.619 & 1.562 \\
\hline$F(000)$ & 2284 & 1288 & 632 \\
\hline$\mu\left[\mathrm{mm}^{-1}\right]$ & 1.205 & 2.859 & 1.879 \\
\hline$T \min / T \max$ & $0.6941 / 0.8943$ & $0.9320 / 0.8703$ & $0.6981 / 0.9403$ \\
\hline$\theta$ range $\left[{ }^{\circ}\right]$ & $1.45-26.76$ & $3.94-65.38$ & $1.72-26.78$ \\
\hline$h k l$ range & $\pm 18, \pm 20,-26-26$ & $\pm 11, \pm 19,-17-18$ & $-8-7, \pm 29, \pm 11$ \\
\hline measured refl. & 42364 & 35045 & 11626 \\
\hline unique refl. [Rint] & $19885[0.0745]$ & $4332[0.0571]$ & 2849 [0.0469] \\
\hline observed refl. $(I>2 \sigma(I))$ & 12932 & 3527 & 2370 \\
\hline data / restraints / param. & 19885 / 2 / 1279 & 4332 / 162 / 402 & $2849 / 0 / 172$ \\
\hline goodness-of-fit $\left(F^{2}\right)$ & 1.122 & 1.020 & 0.996 \\
\hline$R 1, w R 2(I>2 \sigma(I))$ & $0.0788,0.1738$ & $0.0348,0.0862$ & $0.0306,0.0683$ \\
\hline$R 1, w R 2$ (all data) & $0.1249,0.1878$ & $0.0482,0.0941$ & $0.0439,0.0728$ \\
\hline resid. el. dens. $\left[\mathrm{e} / \AA^{3}\right]$ & $-0.703 / 1.090$ & $-0.391 / 0.470$ & $-0.422 / 0.332$ \\
\hline
\end{tabular}


Table A.5: Crystal data and refinement details for 17, 18 and 19 .

\begin{tabular}{|c|c|c|c|}
\hline & 17 & 18 & 19 \\
\hline empirical formula & $\mathrm{C}_{39} \mathrm{H}_{49} \mathrm{~F}_{6} \mathrm{~N}_{15} \mathrm{O}_{11} \mathrm{~S}_{3} \mathrm{Zn}_{2}$ & 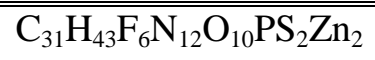 & $\mathrm{C}_{51} \mathrm{H}_{66} \mathrm{Cl}_{4} \mathrm{~N}_{24} \mathrm{O}_{19} \mathrm{Zn}_{4}$ \\
\hline formula weight & 1244.85 & 1083.60 & 1722.56 \\
\hline crystal size $\left[\mathrm{mm}^{3}\right]$ & $0.5 \times 0.5 \times 0.28$ & $0.24 \times 0.15 \times 0.13$ & $0.5 \times 0.48 \times 0.28$ \\
\hline crystal system & Monoclinic & Monoclinic & Monoclinic \\
\hline space group & $P 2_{1}$ & $P 2_{1} / n$ & $C 2 / c$ \\
\hline$a[\AA]$ & $8.9165(3)$ & $8.8487(3)$ & $26.047(5)$ \\
\hline$b[\AA]$ & $27.6888(6)$ & $21.3414(10)$ & $21.052(4)$ \\
\hline$c[\AA]$ & $10.4972(3)$ & $22.6647(8)$ & $16.787(3)$ \\
\hline$\alpha\left[^{\circ}\right]$ & 90.00 & 90.00 & 90.00 \\
\hline$\beta\left[^{\circ}\right]$ & $96.022(2)$ & $99.448(3)$ & $121.14(3)$ \\
\hline$\gamma\left[^{\circ}\right]$ & 90.00 & 90.00 & 90.00 \\
\hline$V\left[\AA^{3}\right]$ & $2577.32(13)$ & $4222.0(3)$ & $7879(3)$ \\
\hline$Z$ & 2 & 4 & 4 \\
\hline$\rho\left[\mathrm{g} / \mathrm{cm}^{3}\right]$ & 1.604 & 1.705 & 1.452 \\
\hline$F(000)$ & 1276 & 2216 & 3520 \\
\hline$\mu\left[\mathrm{mm}^{-1}\right]$ & 1.145 & 1.369 & 1.415 \\
\hline$T \min / T \max$ & $0.5243 / 0.8057$ & $0.6726 / 0.8560$ & - \\
\hline$\theta$ range $\left[{ }^{\circ}\right]$ & $1.47-25.62$ & $1.32-26.80$ & $1.33-25.72$ \\
\hline$h k l$ range & $\pm 10,-32-33, \pm 12$ & $-11-9,-26-25, \pm 28$ & $\pm 31,-25-23, \pm 20$ \\
\hline measured refl. & 32325 & 37276 & 31058 \\
\hline unique refl. [Rint] & $9536[0.0574]$ & 8967 [0.0893] & $7459[0.0628]$ \\
\hline observed refl. $(I>2 \sigma(I))$ & 9331 & 4998 & 5046 \\
\hline data / restraints / param. & $9536 / 3 / 695$ & $8967 / 15$ / 574 & 7459 / $116 / 461$ \\
\hline goodness-of-fit $\left(F^{2}\right)$ & 1.033 & 0.982 & 1.034 \\
\hline$R 1, w R 2(I>2 \sigma(I))$ & $0.0421,0.1119$ & $0.0761,0.1820$ & $0.0763,0.1948$ \\
\hline$R 1, w R 2$ (all data) & $0.0429,0.1126$ & $0.1414,0.2127$ & $0.1087,0.2078$ \\
\hline resid. el. dens. $\left[\mathrm{e} / \AA^{3}\right]$ & $-0.655 / 1.291$ & $-1.059 / 0.761$ & $-0.803 / 1.052$ \\
\hline
\end{tabular}




\section{Bibliography}

[1] a) W. Kaim, B. Schwederski, Bioanorganische Chemie, Vol. 4., durchgesehene Auflage, B. G. Teubner Verlag / GWV Fachverlage GmbH, Wiesbaden, 2005; b) G. Parkin, Chem. Commun. 2000, 1971-1985.

[2] H. Vahrenkamp, Chem. Unserer Zeit 1988, 22, 73-84.

[3] H. Haase, L. Rink, Biol. Unserer Zeit 2010, 40, 314-321.

[4] a) N. M. Meldrum, F. J. W. Roughton, J. Physiol. 1933, 80, 113-142; b) D. Keilin, T. Mann, Biochem J. 1940, 34, 1163-1176.

[5] S. F. Sousa, P. A. Fernandes, M. J. Ramos, J. Am. Chem. Soc. 2007, 129, 13781385.

[6] a) G. Parkin, Chem. Rev. 2004, 104, 699-768; b) H.-B. Kraatz, N. Metzler-Nolte, Concepts and Models in Bioinorganic Chemistry, Wiley-VCH Verlag GmbH \& Co. KGaA, Weinheim, 2006.

[7] J. M. Berg, Y. Shi, Science 1996, 271, 1081-1085.

[8] J. H. Laity, B. M. Lee, P. E. Wright, Curr. Opin. Struct. Biol. 2001, 11, 39-46.

[9] A. E. Eriksson, T. A. Jones, A. Liljas, Proteins: Struct., Funct., Bioinf. 1988, 4, 274-282.

[10] S. Toba, G. Colombo, K. M. Merz, J. Am. Chem. Soc. 1999, 121, 2290-2302.

[11] a) K. M. Merz, L. Banci, J. Am. Chem. Soc. 1997, 119, 863-871; b) M. Hartmann, K. M. Merz, R. van Eldik, T. Clark, J. Mol. Model. 1998, 4, 355-365; c) M. Bräuer, J. L. Pèrez-Lustres, J. Weston, E. Anders, Inorg. Chem. 2002, 41, 14541463.

[12] N. Sträter, W. N. Lipscomb, T. Klabunde, B. Krebs, Angew. Chem. Int. Ed. 1996, $35,2024-2055$.

[13] J. Weston, Chem. Rev. 2005, 105, 2151-2174.

[14] D. E. Wilcox, Chem. Rev. 1996, 96, 2435-2458.

[15] T. Klabunde, N. Sträter, R. Fröhlich, H. Witzel, B. Krebs, J. Mol. Biol. 1996, 259, 737-748.

[16] R. Alsfasser, E. Riedel, C. Janiak, H. J. Meyer, Moderne anorganische Chemie, de Gruyter, 2007.

[17] E. E. Kim, H. W. Wyckoff, J. Mol. Biol. 1991, 218, 449-464.

[18] A. Volbeda, A. Lahm, F. Sakiyama, D. Suck, EMBO J. 1991, 10, 1607-1618. 
[19] C. Romier, R. Dominguez, A. Lahm, O. Dahl, D. Suck, Proteins: Struct., Funct., Bioinf. 1998, 32, 414-424.

[20] N. Sträter, W. N. Lipscomb, T. Klabunde, B. Krebs, Angew. Chem. 1996, 108, 2158-2191.

[21] C. Jackson, H.-K. Kim, P. D. Carr, J.-W. Liu, D. L. Ollis, Biochim. Biophys. Acta, Proteins Proteomics 2005, 1752, 56-64.

[22] M. M. Benning, S.-B. Hong, F. M. Raushel, H. M. Holden, J. Biol. Chem. 2000, 275, 30556-30560.

[23] a) S. D. Aubert, Y. Li, F. M. Raushel, Biochemistry 2004, 43, 5707-5715; b) F. Meyer, Eur. J. Inorg. Chem. 2006, 2006, 3789-3800.

[24] M. I. Page, A. P. Laws, Chem. Comm. 1998, 1609-1617.

[25] R. P. Ambler, Philo. Trans. R. Soc. Lond. B. Biol. Sci. 1980, 289, 321-331.

[26] a) Z. Wang, W. Fast, S. J. Benkovic, Biochemistry 1999, 38, 10013-10023; b) I. Massova, S. Mobashery, Acc. Chem. Res. 1997, 30, 162-168; c) A. Dubus, J. M. Wilkin, X. Raquet, S. Normark, J.-M. Frére, Biochem. J. 1994, 301, 485-494; d) L. Lamotte-Brasseur, G. Dive, O. Dideberg, P. Charlier, J.-M. Frére, J. M. Ghuysen, Biochem. J. 1991, 279, 213-221; e) C. Damblon, X. Raquet, L. Y. Lian, J. Lamotte-Brasseur, E. Fonze, P. Charlier, G. C. Roberst, J.-M. Frére, Proc. Natl. Acad. Sci. USA 1996, 93, 1747-1752.

[27] K. Bush, G. A. Jacoby, A. A. Madeiros, Antimicrob. Agents Chemother. 1995, 39, 1211-1233.

[28] a) S. M. Fabiane, M. K. Sohi, T. Wan, D. J. Payne, J. H. Bateson, T. Mitchell, B. J. Sutton, Biochemistry 1998, 37, 12404-12411; b) E. G. Orellano, J. E. Girardini, J. A. Cricco, E. A. Ceccarelli, A. J. Vila, Biochemistry 1998, 37, 10173-10180.

[29] N. O. Concha, B. A. Rasmussen, K. Bush, O. Herzberg, Structure 1996, 4, 823836.

[30] N. Diaz, D. Suárez, K. M. Merz Jr., J. Am. Chem. Soc. 2000, 122, 4197-4208.

[31] Z. Hu, G. Periyannan, B. Bennett, M. W. Crowder, J. Am. Chem. Soc. 2008, 130, 14207-14216.

[32] Z. Wang, W. Fast, S. J. Benkovic, J. Am. Chem. Soc. 1998, 120, 10788-10789.

[33] M. W. Crowder, J. Spencer, A. J. Vila, Acc. Chem. Res. 2006, 39, 721-728.

[34] C. Bebrone, Biochem. Pharmacol. 2007, 74, 1686-1701.

[35] a) N. Díaz, D. Suárez, K. M. Merz Jr., J. Am. Chem. Soc. 2001, 123, 9867-9879;

b) F. R. Salsbury Jr., M. F. Crowley, C. L. Brooks, Proteins: Struct., Funct., 
Genet. 2001, 44, 448-459; c) G. Estiu, D. Suárez, K. M. Merz Jr., J. Comput. Chem. 2006, 27, 1240-1262.

[36] A. L. Gavrilova, B. Bosnich, Chem. Rev. 2004, 104, 349-384.

[37] a) A. Tamilselvi, M. Nethaji, G. Mugesh, Chem. Eur. J. 2006, 12, 7797-7806; b)

A. Tamilselvi, G. Mugesh, Chem. Eur. J. 2010, 16, 8878-8886.

[38] a) K. Selmeczi, C. Michel, A. Milet, I. Gautier-Luneau, C. Philouze, J.-L. Pierre, D. Schnieders, A. Rompel, C. Belle, Chem. Eur. J. 2007, 13, 9093-9106; b) N. V. Kaminskaia, B. Spingler, S. J. Lippard, J. Am. Chem. Soc. 2000, 122, 6411-6422; c) N. V. Kaminskaia, B. Spingler, S. J. Lippard, J. Am. Chem. Soc. 2001, 123, 6555-6563.

[39] a) J. Chen, X. Wang, Y. Zhu, J. Lin, X. Yang, Y. Li, Y. Lu, Z. Guo, Inorg. Chem. 2005, 44, 3422-3430; b) M. Jarenmark, S. Kappen, M. Haukka, E. Nordlander, Dalton Trans. 2008, 993-996.

[40] M. Jarenmark, E. Csapo, J. Singh, S. Wöckel, E. Farkas, F. Meyer, M. Haukka, E. Nordlander, Dalton Trans. 2010, 39, 8183-8194.

[41] a) M. Yashiro, A. Ishikubo, M. Komiyama, J. Chem. Soc., Chem. Commun. 1995, 1793-1794; b) M. Yashiro, A. Ishikubo, M. Komiyama, Chem. Commun. 1997, 83-84; c) S. Albedyhl, D. Schnieders, A. Jancsó, T. Gajda, B. Krebs, Eur. J. Inorg. Chem. 2002, 2002, 1400-1409.

[42] a) N. V. Kaminskaia, C. He, S. J. Lippard, Inorg. Chem. 2000, 39, 3365-3373; b) C. He, S. J. Lippard, J. Am. Chem. Soc. 2000, 122, 184-185.

[43] a) F. Meyer, S. Beyreuther, K. Heinze, L. Zsolnai, Chem. Ber. 1997, 130, 605613; b) F. Meyer, A. Jacobi, B. Nuber, P. Rutsch, L. Zsolnai, Inorg. Chem. 1998, 37, 1213-1218; c) J. Ackermann, F. Meyer, H. Pritzkow, Inorg. Chim. Acta 2004, 357, 3703-3711; d) A. Prokofieva, A. I. Prikhod'ko, E. A. Enyedy, E. Farkas, W. Maringgele, S. Demeshko, S. Dechert, F. Meyer, Inorg. Chem. 2007, 46, 42984307.

[44] See for example: a) F. Meyer, K. Heinze, B. Nuber, L. Zsolnai, J. Chem. Soc., Dalton Trans. 1998, 207-214; b) J. Ackermann, F. Meyer, E. Kaifer, H. Pritzkow, Chem. Eur. J. 2002, 8, 247-258; c) S. Buchler, F. Meyer, E. Kaifer, H. Pritzkow, Inorg. Chim. Acta 2002, 337, 371-386.

[45] F. Mancin, P. Tecilla, New J. Chem. 2007, 31, 800-817. 
[46] a) C. Bazzicalupi, A. Bencini, A. Bianchi, V. Fusi, C. Giorgi, P. Paoletti, B. Valtancoli, D. Zanchi, Inorg. Chem. 1997, 36, 2784-2790; b) D. Kong, A. E. Martell, J. Reibenspies, Inorg. Chim. Acta 2002, 333, 7-14.

[47] a) P. Molenveld, S. Kapsabelis, J. F. J. Engbersen, D. N. Reinhoudt, J. Am. Chem. Soc. 1997, 119, 2948-2949; b) P. Molenveld, J. F. J. Engbersen, D. N. Reinhoudt, Angew. Chem. Int. Ed. 1999, 38, 3189-3192; c) P. Molenveld, W. M. G. Stikvoort, H. Kooijman, A. L. Spek, J. F. J. Engbersen, D. N. Reinhoudt, J. Org. Chem. 1999, 64, 3896-3906; d) P. Molenveld, J. F. J. Engbersen, D. N. Reinhoudt, Eur. J. Org. Chem. 1999, 1999, 3269-3275.

[48] a) B. Bauer-Siebenlist, F. Meyer, E. Farkas, D. Vidovic, J. A. Cuesta-Seijo, R. Herbst-Irmer, H. Pritzkow, Inorg. Chem. 2004, 43, 4189-4202; b) B. BauerSiebenlist, F. Meyer, E. Farkas, D. Vidovic, S. Dechert, Chem. Eur. J. 2005, 11, 4349-4360.

[49] T. G. Schenck, J. M. Downes, C. R. C. Milne, P. B. Mackenzie, T. G. Boucher, J. Whelan, B. Bosnich, Inorg. Chem. 1985, 24, 2334-2337.

[50] K. J. Oberhausen, J. F. Richardson, R. M. Buchanan, W. Pierce, Polyhedron 1989, $8,659-668$.

[51] L. Casella, O. Carugo, M. Gullotti, S. Doldi, M. Frassoni, Inorg. Chem. 1996, 35, 1101-1113.

[52] L. Casella, M. Gullotti, R. Radaelli, P. Di Gennaro, J. Chem. Soc., Chem. Commun. 1991, 1611-1612.

[53] A. W. Addison, T. N. Rao, J. Reedijk, J. van Rijn, G. C. Verschoor, J. Chem. Soc., Dalton Trans. 1984, 1349-1356.

[54] J. Gałęzowska, F. Meyer, 2008, unpublished results.

[55] B. Bauer-Siebenlist, S. Dechert, F. Meyer, Chem. Eur. J. 2005, 11, 5343-5352.

[56] L.-Z. Yang, Y. Li, X.-M. Zhuang, L. Jiang, J.-M. Chen, R. L. Luck, T.-B. Lu, Chem. Eur. J. 2009, 15, 12399-12407.

[57] M. A. Gil, W. Maringgele, S. Dechert, F. Meyer, Z. Anorg. Allg. Chem. 2007, 633, 2178-2186.

[58] a) S. M. Gorun, R. T. Stibrany, A. Lillo, Inorg. Chem. 1998, 37, 836-837; b) T. Tanase, T. Inagaki, Y. Yamada, M. Kato, E. Ota, M. Yamazaki, M. Sato, W. Mori, K. Yamaguchi, M. Mikuriya, M. Takahashi, M. Takeda, I. Kinoshita, S. Yano, J. Chem. Soc., Dalton Trans. 1998, 713-718; c) A. K. Boudalis, N. Lalioti, G. A. Spyroulias, C. P. Raptopoulou, A. Terzis, V. Tangoulis, S. P. Perlepes, J. 
Chem. Soc., Dalton Trans. 2001, 955-957; d) A. K. Boudalis, N. Lalioti, G. A. Spyroulias, C. P. Raptopoulou, A. Terzis, A. Bousseksou, V. Tangoulis, J.-P. Tuchagues, S. P. Perlepes, Inorg. Chem. 2002, 41, 6474-6487; e) C. Femoni, M. C. Iapalucci, G. Longoni, S. Zacchini, E. Zazzaroni, Dalton Trans. 2007, 26442651.

[59] a) A. Fleming, Brit. Med. Bull. 1944, 2, 4-5; b) E. Chain, H. W. Florey, A. D. Gardner, N. G. Heatley, M. A. Jennings, J. Orr-Ewing, A. G. Sanders, Lancet 1940, 226-228.

[60] F. von Nussbaum, M. Brands, B. Hinzen, S. Weigand, D. Häbich, Angew. Chem. 2006, 118, 5194-5254.

[61] T. Kupka, Spectrochim. Acta, Part A 1997, 53, 2649-2658.

[62] P. M. Blumberg, J. L. Strominger, Bacteriol. Rev. 1974, 38, 291-335.

[63] a) J. T. Groves, R. M. Dias, J. Am. Chem. Soc. 1979, 101, 1033-1035; b) N. P. Gensmantel, P. Proctor, M. I. Page, J. Chem. Soc., Perkin Trans. 2 1980, 17251732; c) M. I. Page, Acc. Chem. Res. 1984, 17, 144-151.

[64] R. W. Hay, A. K. Basak, M. P. Pujari, J. Chem. Soc., Dalton Trans. 1989, 197201.

[65] T. J. Prystas, T. H. Fife, J. Chem. Soc., Perkin Trans. 2 1990, 393-399.

[66] a) T. Koike, M. Takamura, E. Kimura, J. Am. Chem. Soc. 1994, 116, 8443-8449;

b) K. Ogawa, K. Nakata, K. Ichikawa, Chem. Lett. 1998, 797-798; c) M. A. Schwartz, Bioorg. Chem. 1983, 11, 4-18.

[67] N. Díaz, T. L. Sordo, D. Suárez, R. Méndez, J. Martín-Villacorta, New. J. Chem. 2004, $28,15-25$.

[68] a) A. Looney, G. Parkin, R. Alsfasser, M. Ruf, H. Vahrenkamp, Angew. Chem. 1992, 104, 57-58; b) F. Gross, H. Vahrenkamp, Inorg. Chem. 2005, 44, 44334440.

[69] M. Asso, R. Panossian, M. Guiliano, Spectrosc. Lett. 1984, 17, 271 - 278.

[70] R. F. Pratt, M. Dryjanski, E. S. Wun, V. M. Marathias, J. Am. Chem. Soc. 1996, 118, 8207-8212.

[71] B. Bauer-Siebenlist, Dissertation, Georg-August Universität Göttingen (Göttingen), 2004.

[72] J. Koolman, K. H. Röhm, Taschenatlas der Biochemie, Georg Thieme, 2003.

[73] a) J. K. Bashkin, L. A. Jenkins, Comments Inorg. Chem. 1994, 16, 77 - 93; b) D. M. Perreault, E. V. Anslyn, Angew. Chem. 1997, 109, 470-490. 
[74] N. H. Williams, B. Takasaki, M. Wall, J. Chin, Acc. Chem. Res. 1999, 32, 485493.

[75] L. V. Penkova, A. Maciag, E. V. Rybak-Akimova, M. Haukka, V. A. Pavlenko, T. S. Iskenderov, H. Kozłowski, F. Meyer, I. O. Fritsky, Inorg. Chem. 2009, 48, 6960-6971.

[76] a) G. W. Coates, D. R. Moore, Angew. Chem. Int. Ed. 2004, 43, 6618-6639; b) D. J. Darensbourg, Chem. Rev. 2007, 107, 2388-2410.

[77] a) D. J. Darensbourg, M. W. Holtcamp, Coord. Chem. Rev. 1996, 153, 155-174; b) D. J. Darensbourg, M. W. Holtcamp, G. E. Struck, M. S. Zimmer, S. A. Niezgoda, P. Rainey, J. B. Robertson, J. D. Draper, J. H. Reibenspies, J. Am. Chem. Soc. 1999, 121, 107-116.

[78] S. Huang, S. Liu, J. Li, N. Zhao, W. Wei, Y. Sun, Catal. Lett. 2007, 118, 290-294.

[79] a) S. Inoue, H. Koinuma, T. Tsuruta, J. Polym. Sci. Pol. Lett. 1969, 7, 287-292; b) S. Inoue, H. Koinuma, T. Tsuruta, Makromol. Chem. 1969, 130, 210-220.

[80] K. Soga, K. Uenishi, S. Hosoda, S. Ikeda, Makromol. Chem. 1977, 178, 893-897.

[81] D. J. Darensbourg, M. W. Holtcamp, Macromolecules 1995, 28, 7577-7579.

[82] M. Cheng, E. B. Lobkovsky, G. W. Coates, J. Am. Chem. Soc. 1998, 120, 1101811019.

[83] D. J. Darensbourg, S. A. Niezgoda, J. D. Draper, J. H. Reibenspies, J. Am. Chem. Soc. 1998, 120, 4690-4698.

[84] Z. Liu, M. Torrent, K. Morokuma, Organometallics 2002, 21, 1056-1071.

[85] D. J. Darensbourg, J. R. Wildeson, J. C. Yarbrough, J. H. Reibenspies, J. Am. Chem. Soc. 2000, 122, 12487-12496.

[86] K. Nozaki, K. Nakano, T. Hiyama, J. Am. Chem. Soc. 1999, 121, 11008-11009.

[87] K. Nakano, K. Nozaki, T. Hiyama, J. Am. Chem. Soc. 2003, 125, 5501-5510.

[88] Y. Xiao, Z. Wang, K. Ding, Chem. Eur. J. 2005, 11, 3668-3678.

[89] M. R. Kember, P. D. Knight, P. T. R. Reung, C. K. Williams, Angew. Chem. Int. Ed. 2009, 48, 931-933.

[90] J. H. Clements, Ind. Eng. Chem. Res. 2003, 42, 663-674.

[91] K. Tomishige, H. Yasuda, Y. Yoshida, M. Nurunnabi, B. Li, K. Kunimori, Green Chem. 2004, 6, 206-214.

[92] P. Tundo, M. Selva, Acc. Chem. Res. 2002, 35, 706-716.

[93] M. Aresta, A. Dibenedetto, C. Dileo, I. Tommasi, E. Amodio, J. Supercrit. Fluids 2003, 25, 177-182. 
[94] a) K. Tomishige, H. Yasuda, Y. Yoshida, M. Nurunnabi, B. Li, K. Kunimori, Catal. Lett. 2004, 95, 45-49; b) Y. Du, D.-L. Kong, H.-Y. Wang, F. Cai, J.-S. Tian, J.-Q. Wang, L.-N. He, J. Mol. Catal. A: Chem. 2005, 241, 233-237.

[95] X. Zhao, N. Sun, S. Wang, F. Li, Y. Wang, Ind. Eng. Chem. Res. 2008, 47, 13651369.

[96] a) M. Döring, M. Ciesielski, O. Walter, H. Görls, Eur. J. Inorg. Chem. 2002, 2002, 1615-1621; b) M. Fondo, A. M. Garcia-Deibe, M. R. Bermejo, J. Sanmartin, A. L. Llamas-Saiz, J. Chem. Soc., Dalton Trans. 2002, 4746-4750.

[97] B. Bauer-Siebenlist, F. Meyer, D. Vidovic, H. Pritzkow, Z. Anorg. Allg. Chem. 2003, 629, 2152-2156.

[98] STOE \& CIE GmbH, X-AREA, Darmstadt, Germany, 2002.

[99] STOE \& CIE GmbH, $X-R E D$, Darmstadt, Germany, 2002.

[100] a) G. M. Sheldrick, SHELXS-97, Program for Crystal Structure Solution, Göttingen, Germany, 1997; b) G. M. Sheldrick, SHELXL-97, Program for Crystal Structure Refinement, Göttingen, Germany, 1997; c) G. M. Sheldrick, Acta Crystallogr. 2008, A64, 112-122. 


\section{Structures of Ligand Precursors and Ligands}<smiles>CCCCCCc1nccn1C</smiles>

II<smiles>Cn1ccnc1CN(Cc1cc(CN(Cc2nccn2C)Cc2nccn2C)[nH]n1)Cc1nccn1C</smiles>

$\mathbf{L}^{1}$

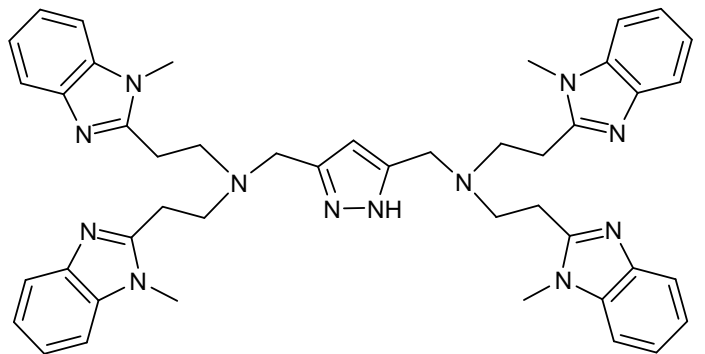

$L^{3}$

V

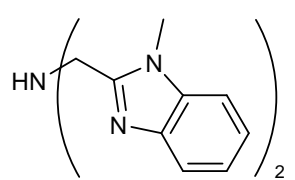<smiles>Cn1c(CN(Cc2cc(CN(Cc3nc4ccccc4n3C)Cc3nc4ccccc4n3C)[nH]n2)Cc2nc3ccccc3n2C)nc2ccccc21</smiles>

$L^{2}$

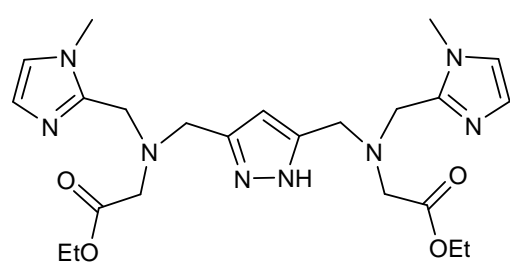

precursor-L ${ }^{4}$<smiles>CCOC(=O)CNCc1nccn1C</smiles>

$\mathbf{X}$ 


\section{Structures of Complexes}

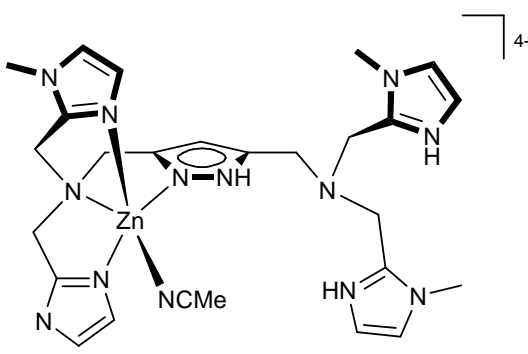

$4\left(\mathrm{ClO}_{4}^{-}\right)$

1

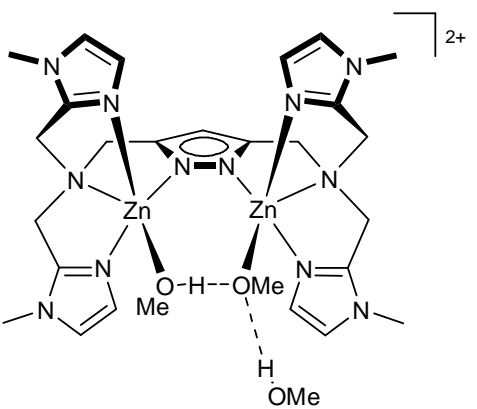

$2\left(\mathrm{ClO}_{4}^{-}\right)$

$4 a$

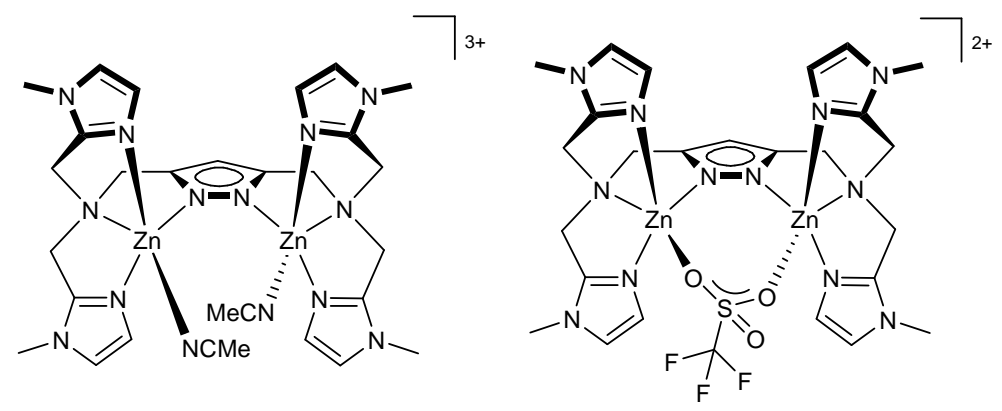

$3\left(\mathrm{ClO}_{4}^{-}\right)$

2

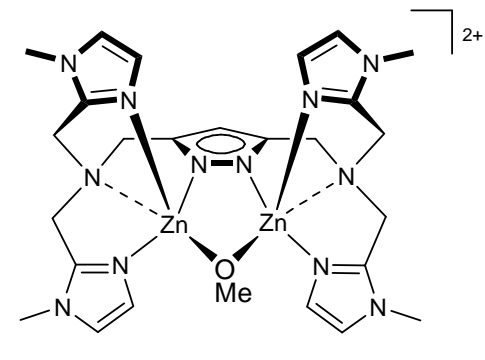

$2\left(\mathrm{ClO}_{4}^{-}\right)$

$4 b$

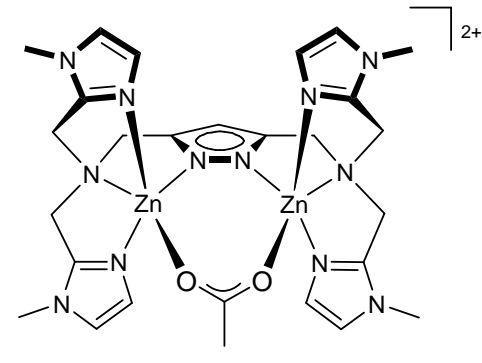

$2\left(X^{-}\right)$

5a $\left(X=\mathrm{CF}_{3} \mathrm{SO}_{3}\right)$ $\mathbf{5 b}\left(\mathrm{X}=\mathrm{ClO}_{4}\right)$

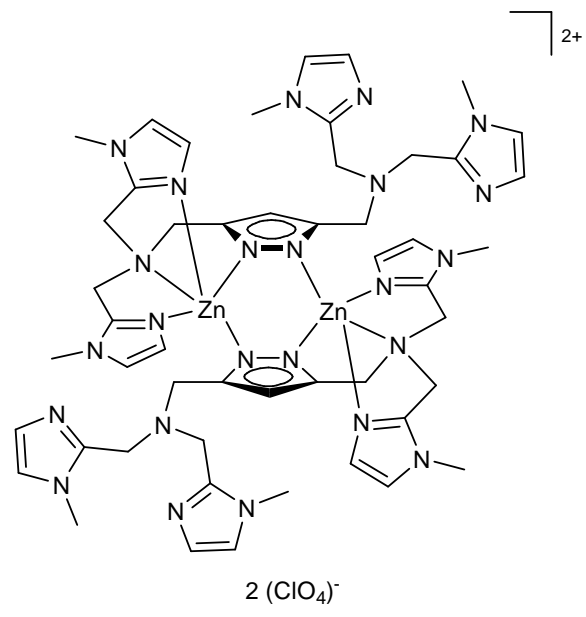

6

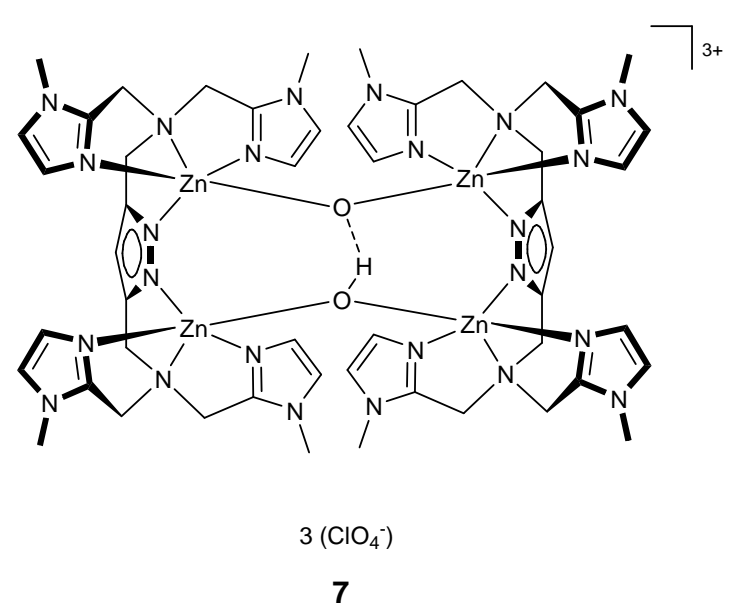




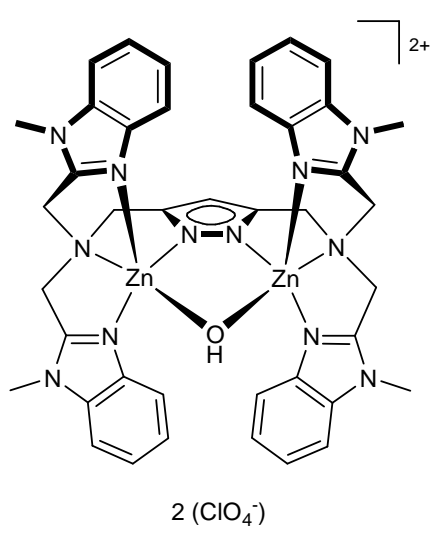

8

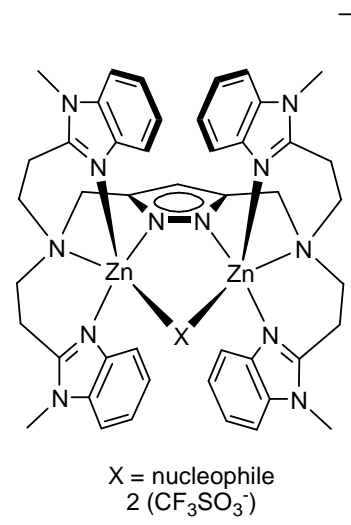

9

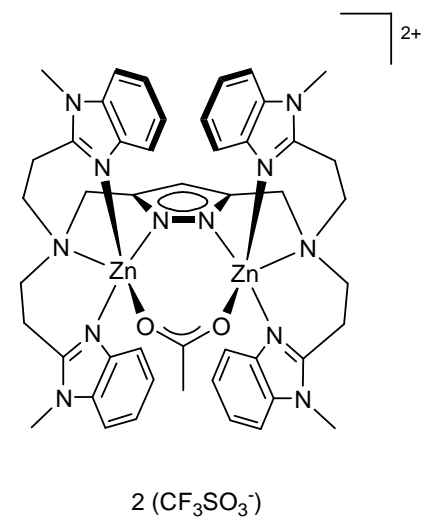

10

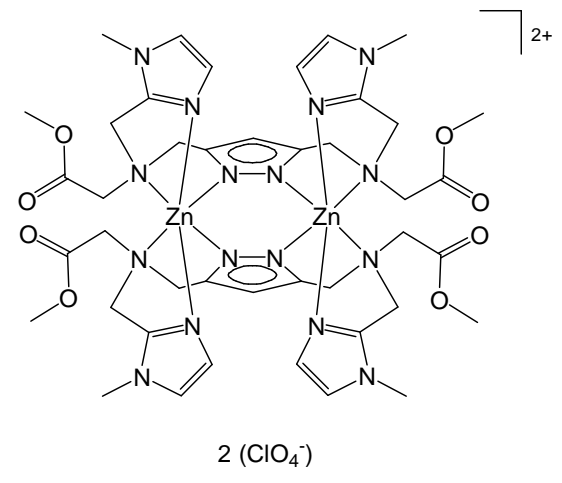

11

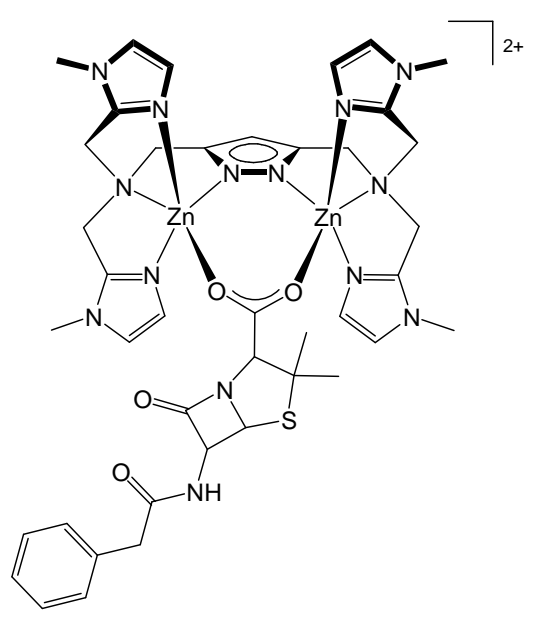

$2\left(\mathrm{ClO}_{4}{ }^{-}\right)$

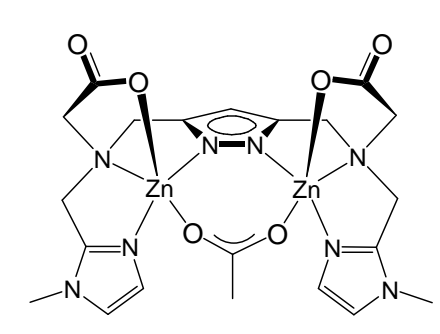

12

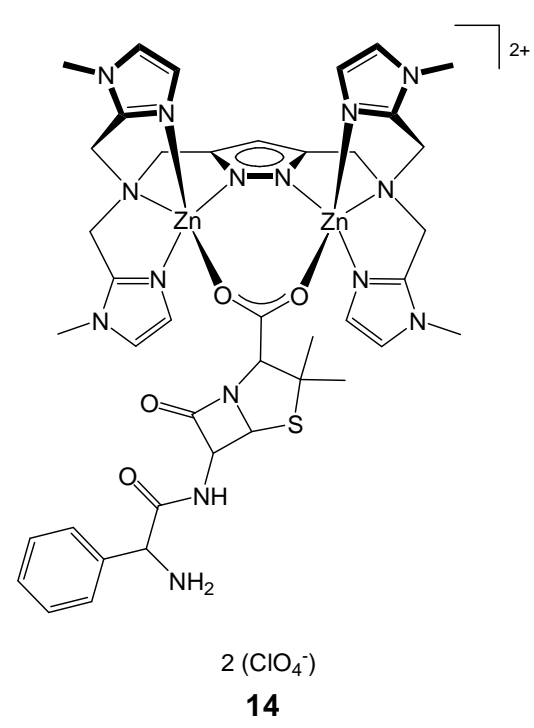




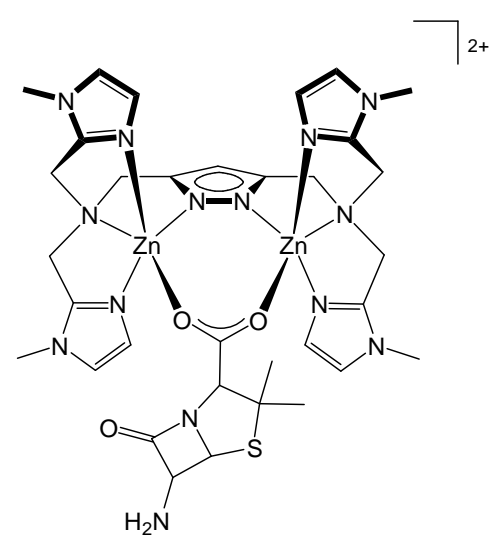

$2\left(\mathrm{ClO}_{4}{ }^{-}\right)$

15

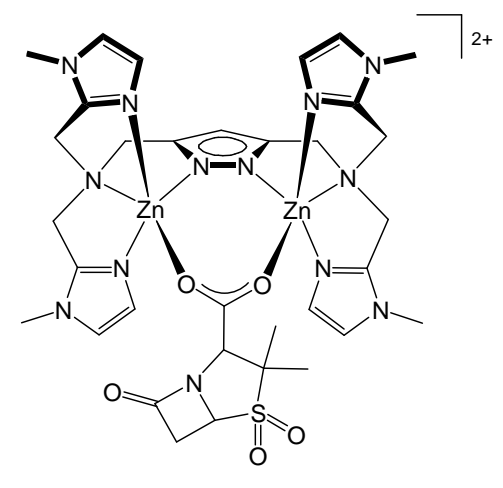

$2\left(\mathrm{CF}_{3} \mathrm{SO}_{3}^{-}\right)$

17

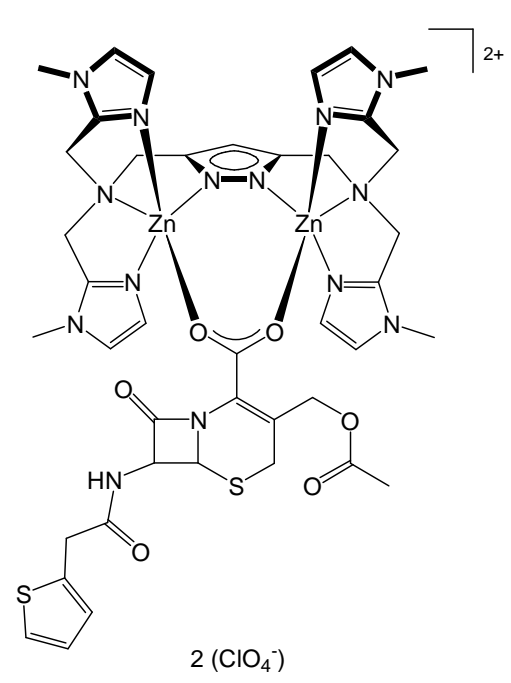

16

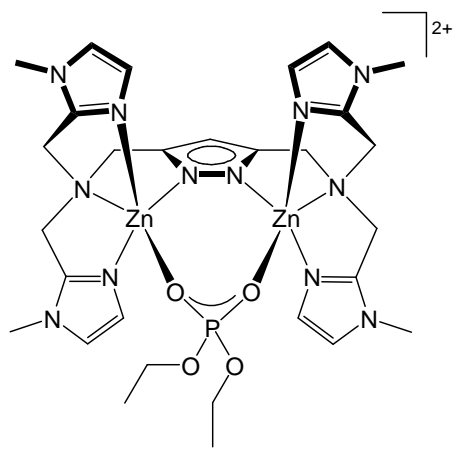

$2\left(\mathrm{SO}_{3} \mathrm{CF}_{3}^{-}\right)$

18

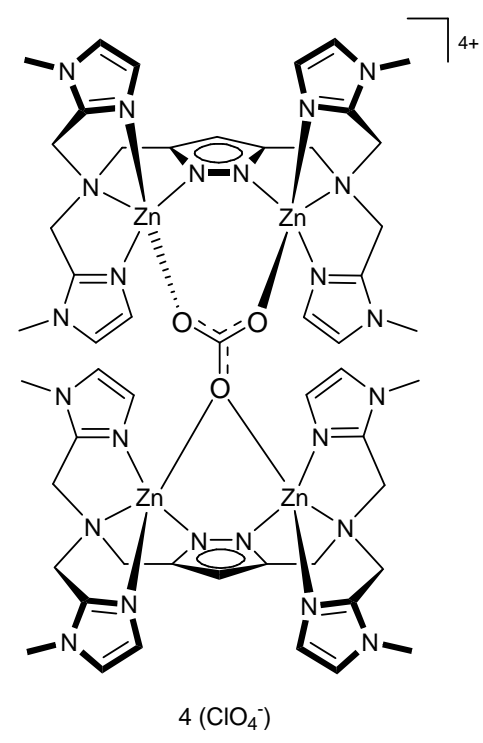

19 


\section{List of Abbreviations}

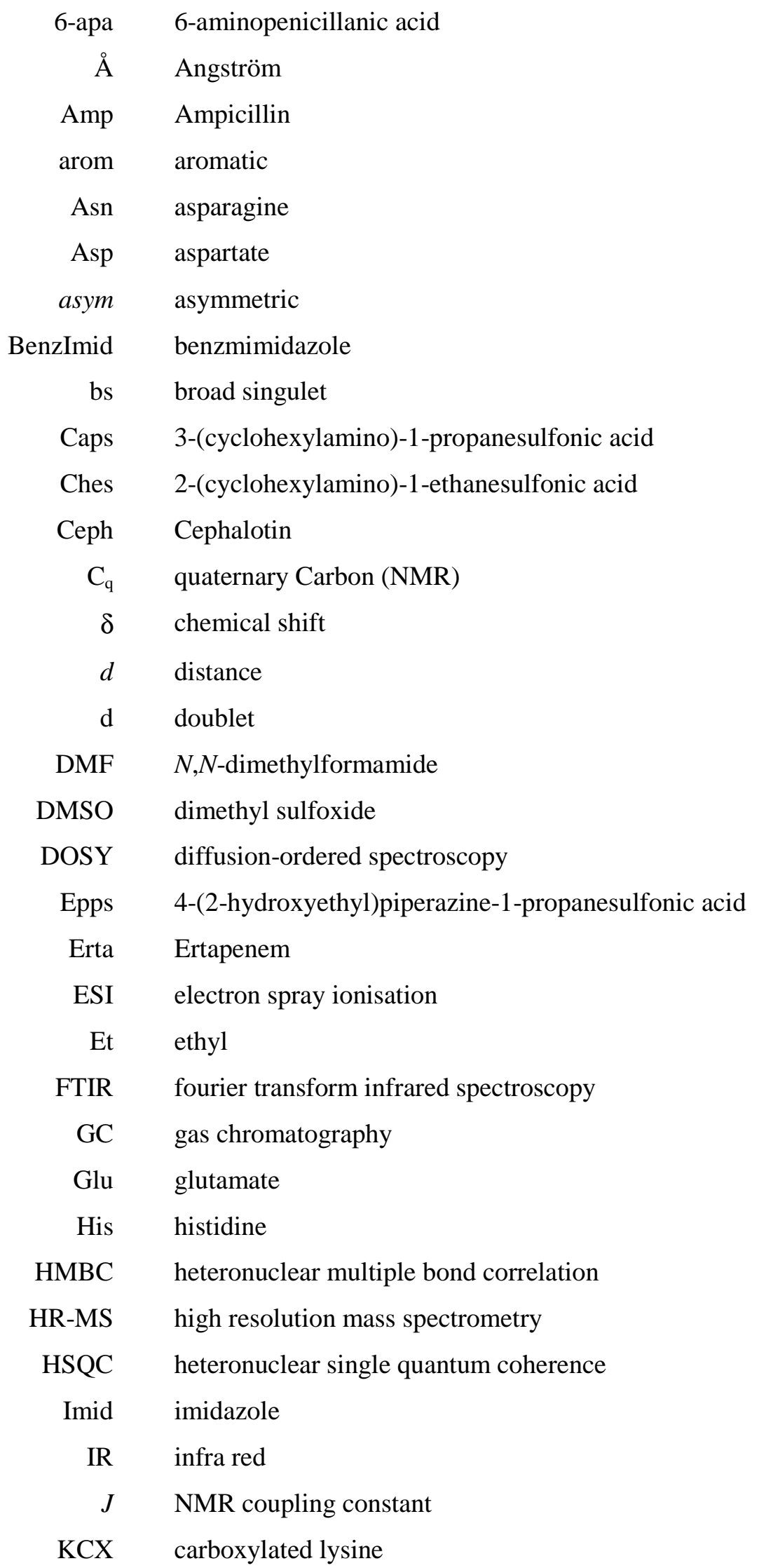




\begin{tabular}{|c|c|}
\hline $\mathrm{L}$ & ligand \\
\hline Lac & $\beta$-lactam substrate \\
\hline Lys & lysine \\
\hline $\mathrm{m}$ & multiplet (NMR), medium (IR) \\
\hline $\mathrm{Me}$ & methyl \\
\hline Mero & Meropenem \\
\hline Mes & 2-( $N$-morpholino)ethanesulfonic acid \\
\hline Mops & 3-(N-morpholino)propanesulfonic acid \\
\hline $\mathrm{mp}$ & melting point \\
\hline MS & mass spectrometry \\
\hline NMR & nuclear magnetic resonance \\
\hline OAc & acetate \\
\hline PenG & Penicillin G \\
\hline $\mathrm{Pz}$ & pyrazole \\
\hline $\mathrm{rt}$ & room temperature \\
\hline $\mathrm{s}$ & singlet (NMR), strong (IR) \\
\hline sh & shoulder \\
\hline Sul & Sulbactam \\
\hline sym & symmetric \\
\hline $\mathrm{t}$ & triplet \\
\hline$t_{R}$ & retention time \\
\hline${ }^{t} \mathrm{Bu}$ & tert-butyl \\
\hline THF & tetrahydrofurane \\
\hline $\operatorname{Trp}$ & tryptophan \\
\hline Tyr & tyrosine \\
\hline$\tilde{v}$ & wavenumber \\
\hline vs & very strong \\
\hline $\mathrm{w}$ & weak \\
\hline
\end{tabular}




\section{List of Scientific Contributions}

\section{PubLiCATIONS}

M. Georgiou, S. Wöckel, V. Konstanzer, S. Dechert, M. John, F. Meyer, "Structural Variations in Tetrasilver(I) Complexes of Pyrazolate-bridged Compartmental N-Heterocyclic Carbene Ligands”, Z. Naturforsch. 2009, 64b, 1542-1552.

M. Jarenmark, E. Csapó, J. Singh, S. Wöckel, E. Farkas, F. Meyer, M. Haukka, E. Nordlander, "Unsymmetrical dizinc complexes as models for the active sites of phosphohydrolases", Dalton Trans. 2010, 39, 8183-8194.

\section{ORAL PRESENTATIONS AT INTERNATIONAL WORKSHOPS}

"Synthetic Models for Dizinc Metallo- $\beta$-lactamases", $5^{\text {th }}$ Workshop of the International Research Training Group 1422 "Metal Sites in Biomolecules: Structures, Regulation and Mechanisms”, Goslar, Germany, February 2010.

\section{POSTERS AT CONFERENCES AND INTERNATIONAL WORKSHOPS}

S. Wöckel, B. Burger, M. Jarenmark, S. Dechert, E. Nordlander, F. Meyer, "New Binucleating Ligands for Mimicking the Dizinc Metallo- $\beta$-Lactamase Active Site“, $9^{\text {th }}$ European Biological Inorganic Chemistry Conference (EuroBIC 9), Wroclaw, Poland, June 2008.

S. Wöckel, S. Dechert. F. Meyer, "Dizinc Complexes Mimicking the Active Site of Metallo- $\beta$-lactamases“, Summer School "Computational Chemistry and Spectroscopy”, Essen, Germany, September 2009.

S. Wöckel, B. Burger, M. Jarenmark, S. Dechert, E. Nordlander, F. Meyer, "Compartmental Ligands and their Dizinc Complexes emulating the Active Site of Metallo- $\beta$-Lactamase “, $4^{\text {th }}$ Workshop of the International Research Training Group 1422 "Metal Sites in Biomolecules: Structures, Regulation and Mechanisms", Copenhagen, Denmark, February 2010. 
S. Wöckel, J. Gałęzowska, B. Burger, S. Dechert, F. Meyer, "Novel Binuclear Zinc Complexes Modelling the Active Site of Metallo- $\beta$-lactamases“, $10^{\text {th }}$ European Biological Inorganic Chemistry Conference (EuroBIC 10), Thessaloniki, Greece, June 2010. 


\section{Acknowledgements}

In the end of my thesis, I would like to thank these people, who helped and supported me during the time here in Göttingen.

At first, I want to thank Prof. Dr. Franc Meyer for the supervision of my thesis. Thank you for giving me the opportunity to work in your group, for your patient guidance and the granted academic freedom I had. Your continuous motivation helped me to bring my scientific work forward. Many thanks go also to Prof Dr. Ulf Diederichsen and Prof. Dr. Ebbe Nordlander, the co-supervisors of this work, and my examination committee: Prof. Dr. Michael Mühlenberg, Dr. Heidrun Sowa, Prof. Dr. Kai Tittmann and Dr. Inke Siewert - for support and review of this work.

I additionally would like to thank Prof. Dr. Ebbe Nordlander for giving me the opportunity to work in his lab during my stay in Lund! Many thanks go also to Dr. Martin Jarenmark, who introduced me into the field of phosphate ester cleavage and supported me in every way (starting from the measurements up to the discussions of the results), Kerstin, Jessica and Lotta - thank you for the nice time in Lund.

My special thanks go also to these people that contributed with their expertise and work to the realisation of this work: in particular to Dr. Joanna Gałęzowska for the measurements and calculations of the potentiometric titrations. I am thankful to Dr. Sebastian Dechert for solving and teaching me how to calculate crystal structures and to Kevin Pröpper for the measurement and calculation of compound 11. Dr. Holm Frauendorf and the employees of the mass department I am thanking for the HR-MS measurements and Frank Hambloch for the GC-MS analyses and the discussions of the results. I also appreciate the work of Dr. Michael John and the employees of the NMR department for the NMR measurements. I am also thankful to the employees of the analytical laboratory.

Many thanks go to Petra Unger and Dr. A. Claudia Stückl for their immense support in administrative matters. Matthias Hesse, Jörg Teichgräber and Andreas Schwarz I want to thank for the supply of chemicals and laboratory equipment. I would like to acknowledge the work of the people of the electrical and machine craft shops, the caretakers, the library, the glassblower craft shop and the cleaning service. 
I want to thank the whole working group, especially Boris, Asia, Maria, Benni, Sebastian, Sarah, Jan, Felix, Vera, Kai and Anni, for the good working atmosphere and the nice time we had. Asia, I want to thank you not only for your support in chemical issues and the nice conversations we had about "zinc", but also for your friendship and the great time we had, when you have been here. You are one of the persons, who understand me the way I am thinking even without saying words. I also want to thank Maria for her friendship and the time we spent together, which helped a lot to brighten the everyday life. I additionally want to thank Asia, Maria and Sarah for the great "Ladies' nights" we had that I enjoyed so much.

Special thanks go to my lab colleague Boris: thank you for all the fruitful discussions we had not only about chemistry, but also about issues of ordinary life, as you explained the world to me so often. Our small fightings strengthened my powers of self-assertion and the lab life with you has never been boring! You supported me with chemicals (ligand and good solvents) and the results of this work would not be the same without your help. Thank you that you have endured to share a lab with me - we have been a good team!

Benni, I want to thank you for the nice time we had in university. I always enjoyed our conversations and I want to thank you for your motivation you gave me when I needed someone to cheer up. Many thanks go also to Sebastian for always having an open ear and to help me solving problems in every way (especially in software issues).

I also want to gratefully acknowledge the work of Martin, Sebastian, Benni, Carla, Boris, Asia and Kristian for reading parts of this thesis.

Research fellowship and financial support of the DFG (IRTG 1422: "Metal Sites in Biomolecules: Structures, Regulation and Mechanisms") is gratefully acknowledged. I also want to thank all members of the IRTG for the good teamwork and for the time we spent together on conferences and workshops, especially to Boris, Asia, Vera, Friederike, Peer, Anja, Michael, Prinson and Angelina.

I also acknowledge all students for their experimental work: Cathrin Conrad, Manuel Kratzke, Galina Pestel, David Engelhard and Ole Schütte.

Finally, I want to thank my family and friends for their support in every way. Loving thanks go to my parents and my sister Kristina, who always have been there for me! I cannot end this part without saying special thanks to Martin and Carla! Carla, thank you 
for your wonderful friendship! I had such great time with you here in Göttingen and I will miss our evenings we spent together. Without you, the time in Göttingen would not have been the same. Loving thanks go also to Martin. Thank you for all your support and encouragement during the last years (especially the last months)! I appreciate that you have always been there for me! 
Curriculum Vitae

PERSONAL DATA

Name:

Date of Birth: $\quad 24^{\text {th }}$ July 1982

Place of Birth: $\quad$ Schleiz

Nationality: German

Marital Status: $\quad$ Unmarried

PRE-ACADEMIC CAREER

09/1989-07/1993 Grundschule Lobenstein

09/1993-07/2001 Staatliches Gymnasium „Christian Gottlieb Reichard“

Lobenstein

Abitur (cumulative grade 1.8)

\section{ACADEMIC CAREER}

$10 / 2001-09 / 2003$

undergraduate student, Universität Leipzig

$09 / 2003$

09/2003-09/2004

09/2004

09/2004-05/2006

02/2005-05/2005

05/2006-03/2007

$03 / 2007$

since $07 / 2007$
Diplomvorprüfung (cumulative grade $g u t$ )

undergraduate student, Universität Leipzig

examination of basic study period (cumulative grade $g u t$ )

diploma student, Universität Leipzig

Erasmus exchange student in the group of Prof. Dr. Han Vos, Dublin City University, Dublin, Ireland, "Synthesis of functionalized bipyridines to form heteroleptic Ru(II)complexes"

diploma thesis in the group of Prof. Dr. Evamarie HeyHawkins, Universität Leipzig, "Monometallische Vorläufer zur Darstellung katalytisch aktiver MOFs (Metal-Organic Frameworks) “

Diplom (cumulative grade sehr gut)

Ph.D. student in the group of Prof. Dr. Franc Meyer,

Georg- August-Universität Göttingen,

Ph.D. thesis "Synthetic Models for Dizinc

Metallohydrolases“ 